\title{
Superficial basal cell carcinoma in the spotlight
}

Citation for published version (APA):

Arits, A. H. M. M. (2013). Superficial basal cell carcinoma in the spotlight. [Doctoral Thesis, Maastricht University]. Maastricht University. https://doi.org/10.26481/dis.20130118aa

Document status and date:

Published: 01/01/2013

DOI:

10.26481/dis.20130118aa

Document Version:

Publisher's PDF, also known as Version of record

\section{Please check the document version of this publication:}

- A submitted manuscript is the version of the article upon submission and before peer-review. There can be important differences between the submitted version and the official published version of record.

People interested in the research are advised to contact the author for the final version of the publication, or visit the DOI to the publisher's website.

- The final author version and the galley proof are versions of the publication after peer review.

- The final published version features the final layout of the paper including the volume, issue and page numbers.

Link to publication

\footnotetext{
General rights rights.

- You may freely distribute the URL identifying the publication in the public portal. please follow below link for the End User Agreement:

www.umlib.nl/taverne-license

Take down policy

If you believe that this document breaches copyright please contact us at:

repository@maastrichtuniversity.nl

providing details and we will investigate your claim.
}

Copyright and moral rights for the publications made accessible in the public portal are retained by the authors and/or other copyright owners and it is a condition of accessing publications that users recognise and abide by the legal requirements associated with these

- Users may download and print one copy of any publication from the public portal for the purpose of private study or research.

- You may not further distribute the material or use it for any profit-making activity or commercial gain

If the publication is distributed under the terms of Article $25 \mathrm{fa}$ of the Dutch Copyright Act, indicated by the "Taverne" license above, 


\section{Superficial}

\section{Basal Cell Carcinoma}

in

The spotlight 

Superficial Basal Cell Carcinoma in the Spotlight 
ISBN: 978-90-817958-2-1

copyright Aimée Arits, Maastricht 2012

Cover design: Harrie Maesen

Cover title: Contradiction

Printing: Schrijen-Lippertz

Realisation: Graphic Services

Facility Company azM 


\title{
Superficial Basal Cell carcinoma in the Spotlight
}

\author{
PROEFSCHRIFT \\ ter verkrijging van de graad van doctor \\ aan de Universiteit Maastricht \\ op gezag van de Rector Magnificus Prof. dr. L.L.G. Soete \\ volgens het besluit van het College van Decanen, \\ in het openbaar te verdedigen \\ op vrijdag 18 januari 2013 om 14.00 uur \\ door
}

Aimée Hortense Monique Marie Arits

Geboren te Maaseik, 10 januari 1982 


\section{Promotor}

Prof. dr. P.M. Steijlen

\section{Copromotores}

Dr. N.W.J. Kelleners-Smeets

Dr. P.J. Nelemans

\section{Beoordelingscommissie}

Prof. dr. F.C.S. Ramaekers (voorzitter)

Prof. dr. H.A.M. Neumann (Erasmus MC Rotterdam)

Prof. dr. M.R. van Dijk (UMC Utrecht)

Prof. dr. V.C.G. Tjan-Heijnen (MUMC Maastricht) 
A mes parents

Vouloir c'est pouvoir 



\section{Contents}

$\begin{array}{lll}\text { Chapter } 1 \text { General introduction } & 11\end{array}$

Chapter 2 Trends in the incidence of basal cell carcinoma by 31 histopathological subtype

Chapter 3 Evidence based treatment of superficial basal cell carcinoma 41

3.1 Treatment of superficial basal cell carcinoma: a systematic review with meta-analysis

Photodynamic therapy vs. topical imiquimod vs. topical 5-

fluorouracil for treatment of superficial basal cell carcinoma: a single blind, noninferiority, randomised controlled trial and cost-effectiveness analysis

Chapter 4 Reliable and valid scar evaluation tools

Chapter 5 Photodynamic therapy related pain: the truth or a myth

Chapter 6 Not everything is what it seems

6.1

Basal cell carcinoma versus sebaceous carcinoma

6.2.1 A possible matter of confusion - case report 130

6.2.2 Differentiation by immunostaining of the androgen receptor 138

$\begin{array}{lll}\text { Chapter } 7 & \text { Summary and general discussion } & 147\end{array}$

Samenvatting 156

List of abbreviations 163

Curriculum vitae 165

$\begin{array}{ll}\text { List of publications } & 167\end{array}$

$\begin{array}{ll}\text { Dankwoord } & 171\end{array}$ 



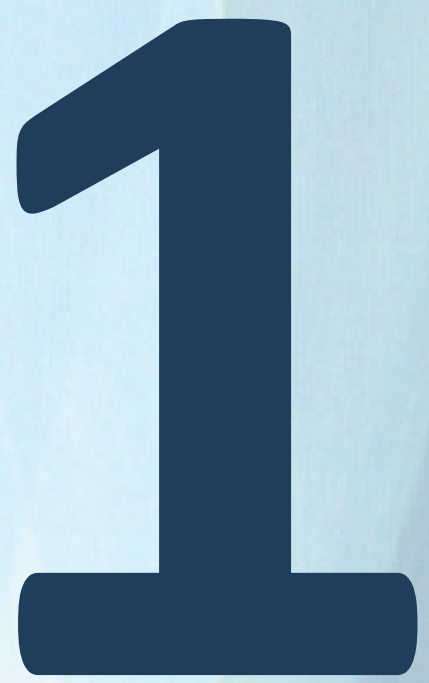

\section{General introduction}

The paragraph on therapy is partly based on the following article:

K. Mosterd, A. Arits, M. Thissen, N. Kelleners-Smeets.

Histology-based treatment of basal cell carcinoma.

Acta derm venereal 2009;89:454-458 



\section{Skin cancer}

Cancer, medically known as malignant neoplasm, is a group of various diseases all involving uncontrolled cell growth invading surrounding tissue. Cancer may also spread to more distant parts of the body through the lymphatic system or the bloodstream. Skin cancer is the most common malignant neoplasm, affecting especially white skinned individuals world wide. ${ }^{1}$ Skin cancer is often divided into malignant melanoma and non melanoma skin cancer (NMSC). Although malignant melanoma comprises only $5 \%$ of all skin cancer, this type of skin cancer is the most aggressive and has the worst prognosis. $^{2}$ Basal cell carcinoma (BCC) and squamous cell carcinoma (SCC) are the two most common types of NMSC. Although they share many similarities, they have different incidence rates and important aetiological differences. ${ }^{1}$ Approximately $80 \%$ of NMSCs are BCCs and $10-20 \%$ is SCC. In addition there is a small group left, consisting of primary cutaneous tumours such as lymphomas, adnexal carcinomas (for example sebaceous carcinomas) and Merkel cell carcinomas. Although BCC rarely metastasizes and thus rarely causes death, it can result in significant morbidity if not correctly diagnosed and managed. Because of the world wide high prevalence and increasing incidence of $\mathrm{BCC}^{3}$, this tumour represents a significant economic burden to health services. ${ }^{4}$ It has been debated whether BCC is truly a malignant tumour. There are four features used to check if a tumour is benign or malignant, i.e. differentiation, rate of growth, local invasion and metastasis. The fact that BCC has the potency to invade through the basal membrane of the epidermis causing local invasion and tissue destruction, argues that it is a malignant rather than a benign tumour. Furthermore it has, although uncommon, metastatic potential (incidence less than 0.1 percent). ${ }^{5}$

So, BCC seems to represent a neoplasm midway between a benign neoplasm and a fully transformed malignancy.

\section{Epidemiology}

Measuring the incidence of BCC is difficult mainly because of poor registration practice in the majority of countries. Usually only the first case of BCC in a patient is registered. Worldwide the overall incidence is increasing significantly by about $3-10 \%$ annually. ${ }^{6,7}$ Between 1973 and 2008, age-adjusted incidence rates in the Netherlands increased approximately threefold from 40 to 148 per 100.000 in males and from 34 to 141 in females. ${ }^{3}$ Lifetime risk of BCC is 1 in 5-6 for Dutch citizens. ${ }^{3}$ One-third of the individuals with a $\mathrm{BCC}$ will develop another BCC within the next five years. ${ }^{8}$ Trends in BCC incidence up till 2020 showed continues increases among all age groups in both sexes. ${ }^{3}$ The rising incidence is partly due to increased patient and physician awareness and better coding of the tumours, but increase in recreational sun exposure is also an important cause. Although BCC may occur at any age, the incidence of BCC increases markedly 
after the age of fifty. ${ }^{3}$ Because of an increase in recreational sun exposure, it is expected that the first BCC will manifest at an increasingly younger age. Most BCCs appear on the head and neck region, although occurrence of BCCs on the trunk and extremities is more frequently observed. ${ }^{3,9}$ Studies on incidence rates of BCC by histological subtype and anatomic location showed that nodular BCC is still the most frequent histological subtype occurring mainly on highly sun-exposed body-sites like the head. ${ }^{10}$ ${ }^{11}$ Also more than sixty percent of the infiltrative BCCs develop in the head and neck region, while superficial $B C C$ is most frequently seen on the trunk. ${ }^{10,11}$ The difference in body-site distribution of the histological subtypes of $B C C$ is surprising. There is a hypothesis suggesting that superficial BCC develops from intense intermittent sun exposure (like recreational sun exposure during holidays) while nodular and infiltrative BCCs are believed to arise from chronically sun exposure (like outside work). ${ }^{9,}{ }^{12}$ The pathomechanism behind this theory is still unknown. Although clinical experience suggests an increase in the proportion of superficial BCC, so far this could only be confirmed in one Australian study. ${ }^{11}$

\section{Aetiology}

\section{Risk factors}

The risk on NMSC, including BCC, is due to a number of life-long risk factors. The major risk factor is exposure to ultraviolet radiation (UVR) which can damage the DNA in skin cells. UV-B radiation (290-320 $\mathrm{nm}$, sunburn rays) is believed to play a greater role in $B C C$ development than UV-A radiation (320-400nm, tanning rays). UV-B directly damages DNA and RNA, while UV-A induces photo-oxidative stress leading to DNA mutations. ${ }^{7}$ Exposure to UVR increases with decreasing latitude, leading to the highest incidence rates of NMSC in Australia. ${ }^{13}$ In particular, chronic sun exposure appears to be important in the development of BCC. Between the time of UV damage and clinical onset of BCC, a typical latent period of 20-50 years occurs. Besides UVR, skin type has a major effect on the geographical distribution of incidence rates world wide. A fair skin type (i.e. Fitzpatrick skin type I and II) is associated with a higher risk of developing skin cancer. This theory is supported by the very low incidence rates observed close to the equator in countries such a Singapore. ${ }^{14}$ Exposure to photosensitizing medication, ionizing radiation and chemicals, immunosuppressive status and genetic predisposition are also risk factors for development of BCC.

\section{Pathogenesis}

BCC is an epithelial tumour that is so named because of the histological resemblance to the cells along the basement membrane of the epidermis. Recently a mouse model based on an active smoothened (SMO) mutant, showed that $\mathrm{BCC}$ arises from long-term resident progenitor cells of the interfollicular epidermis and the upper infundibulum 
rather than the hair follicle bulge stem cells, as suggested earlier. ${ }^{15}$ Nevertheless there is still much discussion about the tumour origin. The last decade evidence became available that deregulated Hedgehog $(\mathrm{HH})$ signalling is of vital importance to understand the molecular pathogenesis. The $\mathrm{HH}$ signalling pathway plays a key role during normal development, regulating both proliferation and cell fate. Initially, patched (PTCH) and HH genes were identified in Drosophila melanogaster, where members of this complex signalling pathway were found to act as segment polarity genes involved in embryonic development. In recent years, it has become evident that an impairment of genes and pathways controlling development is also deeply involved in driving tumourgenesis and cancer development. ${ }^{16}$ Sonic hedgehog $(\mathrm{SHH})$ gene plays a key role in hair follicle morphogenesis. ${ }^{17}$ It is known that mutations in components of the $\mathrm{HH}$ signalling pathway can cause BCC. When screening candidate genes for the hereditary nevoid basal cell carcinoma syndrome (Gorlin syndrome), the human homologue of the PTCH gene, PTCH1, was identified as a tumour suppressor gene associated with this syndrome. ${ }^{18,19}$ The $\mathrm{PTCH} 1$ gene encodes a receptor that mediates $\mathrm{HH}$ signalling (Figure 1a). The significant cellular effects of $\mathrm{HH}$ signalling are mediated by proteins encoded by the glioma (GLI) gene family. The human $\mathrm{HH}$ signalling pathway is complex, with three identified $\mathrm{HH}$ genes (sonic hedgehog, Indian hedgehog and desert hedgehog), two PTCH genes (PTCH1 and PTCH2) and three GLI genes (GLI1, GLI2 and GLI3). The encoded proteins within these families are similar, although they display variations in expression levels in different cells and tissues as well as slightly different modes of interactions. In a normal situation, extracellular HH ligand binds to PTCH1 relieving the inhibition of SMO by PTCH1. Once relieved of inhibition, SMO sends signals through a series of interacting proteins ending in activation of transcription factors of the GLI family. There is evidence that for $\mathrm{HH}$ driven tumourgenesis, wingless (Wnt) signalling needs to be activated downstream of the $\mathrm{HH}$ signalling. ${ }^{20}$

Later studies have shown that inactivating mutations in the PTCH1 gene are also common events in sporadic BCC. Approximately $90 \%$ of sporadic BCCs have identifiable mutations in at least one allele of PTCH1 , and an additional $10 \%$ have activating mutations in the downstream SMO transmembrane protein receptor, which presumably render SMO resistant to inhibition by $\mathrm{PTCH} 1$ (figure $1 \mathrm{~b}$ ). ${ }^{20}$ Mutations identified in PTCH1 are often of a typical UV radiation-caused type. ${ }^{20}$ 

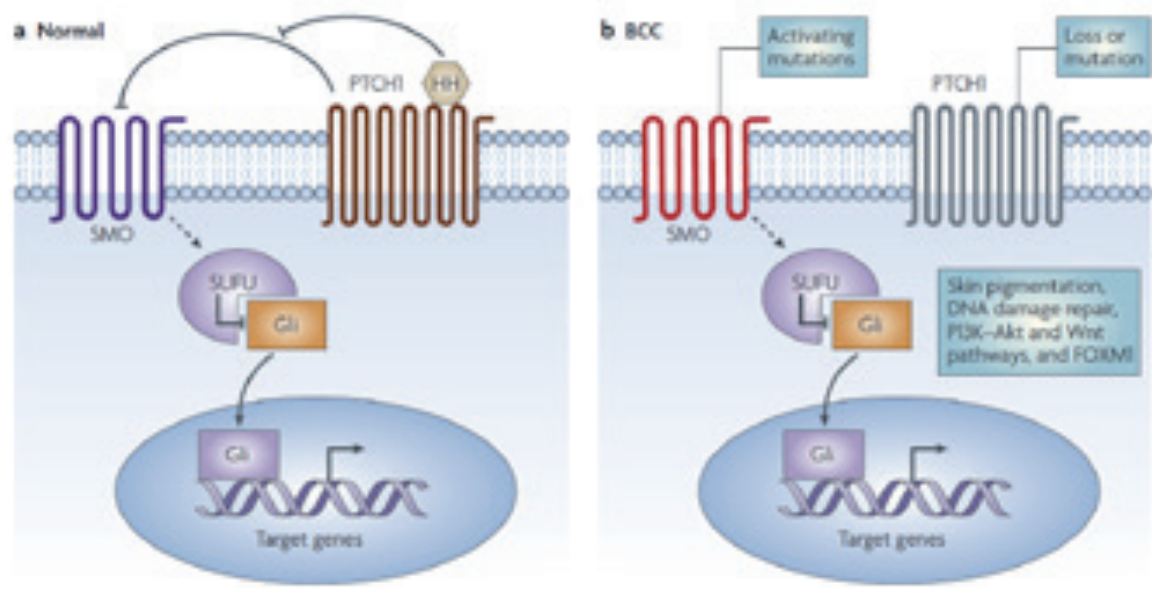

Figure 1. A basic schematic of the Hedgehog $(\mathrm{HH})$ signalling pathway.

a Normal situation The family of extracellular HH ligands, of which there are three in mammals (sonic hedgehog $(\mathrm{SHH})$, Indian hedgehog $(\mathrm{IHH})$ and desert hedgehog $(\mathrm{DHH}))$ bind to the Patched 1 (PTCH1) receptor. This relieves the inhibition of smoothened (SMO) by PTCH1, and SMO sends signals through a series of interacting proteins, including suppressor of fused (SUFU), resulting in activation of the downstream Gli family of transcription factors: GLI1, GLI2 and GLI3. b situation in basal cell carcinoma (BCC) Loss of PTCH1 in patients with basal cell nevus syndrome predisposes them to BCC development. Sporadic BCCs routinely carry mutations in PTCH1 and TP53, consistent with their having been produced ultraviolet radiation and, in $10 \%$ of instances, in SMO. Other mutations have been implicated in BCC development, including genes that regulate skin colour, DNA damage repair genes, members of the phosphoinositide 3-kinase (PI3K) - Akt and the Wnt pathways and FOXM1.

Reprinted by permission from Nature Publishing Group: nat rev Cancer (Epstein EH), copyright 2008. ${ }^{(20)}$

\section{Diagnosis}

Mostly, dermatologists can diagnose BCCs based on their typical clinical characteristics. A morphological classification, based on different forms of growth pattern, divides BCC in subtypes. In the past, twenty-six histological subtypes of BCC have been described. ${ }^{21}$ A simplified morphological classification includes the following growth patterns: superficial, apparently multicentric; nodular, including micronodular; infiltrative, including morphoeic and a mixed type, including a combination of the above types. ${ }^{22}$ More recently BCC was divided in indolent-growth (i.e. superficial and nodular) or aggressivegrowth (i.e. infiltrative and morphoeic) subsets. ${ }^{23}$ However differentiation between these subtypes on clinical characteristics only is very difficult. Histological examination, based on a diagnostic punch biopsy, will confirm clinical diagnosis and reveal histological subtype. The only proven histologic prognosticator of biologic behaviour, and therefore a major determinant of what constitutes an appropriate therapeutic approach, is 
the architectural growth pattern. One must take into account that punch biopsy specimens have an intrinsic error rate of roughly $20 \%$ in predicting classification of BCC subtypes. $^{24}$

Lesions occur on both sun-protected and sun-exposed skin, but often have a different biology and morphology in these locations. ${ }^{23} \mathrm{~A}$ histological stepwise model of BCC progression was proposed by Kaur et al. ${ }^{25}$ They hypothesised the development of superficial-to-nodular-to-infiltrative BCC. The mechanism of this hypothesis is not yet clarified. In addition, the fact that superficial BCC is most frequently localized on the trunk and infiltrative BCC in the head/neck region, is one of the arguments to question this hypothesis.

\section{Superficial basal cell carcinoma}

Superficial BCC commonly presents as an eczema-like erythematous plaque with a diameter varying from few millimetres to centimetres (figure 2a). Superficial BCCs are frequently located on the trunk in the middle aged patient. ${ }^{10}$ By untrained physicians this tumour is commonly mistaken for eczema or psoriasis.

On haematoxylin \& eosin (H\&E) staining slides small buds of proliferating basal cells grow down from the epidermis into the superficial dermis, whilst maintaining there attachment to the base of the epidermis (figure $2 \mathrm{~b}$ ). These buds are separated by normal epidermis and grow often over a wide area, i.e. multifocal growth pattern. Slit-like retraction of the palisaded basal cells from the subjacent stroma is frequently seen.

\section{Nodular basal cell carcinoma}

Nodular BCC typically presents as a pearly erythematous or skin coloured papule with telangiectasia and rolled border and is frequently seen in the head and neck region of elderly people (figure 2c). ${ }^{10,11}$ Frequently scaling or crusting is seen. This is the commonest subtype in which tumour cells grow in rounded masses within the dermis (figure $2 \mathrm{~d}$ ). Peripheral palisading of nuclei of the basaloid cells is prominent and surrounding retraction artifact occurs frequently. The groups of cells are solid and darkly staining with little cytoplasm and show variable degrees of differentiation. The size of the nests of basaloid cells in the dermis is important because micronodular (nests $<0.15 \mathrm{~mm}$ ) has been singled out as a subgroup which is more likely to recur. For that reason this subtype is also frequently classified as an infiltrative BCC.

\section{Infiltrative basal cell carcinoma}

Infiltrative BCC mostly manifests as a depressed scariform erythematous or depigmented plaque (figure 2e). Infiltrative tumours show more frequently ulceration. Also this subtype is most frequently seen in the head and neck region.

The most important feature of this growth pattern is the shape of the group of cells in the dermis. These are of varying size, often with larger groups centrally and superficially. At the periphery groups are small and infiltrate between collagen bundles in the 
dermis (figure 2f). Palisading is poorly developed or absent. The stroma is less myxoid than in the nodular subtype but it may not be as densely collagenous as in the subgroup known as morphoeic BCC.

\section{Mixed basal cell carcinoma}

The above mentioned growth patterns can and often do occur in a combination. These cases are called mixed BCCs in which the most aggressive component is believed to predict the biological behavior and hence will determine treatment choice. A mixture of subtypes is seen in $40-74 \%$ of all BCCs. ${ }^{23,26}$ A punch biopsy can predict the most aggressive growth pattern of primary BCCs in up to eighty percent of cases. ${ }^{26}$

Interestingly, the stroma of the surrounding malignant cells appears to be important not only in the induction and cell survival of BCC but also in the progression. Several studies have shown that transplantation of BCC without its surrounding stroma will often lead to its dead. ${ }^{27}$ Under experimental conditions, it seems very difficult to cultivate $\mathrm{BCC}$.

\begin{tabular}{l|ll}
\hline & Low-risk & High-risk \\
\hline Histological growth pattern & Superficial or nodular & Infiltrative or micronodular \\
Localisation & Trunk & H-zone (Eyes, ears, lips, nose, \\
Size & $<20 \mathrm{~mm}$ & nasolabial fold) \\
Previous treatment & Primary & $>20 \mathrm{~mm}$ \\
\hline \multicolumn{2}{l}{ Table 1. Prognostic factors treatment success basal cell carcinoma } \\
\hline
\end{tabular}

\section{Therapy}

The primary goal for classifying $\mathrm{BCC}$ is to predict the probability of complete treatment response or tumour recurrence after treatment. ${ }^{28}$ Infiltrative tumours and micronodular BCCs are defined as high-risk tumours because of a higher risk of recurrence. In tumours with mixed histology, the choice of treatment should be based on the most aggressive histopathological subtype.

Currently available treatment modalities may be subdivided into invasive and noninvasive therapies. Invasive treatment options include conventional excision, Mohs' micrographic surgery (MMS) and cryosurgery (i.e. tumour debulking followed by application of liquid nitrogen). Non-invasive treatment modalities include radiotherapy, photodynamic therapy, or topical treatment with either imiquimod or 5-FU cream. The disadvantage of non-invasive modalities compared to surgery, is the absence of histological control after treatment to determine the treatment effect. Very recently, new developments have led to the treatment of $\mathrm{BCC}$ with drugs targeting the genetic pathway involved in $\mathrm{BCC}$ development. Phase 2 clinical trials, evaluating the effect of $\mathrm{HH}$ 
signalling inhibitors on $\mathrm{BCC}$ regression, have been carried out. ${ }^{29}$ These drugs are still in the experimental phase and are not yet applied within regular care.

To date, the first-line treatment of BCC is surgical excision. ${ }^{28,30}$ Excision of a BCC with a clinically tumour free margin and histological confirmation is sufficient for most BCCs. Conventional excision means surgical excision with preoperative defined margins. According to the Dutch guidelines conventional excision with $3 \mathrm{~mm}$ margin is indicated for low risk BCCs and $5 \mathrm{~mm}$ margins for high risk BCCs (table 1 ). ${ }^{31}$ In small BCCs $85 \%$ complete clearance occurs with predefined margins of $3 \mathrm{~mm}$, increasing to $95 \%$ when $5 \mathrm{~mm}$ margins are used. ${ }^{31}$ In high-risk BCCs using $5 \mathrm{~mm}$ margin, a complete clearance of $82 \%$ can be achieved. Conventional excision is an effective treatment for BCC showing 5year recurrence rates of $4-10 \%$ for primary $B C C$ and up to $17 \%$ for recurrence $B C C$. $^{32-35}$ In contrast to excision, in MMS preoperative control of the resection margins is applied by horizontal frozen sections. This will lead to $100 \%$ control of the resection margins. MMS can be an alternative treatment for primary BCC with adverse prognostic factors and is the first-line treatment for recurrent BCC in the face. ${ }^{31,36}$ Because cosmetic results after surgical excision were significantly better compared to cryosurgery for superficial and nodular BCCs with no significant difference in recurrence rates, cryosurgery is rarely used for treatment of $\mathrm{BCC} .^{37,38}$

Radiotherapy is an effective treatment for primary BCC and can be used on each body site (relapse rate: 4 to $7.5 \%$ in two to four years). ${ }^{32,39}$ In order to obtain a good cosmetic result, smaller fractions are used, which will result in longer treatment duration (usually 17-20 fractions of 3-3.5 Gy in 4-5 weeks). The patients' burden and costs associated with radiotherapy should be taken into consideration when choosing this therapy. Superficial BCC grows, like its name suggests, from the epidermis in the superficial dermis. Therefore this subtype is easy reachable for non-invasive treatment modalities like photodynamic therapy (PDT), imiquimod cream or 5-fluorouracil (5-FU) cream. The effectiveness of these therapies is lower compared to surgery, but because of good cosmetic results they are increasingly used to treat superficial BCC. ${ }^{33}$ In addition they offer the possibility to relive the busy practice of the dermatologist. Preference for one of these non-invasive treatments often depends on the experience and choice of the physician. Despite missing evidence for improved effectiveness, there seems to be a trend towards more expensive treatment modalities like PDT. With an increase in incidence of skin cancer it is important to have a pragmatic and reliable treatment for BCC. From a health provider's perspective, it is important to balance effectiveness against cost. Because these non-invasive treatments will represent an important part of this thesis, they will be discussed in more detail below. 


\section{Photodynamic therapy (PDT)}

Three important components must work together for a proper functioning of PDT, i.e. oxygen, photosensitizer and light. PDT is based on the activation of a topical applied photosensitizer (5-aminolevulinic acid (ALA) or methylaminolevulinate (MAL)) using illumination of the skin lesion with light of an appropriate wavelength. ALA or MAL is the precursor for the formation of protoporphyrin IX (PpIX) in the biosynthetic pathway of haem. PpIX is produced in larger quantities in neoplastic cells than in normal tissue. When the PpIX containing cells are irradiated, a tissue-toxic photochemical reaction takes place in which reactive singlet oxygen is formed leading to apoptosis of the cells. ${ }^{40,41}$ It is shown to be an effective and safe treatment option with good cosmetic results. $^{42}$ The major drawback of PDT is pain during treatment, sometimes causing extreme distress for the patient. In the past several light sources were used to activate PpIX. In the last few years, light emitting diode (LED) sources have shown considerable development, with improvements in design making these relatively inexpensive sources convenient for wide area irradiation and popular for patient use. Of the two photosensitizers, only MAL is licensed to treat superficial BCC, but studies showed no difference in effect compared to ALA. ${ }^{43}$ We will describe the PDT treatment protocol for BCC that is approved by the European regulatory for BCC. Before the application of the photosensitizer, non-traumatic surface preparation has to be performed (this can be with a gauze or spatula). $16 \%$ MAL (Metvix ${ }^{\circledR}$, Galderma SA) can be applied topically with a wooden spatula to the lesion in a $1 \mathrm{~mm}$ thick layer including 5 to $10 \mathrm{~mm}$ of the surrounding healthy skin. Then the area has to be covered with an occlusive dressing. To block visual light, aluminium foil must be fixed over the dressing. After an incubation period of 3 hours, the excess cream has to be wiped off and the area can be irradiated with a LED light source with an optimum wavelength of $630 \mathrm{~nm}$. It is preferred to irradiate the lesion with a light dose of $37 \mathrm{~J} / \mathrm{cm}^{2}$ per session during two treatment sessions with one week interval. After illumination, the treatment site has to be covered to prevent exposure to daylight during 48 hours. ${ }^{42,44}$

\section{Imiquimod}

Imiquimod is a synthetic compound that is a member of the imidazoquinolone family of drugs. This class of drugs is unique having the properties of topical immune response modifiers and stimulators. Previous studies point to the role of imiquimod as an immune modulator via its binding to the Toll-like receptor 7 (TLR-7) present on dendritic cells, macrophages, and monocytes. ${ }^{45}$ Subsequent activation of these cells leads to release of pro-inflammatory mediators like interleukins. These cytokines are believed to then drive the activation of the adaptive immune response toward the TH-1 or cellmediated pathway and inhibit the TH-2 pathway. This modulation of the immune response, along with creation of an antiviral state including upregulation of NK-cell activity, is thought to be important for control of viruses and tumours. Additionally, topical application of imiquimod has been shown to enhance the functional maturation and migration of Langerhans cells to regional lymph nodes, thus enhancing antigen presen- 
tation to naïve T cells and inducing a more specific immune response. In addition, imiquimod also appears to directly induce apoptosis in various tumour cell lines via the cytochrome C pathway. ${ }^{46}$ Applying imiquimod to a superficial BCC causes inflammation at the tumour site, resulting in erythema, oedema, scaling, and erosions. Because of the immune modelling effect, flew like symptoms have frequently been reported by patients. The most effective and safe method to apply imiquimod cream is once daily, five following days a week during 6 weeks. This protocol is currently approved in the EU and the USA for treatment of superficial BCC. The cream has to be applied in a thin layer including 5 to $10 \mathrm{~mm}$ of the surrounding skin.

Imiquimod cream is on the market under the brand name $5 \%$ Aldara ${ }^{\circledR}$ cream by Meda Pharma.

\section{5-Fluorouracil (5-FU)}

Five percent 5-FU was the first topical therapy approved by the U.S. Food and Drug Administration for the treatment of superficial BCC.

The mechanism of topical 5-FU is thought to be similar to that of intravenous 5-FU which is widely used in treatment of internal organ cancers. 5-FU is a chemical agent that interferes with DNA synthesis by blocking methylation of deoxyuridylic acid and inhibiting thymidylate synthetase and subsequently cell proliferation. The 5-FU induced inhibition of DNA synthesis and lack of normal RNA result in unbalanced cell growth and subsequent cell death. Rapidly multiplying tumour cells require more DNA and RNA than normal cells and therefore accumulate larger amounts of lethal 5-FU. Tumour necrosis occurs leading to local skin reaction like erythema, oedema, scaling, and erosions. This chemotherapeutic agent needs to be applied twice daily during 4 to 6 weeks, depending on the point when the skin becomes erosive. ${ }^{47,48}$ The penetration (and thus the effectiveness) may be increased by applying 5-FU cream under an occlusive dressing.

5-FU cream is commercially available as a $5 \%$ cream called Efudix ${ }^{\circledR}$ or Efudex ${ }^{\circledR}$ by Meda Pharma.

\section{Treatment cost}

The incidence of a cancer has tremendous impact on its costs of management. The more frequent the cancer, the higher the annual cost of cancer management. ${ }^{4}$ Therefore to control costs, it is essential to efficiently handle the most prevalent cancers.

It is clear that there is a big difference in treatment costs using different therapeutics for superficial BCC. Previous studies on treatment costs of NMSC performed in USA, already underlined that maintaining care of NMSC in the office-based setting is more cost-efficient than utilizing ambulatory surgical centres or hospital operating rooms. ${ }^{49}$ From this point of view non-invasive therapies are preferred over surgical excision.

PDT is performed in an outpatient clinical setting. Patients either can stay during the whole treatment or leave the hospital after the photosensitizing cream is applied to the 
tumour and return after 3 hours for illumination. As a result, cost-prices for PDT can vary tremendously between hospitals. In the Maastricht University Medical Centre, the total cost-price for A PDT treatment can amount to $1107.19 € .^{50}$ The high costs for PDT are mainly due to the overhead costs related to an inhospital treatment.

Imiquimod (Aldara ${ }^{\circledR}$ ) cream is available in sachets $(250 \mathrm{mg}$ ) packed in boxes containing 12 sachets. Every sachet can be used once. To treat one superficial BCC with Aldara ${ }^{\circledR}$ cream three boxes (i.e. 36 sachets) are needed. The price for this is $186.15 € .^{51}$

5 -FU (Efudix ${ }^{\circledR}$ ) cream is available in a tube containing $40 \mathrm{~g}$ which costs $41 € .^{51}$ This is more than sufficient to treat one superficial BCC.

The costs of a surgical excision, i.e. the first-line treatment of BCC in terms of effectiveness, show a maximum amount for the treatment of superficial BCC of around $700 € .^{52}$

To date no randomised cost-effectiveness studies comparing PDT, imiquimod and 5-FU cream for superficial BCC have been performed. There are a few cost-effectiveness modelling studies evaluating the cost-effectiveness of different treatments for superficial BCC. Caekelbergh et al. compared costs and effects of MAL-PDT with surgical excision for the management of superficial BCC. ${ }^{53}$ A more recent prospective, observational, one-arm study of Annemans et al. reported a real-life practice study to verify predictions made with the model-based economic evaluation by Caekelbergh et al. ${ }^{54}$ They showed that the total cost for MAL-PDT amounted to 297.92€. However pre-treatment costs for all patients, overhead costs, costs of the light source and additional costs like extra outpatient visits or treating side-effects were not taking into account in their economic evaluation. A study by Vanaclocha et. al reported the direct costs of surgical excision versus imiquimod for superficial BCC. ${ }^{55}$ A decision analysis model was applied under the assumption that patients not cured with first-line treatment were re-treated with surgical excision until $100 \%$ tumour clearance was achieved. The time horizon in this study was one year. The cost of imiquimod without the cost of second-line treatment of $533 €$ was found. No study involving the costs and effects of $5 \mathrm{FU}$ has been carried out. The question remains how well the estimated costs of a study model correspond to the actual treatment costs. 

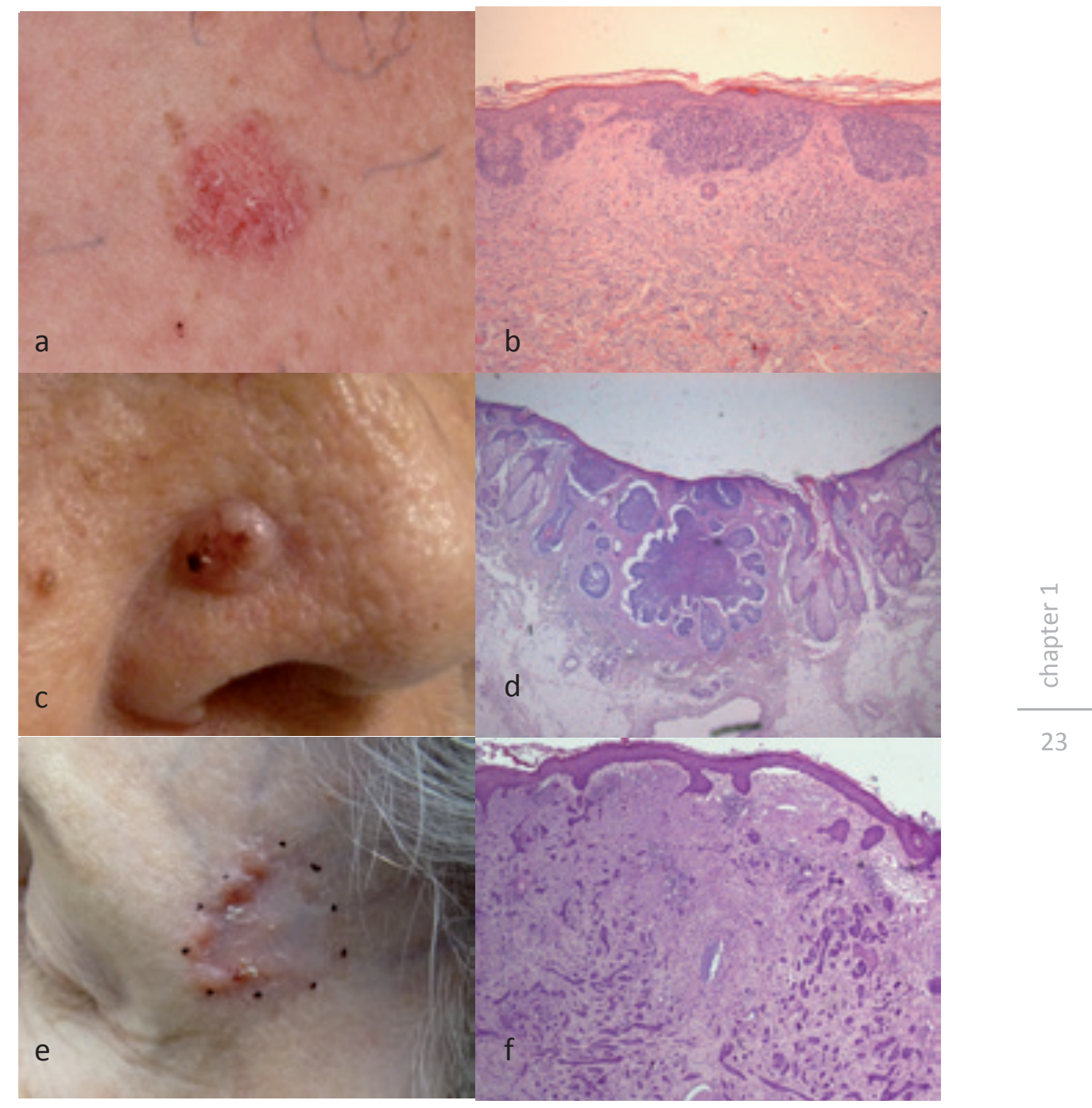

Figure 2. Clinical and histological presentation of basal cell carcinoma (BCC). (a,b) superficial BCC; (a) clinical presentation and (b) histological presentation. (c,d) nodular BCC; (c) clinical presentation and (d) histological presentation. (e,f) infiltrative BCC; (e) clinical presentation and (f) histological presentation. 


\section{Aims of this thesis}

The main aim was to evaluate which of the mostly used non-invasive treatment options for superficial BCC is the most cost-effective and should become the first-line treatment (see chapter 3).

The most effective method to treat BCC is by surgical excision. ${ }^{26,}{ }^{28}$ However, superficial BCC is easily accessible with topical treatment because the tumour cells are continuous with the epidermis and do not extend beyond the mid-dermal skin layer. An international consensus on the use of PDT in NMSC, recommended PDT as first line treatment for superficial BCC. ${ }^{42}$ However, both 5 -FU cream and imiquimod cream can be considered as an alternative treatment for this type of $\mathrm{BCC} .{ }^{55}$ Although PDT is most commonly used for treating superficial BCC, evidence that its effectiveness is higher compared to imiquimod and 5-FU cream is lacking.

Nowadays, worldwide problems with budget deficit and national debt are a hot topic. Within this framework, also health care needs to cut down. So by choosing the most cost-effective treatment option for BCC, we can save money. With equal effectiveness, imiquimod and 5-FU cream can be money-saving compared to PDT for treatment of superficial BCC.

We know that NMSC is among the most costly of all cancers. ${ }^{56}$ BCC is by far the most common type of NMSC. An increase of $80 \%$ in the total number of skin cancer patients by 2015 is expected in the Netherlands. ${ }^{57}$ The number of cases of BCC will increase by $78 \%$, with the largest increase for those younger than 65 years with a tumour outside the head-neck region. ${ }^{57}$ We know that nodular BCC is the most common subtype and it is mostly localized in the head and neck region. ${ }^{10}$ Clinical practice suggests an increase in the number of superficial BCC. This type of BCC is assumed to occur more frequently in younger patients on the trunk. ${ }^{9}$

Good cosmetic outcome is one of the advantages of non-invasive treatment options over surgery. However cosmetic results following non-invasive treatments are difficult to compare. Although qualified objective scar assessment scales are available, they are not used in dermatological studies. Usually a 4-point scale is used in dermatological scars. The reproducibility of this method has never been evaluated. Moreover, significant specific scar characteristics are lacking.

Although PDT is recommended as first line treatment for superficial BCC, the major drawback is treatment related pain sometimes causing extreme distress for the patient. Clinically, the intensity of this painful burning sensation seems to vary considerably between patients. It has been reported that the type of lesion, the site of the lesion and the size of the treated area are important factors to predict the intensity of the pain sensation. $^{58}$

Mostly BCC has a typical clinical and histological presentation. However, sometimes confusion with other epidermal tumours occurs. Distinction between skin neoplasms is 
important because they have a different biological behaviour and need different treatment. In cases where differentiation is not possible on H\&E staining slides, immunohistochemistry can provide a solution.

The aim of chapter $\mathbf{2}$ is to confirm the assumption that the proportion of superficial $B C C$ is increasing and that this subtype is most frequently localised on the trunk in young women. Based on a retrospective registry-based study we will confirm this hypothesis. Because of the rising incidence of superficial BCC, the need for an evidence based treatment concensus on superficial BCC becomes clear.

The aim of chapter $\mathbf{3}$ is to find out which of the mostly used non-invasive therapies for superficial BCC is the most (cost-)effective. This chapter consists of two parts. In chapter 3.1 the current state of affairs of the treatment of superficial BCC with non-invasive therapies is explained based on a systematic review with meta-analysis. The hypothesis underlying this study is that there is no difference in effectiveness between the most frequently used non-invasive modalities i.e. imiquimod, PDT and 5-FU. Chapter 3.2 discusses the results of a noninferiority randomised controlled trial comparing PDT, imiquimod and 5-FU cream for the treatment of primary superficial BCC. The hypothesis underlying this study was that imiquimod and 5-FU cream were at least equally effective compared to PDT for treatment of superficial BCC and may be cost-saving.

Chapter $\mathbf{4}$ is devoted to find a valid scoring system to assess the cosmetic result after non-invasive therapies in dermatology. Fiftly-four lesions following non-invasive treatment for superficial BCC were evaluated independently by three observers using the 4point Vancouver scare scale and the patient and observer scar assessment scal (POSAS). An answer is given to the question what scar characteristics are most predictive for the overall opinion of the physician and the patient.

The aim of chapter $\mathbf{5}$ is to gain insight into the intensity of and predictive factors for painful burning sensation associated with PDT. The results of a prospective cohort study are discussed.

Chapter 6 illustrates that, based on both clinical and histological characteristics, BCC can be confused with less frequent benign or malignant tumours of the skin appendages. The aim of this chapter is to find out if in those cases additional immunohistochemical staining may be useful to help differentiate between tumours.

Chapter 7 provides a general discussion about the findings of this thesis. 


\section{References}

1. Lomas A, Leonardi-Bee J, Bath-Hextall F. A systematic review of worldwide incidence of nonmelanoma skin cancer. The British journal of dermatology. 2012; 166(5): 1069-80.

2. Hollestein LM, van den Akker SA, Nijsten T, Karim-Kos HE, Coebergh JW, de Vries E. Trends of cutaneous melanoma in The Netherlands: increasing incidence rates among all Breslow thickness categories and rising mortality rates since 1989. Annals of oncology : official journal of the European Society for Medical Oncology / ESMO. 2012; 23(2): 524-30.

3. Flohil SC, de Vries E, Neumann HA, Coebergh JW, Nijsten T. Incidence, prevalence and future trends of primary basal cell carcinoma in the Netherlands. Acta dermato-venereologica. 2011; 91(1): 24-30.

4. Housman TS, Feldman SR, Williford PM, Fleischer AB, Jr., Goldman ND, Acostamadiedo JM, et al. Skin cancer is among the most costly of all cancers to treat for the Medicare population. Journal of the American Academy of Dermatology. 2003; 48(3): 425-9.

5. Spates ST, Mellette JR, Jr., Fitzpatrick J. Metastatic basal cell carcinoma. Dermatologic surgery : official publication for American Society for Dermatologic Surgery [et al]. 2003; 29(6): 650-2.

6. Karagas MR, Stukel TA, Greenberg ER, Baron JA, Mott LA, Stern RS. Risk of subsequent basal cell carcinoma and squamous cell carcinoma of the skin among patients with prior skin cancer. Skin Cancer Prevention Study Group. JAMA : the journal of the American Medical Association. 1992; 267(24): 3305-10.

7. Roewert-Huber J, Lange-Asschenfeldt B, Stockfleth E, Kerl H. Epidemiology and aetiology of basal cell carcinoma. The British journal of dermatology. 2007; 157 Suppl 2: 47-51.

8. Flohil SC, Koljenovic S, de Haas ER, Overbeek LI, de Vries E, Nijsten T. Cumulative risks and rates of subsequent basal cell carcinomas in the Netherlands. The British journal of dermatology. 2011; 165(4): 874-81.

9. Bastiaens MT, Hoefnagel JJ, Bruijn JA, Westendorp RG, Vermeer BJ, Bouwes Bavinck $J N$. Differences in age, site distribution, and sex between nodular and superficial basal cell carcinoma indicate different types of tumors. The Journal of investigative dermatology. 1998; 110(6): 880-4.

10. Betti R, Radaelli G, Mussino F, Menni S, Crosti C. Anatomic location and histopathologic subtype of basal cell carcinomas in adults younger than 40 or 90 and older: any difference? Dermatologic surgery : official publication for American Society for Dermatologic Surgery [et al]. 2009; 35(2): 201-6.

11. Raasch BA, Buettner PG, Garbe C. Basal cell carcinoma: histological classification and body-site distribution. The British journal of dermatology. 2006; 155(2): 401-7. 
12. de Vries E, Louwman M, Bastiaens M, de Gruijl F, Coebergh JW. Rapid and continuous increases in incidence rates of basal cell carcinoma in the southeast Netherlands since 1973. The Journal of investigative dermatology. 2004; 123(4): 634-8.

13. Staples MP, Elwood M, Burton RC, Williams JL, Marks R, Giles GG. Non-melanoma skin cancer in Australia: the 2002 national survey and trends since 1985. The Medical journal of Australia. 2006; 184(1): 6-10.

14. Sng J, Koh D, Siong WC, Choo TB. Skin cancer trends among Asians living in Singapore from 1968 to 2006. Journal of the American Academy of Dermatology. 2009; 61(3): 426-32.

15. Youssef KK, Van Keymeulen A, Lapouge G, Beck B, Michaux C, Achouri Y, et al. Identification of the cell lineage at the origin of basal cell carcinoma. Nature cell biology. 2010; 12(3): 299-305.

16. Toftgard R. Hedgehog signalling in cancer. Cellular and molecular life sciences : CMLS. 2000; 57(12): 1720-31.

17. Chiang C, Swan RZ, Grachtchouk M, Bolinger M, Litingtung $Y$, Robertson EK, et al. Essential role for Sonic hedgehog during hair follicle morphogenesis. Developmental biology. 1999; 205(1): 1-9.

18. Hahn H, Wicking C, Zaphiropoulous PG, Gailani MR, Shanley S, Chidambaram A, et al. Mutations of the human homolog of Drosophila patched in the nevoid basal cell carcinoma syndrome. Cell. 1996; 85(6): 841-51.

19. Johnson RL, Rothman AL, Xie J, Goodrich LV, Bare JW, Bonifas JM, et al. Human homolog of patched, a candidate gene for the basal cell nevus syndrome. Science. 1996; 272(5268): 1668-71.

20. Epstein EH. Basal cell carcinomas: attack of the hedgehog. Nature reviews Cancer. 2008; 8(10): 743-54.

21. Rippey JJ. Why classify basal cell carcinomas? Histopathology. 1998; 32(5): 393-8.

22. Russell EB, Carrington PR, Smoller BR. Basal cell carcinoma: a comparison of shave biopsy versus punch biopsy techniques in subtype diagnosis. Journal of the American Academy of Dermatology. 1999; 41(1): 69-71.

23. Crowson AN. Basal cell carcinoma: biology, morphology and clinical implications. Modern pathology : an official journal of the United States and Canadian Academy of Pathology, Inc. 2006; 19 Suppl 2: S127-47.

24. Kaur P, Mulvaney M, Carlson JA. Basal cell carcinoma progression correlates with host immune response and stromal alterations: a histologic analysis. The American Journal of dermatopathology. 2006; 28(4): 293-307.

25. Roozeboom MH, Mosterd K, Winnepenninckx VJ, Nelemans PJ, Kelleners-Smeets NW. Agreement between histological subtype on punch biopsy and surgical excision in primary basal cell carcinoma. Journal of the European Academy of Dermatology and Venereology : JEADV. 2012. 
26. Lyles TW, Freeman RG, Knox JM. Transplantation of basel cell epitheliomas. The Journal of investigative dermatology. 1960; 34: 353.

27. Mosterd K, Arits AH, Thissen MR, Kelleners-Smeets NW. Histology-based treatment of basal cell carcinoma. Acta dermato-venereologica. 2009; 89(5): 454-8.

28. Lear JT. Oral hedgehog-pathway inhibitors for basal-cell carcinoma. The New England journal of medicine. 2012; 366(23): 2225-6.

29. Bath-Hextall FJ, Perkins W, Bong J, Williams HC. Interventions for basal cell carcinoma of the skin. Cochrane Database Syst Rev. 2007; (1): CD003412.

30. Beljaards RC, Canninga-van Dijk MR, Krekels GA, Olderbruger F, Reinders JG, Sigurdsson $V$, et al. Evidence based richtlijn behandeling van het basaalcelcarcinoom. 2007: http://www.cbo.nl/Downloads/320/rl_bcc_07.pdf.

31. Avril MF, Auperin A, Margulis A, Gerbaulet A, Duvillard P, Benhamou E, et al. Basal cell carcinoma of the face: surgery or radiotherapy? Results of a randomized study. British journal of cancer. 1997; 76(1): 100-6.

32. Rhodes LE, de Rie MA, Leifsdottir R, Yu RC, Bachmann I, Goulden V, et al. Five-year follow-up of a randomized, prospective trial of topical methyl aminolevulinate photodynamic therapy vs surgery for nodular basal cell carcinoma. Archives of dermatology. 2007; 143(9): 1131-6.

33. Rowe DE, Carroll RJ, Day CL, Jr. Long-term recurrence rates in previously untreated (primary) basal cell carcinoma: implications for patient follow-up. The Journal of dermatologic surgery and oncology. 1989; 15(3): 315-28.

34. Mosterd K, Krekels GA, Nieman FH, Ostertag JU, Essers BA, Dirksen CD, et al. Surgical excision versus Mohs' micrographic surgery for primary and recurrent basal-cell carcinoma of the face: a prospective randomised controlled trial with 5 years' follow-up. The lancet oncology. 2008; 9(12): 1149-56.

35. Smeets NW, Krekels GA, Ostertag JU, Essers BA, Dirksen CD, Nieman FH, et al. Surgical excision vs Mohs' micrographic surgery for basal-cell carcinoma of the face: randomised controlled trial. Lancet. 2004; 364(9447): 1766-72.

36. Thissen MR, Nieman FH, Ideler AH, Berretty PJ, Neumann HA. Cosmetic results of cryosurgery versus surgical excision for primary uncomplicated basal cell carcinomas of the head and neck. Dermatologic surgery : official publication for American Society for Dermatologic Surgery [et al]. 2000; 26(8): 759-64.

37. Kuijpers DI, Thissen MR, Berretty PJ, Ideler FH, Nelemans PJ, Neumann MH. Surgical excision versus curettage plus cryosurgery in the treatment of basal cell carcinoma. Dermatologic surgery : official publication for American Society for Dermatologic Surgery [et al]. 2007; 33(5): 579-87.

38. Hall VL, Leppard BJ, McGill J, Kesseler ME, White JE, Goodwin P. Treatment of basal-cell carcinoma: comparison of radiotherapy and cryotherapy. Clin Radiol. 1986; 37(1): 33-4. 
39. Kennedy JC, Pottier RH, Pross DC. Photodynamic therapy with endogenous protoporphyrin IX: basic principles and present clinical experience. Journal of photochemistry and photobiology B, Biology. 1990; 6(1-2): 143-8.

40. Peng $Q$, Berg K, Moan J, Kongshaug M, Nesland JM. 5-Aminolevulinic acid-based photodynamic therapy: principles and experimental research. Photochemistry and photobiology. 1997; 65(2): 235-51.

41. Morton CA, McKenna KE, Rhodes LE. Guidelines for topical photodynamic therapy: update. The British journal of dermatology. 2008; 159(6): 1245-66.

42. Kuijpers DI, Thissen MR, Thissen CA, Neumann MH. Similar effectiveness of methyl aminolevulinate and 5-aminolevulinate in topical photodynamic therapy for nodular basal cell carcinoma. Journal of drugs in dermatology : JDD. 2006; 5(7): 642-5.

43. Braathen LR, Szeimies RM, Basset-Seguin N, Bissonnette R, Foley P, Pariser D, et al. Guidelines on the use of photodynamic therapy for nonmelanoma skin cancer: an international consensus. International Society for Photodynamic Therapy in Dermatology, 2005. Journal of the American Academy of Dermatology. 2007; 56(1): 125-43.

44. Navi D, Huntley A. Imiquimod 5 percent cream and the treatment of cutaneous malignancy. Dermatology online journal. 2004; 10(1): 4.

45. Schon M, Bong AB, Drewniok C, Herz J, Geilen CC, Reifenberger J, et al. Tumorselective induction of apoptosis and the small-molecule immune response modifier imiquimod. Journal of the National Cancer Institute. 2003; 95(15): 1138-49.

46. Breuninger H, Sebastian G, Kortmann RD, Schwipper V, Werner J, Garbe C. [Brief guidelines: Basal cell carcinoma of the skin]. Journal der Deutschen Dermatologischen Gesellschaft = Journal of the German Society of Dermatology : JDDG. 2006; 4(5): 441-3.

47. Goette DK. Topical chemotherapy with 5-fluorouracil. A review. Journal of the American Academy of Dermatology. 1981; 4(6): 633-49.

48. http://www.azm.nl/Passantentarieflijst_per_1-6.pdf.

49. College voor zorgverzekeringen. Farmacotherapeutisch Kompas. 2010.

50. Essers BA, Dirksen CD, Nieman FH, Smeets NW, Krekels GA, Prins MH, et al. Costeffectiveness of Mohs Micrographic Surgery vs Surgical Excision for Basal Cell Carcinoma of the Face. Archives of dermatology. 2006; 142(2): 187-94.

51. John Chen G, Yelverton CB, Polisetty SS, Housman TS, Williford PM, Teuschler HV, et al. Treatment patterns and cost of nonmelanoma skin cancer management. Dermatologic surgery : official publication for American Society for Dermatologic Surgery [et al]. 2006; 32(10): 1266-71.

52. Caekelbergh K, Annemans L, Lambert J, Roelandts R. Economic evaluation of methyl aminolaevulinate-based photodynamic therapy in the management of actinic keratosis and basal cell carcinoma. The British journal of dermatology. 2006; 155(4): 784-90. 
53. Annemans L, Caekelbergh K, Roelandts R, Boonen H, Leys C, Nikkels AF, et al. Reallife practice study of the clinical outcome and cost-effectiveness of photodynamic therapy using methyl aminolevulinate (MAL-PDT) in the management of actinic keratosis and basal cell carcinoma. European journal of dermatology : EJD. 2008; 18(5): 539-46.

54. Vanaclocha F, Dauden E, Badia X, Guillen C, Conejo-Mir JS, Sainz de Los Terreros M, et al. Cost-effectiveness of treatment of superficial basal cell carcinoma: surgical excision vs. imiquimod 5\% cream. The British journal of dermatology. 2007; 156(4): 769-71.

55. Telfer NR, Colver GB, Morton CA. Guidelines for the management of basal cell carcinoma. The British journal of dermatology. 2008; 159(1): 35-48.

56. de Vries E, van de Poll-Franse LV, Louwman WJ, de Gruijl FR, Coebergh JW. Predictions of skin cancer incidence in the Netherlands up to 2015. The British journal of dermatology. 2005; 152(3): 481-8.

57. Grapengiesser S, Ericson M, Gudmundsson F, Larko O, Rosen A, Wennberg AM. Pain caused by photodynamic therapy of skin cancer. Clinical and experimental dermatology. 2002; 27(6): 493-7. 


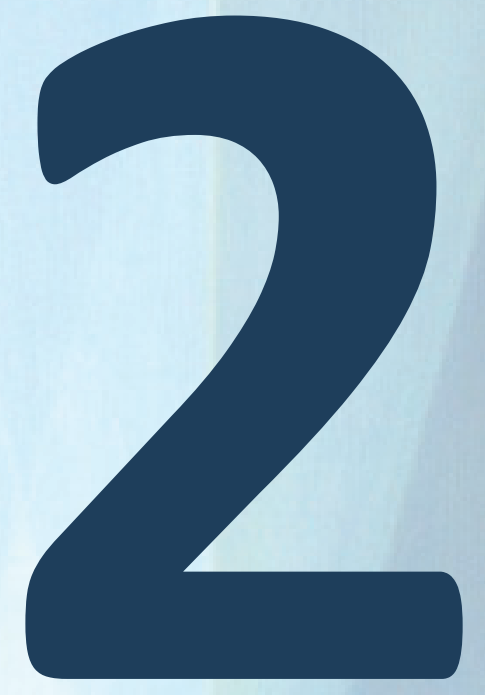

\section{Trends in the incidence of basal cell carcinoma by histopathological subtype}

A. Arits, M. Schlangen, P. Nelemans, N. Kelleners-Smeets.

Trends in the incidence of basal cell carcinoma by histopathological subtype.

J Eur Acad Dermatol Venereol 2011;25(5): 565-9. 



\section{Abstract}

Background. As a result of the high prevalence, basal cell carcinoma (BCC) causes a significant and expensive health care problem.

Objective. In this study, we evaluate the proportional increase in BCC by histological subtype over the two last decades.

Methods. We retrospectively reviewed all primary histological confirmed BCCs diagnosed in the Maastricht University Medical Centre in The Netherlands in the years 1991, 1999 and 2007.

Results. An annual increase of the number of BCCs of $7 \%$ for both genders was shown. The age-standardized incidence rates for BCC increased between 1991 and 2007 from 54.2 to 162.1 per 100000 men and from 61.7 to 189.8 per 100000 females. The proportion of superficial BCC increased significantly from $17.6 \%$ to $30.7 \%$.

Conclusion. The incidence of BCC is continuing to increase this century. The observed shift to the superficial histological subtype, which can be treated non-surgically, might reduce the workload in the busy dermatologists practice. 


\section{Introduction}

Basal cell carcinoma (BCC) is the most common type of all (skin) cancers in the white population. Worldwide only few cancer registries record BCC and thus exact incidence rates are lacking, probably because mortality rates are low.

As a result of the high prevalence, BCC is starting to represent a large and expensive health care problem. Worldwide the overall incidence is increasing significantly by about $3-10 \%$ annually. ${ }^{1,2}$

Nodular BCC ( $\mathrm{BBCC}$ ) has always been the most common subtype (proportion 57.678.7\%). Superficial BCC (sBCC; proportion 14.8-17.5\%) and infiltrative BCC (iBCC; proportion $6.2-26.2 \%$ ), comprising several aggressive subtypes, are less common. ${ }^{3-7}$ In the nineties new insights about basic characteristics of the different histological subtypes of $\mathrm{BCC}$ were published. ${ }^{4-6} \mathrm{SBCC}$ is diagnosed at a younger age and is most commonly located on the trunk, whereas the other histological subtypes are mostly seen in the head and neck region. ${ }^{4-6,8}$ Although clinical experience suggests an increase in the proportion of sBCC, so far this could only be confirmed in one Australian study. ${ }^{9}$

In this report we want to confirm the hypothesis of a relative increase of SBCC and verify the dissimilarities of the basic characteristics of histological subtypes. The supposed increasing proportion of $\mathrm{SBCC}$ can lead to a greater applicability of non-invasive techniques for treating $\mathrm{BCC}$ and ease the busy dermatologists practice.

\section{Materials and methods}

This registry-based study was performed in the Maastricht University Medical Centre (MUMC), a referral hospital for dermatologic oncology in The Netherlands but also the only hospital in the region of Maastricht.

All primary BCCs which were histopathologically diagnosed in the MUMC, in the years 1991, 1999 and 2007 were retrospectively studied by using the PALGA (pathologisch anatomisch landelijk geautomatiseerd archief) database. This is an electronic archive recording all pathological diagnoses made by affiliated pathology departments. By using a combination of the search term 'basal cell carcinoma' and the limitation 'years 1991, 1999 and 2007', we retrieved 1894 BCCs occurring in 1356 patients.

Excluded were slides sent from other laboratories to our department of Pathology for confirmation of diagnosis (239 patients, 299 BCCs), patients from geographical areas other than those of the adherence area of the MUMC (129 patients, 197 BCCs), patients with recurrent BCC (114 patients, 118 BCCs) and patients with a genetic aetiology of the skin tumour, like Xeroderma Pigmentosum and Basal Cell Nevus Syndrome (12 patients, 75 BCCs). These exclusion criteria were chosen to ensure that the observed changes in histological subtype are minimally affected by specific population-based characteristics. 
Patient's records and pathology reports were used to collect patient and tumour characteristics. Patient data included gender, age at diagnosis and number of BCC in medical history. Tumour data included localization, size, histological subtype and therapy. Tumour localization was classified into four categories: head and neck, trunk, upper and lower extremities. For tumour size the largest diameter of the clinical lesion in millimetres was used.

The histological subclassification of BCC used by the pathologists follows the suggestion of the World Health Organization (WHO). Because several editions have been published and used over time, we converted the original histopathological diagnosis as suggested by Rippey to: superficial, nodular and infiltrative BCC. ${ }^{10}$ In cases of mixed architecture, we classified the tumour into the group of the most aggressive component. If histology was not classified by the pathologist, the histological type was considered as unspecified. Sometimes the tumor was excised immediately without previously taken a biopsy. In these cases the excision slide was used to determine histopathological tumor type.

\section{Statistical analysis}

Gender-specific age-standardized incidence rates per 100000 inhabitants were calculated using the Dutch population in the year 1999 as standard. Five-year age groups were used. Data were derived from the archives of the central bureau of statistics (Statistics Netherlands).

The chi-square test was used to test for differences in proportions between the groups of patients identified in the years 1991, 1999 and 2007. Analysis of variance was used to test for differences in means between the 3-year groups. Analysis of trends over time was performed using logistic regression analysis, where year was entered as an ordinal independent variable.

A two-sided $P$-value $<0.05$ was considered as statistically significant.

All statistical analyses were performed using the program Statistical Package for the Social Sciences for Windows version 15.0. The graphs and figures were obtained with Microsoft Office Excel 2003.

\section{Results}

862 patients with 1205 BCCs met the inclusion criteria.

\section{Trends}

We found an increase in the number of BCCs that were histopathologically diagnosed in the MUMC between 1991, 1999 and 2007 (resp. 153 vs. 372 vs. 680 BCCs) (Figure 1). The age-standardized incidence rate for BCC in men and women calculated per 100000 inhabitants are listed in table 1 . The results are compatible with a mean annual increase 
of 7\% for both genders. The mean annual increase of BCC between the years 1991 and 1999 is $11 \%$ compared to 3\% between the years 1999 and 2007.

The $\mathrm{nBCC}$ remains the most common histological subtype, although the percentage of nBCC decreased from $60.8 \%$ in 1991 to $40.6 \%$ in 2007 (Table 2). We found a significant increase in the proportion of sBCC from $17.6 \%$ in 1991 to $30.7 \%$ in $2007(P<0.0001)$. The proportion of iBCC also increased from $11.1 \%$ in 1991 to $28.7 \%$ in $2007(P<0.0001)$ (Table 2).

The percentage of BCCs located in the head and neck region decreased from $73.9 \%$ in 1991 to $44.3 \%$ in 2007, while the percentage of BCCs located on the trunk increased from $17.6 \%$ to $45.3 \%$ in 1991 and 2007, respectively (Table 2).

The mean tumour size did not change significantly over the years, but the mean number of BCC per person increased.

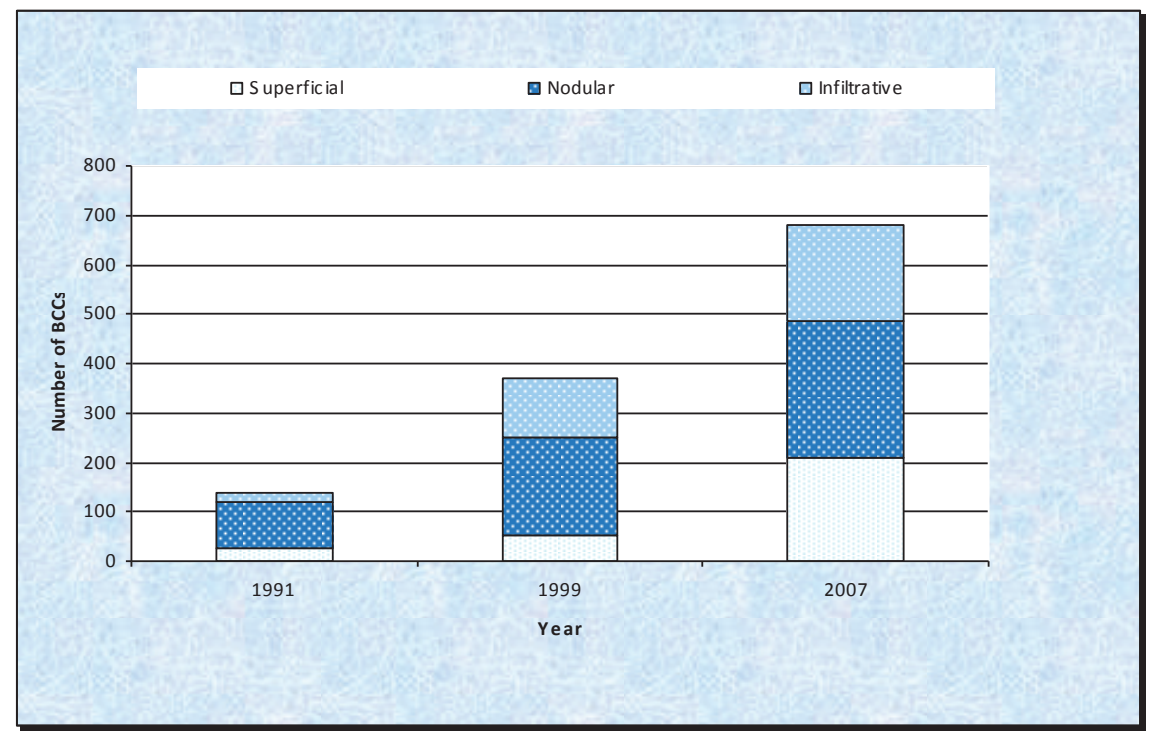

Figure 1. Total number of basal cell carcinoma (BCC) per histological subtype per year

\section{Basic characteristics of histological subtypes}

The mean age of patients with SBCC was significantly lower than that of patients with other histological subtypes (65 years compared to 69.5 years; $P<0.0001$ ) (Table 3 ). The mean tumour size did not differ comparing the three histological subtypes (Table 3); $65.1 \%$ of $\mathrm{nBCC}$ and $74.4 \%$ of $\mathrm{iBCC}$ were localized in the head and neck region, while $14.3 \%$ of all SBCC was located in the head and neck region $(P<0.0001)$ (Table 3). sBCC was more common on the trunk (66.2\%) (Table 3 ). For each histological subtype, more women than men were diagnosed. 


\begin{tabular}{l|llllll}
\hline & \multicolumn{3}{|c}{$\mathbf{1 9 9 1}$} & \multicolumn{1}{c}{$\mathbf{1 9 9 9}$} & \multicolumn{2}{c}{$\mathbf{2 0 0 7}$} \\
\hline & Men & Females & Men & Females & Men & Females \\
Superficial BCC & 8.2 & 5.1 & 12.5 & 27.7 & 43.1 & 39.5 \\
Nodular BCC & 35.2 & 41.9 & 71.6 & 83.2 & 61.2 & 97 \\
Infiltrative BCC & 6.8 & 6.0 & 38.1 & 46.0 & 57.8 & 53.3 \\
BCC & $\mathbf{5 4 . 2}$ & $\mathbf{6 1 . 7}$ & $\mathbf{1 2 3 . 1}$ & $\mathbf{1 5 7 . 8}$ & $\mathbf{1 6 2 . 1}$ & $\mathbf{1 8 9 . 8}$ \\
\hline
\end{tabular}

*Rates per 100000

Table 1. Age-standardized incidence rates per histological type of basal cell carcinoma (BCC) per year

\begin{tabular}{l|llll}
\hline Year & 1991 & 1999 & $\mathbf{2 0 0 7}$ & Total \\
\hline Number patients & 113 & 309 & 440 & 862 \\
Number tumours & 153 & 372 & 680 & 1205 \\
Women/men* & $55.8 / 44.2$ & $57.6 / 42.4$ & $53.4 / 46.6$ & $54.4 / 44.1$ \\
& $(63 / 50)$ & $(178 / 131)$ & $(235 / 205)$ & $(476 / 386)$ \\
Mean patient age in years & 66.2 & 68.4 & 68.3 & 68.1 \\
Histological subtype* & & & & \\
Superficial & $17.6(27)$ & $13.7(51)$ & $30.7(209)$ & $23.8(287)$ \\
Nodular & $60.8(93)$ & $53.2(198)$ & $40.6(276)$ & $47.1(567)$ \\
Infiltrative & $11.1(17)$ & $32.3(120)$ & $28.7(195)$ & $27.6(332)$ \\
Unspecified & $10.5(16)$ & $0.8(3)$ & $0.0(0)$ & $1.6(19)$ \\
Mean number basal cell carcinoma & 1.35 & 1.2 & 1.6 & 1.4 \\
/ patient & & & & 9.0 \\
Mean tumour size (mm) & 9.0 & 9.5 & 8.8 & \\
Tumour localization* & & & & \\
Head/neck & $73.9(113)$ & $69.6(259)$ & $44.3(301)$ & $55.9(674)$ \\
Trunk & $17.6(27)$ & $19.9(74)$ & $45.3(308)$ & $33.9(408)$ \\
Arms & $0.0(0)$ & $4.0(15)$ & $4.1(28)$ & $3.6(43)$ \\
Legs & $4.6(7)$ & $5.9(22)$ & $6.3(43)$ & $6.0(72)$ \\
Unspecified & $3.9(6)$ & $0.5(2)$ & $0.0(0)$ & $0.7(8)$ \\
\hline *Data are presented as percentages & (no.) & & & \\
Table 2. Tumour and patient characteristics per year & & & \\
\hline
\end{tabular}

\section{Discussion}

This registry-based study is the first to report subtype-specific incidence rates for BCC in Europe.

The $\mathrm{nBCC}$ remains the most common histological subtype, but a significant increase in the proportion of $\mathrm{SBCC}$ and $\mathrm{iBCC}$ was reported. Furthermore $\mathrm{SBCC}$ occurred in younger patients and was predominantly located on the trunk compared to the $\mathrm{nBCC}$ and $\mathrm{BBCC}$, which were mainly localized in the head and neck region.

Epidemiological data of most types of cancer in the Netherlands can be retrieved from the eight Comprehensive Cancer Centres (CCCs), comprising electronic cancer registration of multiple hospitals. However, data on BCC subtypes are not registered. 


\begin{tabular}{l|lll}
\hline Histological subtype & Superficial BCC & Nodular BCC & Infiltrative BCC \\
\hline Number patients & 160 & 441 & 246 \\
Number tumours & 287 & 567 & 332 \\
Mean patient age in years & 65 & 68 & 71 \\
Mean tumour size (mm) & 8 & 8 & 10 \\
Women/men* & $52.5 / 47.5$ & $58.3 / 41.7$ & $50.8 / 49.2$ \\
& $(84 / 76)$ & $(257 / 184)$ & $(125 / 121)$ \\
Tumour localization* & $14.3(41)$ & $65.1(369)$ & $74.4(247)$ \\
Head/neck & $66.2(190)$ & $27.2(154)$ & $18.7(62)$ \\
Trunk & $6.3(18)$ & $3.2(18)$ & $2.1(7)$ \\
Arms & $12.5(36)$ & $3.7(21)$ & $4.5(15)$ \\
Legs & $0.7(2)$ & $0.9(5)$ & $0.3(1)$ \\
Unspecified & &
\end{tabular}

Because we were especially interested in the proportional increase of each histological subtype, we had to turn to the PALGA-registry, a hospital based registration of BCC by histological subtype. A part of the observed increase in incidence of BCC may result from better histological verification and more complete registration. Because the MUMC is a referral centre for dermatologic oncology in which almost all BCC suspect lesions are histologically confirmed by biopsy, the histological registration of BCC in the MUMC adherence area over the last decades has been rather complete.

Previous studies already showed a remarkable difference in some basic characteristics of BCC histological subtypes. ${ }^{2,4,5}$ The results of this study are in accordance with those reported by Bastiaens et al., who also showed a predominance of SBCC on the trunk in younger patients compared to nBCCs which were often located in the head and neck region. ${ }^{4}$

On top, we find a proportional increase in SBCC from $17.6 \%$ in 1991 to $30.7 \%$ in 2007. Two hypotheses could contribute to the tremendous increase in the proportion of SBCC over the last two decades and their preferential localization on the trunk. The first hypothesis is that $\mathrm{SBCC}$ develops from intense intermittent sun exposure (recreational sun exposure during vacation), whereas $\mathrm{nBCC}$ and $\mathrm{B} B C \mathrm{C}$ are believed to arise from chronically sun exposed regions (outside work). ${ }^{3,4,6}$ This supposed difference in aetiology could explain that $\mathrm{SBCC}$ will be predominantly localized on the trunk, while $\mathrm{nBCC}$ and $\mathrm{iBCC}$ will arise more commonly in the head and neck region. ${ }^{4-6,8}$ Since the seventies, an increase in recreational sun exposure was seen that can lead to the increase in SBCC. A second hypothesis is that BCC progresses from superficial to nodular to infiltrative subtype. This so-called histological stepwise model of BCC progression was proposed by Kaur et al. $^{8}$ Together with the higher awareness of skin malignancies among the general population and health care professionals ${ }^{11}$, this second hypothesis could also contribute to the observed increase in the proportion of SBCC. This histological stepwise model also provides an explanation for the observation that the mean age of patients differed with the histological subtype: mean age of patients with a SBCC was 65 years compared to 
68 years for $\mathrm{nBCC}$ and 71 years for $\mathrm{B} B C \mathrm{C}$. The trigger to develop into a more 'aggressive' histological subtype is unknown.

However, the above-mentioned hypotheses can not explain the observed increase in the proportion of $\mathrm{iBCC}$. Genetic factors may play a role; further research is needed on this topic. At present time there is no clear relationship between the type of genetic change and a specific histological subtype. ${ }^{12}$

Additional findings in this study are a high proportional increase of BCCs located on the trunk, higher age-standardized incidence rates in women compared to men and a higher increase in incidence of BCC between 1991 and 1999 compared to 1999 and 2007. These three findings are compatible with a better health awareness and more healthseeking behaviour, factors which should not be underestimated. Possibly women are more aware of their body and consult the doctor more for these lesions compared to men. Furthermore the MUMC is a reference centre for dermatologic oncology in which total body check of all patients is a standard procedure. So the increase in SBCC on the trunk may also be due to higher case findings. The effort of sun avoidance campaigns could possibly help to explain the decline in overall BCC increase over the last decade (3\% between 1999 and 2007 compared to 11\% between 1991 and 1999).

A limitation of this study may be that data were derived from one university hospital in the Netherlands. Data on BCC subtypes, that are needed to evaluate the proportional increase of BCC by histological subtype, had to be derived from a hospital based registry. Unfortunately, these data were not available from the Dutch cancer registries. The MUMC is a referral centre for dermatologic oncology and therefore the BCCs diagnosed could represent a selected sample. In order to prevent selection bias we excluded the patients who did not live in the adherence area of the MUMC. Therefore, it seems reasonable to assume that the observed changes in proportions of BCC subtypes in the MUMC adherence region are representative of a nationwide trend. Of course, it would be interesting if other studies could corroborate the findings in this study.

In conclusion, the increase in incidence of BCC confronts specialists and governments worldwide with higher costs and increasing demands for capacity to treat BCC. The observed increase in SBCC, which can be treated by less costly and time-consuming modalities, might cause some relief to the dermatologists practice. 


\section{References}

1. Karagas MR, Greenberg ER, Spencer SK et al. Increase in incidence rates of basal cell and squamous cell skin cancer in New Hampshire, USA. New Hampshire Skin Cancer Study Group. Int J Cancer 1999; 81: 555-9.

2. Roewert-Huber J, Lange-Asschenfeldt B, Stockfleth E et al. Epidemiology and aetiology of basal cell carcinoma. Br J Dermatol 2007; 157 Suppl 2: 47-51.

3. de Vries $E$, Louwman $M$, Bastiaens $M$ et al. Rapid and continuous increases in incidence rates of basal cell carcinoma in the southeast Netherlands since 1973. J Invest Dermatol 2004; 123: 634-8.

4. Bastiaens MT, Hoefnagel JJ, Bruijn JA et al. Differences in age, site distribution, and sex between nodular and superficial basal cell carcinoma indicate different types of tumors. J Invest Dermatol 1998; 110: 880-4.

5. Scrivener Y, Grosshans E, Cribier B. Variations of basal cell carcinomas according to gender, age, location and histopathological subtype. Br J Dermatol 2002; 147: 41-7.

6. McCormack CJ, Kelly JW, Dorevitch AP. Differences in age and body site distribution of the histological subtypes of basal cell carcinoma. A possible indicator of differing causes. Arch Dermatol 1997; 133: 593-6.

7. Betti R, Inselvini E, Carducci $M$ et al. Age and site prevalence of histologic subtypes of basal cell carcinomas. Int J Dermatol 1995; 34: 174-6.

8. Kaur P, Mulvaney M, Carlson JA. Basal cell carcinoma progression correlates with host immune response and stromal alterations: a histologic analysis. Am J Dermatopathol 2006; 28: 293-307.

9. Raasch BA, Buettner PG, Garbe C. Basal cell carcinoma: histological classification and body-site distribution. Br J Dermatol 2006; 155: 401-7.

10. Rippey JJ. Why classify basal cell carcinomas? Histopathology 1998; 32: 393-8.

11. Halpern AC, Kopp LJ. Awareness, knowledge and attitudes to non-melanoma skin cancer and actinic keratosis among the general public. Int J Dermatol 2005; 44: 10711.

12. Lacour JP. Carcinogenesis of basal cell carcinomas: genetics and molecular mechanisms. Br J Dermatol 2002; 146 Suppl 61: 17-9. 


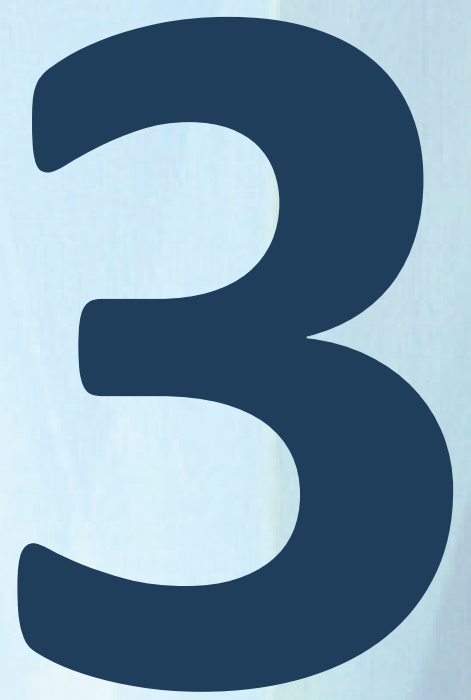

\section{Evidence based treatment of superficial basal cell carcinoma}

M. Roozeboom, A. Arits, P. Nelemans, N kelleners-Smeets.

Overall treatment success after treatment of primary superficial basal cell carcinoma: a systematic review and metaanalysis of randomised and non-randomised trials. Br J Dermatol. 2012 May 21.

doi: 10.1111/j.1365-2133.2012.11061.x. [Epub ahead of print]

A. Arits, B. Essers, K. Mosterd, E. Spoorenberg, A. Sommer, M. De Rooij, H. van Pelt, P. Quaedvlieg, G. Krekels, P. van Neer, J. Rijzewijk, A. van Geest, P. Steijlen, P. Nelemans, N. Kelleners-Smeets.

Photodynamic therapy versus topical imiquimod versus topical 5-fluorouracil for treatment of superficial basal cell carcinoma: a single blind, noninferiority, randomised controlled trial and cost-effectiveness analysis.

Manuscript submitted 



\title{
3.1 Treatment of superficial basal cell carcinoma: a systematic review with meta-analysis
}

\begin{abstract}
Background: Several non-invasive treatment modalities are available for superficial basal cell carcinoma (sBCC).
\end{abstract}

Objectives: This systematic review has the aim to determine residue, recurrence and tumour- free survival probabilities of patients with primary SBCC treated with the currently most frequently used therapies.

Methods: Pubmed (January 1946 - October 2010), EMBASE (January 1989 - October 2010), Cochrane databases (January 1993 - October 2010) and reference lists were searched without date restriction. Inclusion criteria were studies that included primary, histologically proven $\mathrm{SBCC}$, had to report on residue and/or recurrence probabilities after treatment and had to have a minimum follow-up period of 12 weeks. Both randomised and non-randomised studies were included. Primary and secondary outcomes were probability of complete response and tumour-free survival, respectively. Two independent reviewers selected 36 studies (14 randomised and 22 non-randomised) and extracted residue, cumulative recurrence and tumour-free survival probabilities.

Results: Pooled estimates of percentages of sBCC with complete response at 12 weeks posttreatment derived from 28 studies were $86.2 \%(95 \% \mathrm{Cl} 82-90 \%)$ and $79.0 \%(95 \% \mathrm{Cl}$ $71-87 \%)$ for imiquimod and photodynamic therapy, respectively. With respect to tumourfree survival at one year, pooled estimates derived from 23 studies were $87.3 \%$ for imiquimod (95\% Cl $84-91 \%$ ) and $84.0 \%$ for PDT (95\% Cl 78-90\%). Only a small number of studies reported on results of SBCC treatment with 5-fluorouracil (2), surgical excision (1) and cryotherapy (2).

Conclusions: Pooled estimates from randomised and non-randomised studies showed similar tumour-free survival at one year for imiquimod and PDT. The PDT tumour-free survival was higher in studies with repeated treatments. However, these results were largely derived from non-randomised studies and randomised studies with head-to-head comparison of imiquimod and PDT are lacking. There is a need for head-to-head comparison studies between PDT, imiquimod and other treatments with long-term follow-up to enable better recommendations for optimal SBCC treatment. 


\section{Introduction}

Basal cell carcinoma (BCC) is the most common skin cancer in Caucasians with a remarkable increasing incidence of $3-10 \%$ annually. ${ }^{1-3}$ Treatment of BCC is becoming a major health care problem, causing enormous health care costs and an increased workload for dermatologists and many other physicians. In the past, it was a disease of elderly patients but as a consequence of recreational sun exposure and tanning beds, a larger number of young people develop skin cancer as well. ${ }^{4,5}$ Persons who develop one BCC are at a 10 -fold increased risk to develop subsequent Backs at other body sites. ${ }^{6,7}$ A study from the Netherlands in 2004 predicts the number of patients with BCC to increase by $78 \%$ in $2015 .{ }^{1}$

The histopathological diagnosis of BCC can be assessed by punch biopsy. ${ }^{8}$ There are three major histological subtypes corresponding with several clinical manifestations. The most common subtype is the nodular BCC ( $40 \%$ of BCC cases). However, a rapid rise in relative proportions has been observed in the superficial subtype of BCC from $18 \%$ to $31 \%$ in the last twenty years. ${ }^{9}$ Surgical excision remains the standard of care in most Backs because histopathologic examination ensures tumour clearance. However, a good cosmetic outcome is becoming more important with the growing affected young population. Superficial $B C C(s B C C)$ is the least aggressive subtype, requiring less destructive therapeutic options. Nowadays, sBCC can be treated by a variety of non-surgical techniques such as photodynamic therapy (PDT), immunotherapy, local chemotherapeutic crème and cryotherapy. ${ }^{8,10}$ These treatments avoid scarring, which is frequently seen after surgical excision. Furthermore, they can relieve the busy dermatologists practice. However, there is no consensus on the treatment of SBCC. Which treatment the patient will receive relies on some tumour characteristics (localization and size) and patient characteristics (age, history of previous treatments and general health) ${ }^{11}$ but mostly on the preference of the treating physician. ${ }^{12}$ In addition, cosmetic outcome, after-care and costs should be taken into consideration.

The objective of this study was to systematically review published studies in order to compare the percentages with complete response (primary outcome) and long-term tumour-free survival (secondary outcome) for patients with primary SBCC between frequently used treatments of SBCC. Combined results from a meta-analysis result in a more reliable estimate than results from individual studies. Cosmetic outcome, aftercare and costs will not be the subject of this review.

\section{Materials and methods}

This systematic review was performed according to the PRISMA statement for systematic reviews and meta-analyses. ${ }^{13}$ No online review protocol was made prior to this study. 


\section{Search}

A systematic search for papers in the English language was performed in three wellestablished databases: PubMed (January 1946 - October 2010), EMBASE (January 1989 October 2010) and Cochrane Library (January 1993 - October 2010). PubMed is a free search engine for accessing the MEDLINE database of citations and abstracts of biomedical research articles. EMBASE is also an abstract and indexing database specialized in the biomedical field. The Cochrane Library is a collection of databases and contains Cochrane reviews which represent the highest level of evidence. The following search terms (including derivatives and analogues) were used: carcinoma, basal cell, superficial in combination with therapy using the following limits randomised controlled trial, clinical trial and human. There was no date restriction and the last search was run on the $1^{\text {st }}$ of October 2010. Further eligible publications were subsequently identified from the reference lists and used for this systematic review.

\section{Data sources and study selection}

Eligible for review were studies which met the prespecified inclusion criteria. Studies had to report on treatment success of a modality for treatment of SBCC and had to include only patients with primary and histologically proven SBCC. Furthermore, studies had to have a follow-up period of at least 12 weeks after treatment. Data on numbers of patients treated and numbers of patients with treatment failure had to be available for at least one time point during follow-up. Because there were limited randomised controlled trials (RCTs), both randomised and non-randomised studies were considered eligible, as well as prospective and retrospective studies, in order to include studies with results after longterm follow-up. We excluded case series, case reports, reviews, studies in which the recurrence probability of $S B C C$ was not described separately from the other histological BCC subtypes, and studies in which results of two or more treatments were combined. Different papers by the same author or research group were included for review only when it was obvious that a different sample of patients was used. Two independent reviewers carefully screened titles and abstracts for relevancy. If necessary, authors were contacted by email or telephone to obtain and confirm their data.

\section{Data extraction}

Two reviewers independently read the full text of the articles that were considered for inclusion using structured forms for extraction of relevant data. Any disagreements between reviewers were discussed with a third reviewer and further resolved by consensus. From studies which reported results of treatment of different BCC subtypes, only the subset of SBCC data was included. The outcomes that were considered of interest in this review were probability of residual tumour/incomplete response, cumulative probability of recurrence and probability of tumour-free survival (sustained clearance) at the end of follow-up. If any tumour tissue was present at the first control visit after treatment, the response to treatment was considered to be incomplete and the lesion was regarded as a residual tumour. Recurrence was defined as presence of tumour tissue that was detected 
later during follow-up in patients who had no residual tumour tissue. Tumour-free survival was defined as absence of both residual tumour and recurrence.

Information was extracted from individual studies regarding (1) treatment modality including type, dose, frequency, duration, margin of cream application, illumination source and its tuning; (2) data required for estimation of probability of residual tumour/incomplete response, cumulative probability of recurrence and probability of tumour-free survival at the end of follow-up; (3) methodological aspects including sample size, selection of study population such as restriction to tumours $\leq 2$ or $>2 \mathrm{~cm}$ in diameter, study design (randomised versus non-randomised), duration of follow-up, verification of residual tumour by clinical or a combined clinical and histopathological examination, use of time-to-event analysis (yes versus no), sponsored by pharmaceutical industry (yes or no), type of comparison (with placebo, other treatment or no treatment); (4) distribution of patients' characteristics including age, co-morbidities and tumour characteristics such as localisation and size.

\begin{tabular}{l|l}
\hline Item & Score \\
\hline 1. Use of a representative study population without restriction to subgroups & Yes/no \\
2. Use of a well described and standardized intervention & Yes/no \\
3. Evaluation of treatment response by histological verification & Yes/no \\
4. Definition of success as complete response (instead of partial response) & Yes/no \\
5. Prospective design & Yes/no \\
6. Inclusion of all treated patients in evaluation of long-term prognosis & Yes/no \\
7. Percentage lost to follow up & $<10 \%$ or $\geq 10 \%$ \\
8. Use of survival analysis & Yes/no \\
\hline Non-randomised controlled trials could receive a quality score ranging from 0 (poor) to 8 (excellent) points. \\
Table 1. Items scored to evaluate methodological quality of non-randomised controlled trials. \\
\hline
\end{tabular}

\section{Risk of bias}

To evaluate methodological quality of the studies we scored eight items that are related to representativeness of the study population, description of the intervention, evaluation of clinical outcome, design-specific sources of bias and the analysis of data (Table 1). ${ }^{14}$ The scores range from 0 to 8 with higher scores indicating better methodological quality and less potential for biased estimates.

\section{Statistical analysis}

Percentages of patients with complete response to treatment were derived from the individual studies. The number of patients with no residual tumour at the first control visit after treatment was divided by the number of patients that were included for treatment irrespective of whether patients were actually treated and/or finished treatment. Patients with adverse events (e.g. local skin reactions to imiquimod) were not considered to be treatment failures. This approach was chosen according to the intention-to-treat principle to prevent biased estimates due to selective loss-to-follow-up.

Valid estimation of long-term risk of recurrence and tumour-free survival after treatment requires time-to-event analysis. If studies had not performed survival analysis, such as 
Kaplan Meier analysis or life table analysis, efforts were made to extract data required for life table analysis. The number of patients at risk at the start of each 1-year interval as well as the number lost-to-follow-up and the number having recurrence during each interval were used to calculate cumulative probabilities of sustained clearance. Only patients with complete response to treatment were considered for these analyses. Probability of tumour-free survival at the end of follow-up was calculated by multiplying the probability of complete response by the cumulative probability of sustained clearance. Standard errors were calculated using the Peto formula. ${ }^{15}$

For pooling, a random effects model as proposed by DerSimonian and Leird was performed using the inverse of the standard errors of the percentages from the individual studies as weights. ${ }^{16}$ The $\mathrm{I}^{2}$ index was used to test for heterogeneity between study results. Significance of this index indicates that differences between studies cannot solely be attributed to sampling variation and that differences in study population, design and analysis are responsible for variation between study results. The $\mathrm{I}^{2}$ index ranges from 0 to 100 percent. Statistical heterogeneity was defined as a $\mathrm{I}^{2}$ index of more than $50 \%{ }^{17}$ Exploratory subgroup analyses were performed to identify sources of variation between study results. These subgroup analyses were not prespecified, but studies were categorized into subgroups according to several study characteristics that can potentially affect study results. Publication bias was examined statistically using the Egger's test. ${ }^{18}$ All analyses were performed using STATA version 11.0 (STATA Corp, College Station, TX).

\section{Results}

The literature search identified 903 papers from which 36 studies fulfilled the inclusion criteria (Figure 1). Two papers could not be obtained. ${ }^{19,20}$ Included studies were conducted in the USA, Europe, Australia, New-Zealand and Brazil and were published between 1994 and 2010. The selected studies often excluded patients with SBCC in the anogenital area or areas within $1 \mathrm{~cm}$ of the $\mathrm{H}$-zone or pigmented or morpheaform BCC. Patients with dermatologic conditions that interfere with treatment, genetic skin disorders, immunosuppressive therapy, or who were pregnant or breastfeeding were also often excluded.

Fourteen studies were RCTs in which two or more treatment protocols were directly compared (Table 2). Eight RCTs were dose finding studies ${ }^{21-25}$ of which three also included a placebo study arm. ${ }^{26-28}$ The other six RCTs compared imiquimod with placebo ${ }^{29}$ or PDT with another treatment. ${ }^{30-34}$ The remaining 22 studies were non-RCTs and reported results of one treatment modality. ${ }^{11,35-55}$ One study compared imiquimod with methylaminolevulinate (MAL)-PDT in a non-randomised trial. ${ }^{45}$ The majority of studies provided data on the results of treatment with PDT $(16)^{11,30-34,43,45,48-50,52-56}$ or imiquimod (15)..$^{21-24,27-29,35-}$ $37,40,42,44,45,47$ Other treatments that were evaluated were pulsed dye laser ${ }^{38,39,51}, 5-\mathrm{FU}^{25,41}$, cryotherapy $^{30,33}$, surgical excision ${ }^{31}$ and PEP005. ${ }^{26}$ The latter is also known as Ingenol mebutate. ${ }^{57}$ Pooling of results was restricted to PDT and imiquimod studies. 
Probabilities of complete response after treatment could be derived from 34 of 36 studies $^{11,21-32,34-42,44,45,47-56}$ and information on recurrence probabilities during follow-up was available in 23 of 36 studies. ${ }^{11,21,30-37,39,40,42-45,48-50,52-54,56}$ Four studies did not use a single standardized treatment protocol, but presented study results of combinations of treatment regimens. Subgroup analyses were not performed. ${ }^{11,33,36,44}$ The follow-up period for evaluation of recurrence differed from three months to five years after the first control visit. Probability of tumour-free survival at one year follow-up could be derived from 14 studies $^{21,30,31,33-37,39,40,42,44,46,50}$, but estimates at two, three, four and five years of follow-up were only available in $6^{30,34,35,37,40,44}, 5^{30,35,40,43,44}, 3^{30,35,40}$ and $3^{30,35,40}$ studies, respectively.

In most studies, analyses were performed on tumour level. One study on treatment with imiquimod reported results from analysis solely on a patient level. ${ }^{21}$ Ezughah et al. and Wennberg et al. calculated residue probability by dividing the number of residues by the number of patients/sBCC that actually finished treatment instead of the number that was included at start of study. ${ }^{21,53}$ In all studies, response to treatment was verified by clinical verification. An additional histopathological verification was performed in 18 of 34 studies that reported residue probabilities, of which most were studies on imiquimod. ${ }^{22-}$ 29,37,38,41,42,45,47,48,51-53 From the 23 studies that reported recurrence probabilities, two studies performed an additional histopathologic verification of the diagnosis. ${ }^{33,44}$ 
Search conducted on dasabases. PubMedt. EMENSE; and Cochrane Lbraty

Search strabegies

$t$ (Meshi Tems) basal cel caroinoma CR (Mesh Tems) therapy AND superficial basal cell carcinoma

Limit randomized contelled triaks clinical trial english language, human

¿ (fthesaurus) focus basal cell carcinoma AND (Thesaurus) exp therapy CR superficial basal cell carcinoma.

Limit jeumal a aftele, embase or medine, english language AND (clinical thal OR randomized

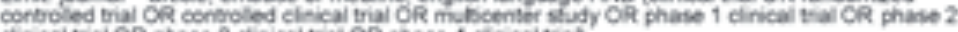
dincal trai OR phase 3 cinical tral Ofe phase 4 clincal that

ל̧ lasal cet cardinoma
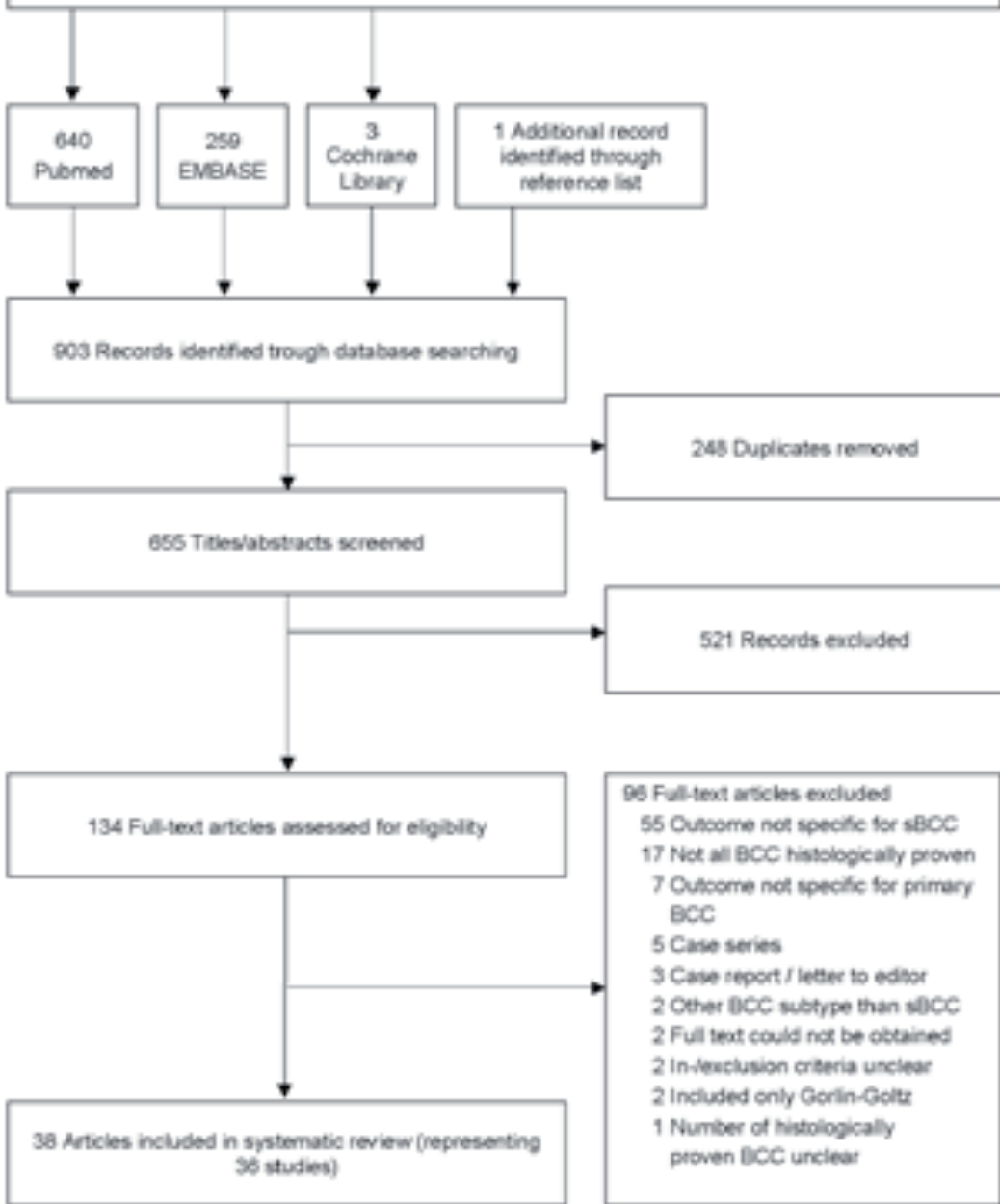

Figure 1. Flow diagram of study selection in systematic review. 


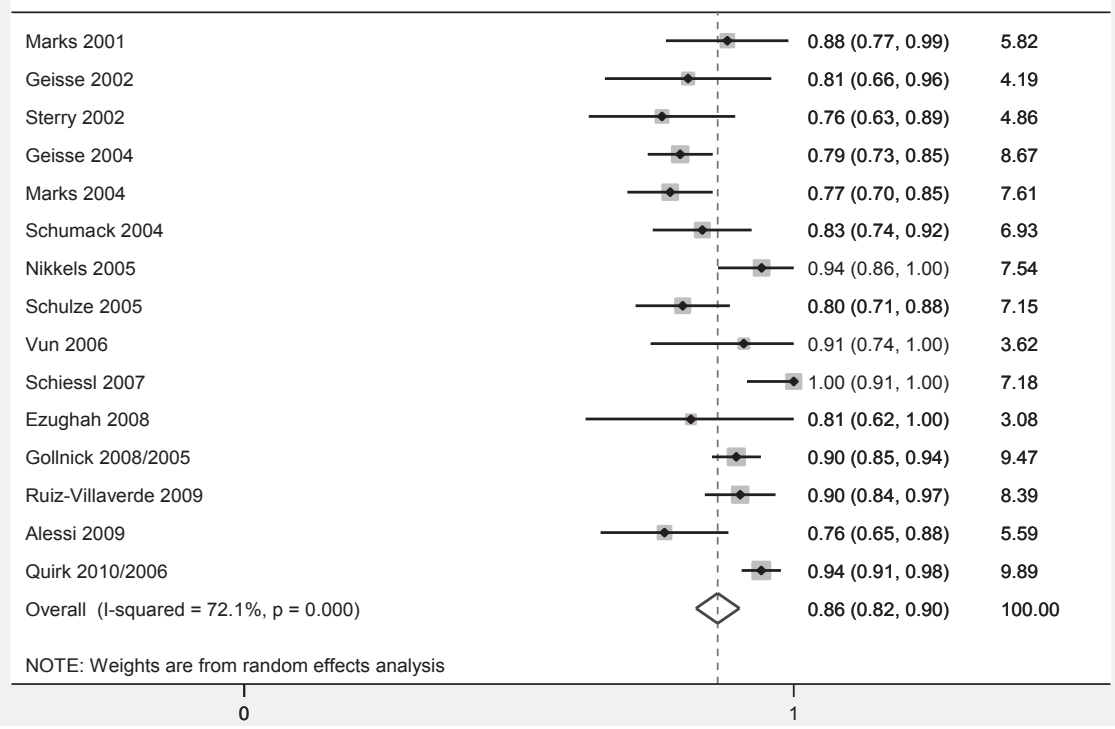

Figure 2 (a). Forest plot of results from imiquimod studies on complete response probability at first control visit

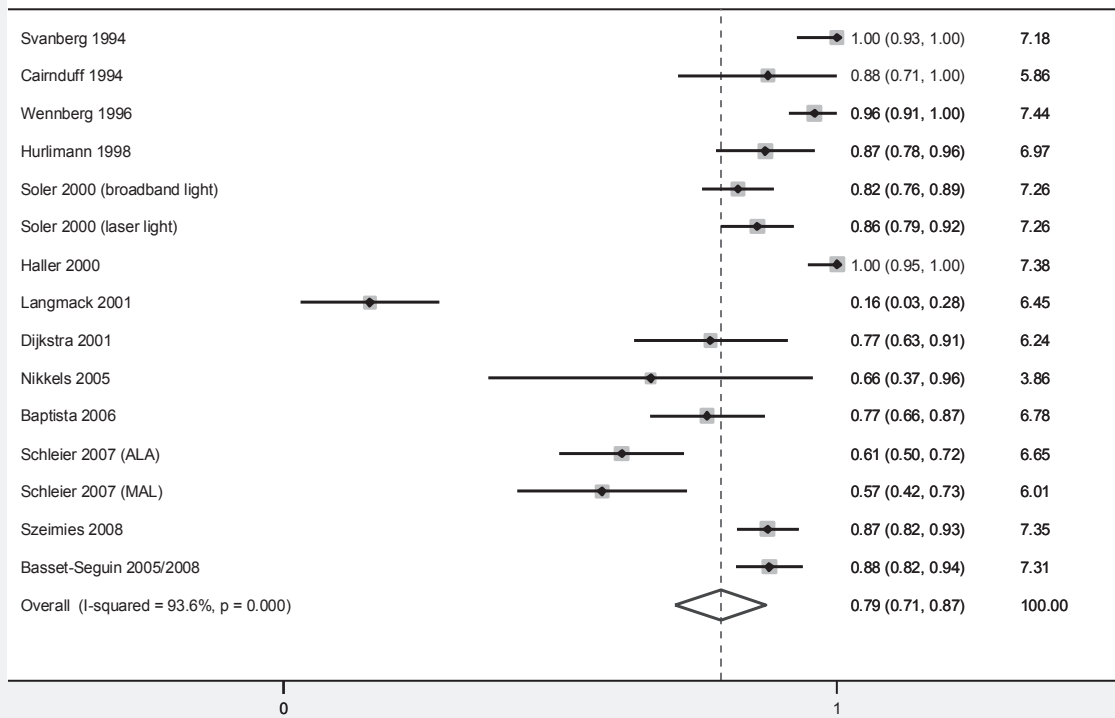

Figure $\mathbf{2}$ (b). Forest plot of results from PDT studies on complete response probability at first control visit 


\section{Probability of complete response after treatment with imiquimod and PDT}

Probabilities of complete response after treatment with imiquimod could be derived from 15 studies with a total of 1088 sBCCs. ${ }^{21-24,27-29,35-37,40,42,44,45,47}$ From six dose finding studies, data were used from only one study arm. ${ }^{21-24,27,28}$ Preferred was the arm with a dosing regimen most similar to the widely used protocol of imiquimod 5 days a week during 6 weeks. Schedules differed from three times a week to once daily every day. Treatment duration ranged from 4 to 12 weeks and the first control visit to evaluate response to treatment was scheduled at 6 to 19 weeks post-treatment. Figure 2a shows a forest plot with proportions of patients with complete response and $95 \%$ confidence intervals for individual imiquimod studies. The pooled estimate was $86.2 \%(95 \% \mathrm{Cl} 82-90 \%)$, with large heterogeneity $\left(\mathrm{I}^{2}\right.$ index $=72 \%$ and $\left.\mathrm{p}<0.0001\right)$.

Probabilities of complete response after treatment with PDT could be derived from 13 studies with a total of 934 sBCCs. ${ }^{11,30-32,34,45,48-50,52-55}$ From three illumination dose finding studies, data were used from only one study arm. ${ }^{48,49,53}$ The arm most similar to the current regimen was preferred; $100 \mathrm{~J} / \mathrm{cm} 2$, one time $20 \%$ aminolevulinic acid (ALA)-PDT illumination or one cycle (on day 1 and 8) 20\% MAL-PDT illumination. Despite this aim, the frequency of illumination ranged from one to four times. Two studies compared different light sources and light sensitive agents. ${ }^{32,34}$ From each study both study arms were used for analysis.

The majority of PDT studies used 20\% ALA as a light-sensitive agent. The first control visit to evaluate response to treatment was scheduled 4 to 26 weeks post-treatment. Figure $2 \mathrm{~b}$ shows a forest plot with proportions of SBCCs with complete response and $95 \%$ confidence intervals for individual PDT studies. The pooled estimate for proportion of SBCC with complete response to treatment was $79.0 \%$ (95\% Cl 71-87\%) with large heterogeneity $\left(1^{2}\right.$ index $=94 \%$ and $\left.p<0.0001\right)$. The difference of $7.2 \%$ in pooled estimates of complete response probability between imiquimod and PDT did not reach statistical significance $(p=0.171)$. This pooled estimate included the complete response probabilities of Szeimies et al. (87.4\%) and Basset-Seguin et al. (87.7\%) after one or two cycles of MAL-PDT. ${ }^{30,31}$ An analysis which excluded patients who received two cycles in these studies, resulted in a pooled estimate of $75.6 \%$, which was not significantly different from the estimate of $86.2 \%$ for imiquimod $(p=0.057)$.

\section{Cumulative probabilities of recurrence and tumour-free survival}

Cumulative probabilities of recurrence and tumour-free survival that could be derived from studies for one, two and five years post-treatment are given in Table 3. Figure 3a and $3 \mathrm{~b}$ show forest plots with proportions of patients with tumour-free survival and $95 \%$ confidence intervals for individual imiquimod and PDT studies, respectively. The pooled estimate at one year after imiquimod treatment was $87.3 \%$ (95\% Cl 84-91\%) without significant heterogeneity $\left(\mathrm{I}^{2}\right.$ index $=22 \%$ and $\left.\mathrm{p}=0.263\right)$. PDT studies showed a lower pooled estimate of $84.0 \%(95 \% \mathrm{Cl} 78-90 \%)$ with large heterogeneity $\left(\mathrm{I}^{2}=73 \%\right.$ and $\left.\mathrm{p}=0.005\right)$. The difference of $3.3 \%$ in pooled estimates of tumour-free survival at one year between imiquimod and PDT was not statistically significant $(p=0.469)$. 


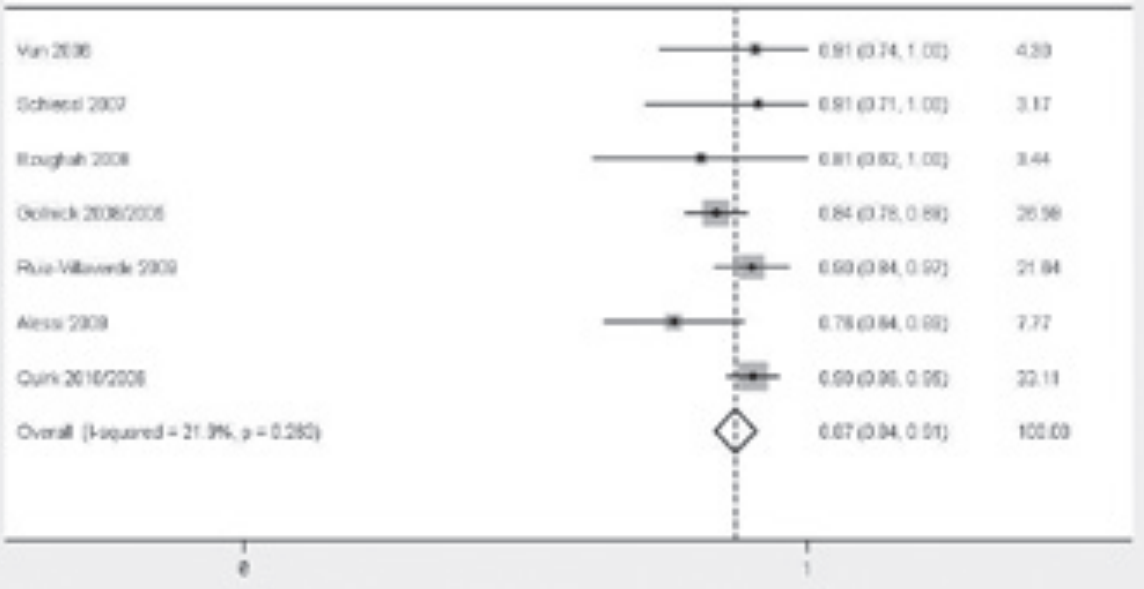

Figure 3 (a). Forest plot of results from imiquimod studies on tumour-free survival at one year 


\section{Tumour-free survival after other treatments}

There are not enough studies on pulse dye laser, 5-FU, cryotherapy, surgical excision and PEP005 in the treatment of SBCC to perform a meta-analysis (Table 2). ${ }^{25,26,30,31,33,38,39,41,51}$ Tumour-free survival could be calculated for three individual studies (Table 3). ${ }^{30,31,39} \mathrm{Cam}$ polmi's study on treatment with pulsed dye laser resulted in $79 \%$ tumour-free survival after 1 year. ${ }^{39}$ Patients treated with one or two double freeze-thaw cycles of cryotherapy in Basset-Seguin's study showed a tumour-free survival of $67 \%$ at 5 years. ${ }^{30}$ Surgical excision by Szeimies et al. demonstrated a high tumour-free survival with $89 \%(117 / 135)$ at 1 year. ${ }^{31}$ However, in this study 17 of the included SBCCs received no surgical excision because of patients' request. Tumour-free survival at one year was 99\% (117/118) for patients actually receiving surgical excision.

\section{Publication bias}

The Egger's test shows that for PDT and imiquimod studies the intercepts were -5.94 $(p=0.012)$ and $-1.92(p=0.082)$, respectively. This deviation of the intercept from zero indicates that smaller studies showed higher success rates than larger studies and thus publication bias is likely to be present.

\section{Subgroup analyses}

Subgroup analyses were performed to identify sources of heterogeneity in study results. Results are presented in Tables 4 and 5 for imiquimod en PDT studies, respectively. For Imiquimod studies, the pooled estimates for complete response from randomised studies were lower than for non-randomised studies (79.8\% versus $90.7 \%$ ). For PDT studies, pooled estimates differed substantially between subgroups of studies with lower and higher scores for methodological quality (92.0\% versus $72.5 \%$ ) However, these study characteristics do not fully explain the observed heterogeneity between study results, because within subgroups of studies the $\mathrm{I}^{2}$-index remained high. 


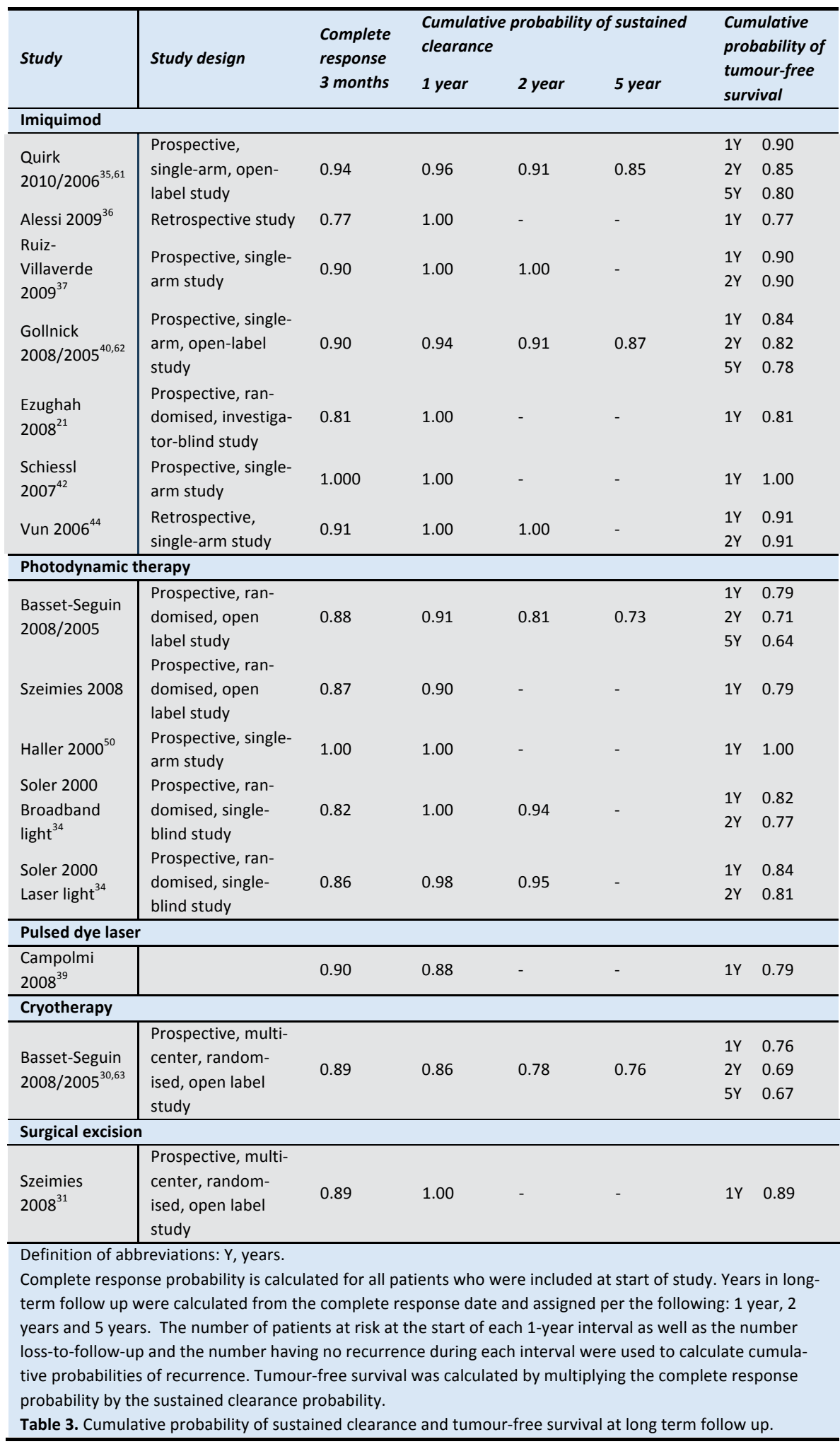




\section{Sensitivity analyses}

Robustness of the results of this review was evaluated by performing sensitivity analyses. With respect to complete response at the first control visit after treatment, results of all imiquimod (15) and PDT (15) study arms were pooled. A first sensitivity analysis was performed by including only patients who actually finished treatment. Using these percentages, the pooled estimate for complete response of 1065 sBCCs treated with imiquimod therapy was higher with $87.6 \%\left(95 \% \mathrm{Cl} 84-91 \%, \mathrm{I}^{2}=67 \%, \mathrm{p}<0.0001\right)$ instead of $86.2 \%$. A higher pooled estimate of $82.3 \%$ (95\% Cl $75-90 \%)$ instead of $79.0 \%$ was also found for the patients with 914 sBCCs that actually finished treatment with PDT $\left(I^{2}=94 \%, p<0.0001\right)$.

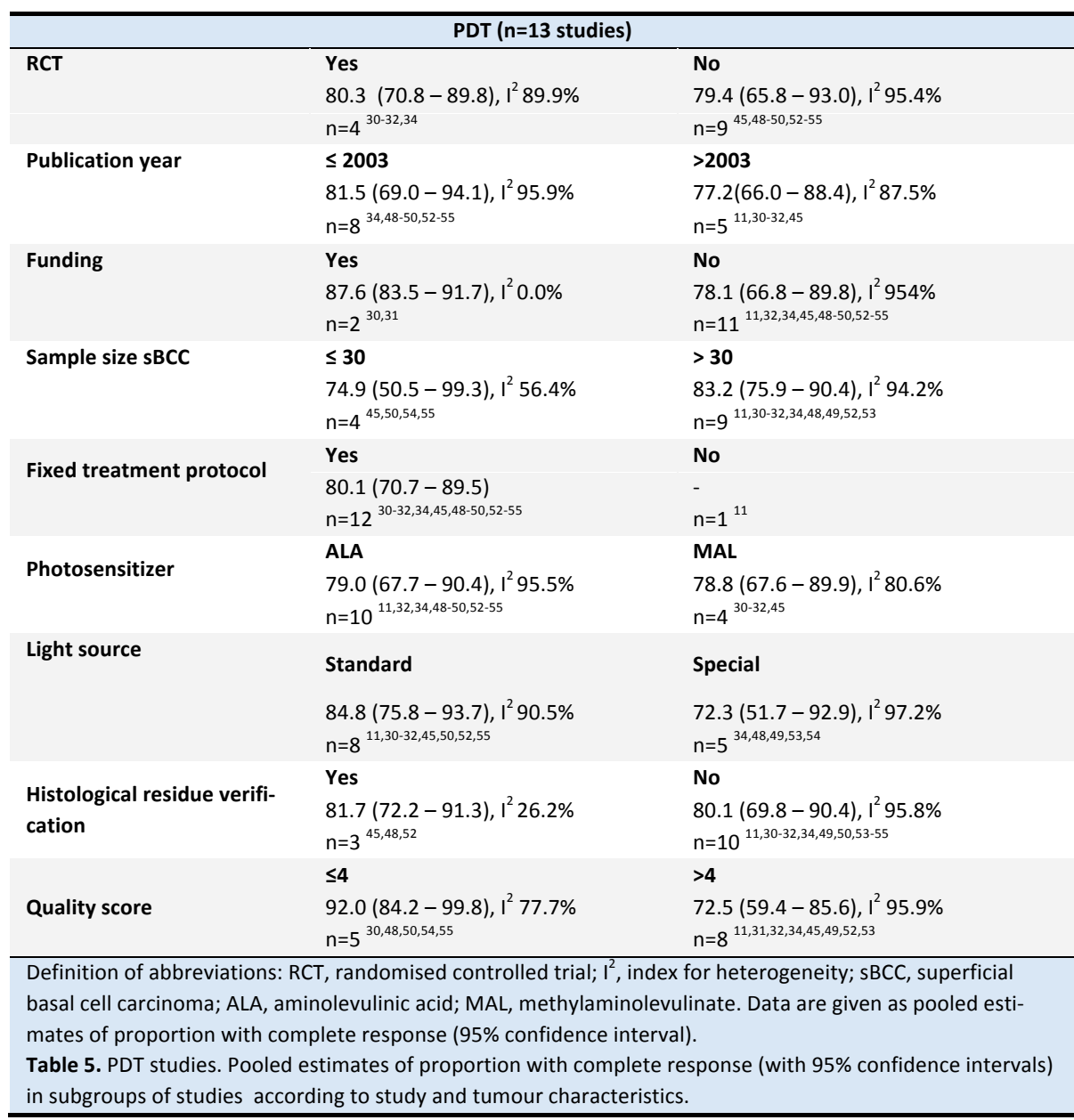

Secondly, we pooled the results of five imiquimod studies with a dosing regimen of 5 days a week during 6 weeks. ${ }^{22,27,40,42,47}$ A similar pooled estimate for proportion with complete 
response of $85.8 \%\left(95 \% \mathrm{Cl} 79-93 \%, \mathrm{I}^{2}=82 \%, \mathrm{p}<0.0001\right)$ was found compared to $86.2 \%$ (95\% $\mathrm{Cl} 82-90 \%)$ for all imiquimod studies.

In the third sensitivity analysis, we excluded the PDT study by Haller et al. wherein patients were illuminated not once but twice with ALA-PDT. ${ }^{50}$ The pooled estimate for proportion with complete response decreased from $79.0 \%$ to $77.3 \%$ and for proportion of tumour-free survival from $84.0 \%$ to $81.1 \%$. In that case, the difference of $6.4 \%$ in pooled estimates of tumour-free survival at one year between imiquimod and PDT was statistically significant $(p=0.033)$.

Fourthly, MAL-PDT studies by Szeimies and Basset-Seguin re-treated patients who at 3 months had not responded to treatment with one PDT cycle (day 1 and 8). ${ }^{30,31}$ When including only results of Backs treated with one PDT cycle in these two studies the complete response probabilities were $70.3 \%(90 / 128)$ and $61.4 \%(70 / 114)$ in Szeimies and BassetSeguin, respectively. ${ }^{30,31}$ The pooled estimate of PDT complete response probability decreased from $79.0 \%$ to $75.6 \%$ which was not significantly lower than that for Imiquimod $(p=0.057)$. Restriction of the analysis to PDT studies with exactly one year follow-up resulted in a decrease of the pooled estimate of tumour-free survival from $84.0 \%$ to $76.2 \%$ (95\% Cl 62-90\%, $\left.\mathrm{I}^{2}=95 \%\right)$.

\section{Discussion}

This review of the literature on treatment of sBCC in RCTs and non-RCTs provides evidence that treatment with imiquimod and PDT results in nearly equal tumour-free survival rates one year after treatment. However, this review reveals that RCTs with direct comparisons of imiquimod with PDT are totally lacking and that the number of studies with follow-up longer than one year after treatment is very limited. Studies reporting on treatment effect after pulsed dye laser, 5-FU, cryotherapy, surgical excision and PEP005 were scarce and, therefore, reliable evaluation of the results of these treatment modalities was not possible.

The extensive search of the literature revealed that evidence on the comparative effectiveness of treatment modalities of SBCC is not widely available. We experienced various difficulties with inclusion of possible relevant studies in this systematic review. Many studies used heterogeneous study populations, including genetic skin disorders, different BCC subtypes, both histologically and clinically proven $\mathrm{SBCC}$ prior to treatment, both primary and recurrent SBCC, whereas subgroup analyses to provide results for separate groups were not performed. Therefore, we had to exclude these studies. Most of the studies included in the review had limited follow-up. Long-term follow-up is essential to predict the probability of treatment success after many years. Although most recurrences occur within the first two years after treatment, treatment failure is also reported after a longer follow-up period. . $^{30,31,35}$

This review reveals a lack of head-to-head comparison RCTs, in which treatment effects of imiquimod and PDT are directly compared. ${ }^{58}$ Such RCTs provide the most rigid and valid 
evidence on the relative effects of different interventions. The results from the present review are based on indirect comparison of both treatment modalities and can be biased by differences in study population and design between imiquimod and PDT studies. The literature search points to a need for well-designed RCTs comparing one or more treatment modalities with long-term follow-up. Such trials guarantee comparability of patients who are assigned to different treatments and allow for more valid conclusions on the relative effectiveness of competing treatment options.

A common problem in meta-analysis is the large heterogeneity of study results. The subgroup analyses that were performed to identify sources of the large variation in success rates suggest that several study characteristics may have led to overly optimistic estimates. An interesting finding in this respect is that imiquimod studies using histological verification of tumour clearance reported a higher failure rate than those with only a clinical verification. ${ }^{40,42,59}$. This discrepancy was not found in PDT studies. The most accurate way to determine tumour clearance is complete excision as in a single biopsy sample error is still possible. However, long-term follow-up and evaluation of non-invasive treatment effects are impossible after surgical excision. In daily practice, clinical examination will reveal residues and recurrences as $S B C C$ will eventually develop into a visible tumour on long-term follow-up.

An interesting finding of this systematic review is that the effectiveness of PDT may strongly depend on numbers of cycles used. When repetitive PDT treatments are used, the pooled estimate increased for both PDT complete tumour response (75.6\% to $79.0 \%$ ) and tumour-free survival $(76.2 \%$ to $84.0 \%$ ). Therefore, PDT illumination might result in optimizing clinical outcome of treatments by fractionating ALA-PDT or providing two cycles of MAL-PDT. ${ }^{30,31,43,49,50,60}$ Disadvantages of more frequent illuminations will be higher costs and more frequent treatment appointments. As not all patients are capable or willing to visit the hospital multiple times for PDT treatment and other patient are not capable or willing to apply imiquimod crème for six weeks, treatment choice will also depend on patient preferences and tumour characteristics.

Both the subgroup analyses and the Egger's test indicate that studies with smaller sample size showed higher success rates than studies with larger sample size. This finding is suggestive of publication bias. This is a widespread problem and arises from the fact that small studies showing favourable results are more likely to be published and submitted for publication than small studies showing less favourable results. The presence of publication bias may imply that the actual benefit from PDT and imiquimod is lower than suggested by the studies included in this review.

In conclusion, treatment of SBCC with imiquimod and PDT results in similar long-term tumour-free survival probabilities. Treatment results after PDT might be optimized by repetitive treatments. Better designed large randomised controlled trials with a head-tohead comparison of current treatment modalities for SBCC with long-term follow-up are needed to establish the relative effectiveness of the various therapeutic options. Information from such trials enables more evidence based recommendations in treatment of SBCC in the future. 


\section{References}

1. de Vries E, van de Poll-Franse LV, Louwman WJ, et al. Predictions of skin cancer incidence in the Netherlands up to 2015. Br J Dermatol 2005;152:481-8.

2. Roewert-Huber J, Lange-Asschenfeldt B, Stockfleth E, et al. Epidemiology and aetiology of basal cell carcinoma. Br J Dermatol 2007;157 Suppl 2:47-51.

3. Holterhues $\mathrm{C}$, Vries $\mathrm{E}$, Louwman $\mathrm{MW}$, et al. Incidence and trends of cutaneous malignancies in the Netherlands, 1989-2005. J Invest Dermatol 2010;130:1807-12.

4. Bath-Hextall F, Leonardi-Bee J, Smith C, et al. Trends in incidence of skin basal cell carcinoma. Additional evidence from a UK primary care database study. Int J Cancer 2007;121:2105-8.

5. Birch-Johansen F, Jensen A, Mortensen L, et al. Trends in the incidence of nonmelanoma skin cancer in Denmark 1978-2007: Rapid incidence increase among young Danish women. Int J Cancer 2010;127:2190-8.

6. Marcil I, Stern RS. Risk of developing a subsequent nonmelanoma skin cancer in patients with a history of nonmelanoma skin cancer: a critical review of the literature and meta-analysis. Archives of dermatology 2000;136:1524-30.

7. Kiiski V, de Vries E, Flohil SC, et al. Risk factors for single and multiple basal cell carcinomas. Archives of dermatology 2010;146:848-55.

8. Telfer NR, Colver GB, Morton CA. Guidelines for the management of basal cell carcinoma. Br J Dermatol 2008;159:35-48.

9. Arits $A$, Schlangen $M$, Nelemans $P$, et al. Trends in the incidence of basal cell carcinoma by histopathological subtype. J Eur Acad Dermatol Venereol 2010;25:56569.

10. Bath-Hextall FJ, Perkins W, Bong J, et al. Interventions for basal cell carcinoma of the skin. Cochrane Database Syst Rev 2007:CD003412.

11. Baptista J, Martinez C, Leite L, et al. Our PDT experience in the treatment of nonmelanoma skin cancer over the last 7 years. J Eur Acad Dermatol Venereol 2006;20:693-7.

12. Thissen MR, Neumann MH, Schouten LJ. A systematic review of treatment modalities for primary basal cell carcinomas. Archives of dermatology 1999;135:1177-83.

13. Moher D, Liberati A, Tetzlaff J, et al. Preferred reporting items for systematic reviews and meta-analyses: the PRISMA statement. J Clin Epidemiol 2009;62:1006-12.

14. von Elm E. Commentary: Assessing the quality of observational studies--or a lesson from Mars. Int J Epidemiol 2007;36:677-8.

15. Cantor AB. Projecting the standard error of the Kaplan-Meier estimator. Stat Med 2001;20:2091-7.

16. DerSimonian R, Laird N. Meta-analysis in clinical trials. Control Clin Trials 1986;7:17788.

17. Higgins JP, Thompson SG, Deeks JJ, et al. Measuring inconsistency in meta-analyses. BMJ 2003;327:557-60. 
18. Egger M, Davey Smith G, Schneider M, et al. Bias in meta-analysis detected by a simple, graphical test. BMJ 1997;315:629-34.

19. Healy JB. The use of topical 5-fluorouracil in the treatment of skin tumours-preliminary report. J Ir Med Assoc 1969;62:41-6.

20. Zouboulis CC, Blume U. Outcomes of cryosurgery in patients with basal-cell carcinoma. Skin Cancer 1994;9:7-22.

21. Ezughah $\mathrm{FI}$, Dawe RS, Ibbotson $\mathrm{SH}$, et al. A randomised parallel study to assess the safety and efficacy of two different dosing regimens of $5 \%$ imiquimod in the treatment of superficial basal cell carcinoma. J Dermatolog Treat 2008;19:111-7.

22. Marks R, Owens M, Walters SA. Efficacy and safety of $5 \%$ imiquimod cream in treating patients with multiple superficial basal cell carcinomas. Archives of dermatology 2004;140:1284-5.

23. Marks R, Gebauer K, Shumack $S$, et al. Imiquimod $5 \%$ cream in the treatment of superficial basal cell carcinoma: results of a multicenter 6-week dose-response trial. J Am Acad Dermatol 2001;44:807-13.

24. Sterry W, Ruzicka T, Herrera E, et al. Imiquimod $5 \%$ cream for the treatment of superficial and nodular basal cell carcinoma: randomised studies comparing lowfrequency dosing with and without occlusion. Br J Dermatol 2002;147:1227-36.

25. Miller BH, Shavin JS, Cognetta A, et al. Nonsurgical treatment of basal cell carcinomas with intralesional 5-fluorouracil/epinephrine injectable gel. J Am Acad Dermatol 1997;36:72-7.

26. Siller G, Rosen R, Freeman M, et al. PEP005 (ingenol mebutate) gel for the topical treatment of superficial basal cell carcinoma: results of a randomised phase lla trial. Australas J Dermatol 2010;51:99-105.

27. Geisse J, Caro I, Lindholm J, et al. Imiquimod 5\% cream for the treatment of superficial basal cell carcinoma: results from two phase III, randomised, vehicle-controlled studies. J Am Acad Dermatol 2004;50:722-33.

28. Geisse JK, Rich P, Pandya A, et al. Imiquimod $5 \%$ cream for the treatment of superficial basal cell carcinoma: a double-blind, randomised, vehicle-controlled study. J Am Acad Dermatol 2002;47:390-8.

29. Schulze HJ, Cribier B, Requena L, et al. Imiquimod 5\% cream for the treatment of superficial basal cell carcinoma: results from a randomised vehicle-controlled phase III study in Europe. Br J Dermatol 2005;152:939-47.

30. Basset-Seguin N, Ibbotson SH, Emtestam L, et al. Topical methyl aminolaevulinate photodynamic therapy versus cryotherapy for superficial basal cell carcinoma: a 5 year randomised trial. Eur J Dermatol 2008;18:547-53.

31. Szeimies RM, Ibbotson S, Murrell DF, et al. A clinical study comparing methyl aminolevulinate photodynamic therapy and surgery in small superficial basal cell carcinoma (8-20 mm), with a 12-month follow-up. J Eur Acad Dermatol Venereol 2008;22:1302-11. 
32. Schleier $P$, Berndt $A$, Kolossa $S$, et al. Comparison of aminolevulinic acid (ALA)thermogel-PDT with methyl-ALA-thermogel-PDT in basal cell carcinoma. Photodiagn Photodyn Ther 2007;4:197-201.

33. Wang I, Bendsoe N, Klinteberg CA, et al. Photodynamic therapy vs. cryosurgery of basal cell carcinomas: results of a phase III clinical trial. Br J Dermatol 2001;144:83240.

34. Soler AM, Angell-Petersen E, Warloe T, et al. Photodynamic therapy of superficial basal cell carcinoma with 5-aminolevulinic acid with dimethylsulfoxide and ethylendiaminetetraacetic acid: a comparison of two light sources. Photochem Photobiol 2000;71:724-9.

35. Quirk C, Gebauer K, De'Ambrosis B, et al. Sustained clearance of superficial basal cell carcinomas treated with imiquimod cream $5 \%$ : results of a prospective 5 -year study. Cutis 2010;85:318-24.

36. Alessi SS, Sanches JA, Oliveira WR, et al. Treatment of cutaneous tumors with topical 5\% imiquimod cream. Clinics (Sao Paulo) 2009;64:961-6.

37. Ruiz-Villaverde R, Sanchez-Cano D, Burkhardt-Perez P. Superficial basal cell carcinoma treated with imiquimod $5 \%$ topical cream for a 4-week period: a case series. J Eur Acad Dermatol Venereol 2009;23:828-31.

38. Shah SM, Konnikov N, Duncan LM, et al. The effect of $595 \mathrm{~nm}$ pulsed dye laser on superficial and nodular basal cell carcinomas. Lasers Surg Med 2009;41:417-22.

39. Campolmi $\mathrm{P}$, Troiano $\mathrm{M}$, Bonan $\mathrm{P}$, et al. Vascular based non conventional dye laser treatment for basal cell carcinoma. Dermatol Ther 2008;21:402-5.

40. Gollnick H, Barona CG, Frank RG, et al. Recurrence rate of superficial basal cell carcinoma following treatment with imiquimod $5 \%$ cream: conclusion of a 5 -year long-term follow-up study in Europe. Eur J Dermatol 2008;18:677-82.

41. Gross K, Kircik L, Kricorian G. 5\% 5-Fluorouracil cream for the treatment of small superficial Basal cell carcinoma: efficacy, tolerability, cosmetic outcome, and patient satisfaction. Dermatol Surg 2007;33:433-9; discussion 40.

42. SchiessI C, Wolber C, Tauber M, et al. Treatment of all basal cell carcinoma variants including large and high-risk lesions with 5\% imiquimod cream: histological and clinical changes, outcome, and follow-up. J Drugs Dermatol 2007;6:507-13.

43. Star WM, van't Veen AJ, Robinson DJ, et al. Topical 5-aminolevulinic acid mediated photodynamic therapy of superficial basal cell carcinoma using two light fractions with a two-hour interval: long-term follow-up. Acta Derm Venereol 2006;86:412-7.

44. Vun $Y$, Siller $G$. Use of $5 \%$ imiquimod cream in the treatment of facial basal cell carcinoma: a 3-year retrospective follow-up study. Australas J Dermatol 2006;47:16971.

45. Nikkels AF, Pierard-Franchimont C, Nikkels-Tassoudji N, et al. Photodynamic therapy and imiquimod immunotherapy for basal cell carcinomas. Acta Clin Belg 2005;60:22734. 
46. Naidenov N, Dencheva R, Tsankov N. Recurrence rate of basal cell carcinoma after topcial aminolevulinic acid-based photodynamic therapy. Acta Dermatovenerol Croat 2004;12:157-61.

47. Shumack S, Gebauer K, Quirk $C$, et al. $5 \%$ imiquimod cream for the treatment of large superficial basal cell carcinoma. Archives of dermatology 2004;140:1286-7.

48. Dijkstra AT, Majoie IM, van Dongen JW, et al. Photodynamic therapy with violet light and topical 6-aminolaevulinic acid in the treatment of actinic keratosis, Bowen's disease and basal cell carcinoma. J Eur Acad Dermatol Venereol 2001;15:550-4.

49. Langmack K, Mehta R, Twyman $P$, et al. Topical photodynamic therapy at low fluence rates--theory and practice. J Photochem Photobiol B 2001;60:37-43.

50. Haller JC, Cairnduff F, Slack G, et al. Routine double treatments of superficial basal cell carcinomas using aminolaevulinic acid-based photodynamic therapy. $\mathrm{Br} \mathrm{J}$ Dermatol 2000;143:1270-5.

51. Humphreys TR, Malhotra R, Scharf MJ, et al. Treatment of superficial basal cell carcinoma and squamous cell carcinoma in situ with a high-energy pulsed carbon dioxide laser. Archives of dermatology 1998;134:1247-52.

52. Hurlimann AF, Hanggi G, Panizzon RG. Photodynamic therapy of superficial basal cell carcinomas using topical 5-aminolevulinic acid in a nanocolloid lotion. Dermatology 1998;197:248-54.

53. Wennberg AM, Lindholm LE, Alpsten M, et al. Treatment of superficial basal cell carcinomas using topically applied delta-aminolaevulinic acid and a filtered xenon lamp. Arch Dermatol Res 1996;288:561-4.

54. Cairnduff F, Stringer MR, Hudson EJ, et al. Superficial photodynamic therapy with topical 5-aminolaevulinic acid for superficial primary and secondary skin cancer. $\mathrm{Br} \mathrm{J}$ Cancer 1994;69:605-8.

55. Svanberg K, Andersson T, Killander D, et al. Photodynamic therapy of non-melanoma malignant tumours of the skin using topical delta-amino levulinic acid sensitization and laser irradiation. Br J Dermatol 1994;130:743-51.

56. Naidenov N, Dencheva R, Tsankov N. Recurrence rate of basal cell carcinoma after topical aminolevulinic acid-based photodynamic therapy. Acta Dermatovenerol Croat 2004;12:157-61.

57. Challacombe JM, Suhrbier A, Parsons PG, et al. Neutrophils are a key component of the antitumor efficacy of topical chemotherapy with ingenol-3-angelate. J Immunol 2006;177:8123-32.

58. Song $\mathrm{F}$, Loke $\mathrm{YK}$, Walsh $\mathrm{T}$, et al. Methodological problems in the use of indirect comparisons for evaluating healthcare interventions: survey of published systematic reviews. BMJ 2009;338:b1147.

59. Ezughah Fl, Affleck AG, Evans A, et al. Confirmation of histological clearance of superficial basal cell carcinoma with multiple serial sectioning and Mohs' micrographic surgery following treatment with imiquimod 5\% cream. J Dermatolog Treat 2008;19:156-8. 
60. de Haas ER, Kruijt B, Sterenborg HJ, et al. Fractionated illumination significantly improves the response of superficial basal cell carcinoma to aminolevulinic acid photodynamic therapy. J Invest Dermatol 2006;126:2679-86.

61. Quirk C, Gebauer K, Owens M, et al. Two-year interim results from a 5-year study evaluating clinical recurrence of superficial basal cell carcinoma after treatment with imiquimod 5\% cream daily for 6 weeks. Australas J Dermatol 2006;47:258-65.

62. Gollnick H, Barona CG, Frank RG, et al. Recurrence rate of superficial basal cell carcinoma following successful treatment with imiquimod 5\% cream: interim 2-year results from an ongoing 5-year follow-up study in Europe. Eur J Dermatol 2005;15:374-81.

63. Basset-Seguin N, Ibbotson SH, Emtestam L, et al. Methyl aminolevulinate photodynamic therapy vs cryotherapy in primary superficial basal cell carcinoma: results of a 36 month follow-up. Br J Dermatol 2005;153:29. 


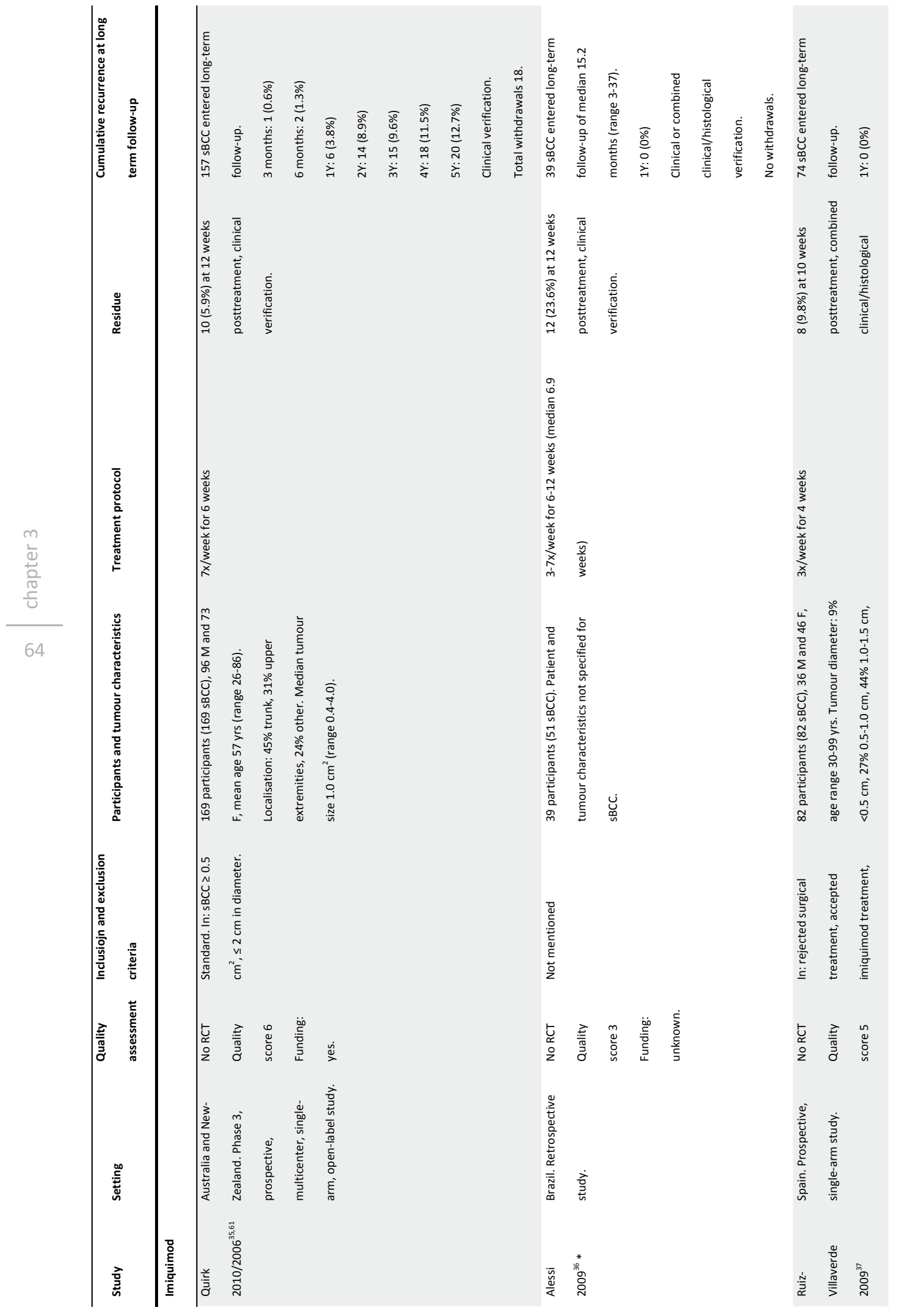




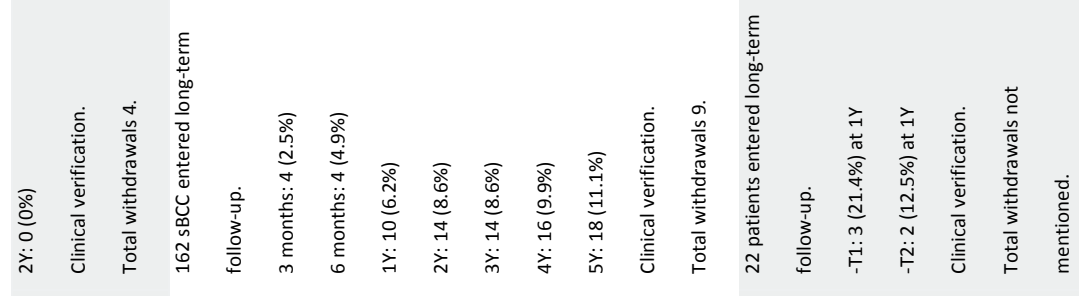

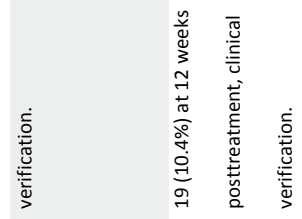

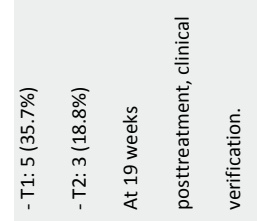

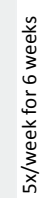

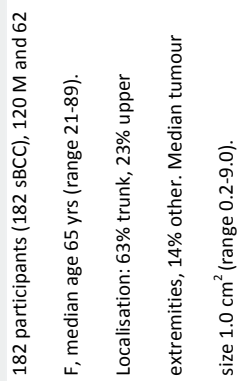

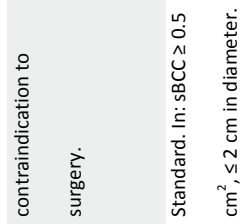

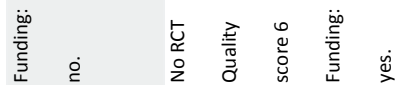

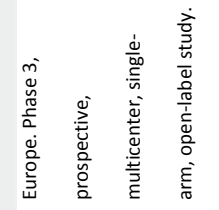

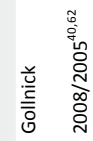

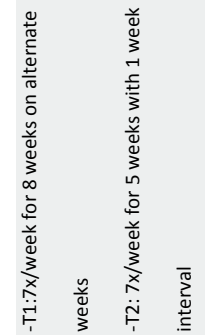

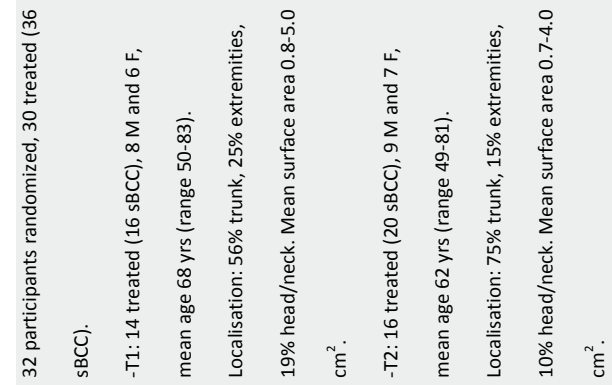

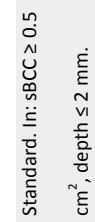

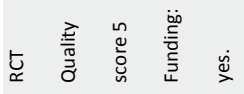

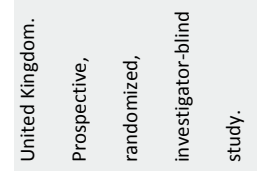

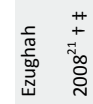




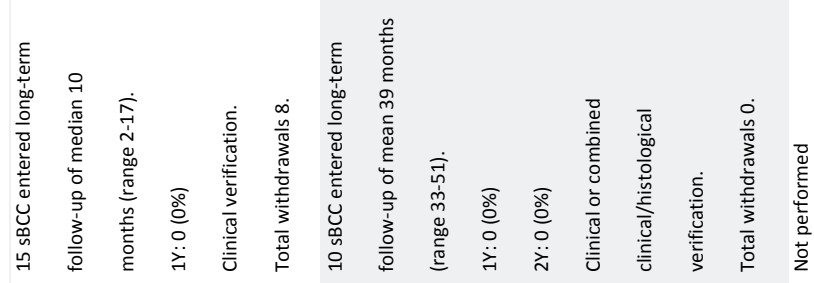

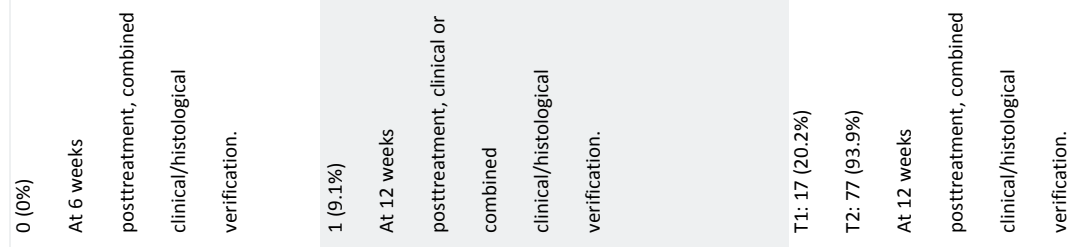

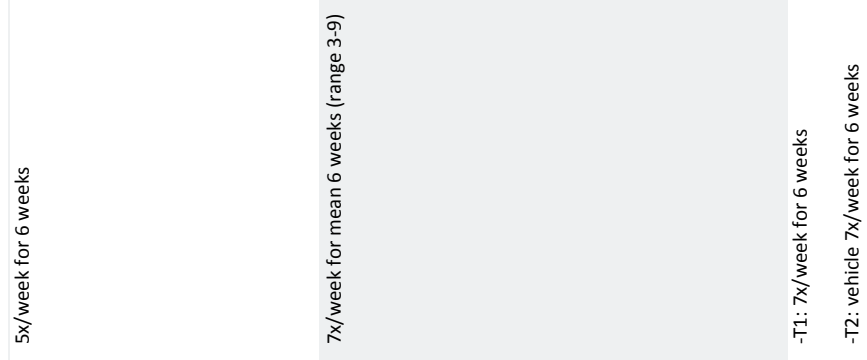

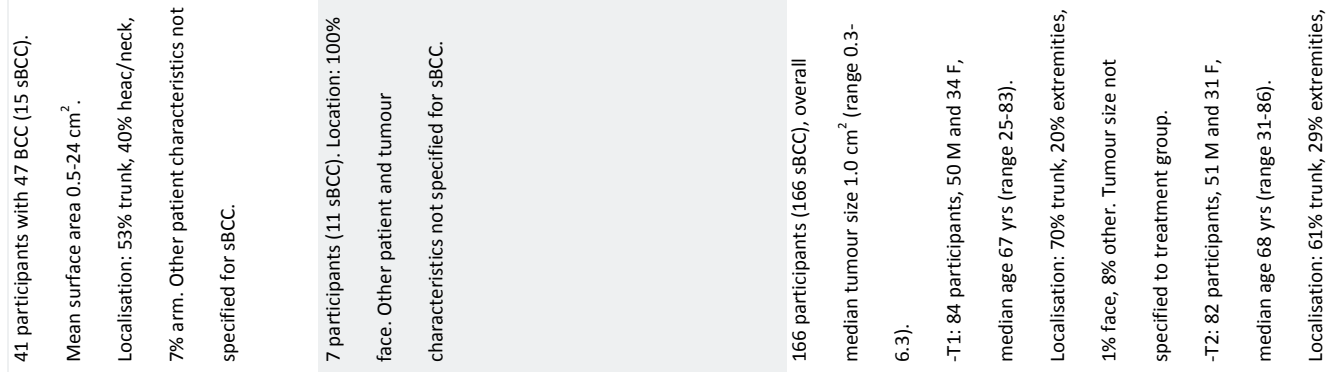

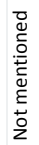

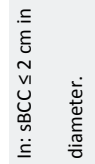

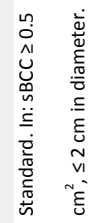

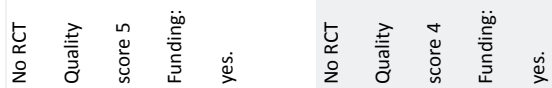

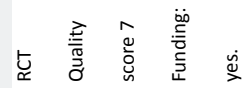

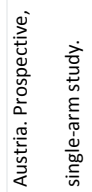

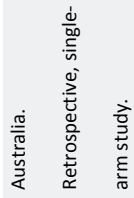

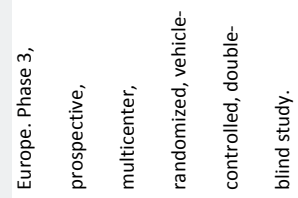

要采

产

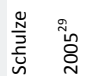




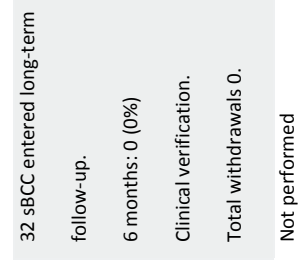

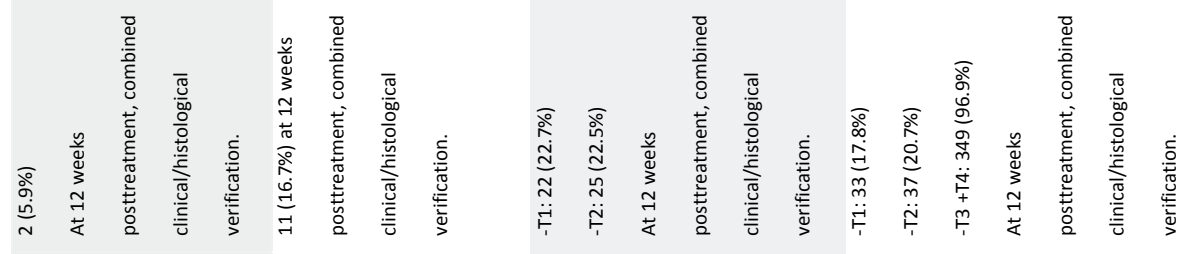

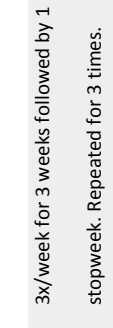

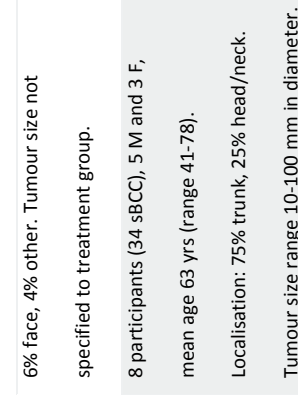

$\frac{20}{20}$

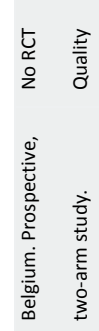

I

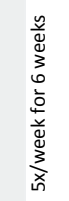

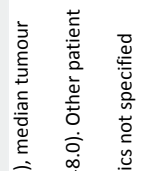

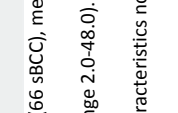

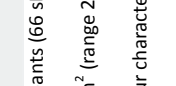

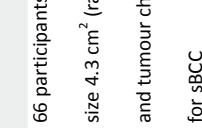

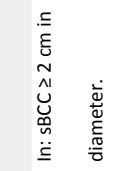

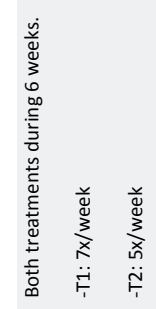

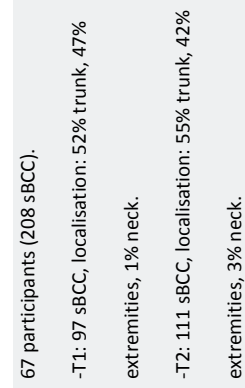

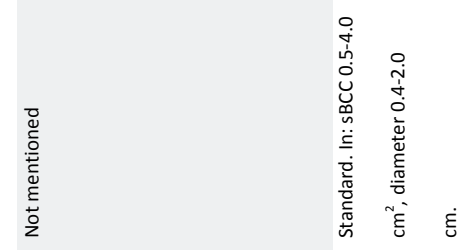

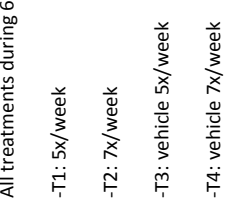

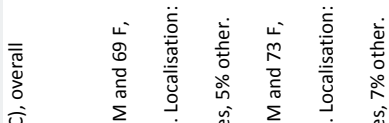

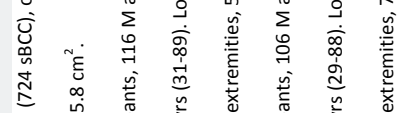

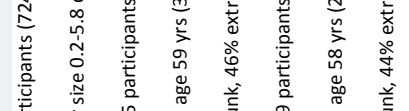

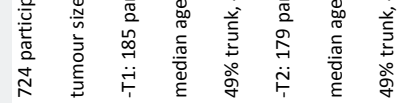




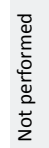

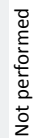

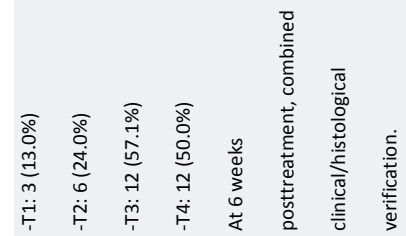

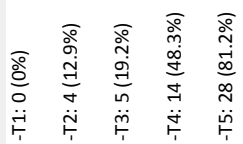
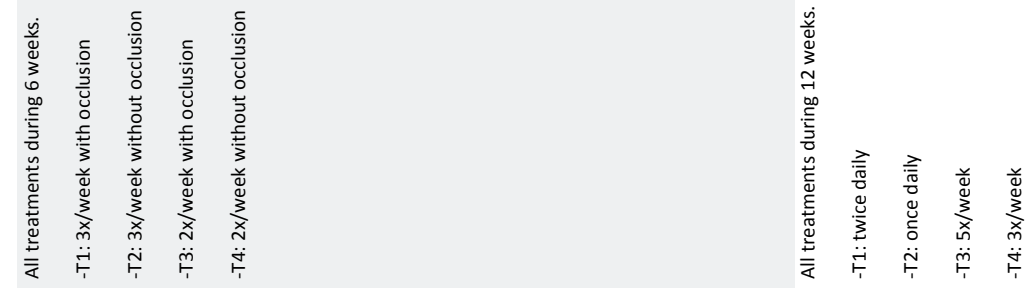

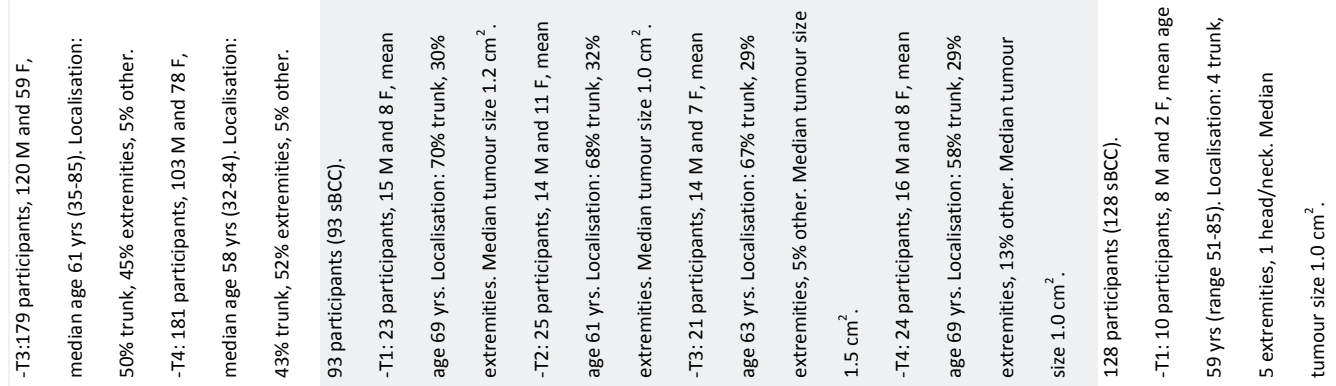

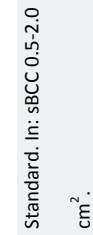

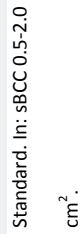

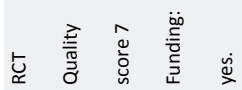

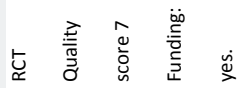

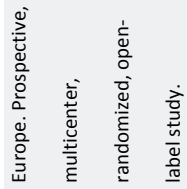

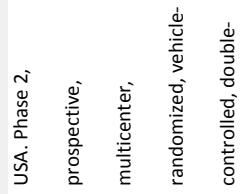

㷼 


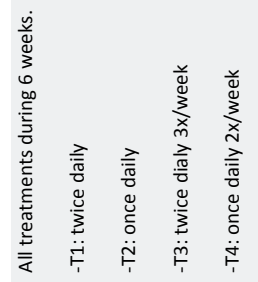

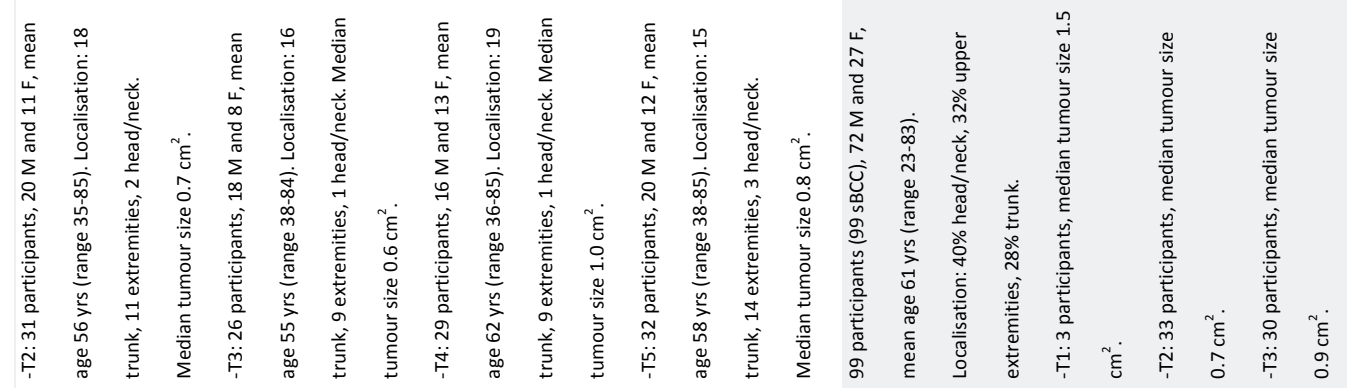

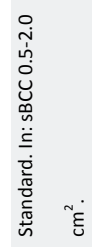

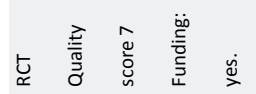

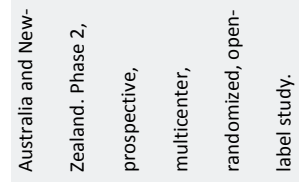




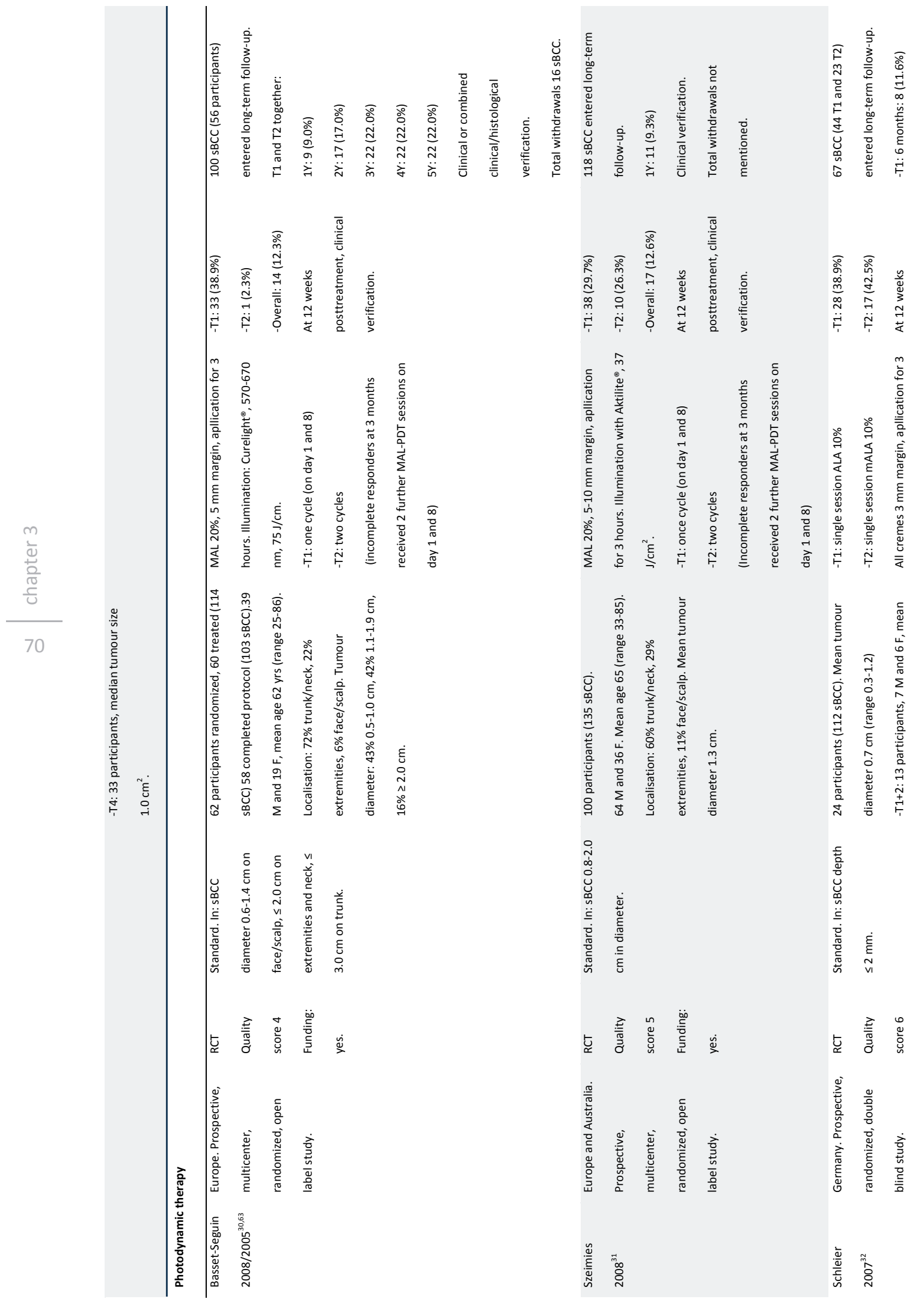




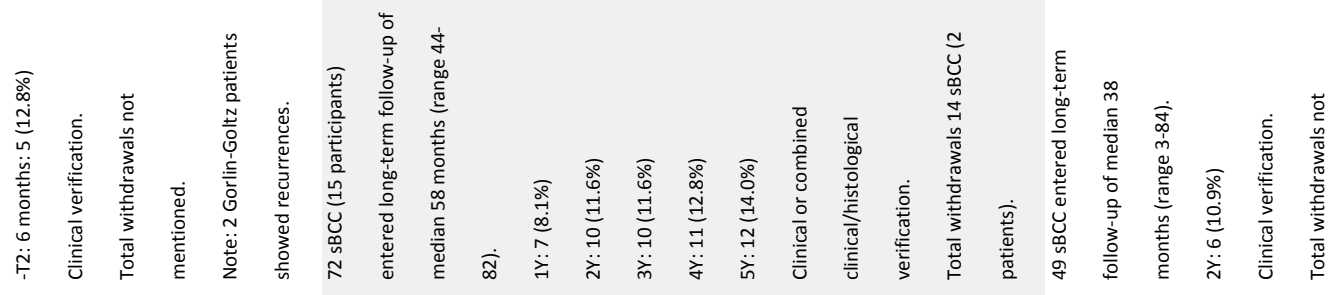

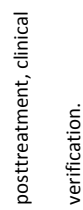

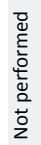

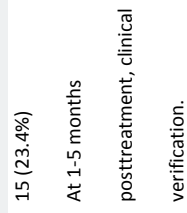

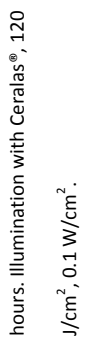
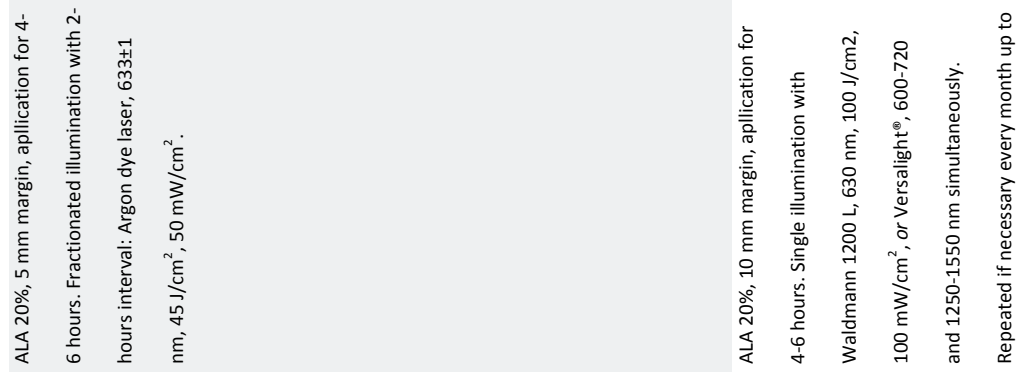

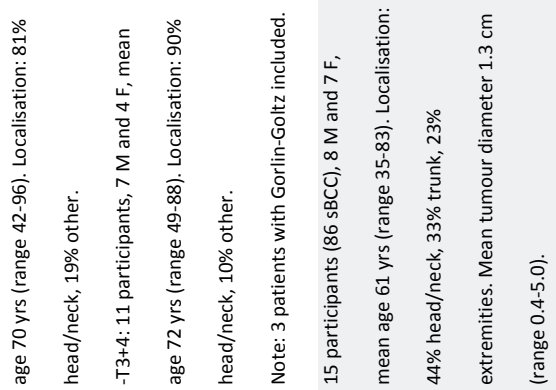

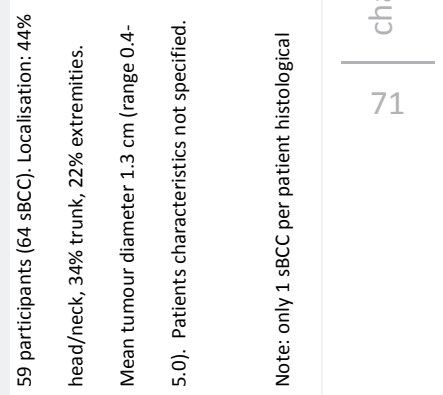

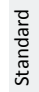

要

范

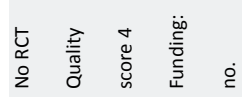

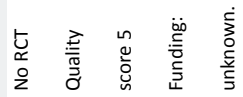

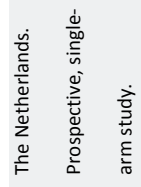

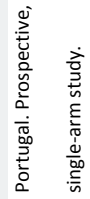

ஸे 


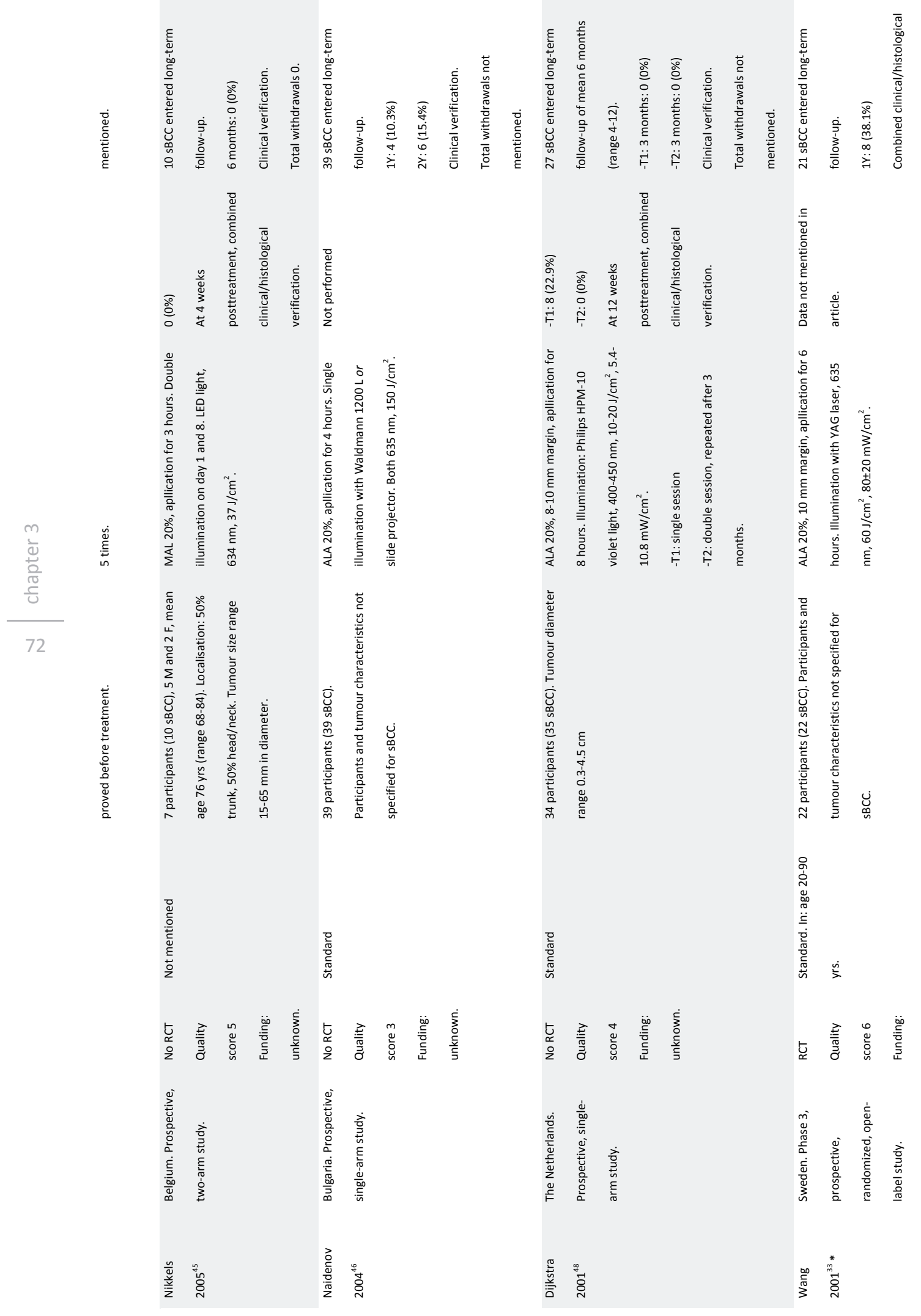




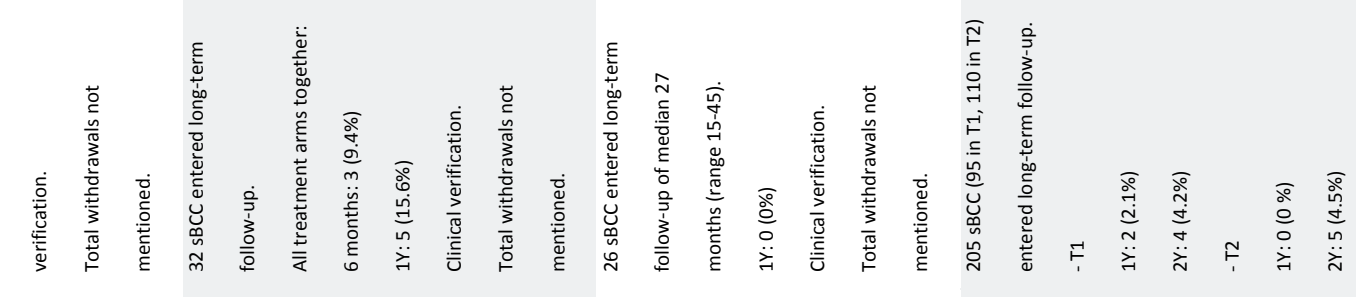

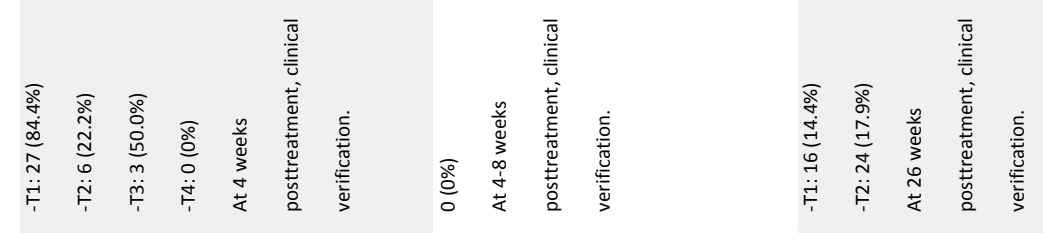

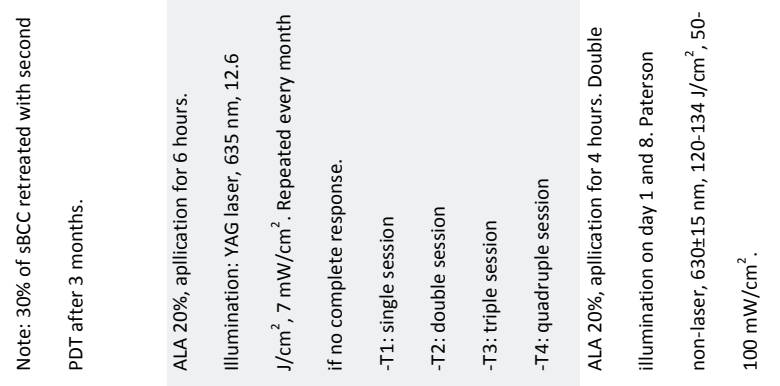

III

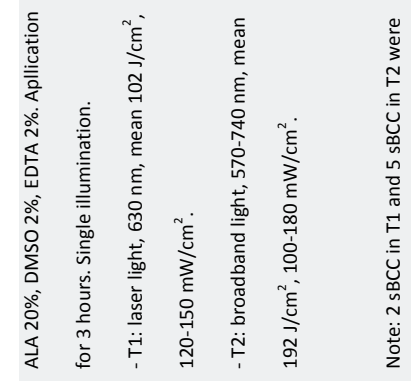

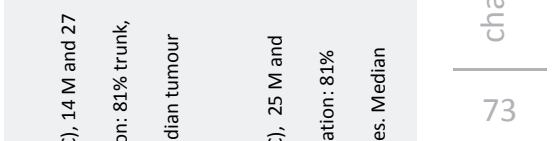

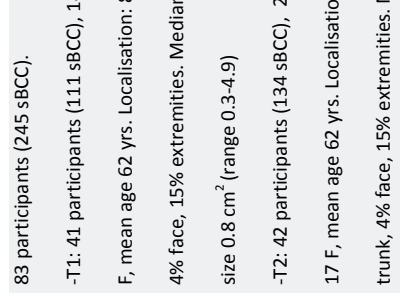

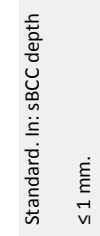

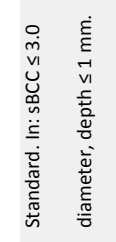

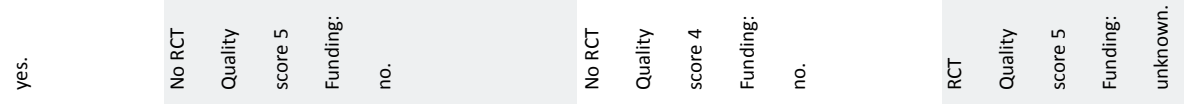

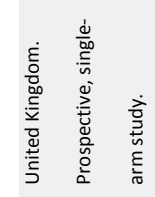

毫毫

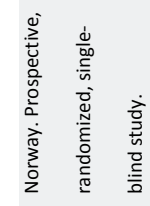

站

锌采

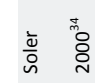




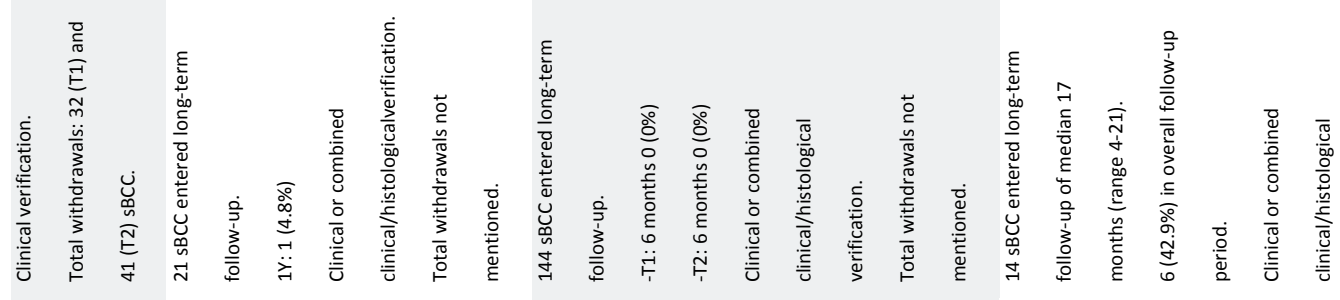

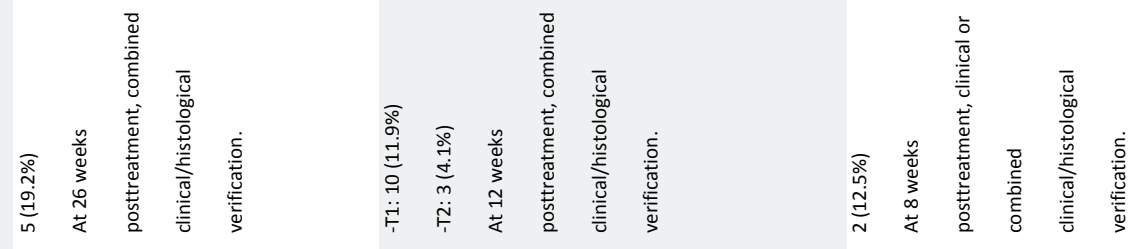

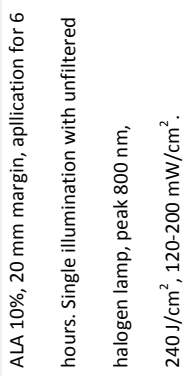

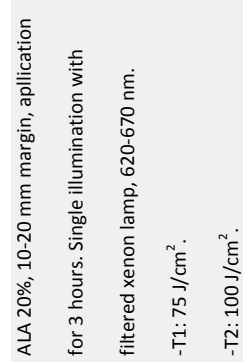

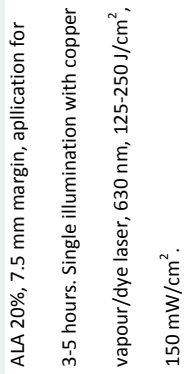

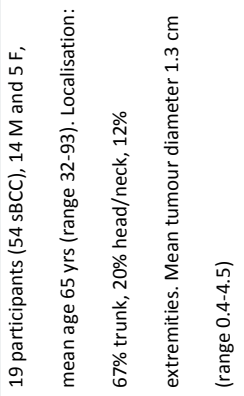

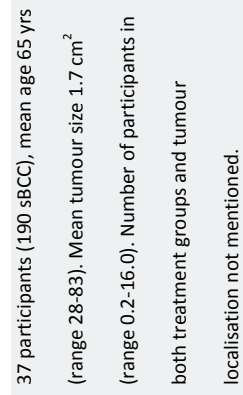

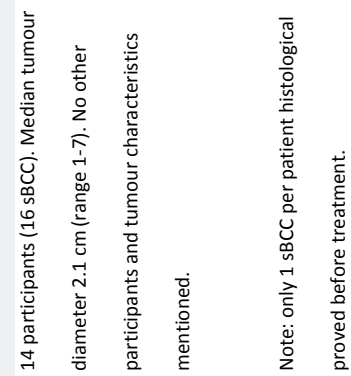

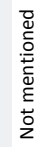

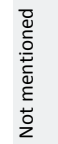

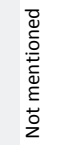

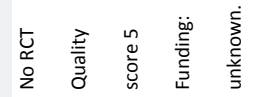

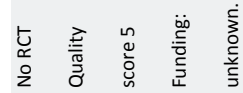

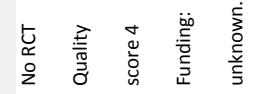

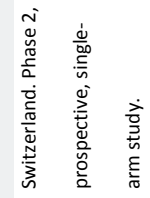

$\sqrt{1}$

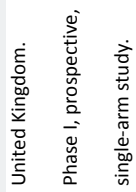

I

In

旁章 


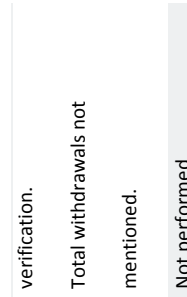

$$
\text { MIII }
$$

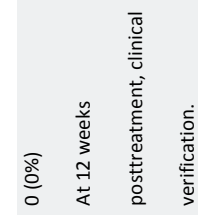
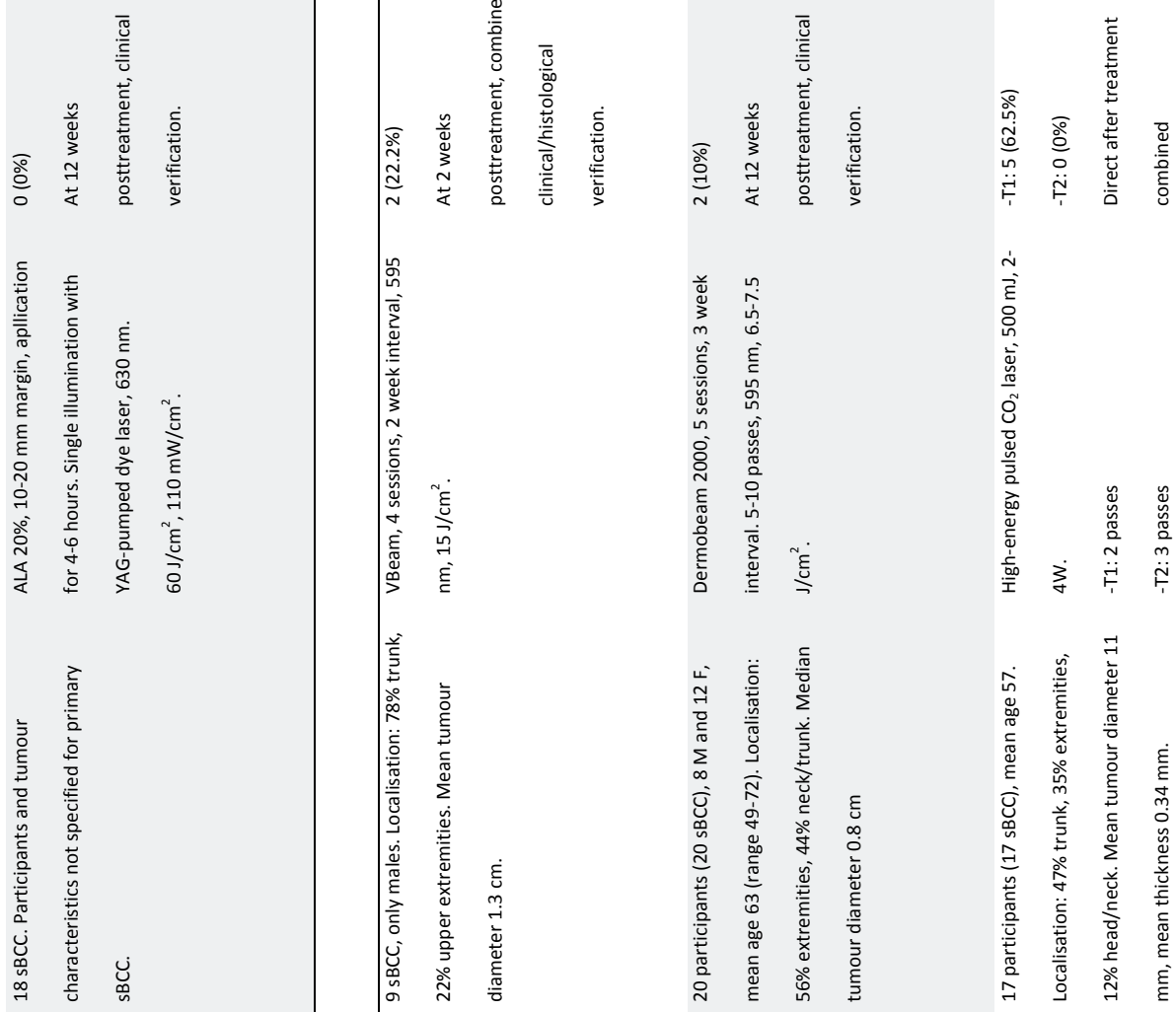

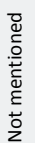

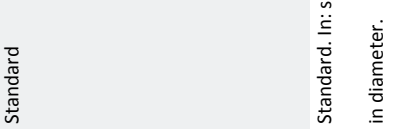

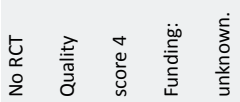

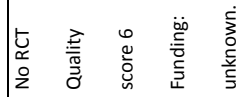

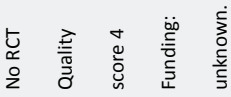

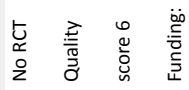

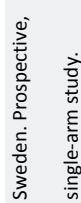

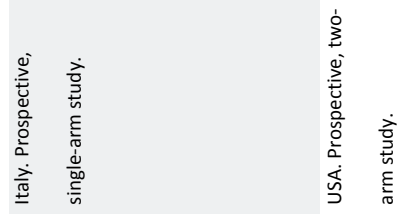

กั

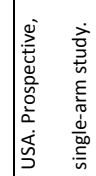

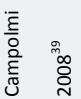

亳兽 


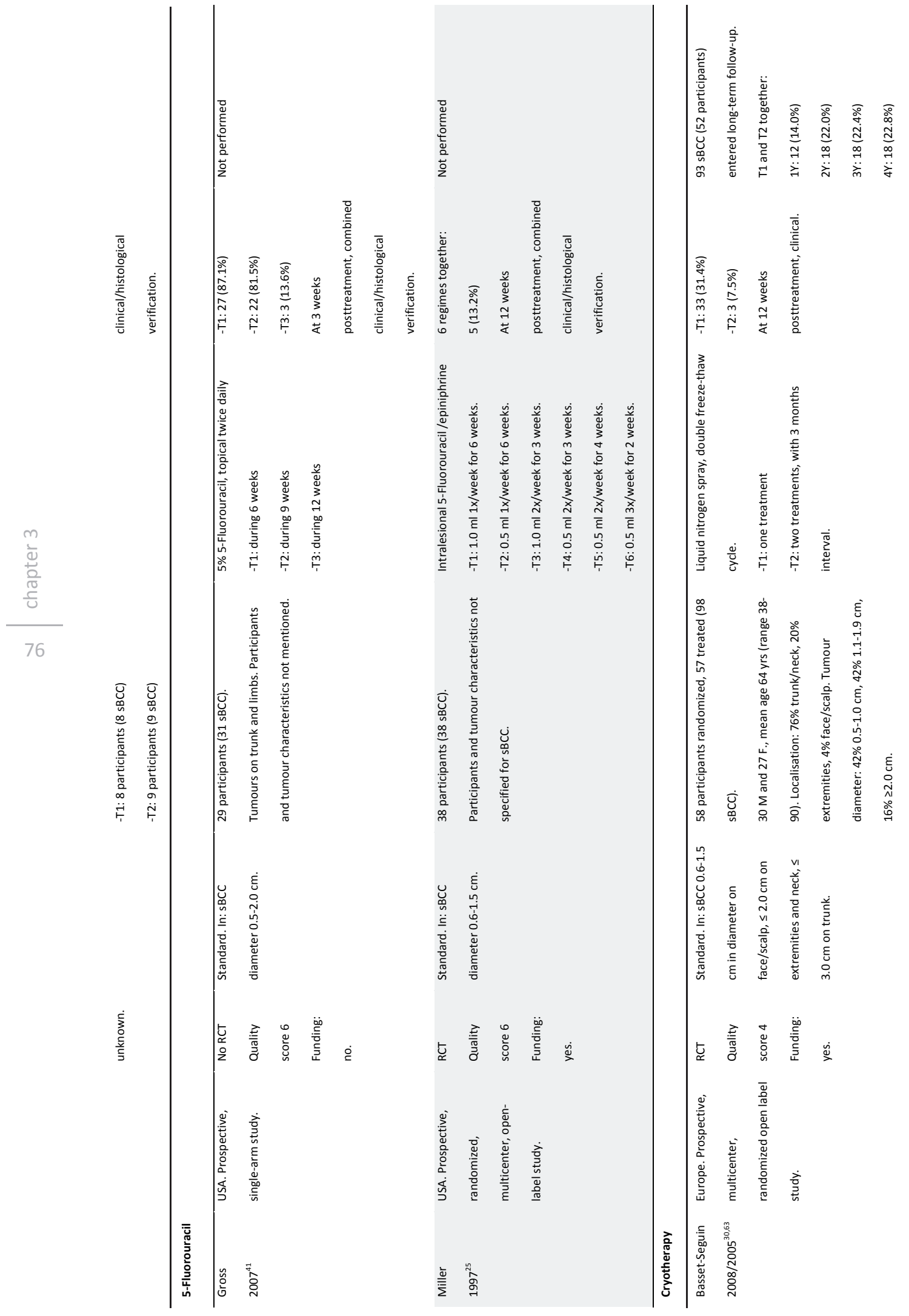




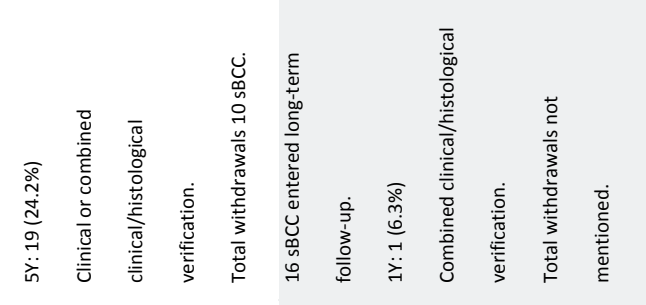

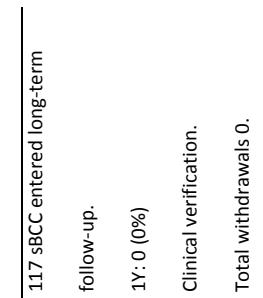

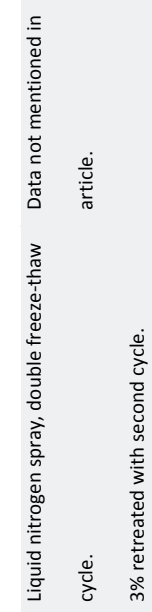

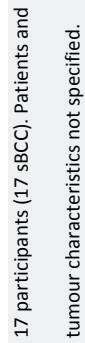

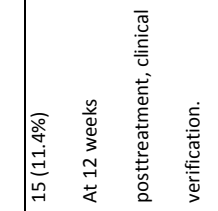

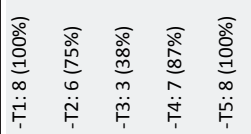

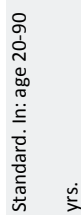

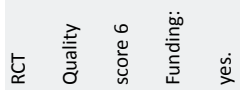

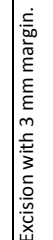

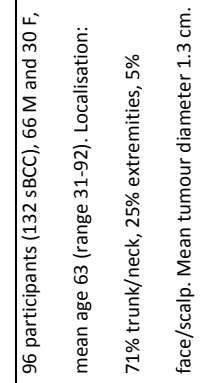

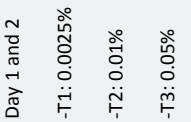

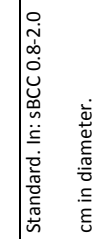

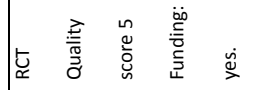

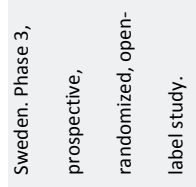

章

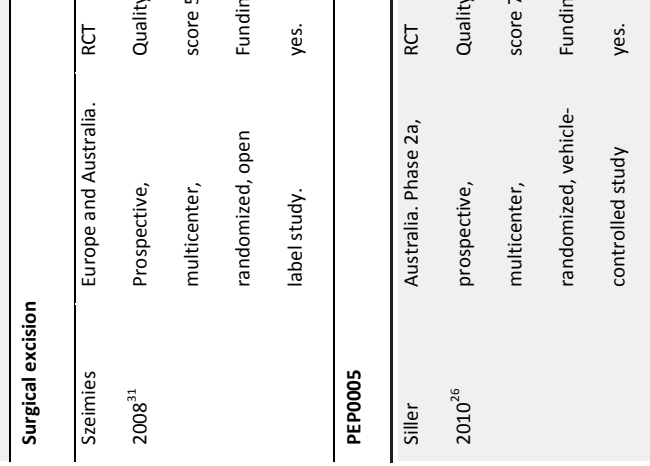




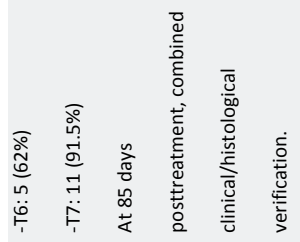

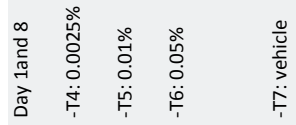

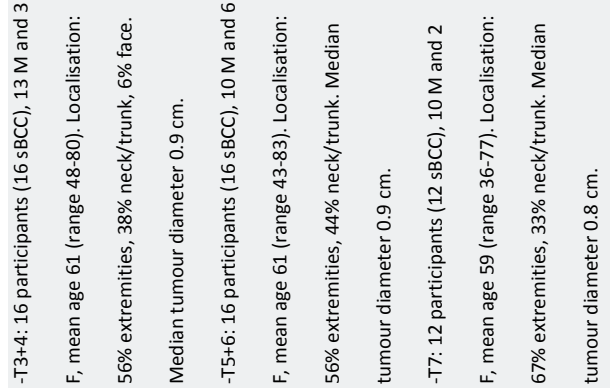

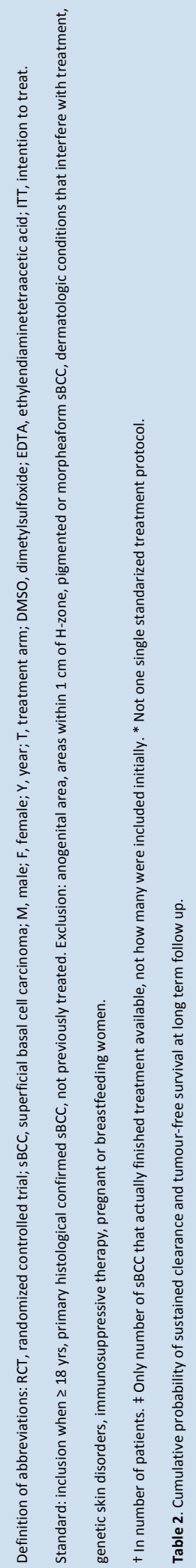




\title{
3.2 Photodynamic therapy vs. topical imiquimod vs. topical 5- fluorouracil for treatment of superficial basal cell carcinoma: a single blind, noninferiority, randomised controlled trial and cost-effectiveness analysis
}

\begin{abstract}
Backgroun.d The sustained rise in the incidence of basal cell carcinoma (BCC) causes high medical consumption and health care costs. Three histological subtypes are distinguished, of which one-third belongs to the superficial type.
\end{abstract}

Objective. The majority of superficial BCC is treated with a topical non-invasive technique known as photodynamic therapy (PDT). Some experts consider PDT preferable because of better aesthetic outcome, but a randomised controlled trial comparing PDT with topical therapies like imiquimod or 5-fluorouracil (5-FU) cream is lacking.

Methods. In this single blind, noninferiority, randomised controlled multicentre trial, we enrolled patients with a histologically proven superficial BCC at seven hospitals in the Netherlands between March 1, 2008 and August 31, 2010. Patients were randomly assigned to receive treatment with methylaminolevulinate (MAL)-PDT (two sessions with an interval of one week), imiquimod cream (once daily, five times a week for 6 weeks), or 5FU cream (twice daily during 4 weeks). Follow-up occurred at three and twelve months post-treatment. The primary outcome measure was the proportion of patients free of tumour one year after treatment. Secondary outcomes were cost-effectiveness, aesthetic outcome, compliance and adverse reactions. A pre-specified noninferiority margin of $10 \%$ was used and intention-to-treat analyses were performed (ISRCTN 79701845).

Results. A total of 601 patients was randomised. The proportion of patients tumour-free at one year follow-up was $\mathbf{7 2 \cdot 8 \%}$ for MAL-PDT, $83.4 \%$ for imiquimod cream, and $80.1 \%$ for 5 FU cream. The difference between imiquimod and MAL-PDT was $10.6 \%[95 \% \mathrm{Cl} 1.5$ to 19.5; $p=0.021$ ] and 7.3\% [95\% $\mathrm{Cl}-1.9$ to $16.5 ; p=0.120]$ ) between 5-FU and MAL-PDT. Both imiquimod and 5-FU cream were cost-effective compared to MAL-PDT. Aesthetic outcome was superior for MAL-PDT compared to imiquimod and 5-FU cream.

Conclusion. Results of this trial show that 5-FU is not inferior and imiquimod is even superior to MAL-PDT for treatment of superficial BCC. Both, imiquimod and 5-FU cream are cost-effective therapies compared to MAL-PDT. However, all aspects influencing treatment choice should be weighted to select the most optimal treatment for an individual patient with a primary superficial BCC. 


\section{Introduction}

Basal cell carcinoma (BCC), the most common skin cancer, is an important health problem worldwide. Its incidence has been increasing the last decennia and predictions of future trends showed no signs of stasis. ${ }^{1,2}$ Lifetime risk of BCC has been estimated at one in five for Dutch citizens. ${ }^{2}$ One-third of patients with a first BCC will develop one or more subsequent BCCs within the next 5 years. ${ }^{3}$ Therefore BCC is a common medical condition causing high medical consumption and health care costs. There are three histological subtypes of BCC: superficial, nodular and infiltrative. ${ }^{4}$ One-third of all BCCs belongs to the superficial histological subtype. ${ }^{5}$ This type of BCC often appears on the trunk and looks like a small eczema-like plaque. Superficial BCC is easily accessible with topical treatment because the tumour cells are continuous with the epidermis and do not extend beyond the mid-dermal skin layer. An international consensus on the use of photodynamic therapy (PDT) in non melanoma skin cancer (NMSC), recommended PDT as first-line treatment for superficial BCC. ${ }^{6}$ However, both 5-fluorouracil (5-FU) cream and imiquimod cream can be considered as an alternative treatment for this type of $\mathrm{BCC}^{7}{ }^{7}$ Up till now a randomised controlled trial (RCT) directly comparing the effectiveness and costs of PDT, 5-FU cream and imiquimod cream has not yet been performed. The hypothesis underlying this study is that the effectiveness of imiquimod and 5-FU cream is not inferior compared to the effectiveness of PDT for treatment of superficial BCC and that both creams may be cost-saving. The study was designed as a noninferiority RCT with respect to tumour clearance and costeffectiveness one year after treatment.

\section{Methods}

\section{Patients}

A single blind, randomised controlled multicentre trial was performed in the coordinating Maastricht University Medical Centre (MUMC) located in Maastricht and six other hospitals in the southern part of the Netherlands. The study was performed in accordance with the Declaration of Helsinki. The protocol was approved by the Ethical Committee of the MUMC. All patients provided written informed consent.

Patients referred to the dermatology outpatient departments of the seven participating centres between March 1, 2008 and August 31, 2010, who had a primary histologically proven superficial BCC, were eligible to participate in the trial. Histology of the lesion was obtained by a $3 \mathrm{~mm}$ punch biopsy and was evaluated by a variety of (dermato)pathologists at the participating hospitals which reflects clinical practice. A consensus was reached, defining a superficial BCC as an epidermal tumour existing of small, discrete islands of basaloid cells with peripheral palisading and stromal retraction, presenting intermittently along the basal layer of the epidermis. ${ }^{8}$

We chose to include one BCC per patient to ensure independence of observations. When a patient had more than one BCC eligible for inclusion, the tumour most accessible for 
treatment was chosen (for example: when a patient had a BCC on the arm and on the back, the lesion on the arm was included). When all lesions were equally accessible, the tumour with the largest size was included in the trial. Excluded were patients using immunosuppressive drugs, patients with genetic skin cancer disorders, patients with location of the tumour in the $\mathrm{H}$-zone or the hairy scalp. The $\mathrm{H}$-zone is the high risk area of the midface including the temporal areas that might be delineated by drawing an ' $\mathrm{H}$ ' on the face, with the horizontal line covering the area around the eyes and the nose. Also breastfeeding or pregnant women were excluded.

\section{Randomisation and masking}

Consecutive patients, who were eligible and gave informed consent, were randomly assigned to one of the three treatments i.e. PDT, imiquimod or 5-FU. After a phone call to the coordinating centre, randomisation occurred by an independent secretary, according to a computer-generated list using random permuted blocks of six in order to ensure concealment of allocation. Stratification by patients' age and tumour location was performed. Patients and treating physicians were not blinded to group assignment. Conversely, follow-up and data collection on clinical outcome was performed by one physician (AA), who was blinded to treatment assignment.

\section{Procedures}

Well defined standard care protocols were used for all three therapies.

Methylaminolevulinate (MAL)-PDT involves the application of $16 \%$ MAL (Metvix', Galderma S.A.) to the tumour (by means of a cream), which is converted within the cells into the photosensitizer protoporphyrin IX. Before the application of the photosensitizer, nontraumatic surface preparation was performed. MAL was applied topically with a wooden spatula to the lesion in a $1 \mathrm{~mm}$ thick layer including 5 to $10 \mathrm{~mm}$ of the surrounding healthy skin. Then the area was covered with an occlusive dressing (Tegaderm ; $3 \mathrm{M}^{\mathrm{TM}}$ ). To block visual light, aluminium foil was fixed over the Tegaderm . After an incubation period of 3 hours, the excess cream was wiped off and the area was irradiated with a light emitting diode (LED) light source, Omnilux (Waldmann) or Aktilite (Galderma S.A.) with an optimum wavelength of around $630 \mathrm{~nm}$. The lesions were irradiated during two treatment sessions with one week interval. Each session took 7.43 minutes with a light dose of 37 $\mathrm{J} / \mathrm{cm}^{2}$. After illumination, the treatment site was covered to prevent exposure to daylight during 48 hours. ${ }^{6,9}$

Treatment with $5 \%$ imiquimod cream (Aldara, Meda Pharma) is based on an immunomodulating mechanism which acts through toll-like receptors and enhances the production of cytokines and natural killer cells, the proliferation of B-lymphocytes and the activation of Langerhans cells. This treatment causes inflammation at the tumour site, due to stimulation of the immune response resulting in erythema, oedema, scaling, and erosions. Participants applied imiquimod cream once daily in a thin layer to the tumour including 5 to $10 \mathrm{~mm}$ of the surrounding skin without complete occlusion of the treatment site. Patients were advised to apply the cream at least one hour before going to bed and after 8 
hours the cream had to be wiped off. This was repeated for five following days per week during six weeks. ${ }^{7,10}$

5\% 5-FU cream (Efudix ${ }^{\circ}$ Meda Pharma) is a topically applied chemical agent that inhibits DNA synthesis, prevents cell proliferation, and causes tumour necrosis. Similar local reactions as mentioned with imiquimod cream occur. Participants applied 5-FU cream twice daily in a thin layer to the tumour including 5 to $10 \mathrm{~mm}$ of the surrounding skin without complete occlusion of the treatment site. Patients were advised to wipe of the remnants before applying a new layer. This was repeated for four weeks. ${ }^{11,12}$

The primary outcome measure was the proportion of patients who were still free of tumour recurrence one year after treatment. Clearance of the target tumour was clinically assessed by one observer (AA) blinded to treatment assignment at three and twelve months post-treatment. In case there was clinical suspicion of BCC recurrence at the follow-up visits, a $3 \mathrm{~mm}$ punch biopsy was taken for histological verification. All treatment failures were treated with surgical excision.

Secondary outcomes were aesthetic outcome, compliance, adverse reactions and costeffectiveness. Aesthetic outcome was evaluated by one blinded observer at the twelve month follow-up visit and was assessed by on a 4-point scale (excellent, good, fair or poor). ${ }^{13}$ Data on compliance with the prescribed regimens for imiquimod and 5-FU were obtained from a personal diary filled in by the patients during treatment. Compliance was calculated as number of cream applications performed by the patient divided by the total prescribed number of cream applications and was presented in percentages. The prescribed number for imiquimod was 30 times (once a day, five times per week during six weeks). For 5-FU, the prescribed number was 56 times (twice a day, seven times per week during four weeks). All adverse reactions were recorded. We distinguished expected adverse reactions from Suspected Unexpected Serious Adverse Reactions (SUSARs). Only SUSAR's, i.e. those adverse serious reactions, which are not described in the information on the investigational medicinal product are described here. The economic evaluation was performed to investigate the cost-effectiveness of topical imiquimod and 5-FU cream compared to MAL-PDT. A health care perspective was chosen for analysis since costs outside health care, like productivity loss, were considered to be minimal. The Incremental Cost-Effectiveness Ratio (ICER) was defined as the incremental costs per additional patient free of tumour recurrence and was calculated as the difference in costs divided by the difference in effectiveness.

For the cost-analysis, a distinction was made between pre-treatment, treatment and posttreatment costs. Pre-treatment costs consisted of an outpatient visit, a clinical photograph, a biopsy and a telephonic consultation. Treatment costs covered costs of personnel, cream, material like self-adhesive dressings and light source. The costs for the Metvix cream were based on a median tumour size of $50 \mathrm{~mm}^{2}$ as calculated within the clinical trial. Based on expert opinion, 2.55 lesions of this size are treated with one tube of cream resulting in costs of $€ 101.76$ per lesion per session. Depreciation costs for the Aktilite ( $€$ 11.800 incl. VAT) were calculated over a period of 10 years with an interest of $4.5 \%$, leading to costs of $€ 5.96$ for two sessions. Post-treatment costs included outpatient control 
visits, additional control visits related to SUSARs, any extra visits or telephone consultations related to questions about therapy, diagnostic procedures and other material. The costs of a control visit were calculated using half the price of a regular outpatient visit since the time investment was considered less compared to a regular visit. The cost price of an outpatient visit already included hospital overhead cost. However, general hospital overhead was additionally allocated to the direct treatment costs of MAL-PDT as an overall percentage, in accordance with the Dutch guidelines for cost calculation. ${ }^{14}$ Since imiquimod and 5-FU are applied by the patient at home, no additional overhead percentage was added to the treatment costs of these therapies. Table 1 presents an overview of the costs per unit. Real resource use was collected from the hospital information systems of the different hospitals. Since all data with regard to the costs and effectiveness were collected within one year, no discounting was applied. All costs are indexed to 2010.

\section{Statistical analyses}

The objective of this study was to evaluate whether alternative treatment of superficial BCC with topical imiquimod or 5-FU is not inferior to treatment with MAL-PDT, which was considered as active control. A pre-specified noninferiority margin of $10 \%$ was used and it was calculated that a sample size of 197 patients per treatment group was required to establish noninferiority with a power of $80 \%$ and one-sided type I error of $5 \% .{ }^{15}$ Hereby, it was assumed that the proportion of patients free of tumour recurrence one year after treatment with MAL-PDT is $80 \% .{ }^{6,7}$ The primary outcome was defined as the probability that a patient will be free of recurrence at twelve months after treatment given that the patient had no residual tumour at three months. The need for retreatment was considered as a failure. The overall estimate of treatment success was calculated by multiplying the percentage with initial clearance at three months by the percentage with sustained clearance during the next nine months of follow-up. Corresponding $95 \%$ confidence intervals (Cls) were estimated using the Greenwood's formula. ${ }^{16}$

The $95 \% \mathrm{Cls}$ for absolute difference in percentages between groups were calculated using the Wald method with continuity correction. Difference in proportions between groups was tested for statistical significance using the Chi-square test. Multivariable logistic regression analysis was used to adjust for patient age and tumour localization because randomisation was stratified for these factors. The odds ratio (with $95 \% \mathrm{Cl}$ ) for treatment with imiquimod or 5-FU (with MAL-PDT as reference category) from the crude model were compared with adjusted odds ratios. Comparison of clinical outcomes between the treatment groups was performed using an intention-to-treat analysis as well as a per-protocol analysis. In the intention-to-treat analysis patients were analysed in the group to which they were assigned by randomisation, whereas in the per-protocol analysis patients were analysed according to the treatment they actually received.

The cost-effectiveness analysis was performed based on intention-to-treat. Multiple imputations were used for missing data related to costs and effects. Since cost data are generally skewed, bootstrapping was used to generate confidence intervals for the incremental costs. To account for the uncertainty surrounding the cost-effectiveness ratios, bootstrap- 
ping was also applied (1000 replications). ${ }^{17}$ Results of the bootstrap analysis for the ICER are presented in cost-effectiveness planes and acceptability curves. A cost-effectiveness plane is a graphical presentation of four quadrants in which additional costs and effects of a new therapy are compared to standard care. The acceptability curve shows the probability of a treatment being more cost-effective compared to standard care for a range of possible threshold values. Bootstrapping was performed using Excel 2003. Univariate sensitivity analyses were conducted to test the robustness of the cost-effectiveness results. The following two parameters were chosen: (1) costs for the Metvix cream were varied by assuming that four lesions could be treated with one tube, (2) the standard prescription for imiquimod (Aldara ${ }^{\circ}$ ) is three boxes with each twelve sachets. However, based on the treatment schedule of the trial, costs of thirty sachets were calculated.

Reported $p$-values are two-tailed corresponding with a one-sided significance level of $2.5 \%$ for testing noninferiority. All data were analysed by use of the software SPSS (version 18.0) or the statistical software package STATA (version 11.0). This study is registered as an International Standard Randomised controlled trial (ISRCTN 79701845).

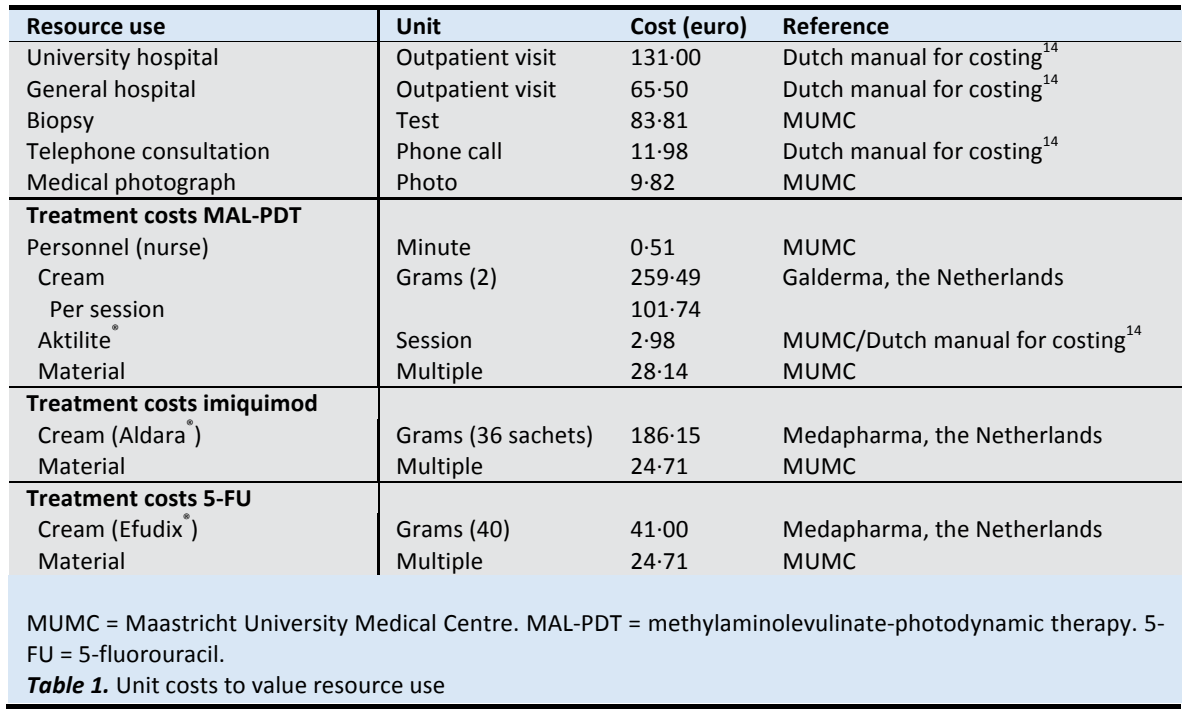

\section{Role of the funding source}

The sponsor of the study had a role in the study design, but not in data collection, data analysis and data interpretation, or writing of the report. The corresponding author had full access to all the data in the study and had final responsibility to submit it for publication. 


\section{Results}

\section{Noninferiority analyses}

Between March, 2008 and September, 2010, 911 patients were eligible to participate in the trial of which 310 patients refused participation, mostly because they had a preference for one of the three therapies. 601 patients with 601 superficial BCCs were randomly assigned to treatment with MAL-PDT ( $n=202)$, topical imiquimod $(n=201)$ or topical 5-FU ( $n=198$ ). Patient and tumour characteristics were balanced between groups (table 2). Of the 601 patients randomised, eleven dropped out before starting intervention and seven patients were lost-to-follow-up before the first control. So, 583 patients were included in the intention-to-treat analyses ( $n=196$ in MAL-PDT, $n=189$ in imiquimod, and $n=198$ in 5FU) (Figure 1). Twenty-six patients (4.4\%) were lost to follow-up. Five crossovers occurred before the start of the assigned treatment. One patient assigned to MAL-PDT was treated with imiquimod cream, because the patient was not able to come to the hospital. One patient assigned to imiquimod cream and three patients assigned to 5-FU cream were treated with MAL-PDT, because they had a strong preference for PDT. None of the patients treated with MAL-PDT reported a SUSAR. In the imiquimod group nine (4.9\%) SUSARs were reported and in the 5-FU group four (2-1\%). All events in the imiquimod group were flu-like symptoms except for one case in which wound infection occurred. In the 5FU group two local wound infections, one erysipelas of the lower extremity, and one leg ulcer occurred. The last two cases were treated with ambulant compression therapy and antibiotics.

The initial and sustained clearance rates with corresponding confidence intervals per treatment group are shown in table 3. The overall estimate of treatment success after one year follow-up was $72 \cdot 8 \%$ ([95\% Cl $66 \cdot 8 \%$ to $79 \cdot 4 \%]$ ) for patients treated with MAL-PDT, $83.4 \%$ ([95\% Cl $78 \cdot 2 \%$ to $88.9 \%]$ ) for patients treated with imiquimod and $80 \cdot 1 \%$ ([95\% Cl $74.7 \%$ to $85.9 \%]$ ) for those treated with 5 -FU (table 3 ). Differences in treatment success between treatments are presented in table 4 . The difference in treatment success between imiquimod and MAL-PDT was $10.6 \%$ ([95\% Cl 1.5\% to $19 \cdot 5 \%] ; \mathrm{P}=0.021)$. The difference between 5-FU and MAL-PDT was $7 \cdot 3 \%$ ([95\% Cl $-1 \cdot 9 \%$ to $16 \cdot 5 \%] ; p=0 \cdot 120)$. The difference between imiquimod and $5-\mathrm{FU}$ was $-3 \cdot 3 \%$ ([95\% $\mathrm{Cl}-11 \cdot 6 \%$ to $5 \cdot 0 \%] ; \mathrm{p}=0 \cdot 435)$. Perprotocol analyses resulted in similar results (not shown). Adjustment for age and tumour localisation with multivariable logistic regression analysis did not affect the results.

\section{Aesthetic outcome and compliance}

Aesthetic outcome was reported for all lesions free of tumour recurrence at 1-year followup. Data on aesthetic outcome of one patient treated with MAL-PDT was missing. Good to excellent aesthetic results were found in $86.6 \%(116 / 134)$ of the lesions treated with MALPDT, in $73.9 \%(113 / 153)$ of the lesions treated with imiquimod and in $72 \cdot 1 \%(111 / 154)$ of the lesions treated with 5-FU cream. Aesthetic outcome after MAL-PDT was superior to imiquimod and 5-FU cream. The difference in proportions with excellent or good aesthetic 
result for MAL-PDT versus imiquimod was $12 \cdot 7 \%(95 \% \mathrm{Cl} 2 \cdot 7 \%-21 \cdot 2 \%)$ and $14 \cdot 5 \%(95 \% \mathrm{Cl}$ $4.4 \%-23.0 \%)$ for MAL-PDT versus $5-F U$.

Compliance in the PDT group was $100 \%$. Less than $100 \%$ compliance was observed in $20.9 \%(40 / 191)$ of patients in the imiquimod group and in $31.3 \%(61 / 195)$ in the 5 -FU group.

\begin{tabular}{|c|c|c|c|c|}
\hline & & $M A L-P D T(n=202)$ & Imiquimod cream ( $n=198)$ & $5-F U$ cream $(n=201)$ \\
\hline \multicolumn{2}{|l|}{ Age (years) } & $63(26-87)$ & $62(30-91)$ & $64(35-86)$ \\
\hline \multicolumn{2}{|l|}{ men } & $96(48 \%)$ & $101(51 \%)$ & $106(53 \%)$ \\
\hline \multicolumn{2}{|c|}{ BCC in medical history } & $102(51 \%)$ & 96 (49\%) & $100(50 \%)$ \\
\hline \multicolumn{5}{|c|}{ Centrum of inclusion } \\
\hline \multicolumn{2}{|l|}{ Maastricht } & $86(43 \%)$ & $72(36 \%)$ & $86(43 \%)$ \\
\hline \multicolumn{2}{|l|}{ Venlo } & $41(20 \%)$ & $41(21 \%)$ & $41(20 \%)$ \\
\hline \multicolumn{2}{|l|}{ Heerlen } & $24(12 \%)$ & $28(14 \%)$ & $32(16 \%)$ \\
\hline \multicolumn{2}{|l|}{ Eindhoven } & $21(10 \%)$ & $22(11 \%)$ & $21(10 \%)$ \\
\hline \multicolumn{2}{|l|}{ Helmond } & $10(5 \%)$ & $12(6 \%)$ & $10(5 \%)$ \\
\hline \multicolumn{2}{|l|}{ Roermond } & $15(7 \%)$ & $14(7 \%)$ & $7(4 \%)$ \\
\hline \multicolumn{2}{|l|}{ Den Bosch } & $5(3 \%)$ & $9(5 \%)$ & $4(2 \%)$ \\
\hline \multicolumn{5}{|c|}{ Tumour location } \\
\hline \multicolumn{2}{|l|}{ Head/neck } & $24(12 \%)$ & $23(12 \%)$ & $31(15 \%)$ \\
\hline \multicolumn{2}{|l|}{ Trunk } & $119(59 \%)$ & $121(61 \%)$ & $120(60 \%)$ \\
\hline \multicolumn{2}{|c|}{ Upper extremities } & $32(16 \%)$ & $26(13 \%)$ & $27(13 \%)$ \\
\hline \multicolumn{2}{|c|}{ Lower extremities } & $27(13 \%)$ & $28(14 \%)$ & $23(12 \%)$ \\
\hline \multicolumn{2}{|c|}{ Tumour size in $\mathrm{mm}^{2}$} & $52(5-1382)$ & $63(5-1413)$ & $63(9-5472)$ \\
\hline \multicolumn{5}{|c|}{$\begin{array}{l}\text { Continuous variables are expressed as median (range) and categorical variables as } \mathrm{n}(\%) \text {. } \\
\text { BCC=basal cell carcinoma. MAL-PDT=methylaminolevulinate-photodynamic therapy. } 5 \text {-FU=5-fluorouracil. } \\
\text { Table 2: Tumour and patient characteristics separated by treatment group }\end{array}$} \\
\hline & \multicolumn{2}{|c|}{$\begin{array}{l}\text { Proportion initial clearance } \\
\text { rate }^{*}\end{array}$} & $\begin{array}{l}\text { Proportion sustained clearance } \\
\text { rate }^{*}\end{array}$ & $\begin{array}{l}\text { Overall estimate of treat- } \\
\text { ment success }^{*}\end{array}$ \\
\hline MAL-PDT & \multicolumn{2}{|c|}{$165 / 196$ (84.2\%) [79.1-89.3] } & $135 / 156(86.5 \%)$ [81.2-91.9] & $72.8 \%[66.8-79.4]$ \\
\hline Imiquimod & \multicolumn{2}{|c|}{$170 / 189$ (90.0\%) [85.7-94.2] } & $153 / 165$ (92.7\%) [88.8-96.7] & $83.4 \%$ [78.2-88.9] \\
\hline 5-FU & \multicolumn{2}{|c|}{$174 / 198$ (87.9\%) [83.3-92.4] } & $154 / 169$ (91.1\%) [86.8-95.4] & $80.1 \%$ [74.7-85.9] \\
\hline \multicolumn{5}{|c|}{$\begin{array}{l}\text { *data presented in } \mathrm{n} / \mathrm{N}(\%),{ }^{*} \text { product of initial and sustained clearance rate. } 95 \% \text { confidence interval [ ]. } \\
\text { MAL-PDT=methylaminolevulinate-photodynamic therapy. } 5 \text {-FU }=5 \text {-fluorouracil. } \\
\text { Table 3: Estimated initial and sustained clearance rate and overall treatment success (intention-to-treat } \\
\text { population) }\end{array}$} \\
\hline
\end{tabular}




\begin{tabular}{lccc}
\hline & Difference (\%) & 95\% Cl & $\begin{array}{l}\text { P- } \\
\text { value }\end{array}$ \\
\hline Imiquimod versus MAL-PDT & 10.6 & 1.5 to 19.5 & 0.021 \\
5-FU versus MAL-PDT & 7.3 & -1.9 to 16.5 & 0.120 \\
5-FU versus imiquimod & -3.3 & -11.6 to 5.0 & 0.435 \\
\hline $\begin{array}{l}\text { MAL-PDT=methylaminolevulinate-photodynamic therapy. 5-FU=5-fluorouracil. } \\
\text { Table 4: Differences in proportions of tumour-free survival at one year follow up between therapies with 95\% } \\
\text { Cl (intention-to-treat population) }\end{array}$ & & \\
\hline
\end{tabular}

\section{Economic evaluation}

Costs analysis. Table 5 presents the cost analysis per patient. At twelve months follow-up, the total mean costs for MAL-PDT amounted to $€ 680$, for imiquimod cream to $€ 526$ and for 5-FU cream to $€ 388$. The significantly higher treatment costs for MAL-PDT compared to imiquimod cream were mainly attributable to overhead costs and personnel costs. The significant cost difference between MAL-PDT and 5-FU cream was a consequence of the higher costs of the Metvix cream, overhead costs, and personnel costs. The significant higher treatment costs for imiquimod compared to 5-FU were due to higher costs of the imiquimod (Aldara ${ }^{\circ}$ cream.

Cost-effectiveness analysis. Both imiquimod cream and 5-FU were cost-effective treatments compared to MAL-PDT (table 6). The cost-effectiveness planes of both imiquimod (figure $2 \mathrm{a}$ ) and 5 -FU (figure $2 \mathrm{~b}$ ) illustrates that over $95 \%$ of all ratios were located in the quadrant where imiquimod and 5-FU were more effective and less costly compared to MAL-PDT.

Subsequently, dividing the incremental costs of imiquimod and 5-FU by their incremental effectiveness showed an ICER of $€ 4181$ per additional patient free of tumour recurrence (table 6). The cost-effectiveness plane shows that eighty percent of all ratios were situated within the quadrant where imiquimod was more effective but also more costly (figure 2c). The results of the sensitivity analysis show that varying the number of lesions treated with one tube of Metvix cream did not have a large impact on the cost-difference between MAL-PDT and imiquimod as well as 5-FU. Using thirty sachets of imiquimod decreased the ICER from $€ 4181$ to $€ 3242$ (table 7). 


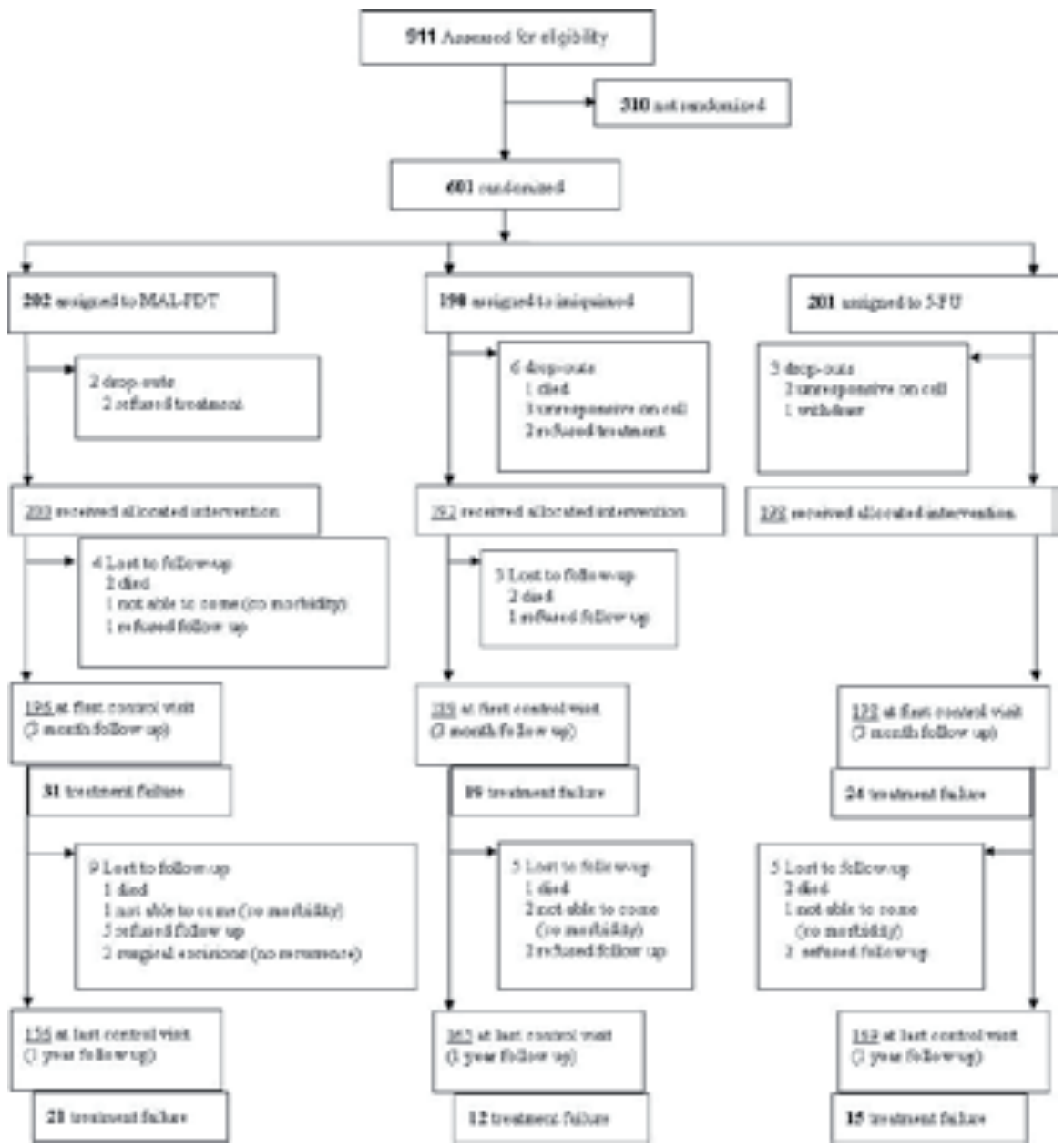

Figure 1. Trial profile 


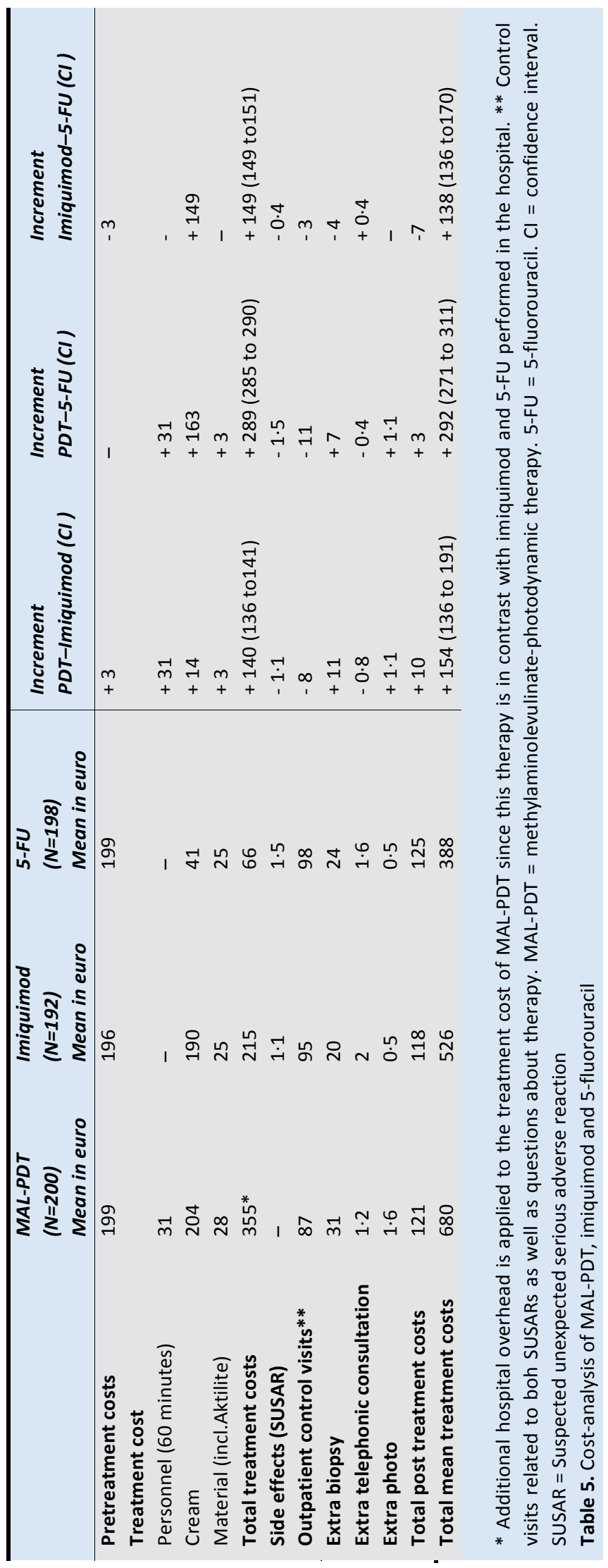



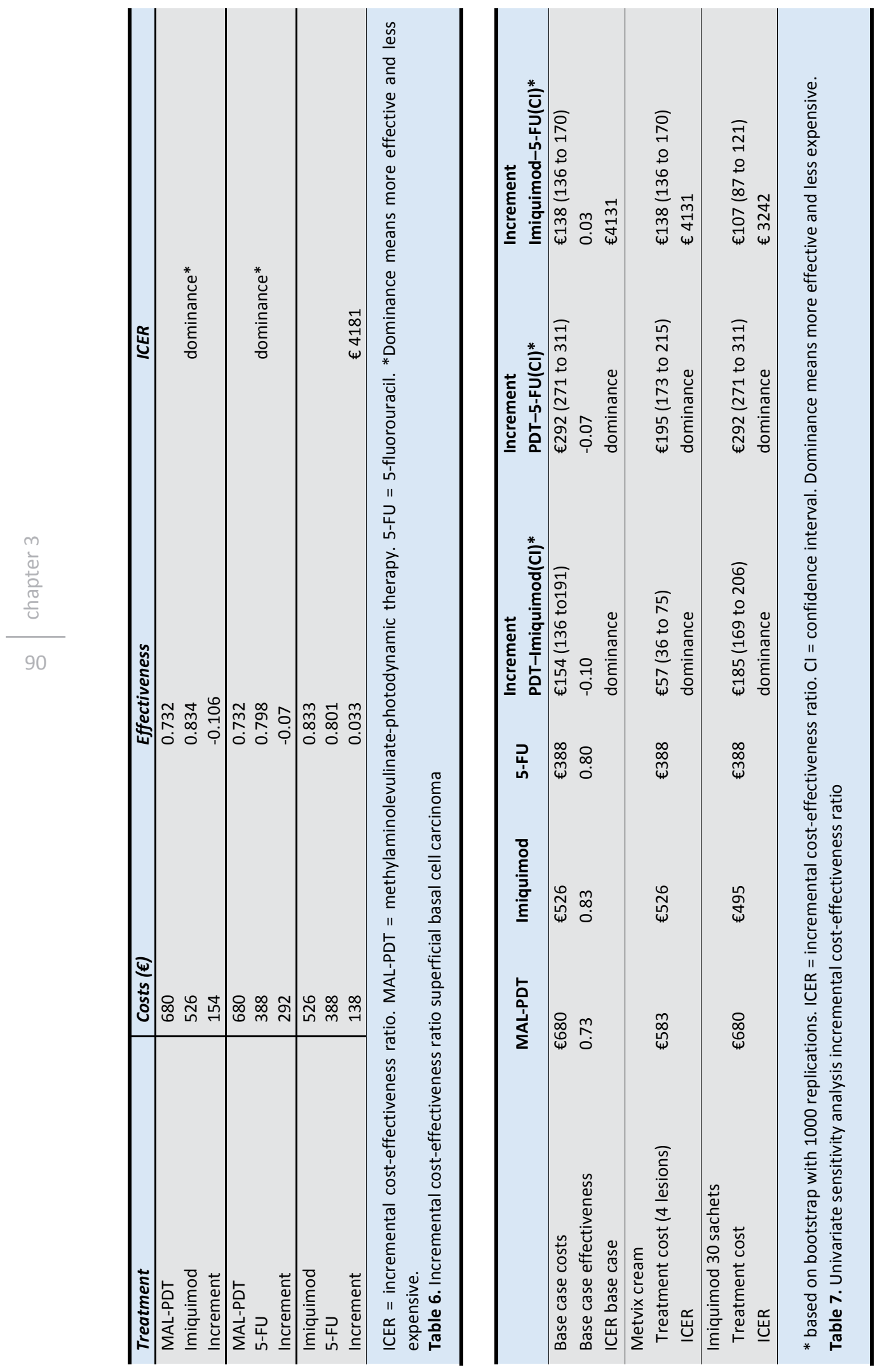
Figuur a

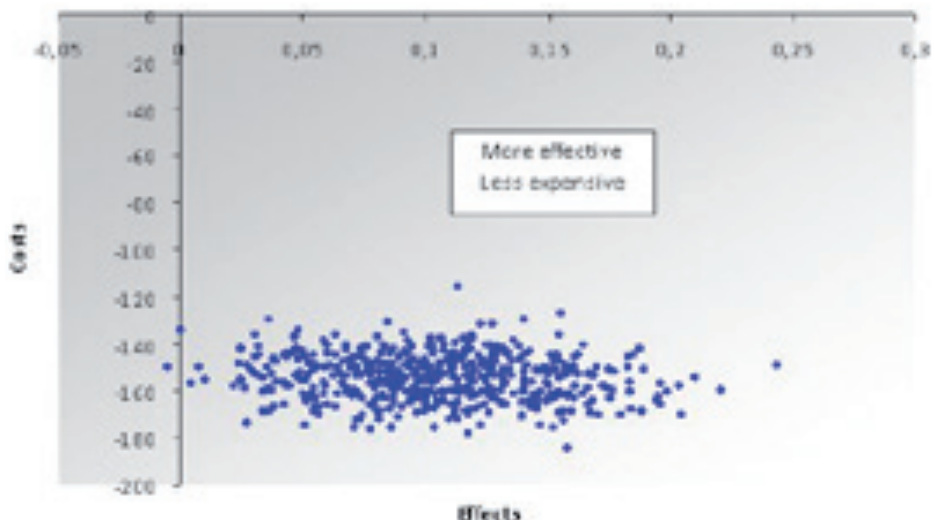

Figuur b

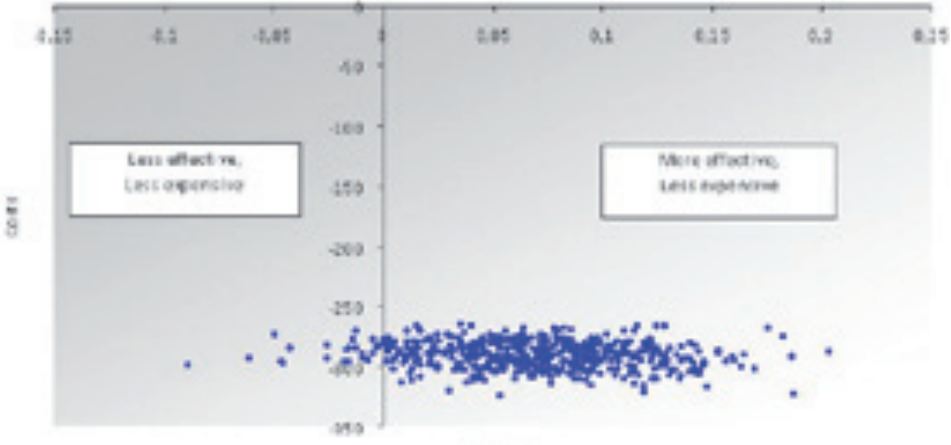

atrocta

Figuur c

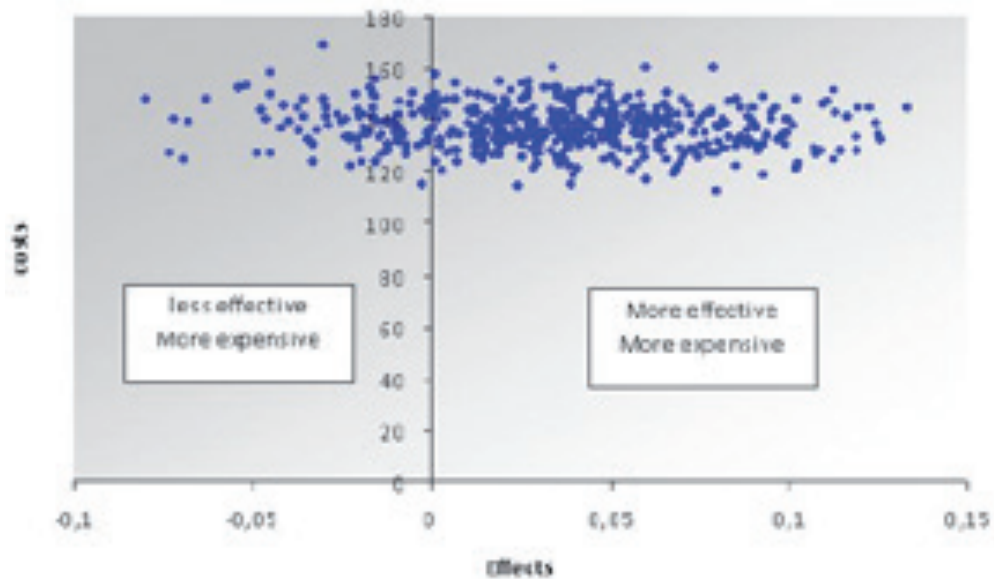

Figure 2. Cost-effectiveness planes. (a) imiquimod versus MAL-PDT; (b) 5-FU versus MAL-PDT; (c) imiquimod versus 5-FU 


\section{Discussion}

This study place compared the effectiveness of MAL-PDT, imiquimod, and 5-FU cream for the treatment of superficial $B C C$ and showed that topical imiquimod is superior to MALPDT and 5-FU is noninferior to MAL-PDT. The result regarding noninferiority of 5-FU compared to imiquimod was inconclusive. Furthermore, aesthetic outcome after MAL-PDT treatment was superior to treatment with imiquimod and 5-FU cream. The economic evaluation showed that both imiquimod and 5-FU as first-line treatments are dominant cost-effective therapies compared to MAL-PDT.

This is the first RCT directly comparing the effectiveness and costs of imiquimod, 5-FU and PDT for treatment of superficial BCC. Previously published studies on effectiveness of PDT or imiquimod for superficial BCC showed heterogeneity of results with large ranges in success rate. ${ }^{18}$ This was probably due to differences in study population, treatment protocols and follow-up duration. There are no one year follow-up studies on topical 5-FU for superficial BCC, so comparative data are lacking.

In this trial, according to the European regulatory approval, one MAL-PDT cycle was performed. This approach was chosen because in this way a well defined MAL-PDT treatment regimen can be compared with the creams. This may be the reason why the proportion with treatment success after MAL-PDT was lower than the estimated $80 \%$ success rate. This estimate was derived from studies on MAL-PDT by Basset-Seguin et al. and Szeimies et al. who retreated non-responding lesions at three months follow up with a second cycle of MAL-PDT. ${ }^{19,20}$ Repeated treatments will probably lead to higher treatment success of PDT but consequently will lead to a greater burden on health care facilities and higher treatment costs.

NMSC, of which BCC comprises nearly eighty percent, is among the most costly of all cancers. ${ }^{21}$ Worldwide problems with budget deficit imply that health care costs need to be cut down and treatment costs are becoming increasingly important in consideration of therapy selection. Based on the results of this RCT, we concluded that both imiquimod and 5-FU compared to MAL-PDT are dominant cost-effective therapies. When comparing imiquimod with 5-FU cream, the results were less conclusive. Dividing the difference in costs of both creams by their difference in effectiveness, led to an ICER of $€ 4131$ per additional patient free of tumour recurrence. A problem with the interpretation of this ICER is that, in contrast with conventional threshold values for a generic quality of life outcome measure like QALY (Quality Adjusted Life Years), no threshold value for the treatment of NMSC currently exists.

Nevertheless, the ratio of $€ 4131$ can be put into perspective by considering the consequences of a recurrent tumour. Since a recurrent superficial BCC can easily be treated with surgical excision, a threshold value should at least include the costs of standard surgery. If we take the costs of a surgical excision as previously calculated, a maximum amount for the treatment of superficial BCC could be around $€ 700 .{ }^{22}$ In that case, imiquimod can not be considered a cost-effective treatment compared to 5-FU cream because the ratio of $€$ 
4133 is above this threshold value. However, long-term follow-up effectiveness data are necessary to achieve more conclusive results regarding the cost-effectiveness of imiquimod versus $5 \mathrm{FU}$ cream.

Besides effectiveness and costs other aspects that impact selection of therapy like aesthetic outcome, compliance and adverse reactions need to be taken into account. Because superficial BCC is a harmless skin tumour in terms of survival, aesthetic outcome after therapy is an important aspect to consider when choosing a therapy. Previous studies showed a better aesthetic outcome after PDT compared to surgical excision for treatment of BCC. ${ }^{23,24}$ This trial shows that in case of treatment success the proportion of patients with excellent or good aesthetic result is highest after MAL-PDT and that in terms of aesthetic outcome MAL-PDT is superior to imiquimod and 5-FU.

Although major adverse events requiring hospitalisation or leading to permanent damage did not occur in this trial, we observed one wound infection in a patient treated with imiquimod cream and four wound infections in patients treated with 5-FU cream. It is important to discuss the possibility of occurrence of this side effect with the patient and familiarize the patient with the symptoms that may indicate or precede such an infection. Prudence is called for older patients with lesions on the lower legs, because wound infection in this area can cause erysipelas and leg ulcers.

The effectiveness and thus the cost-effectiveness of the creams depends on compliance with the treatment protocol. The compliance with MAL-PDT can be assumed to be high, because it is performed in the hospital setting by a nurse. Treatment with a cream requires daily application by the patient at home for several weeks and it was observed that in the setting of this trial less than $100 \%$ compliance was observed in one-fifth of the patients in the imiquimod group and in nearly one-third of the patients in the 5-FU group. The results of this trial show that despite incomplete compliance creams are still more effective than treatment with MAL-PDT. But in individual patients with high risk of poor compliance MAL-PDT may be preferable, for example for BCCs on locations that are not ready accessible for the patient. Moreover, to increase compliance in daily practice of patients treated with a self-applicable cream, we have to make an extra effort to create good information brochures which will guide patients through the treatment.

This RCT was limited by the short follow-up period. Previous studies with longer follow-up have reported that $50-78 \%$ of recurrences occur within the first year after treatment. ${ }^{19,25-}$ ${ }^{29}$ Thus recurrences can occur later and long-term follow-up is desirable.

This RCT comparing non-invasive treatment options for superficial BCC showed that the effectiveness of topical imiquimod is superior and that of 5-FU is noninferior to MAL-PDT. Besides, both creams are cost-effective treatments for superficial BCC compared to MALPDT. All aspects, including effectiveness, costs, aesthetic outcome, compliance and adverse reactions should be weighted to select the most optimal treatment for an individual patient with a primary superficial BCC. 


\section{References}

1. Lomas A, Leonardi-Bee J, Bath-Hextall F. A systematic review of worldwide incidence of nonmelanoma skin cancer. The British journal of dermatology. 2012; 166(5): 106980.

2. Flohil SC, de Vries E, Neumann HA, Coebergh JW, Nijsten T. Incidence, prevalence and future trends of primary basal cell carcinoma in the Netherlands. Acta dermatovenereologica. 2011; 91(1): 24-30.

3. Flohil SC, Koljenovic S, de Haas ER, Overbeek LI, de Vries E, Nijsten T. Cumulative risks and rates of subsequent basal cell carcinomas in the Netherlands. The British journal of dermatology. 2011; 165(4): 874-81.

4. Rippey JJ. Why classify basal cell carcinomas? Histopathology. 1998; 32(5): 393-8.

5. Arits $\mathrm{AH}$, Schlangen $\mathrm{MH}$, Nelemans PJ, Kelleners-Smeets NW. Trends in the incidence of basal cell carcinoma by histopathological subtype. Journal of the European Academy of Dermatology and Venereology : JEADV. 2011; 25(5): 565-9.

6. Braathen LR, Szeimies RM, Basset-Seguin N, Bissonnette R, Foley P, Pariser D, et al. Guidelines on the use of photodynamic therapy for nonmelanoma skin cancer: an international consensus. International Society for Photodynamic Therapy in Dermatology, 2005. Journal of the American Academy of Dermatology. 2007; 56(1): 125-43.

7. Telfer NR, Colver GB, Morton CA. Guidelines for the management of basal cell carcinoma. The British journal of dermatology. 2008; 159(1): 35-48.

8. Raymond L. Barnhill MD. Textbook of Dermatopathology: McGraw-Hill Companies Inc. ; 1998.

9. Morton CA. Methyl aminolevulinate (Metvix) photodynamic therapy - practical pearls. The Journal of dermatological treatment. 2003; 14 Suppl 3: 23-6.

10. Geisse J, Caro I, Lindholm J, Golitz L, Stampone P, Owens M. Imiquimod $5 \%$ cream for the treatment of superficial basal cell carcinoma: results from two phase III, randomized, vehicle-controlled studies. Journal of the American Academy of Dermatology. 2004; 50(5): 722-33.

11. Breuninger H, Sebastian G, Kortmann RD, Schwipper V, Werner J, Garbe C. [Brief guidelines: Basal cell carcinoma of the skin]. Journal der Deutschen Dermatologischen Gesellschaft $=$ Journal of the German Society of Dermatology : JDDG. 2006; 4(5): 4413.

12. Goette DK. Topical chemotherapy with 5-fluorouracil. A review. Journal of the American Academy of Dermatology. 1981; 4(6): 633-49.

13. Mosterd K, Arits AH, Nelemans PJ, Kelleners-Smeets NW. Aesthetic evaluation after non-invasive treatment for superficial basal cell carcinoma. Journal of the European Academy of Dermatology and Venereology : JEADV. 2011.

14. Hakkaart-van Roijen L TS, Bouwmans CAM. Dutch manual for costing in economic evaluation Health care insurance board; 2010. 
15. Blackwelder WC. "Proving the null hypothesis" in clinical trials. Controlled clinical trials. 1982; 3(4): 345-53.

16. Rosner B. Fundamentals of biostatistics. Seventh edition ed. Brooks/Cole: Cengage Learning; 2011.

17. Briggs AH, Wonderling DE, Mooney CZ. Pulling cost-effectiveness analysis up by its bootstraps: a non-parametric approach to confidence interval estimation. Health economics. 1997; 6(4): 327-40.

18. Roozeboom $\mathrm{MH}$, Arits $\mathrm{AH}$, Nelemans PJ, Kelleners-Smeets NW. Overall treatment success after treatment of primary superficial basal cell carcinoma: a systematic review and meta-analysis of randomized and non-randomized trials. The British journal of dermatology. 2012.

19. Basset-Seguin N, Ibbotson SH, Emtestam L, Tarstedt M, Morton C, Maroti M, et al. Topical methyl aminolaevulinate photodynamic therapy versus cryotherapy for superficial basal cell carcinoma: a 5 year randomized trial. European journal of dermatology : EJD. 2008; 18(5): 547-53.

20. Szeimies RM, Ibbotson S, Murrell DF, Rubel D, Frambach Y, de Berker D, et al. A clinical study comparing methyl aminolevulinate photodynamic therapy and surgery in small superficial basal cell carcinoma (8-20 mm), with a 12-month follow-up. Journal of the European Academy of Dermatology and Venereology : JEADV. 2008; 22(11): 1302-11.

21. Housman TS, Feldman SR, Williford PM, Fleischer AB, Jr., Goldman ND, Acostamadiedo $J M$, et al. Skin cancer is among the most costly of all cancers to treat for the Medicare population. Journal of the American Academy of Dermatology. 2003; 48(3): 425-9.

22. Essers BA, Dirksen CD, Nieman FH, Smeets NW, Krekels GA, Prins MH, et al. Costeffectiveness of Mohs Micrographic Surgery vs Surgical Excision for Basal Cell Carcinoma of the Face. Archives of dermatology. 2006; 142(2): 187-94.

23. Cosgarea R, Susan M, Crisan M, Senila S. Photodynamic therapy using topical 5aminolaevulinic acid vs. surgery for basal cell carcinoma. Journal of the European Academy of Dermatology and Venereology : JEADV. 2012.

24. Rhodes LE, de Rie MA, Leifsdottir R, Yu RC, Bachmann I, Goulden V, et al. Five-year follow-up of a randomized, prospective trial of topical methyl aminolevulinate photodynamic therapy vs surgery for nodular basal cell carcinoma. Archives of dermatology. 2007; 143(9): 1131-6.

25. Gollnick H, Barona CG, Frank RG, Ruzicka T, Megahed M, Maus J, et al. Recurrence rate of superficial basal cell carcinoma following treatment with imiquimod $5 \%$ cream: conclusion of a 5-year long-term follow-up study in Europe. European journal of dermatology : EJD. 2008; 18(6): 677-82.

26. Quirk C, Gebauer K, De'Ambrosis B, Slade HB, Meng TC. Sustained clearance of superficial basal cell carcinomas treated with imiquimod cream $5 \%$ : results of a prospective 5-year study. Cutis; cutaneous medicine for the practitioner. 2010; 85(6): 318-24. 
27. Ruiz-Villaverde R, Sanchez-Cano D, Burkhardt-Perez P. Superficial basal cell carcinoma treated with imiquimod $5 \%$ topical cream for a 4-week period: a case series. Journal of the European Academy of Dermatology and Venereology : JEADV. 2009; 23(7): 828-31.

28. Soler AM, Angell-Petersen E, Warloe T, Tausjo J, Steen HB, Moan J, et al. Photodynamic therapy of superficial basal cell carcinoma with 5 -aminolevulinic acid with dimethylsulfoxide and ethylendiaminetetraacetic acid: a comparison of two light sources. Photochemistry and photobiology. 2000; 71(6): 724-9.

29. Vun $Y$, Siller G. Use of $5 \%$ imiquimod cream in the treatment of facial basal cell carcinoma: a 3-year retrospective follow-up study. The Australasian journal of dermatology. 2006; 47(3): 169-71. 


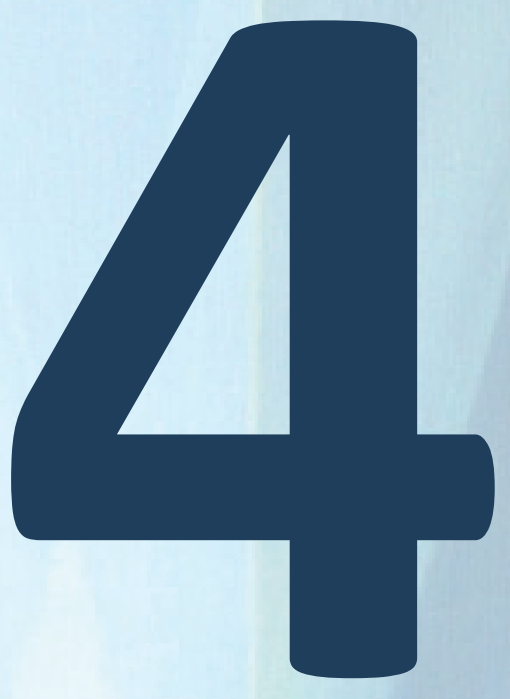

\section{Reliable and valid scar evaluation tools}

K. Mosterd, A. Arits, P. Nelemans, N kelleners-Smeets.

Aesthetic evaluation after noninvasive treatment for superficial basal cell carcinoma.

J Eur Acad Dermatol Venereol 2011 Nov 21.

doi: 10.1111/j.1468-3083.2011.04347.x. [Epub ahead of print] 



\section{Abstract}

Background. Scar evaluation after non-invasive treatment is subjective and cosmetic results of different treatments are difficult to compare. In the absence of a qualified objective scar assessment scale for this type of scars, usually a 4-point scale is used. The reproducibility of this method is never evaluated. Furthermore, specific scar information that is important to evaluate in studies and can be used to improve treatments, is lacking. We compared the 4-point scale to the patient and observer scar assessment scale (POSAS), a scale qualified for the assessments of surgical scars. The POSAS also includes the opinion of a patient. Both methods were used to evaluate scars following different types of noninvasive treatment of superficial BCC.

Methods. 54 scars following non-invasive treatment for basal cell carcinoma (BCC) in 54 patients were evaluated with the traditional 4-point scale and the POSAS.

Results. The 4-point scale showed the best reproducibility and had an intra-class correlation coefficient (ICC) of 0.66 (95\% Cl 0.52-0.77) for a single and 0.85 (95\% Cl 0.77-0.91) for multiple observers. The ICC of the POSAS was $0.41(95 \% \mathrm{Cl} 0.21-0.58)$ for a single and 0.67 $(95 \% \mathrm{Cl} 0.45-0.81)$ for three observers. Vascularity and pigmentation were most decisive for the overall opinion.

Conclusion. The use of the 4-point scale is a valid method to compare scars of non-invasive treatments. Registering scar characteristics vascularity and pigmentation is very valuable in studies. 


\section{Introduction}

Non-invasive therapies are increasingly used to treat superficial basal cell carcinoma (sBCC), because of good aesthetic outcome. For evaluation of aesthetics, reliable and valid scar evaluation tools are mandatory. However, this type of scar is currently not evaluated with validated scar assessment methods.

In dermatologic practice, usually the 4-point scale is used for assessment of aesthetic outcome. It classifies the appearance of scars as excellent, good, fair or poor. ${ }^{1}$ Reliability of this method was never investigated.

The Vancouver Scar Scale (VSS) is the most frequently used qualified assessment scale. ${ }^{2}$ The Patient and Observer Scar Assessment Scale (POSAS), a combination of the Patient Scar Assessment Scale (PSAS) and the Observer Scar Assessment Scale (OSAS) ${ }^{3-5}$ is reliable, valid and comprehensive compared to the VSS. ${ }^{6}$ It includes individual scar characteristics (vascularity, pigmentation, thickness, relief, pliability and surface area) and involves subjective features such as pain and itching. In the Manchester Scar Scale 7 scar parameters are assessed (scar colour, skin texture, relationship to surrounding skin, texture, margins, size and single or multiple) and an overall VAS is added to the individual scores. Both scores added together give an overall score.

Because non-invasive treatment is less effective than surgical excision, objective assessment of the main benefit is essential. Because a less effective treatment is offered, the patient's opinion must be included and subjective features that might influence his opinion, such as pain and itching are important to assess. The POSAS fulfils this requirement and also subclassifies colour into vascularity and pigmentation, both known effects of noninvasive therapies.

We compared the inter observer variability of the 4-point scale and the POSAS and investigated what scar characteristics are most predictive for the overall opinion of the physician and the patient.

\section{Materials and methods}

\section{Patients and procedures}

We included patients treated with photodynamic therapy, imiquimod cream or 5fluorouracil cream for SBCC at the department of dermatology of the Maastricht University Medical Centre in the Netherlands (ISRCTN79701845). Ethics approval was obtained. All patients gave written informed consent to participate.

Lesions were assessed 3 or 12 months after treatment by three independent observers, blinded for treatment. This random selection of physicians working at the dermatooncology department consisted of a dermatologist (DE), an experienced resident (DR) and an intern (DI). Patients were asked to judge their own scar twice; prior to and during a visit to our outpatient department. 


\section{Scar assessment methods}

All scars were assessed with a Dutch POSAS and 4-point scale. First, the 4-point scale was completed, resulting in: (1) excellent; no scarring, atrophy or induration and slight or no redness or change in pigmentation compared with adjacent skin; (2) good: no scarring, atrophy or induration and/or moderate redness or increase in pigmentation compared with adjacent skin; (3) fair: slight to moderate occurrence of scarring, atrophy, induration and/or significant redness or increase in pigmentation compared with adjacent skin; and (4) poor: extensive occurrence of scarring, atrophy, induration and/or redness or increase in pigmentation compared with adjacent skin. ${ }^{1}$ Subsequently, the PSAS was completed by the patient and the OSAS by the physician. ${ }^{5}$ The PSAS assesses scar colour, pliability, thickness, relief, itching and pain (Figure 1) and the OSAS scar vascularity and pigmentation (both defined as colour), pliability, thickness, relief and surface area (Figure 2). Each variable has a 10 -point scoring system ( $1=$ normal skin; $10=$ worst scar imaginable). The total score is the sum of all six items (range 6-60). Some items were subclassified. Finally, an overall opinion was rated (range 1-10).

\begin{tabular}{|c|c|c|}
\hline \multirow[b]{2}{*}{ Parameters } & \multicolumn{2}{|c|}{ Reliability } \\
\hline & ICC 1 observer $(95 \% \mathrm{CI})$ & ICC 3 observers ( $95 \% \mathrm{CI})$ \\
\hline Total OSAS score & $0.405(0.213-0.581)$ & $0.672(0.449-0.806)$ \\
\hline Vascularity & $0.381(0.215-0.547)$ & $0.648(0.451-0.783)$ \\
\hline Pigmentation & $0.466(0.216-0.659)$ & $0.724(0.452-0.853)$ \\
\hline Thickness & $0.616(0.474-0.738)$ & $0.826(0.730-0.894)$ \\
\hline Relief & $0.511(0.352-0.657)$ & $0.758(0.619-0.852)$ \\
\hline Pliability & $0.197(0.043-0.373)$ & $0.424(0.119-0.640)$ \\
\hline Surface area & $0.049(0-0.288)$ & $0.093(0-0.448)$ \\
\hline Overall opinion & $0.643(0.508-0.759)$ & $0.844(0.756-0.904)$ \\
\hline 4-point scale & $0.658(0.522-0.771)$ & $0.853(0.766-0.910)$ \\
\hline
\end{tabular}




\section{Patient and Observer Scar Assessment Scale: Patient Scale}

No, not at all $1 \begin{array}{llllllllll}2 & 3 & 4 & 5 & 6 & 7 & 8 & 9 & 10 & \text { Yes, very much }\end{array}$

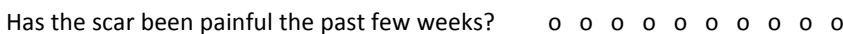

Has the scar been itching the past few weeks? $\quad \begin{array}{lllllllllllllllllll}0 & 0 & 0 & 0 & 0 & 0 & 0 & 0\end{array}$

No, as normal skin $1 \quad 2 \quad 3 \quad 4 \quad 5 \quad 6 \quad 7 \quad 8 \quad 9 \quad 10$ Yes, very different

Is the scar color different from the color of your normal skin at present?

$0 \quad 0 \quad 0 \quad 0 \quad 000000$

Is the stiffness of the scar different from your

normal skin at present?

$0 \begin{array}{lllllllllllllllllllll}0 & 0 & 0 & 0 & 0 & 0 & 0 & 0 & 0 & 0\end{array}$

Is the thickness of the scar different from your normal skin at present?

$\begin{array}{lllllllllllllllllllll}0 & 0 & 0 & 0 & 0 & 0 & 0 & 0 & 0 & 0\end{array}$

Is the scar more irregular than your normal skin at present?

As normal skin $1 \quad 2 \quad 3 \quad 4 \quad 5 \quad 6 \quad 7 \quad 8 \quad 9 \quad 10$ Very different

What is your overall opinion of the scar compared to normal skin?

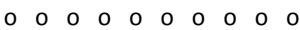

Figure 1. Patient Scale developmed and previously published by Draaijers et al. ${ }^{3}$ 


\section{Patient and Observer Scar Assessment Scale: Observer Scale}

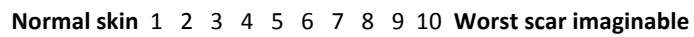

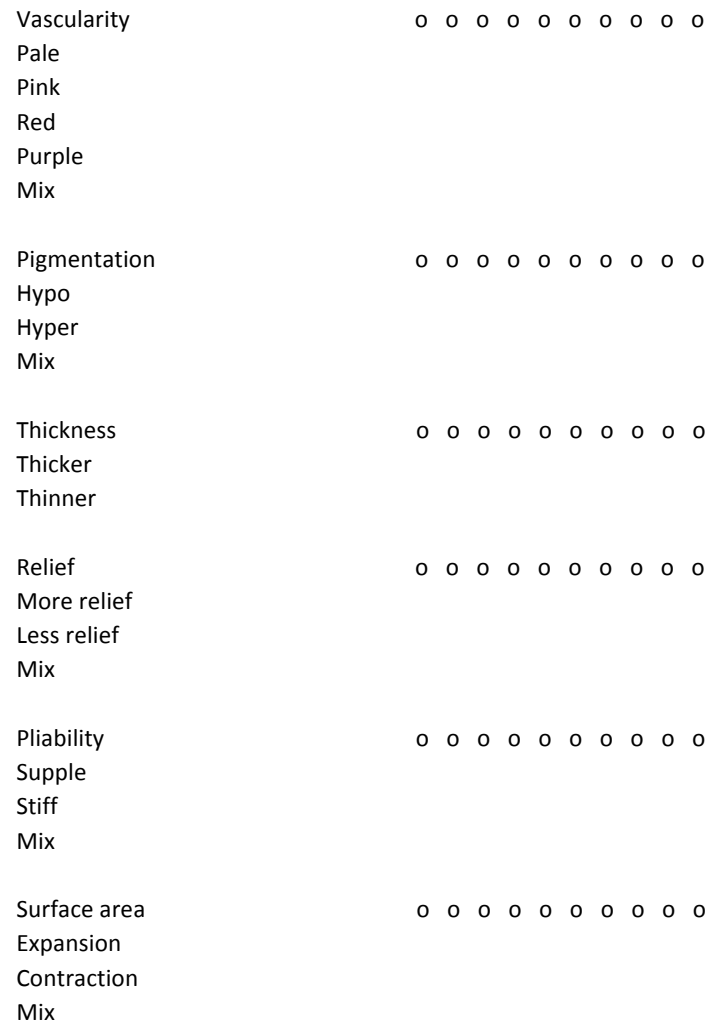

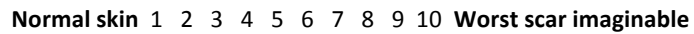

Figure 2. Observers Scale developed and previously published by Draaijers et al. ${ }^{3}$ 


\section{Statistical analysis}

Reliability was measured using the intra-class correlation coefficient (ICC), ${ }^{7}$ the ratio of variability between patients to the total variability (the sum of between-patient variability and measurement error). It reflects the extent to which a measurement instrument can differentiate among patients. ${ }^{8}$ Zero indicates no reliability and one no measurement error and perfect reliability. An ICC $<0.4$ indicates poor reproducibility, $\geq 0.4$ and $<0.75$ fair to good reproducibility and $\geq 0.75$ excellent reproducibility. ${ }^{9}$ Following available literature, we assumed that 50 patients were required to obtain a $95 \%$ confidence interval of \pm 0.1 around an expected ICC value of $0.8 .^{4,10}$

The ICC and corresponding 95\% confidence interval were calculated for the 4-point scale, the separate items of the POSAS, the total POSAS score and the 'overall opinion'. The twoway random effect model with absolute agreement was used to calculate the ICC and assess the reliability of scores by one observer (single measurement) and three observers (average measurement). Correlation between scores obtained using the two different methods was analysed with the Spearman's correlation coefficient.

Linear multivariate regression analyses were performed to evaluate which scar characteristics were most predictive for the overall opinion. The dependent variable was the overall opinion score as rated by the physician or patient and the independent variables were the scores on the individual scar characteristics. The regression coefficient with the corresponding $95 \%$ confidence interval indicates whether a scar characteristic is a significant predictor of the overall opinion. A $p$-value $\leq 0.05$ was considered to indicate statistical significance. All data were analysed by SPSS-pc, version 16.0.

\section{Results}

54 scars were assessed in 54 patients. The mean age was 61 years (36-75) and 29 were male.

The OSAS score was generally low; the maximum score of DE was 39 points and de maximum score of other observers was even lower (24 and 18 points). The limited variability of the scores was confirmed by a low interquartile range, the difference between $75^{\text {th }}$ percentile and the $25^{\text {th }}$ percentile. All individual characteristics showed low maximum scores with limited variability in all observers. The median score on the PSAS was 8.5, whereas the highest score possible was 60 . The scores of the 4-point scale covered the entire possible range from 1-4. The observers scored $5-7 \%$ of the scars as poor, $24-43 \%$ as fair, $33-$ $48 \%$ as good and $17-28 \%$ as excellent. Of all patients $6 \%$ scored their scar as poor, $24 \%$ as fair, $57 \%$ as good and $13 \%$ as excellent.

The ICC for the 4-point scale, the overall opinion, the OSAS and the scores on the separate items of the OSAS are shown in Table 1. In general, the ICC values of the 4-point scale were higher than the OSAS, but comparable to the overall opinion. The OSAS showed fair reproducibility. The overall opinion and the 4-point scale showed good reproducibility. Regarding the separate items of the OSAS, pliability, surface area and vascularity showed 
poor reproducibility. Pigmentation, relief and thickness showed fair to good reproducibility. By using the average score of three observers, a higher ICC is obtained for all methods: reliability increases. The Spearman's correlation coefficient between the investigated methods was good and ranged from 0.75 to 0.82 for the three observers.

Vascularity and pigmentation had significant impact on the overall opinion of all three observers (Table 2). Thickness was decisive for two of the three observers (DR, DI). Only colour (and not pain and itching) had a significant influence on the patient's overall opinion.

\section{Discussion}

Because of improved efficacy of therapies for BCC and younger ages of onset, aesthetic outcome becomes more important. A reliable and valid method to evaluate aesthetics is needed. We compared the 4-point scale to the POSAS, a qualified scar assessment method. ${ }^{4}$ The results show that the 4-point scale has a better reliability (ICC) than the OSAS. Reliability may be improved by using the average score of multiple observers. Scar vascularity and pigmentation appear to be most predictive for the overall opinion of the physician and scar colour for the patient.

The low ICC of the POSAS was not in agreement with the results that were reported previously in linear surgical scars and burn scars. ${ }^{4-6} \mathrm{~A}$ possible explanation for this discrepancy is that the ICC is very dependent on the study population. The ICC relates measurement error to the variability between persons and therefore tends to be higher in more heterogeneous populations. ${ }^{8}$ The low median of the scores and the low interquartile range of POSAS scores indicate that the cosmetic outcome in the present study was more homogeneous than in previous studies. When assessed with the POSAS, non invasive treatments have a relatively good aesthetic result, compared to surgical methods. However, if scored with the 4-point method, there appears to be more variability and the entire spectrum of the scale is used. This proves that there is some variation in the aesthetic results of noninvasive treatments, which can be captured by the 4-point scale, but not by the POSAS. The good correlation between the investigated methods proves that the methods are consistent in ranking the scars.

Inter-observer variability is reduced when the average score of multiple observers is used. Measurement errors are random and those associated with each observation are averaged out. ${ }^{8}$ Therefore, scar assessment in a randomised controlled trial is preferably done by multiple observers. With a single observer, both investigated methods might be inadequate to detect a statistically significant difference between aesthetic outcomes.

An advantage of the POSAS was that it showed what aspects of the scar influence the final appreciation. It enabled identification of the criteria that physicians and patients use to evaluate the cosmetic result and showed how much weight they assigned to these criteria. It might be useful to add the scoring of relevant individual scar characteristics (vascularity and pigmentation), for interpretation, to the 4-point score. 


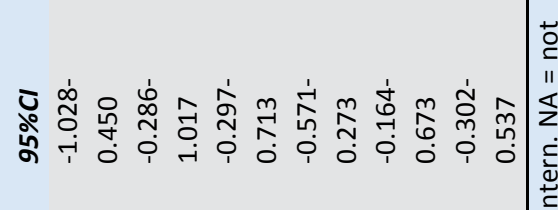

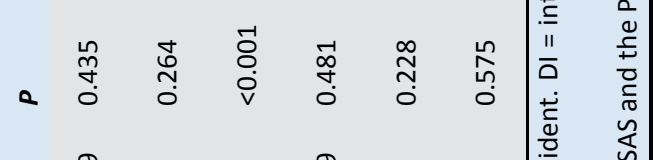

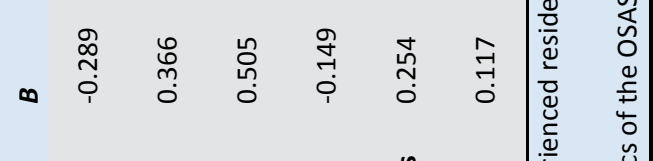

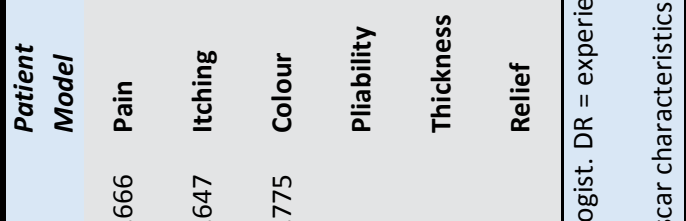

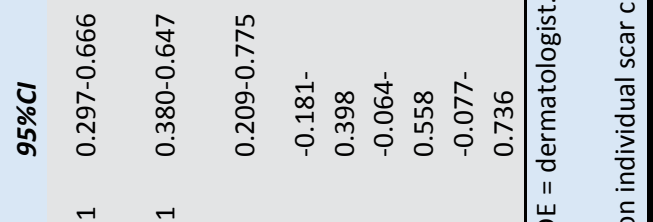

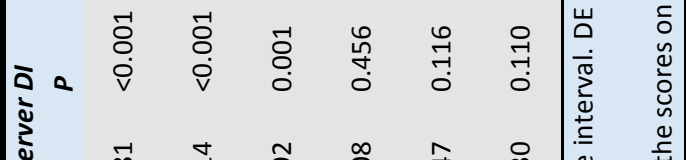

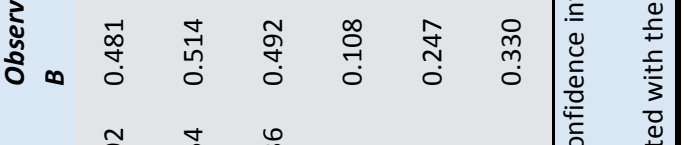

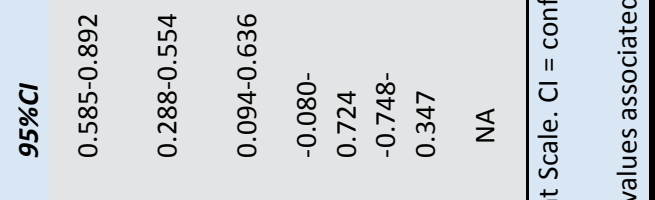

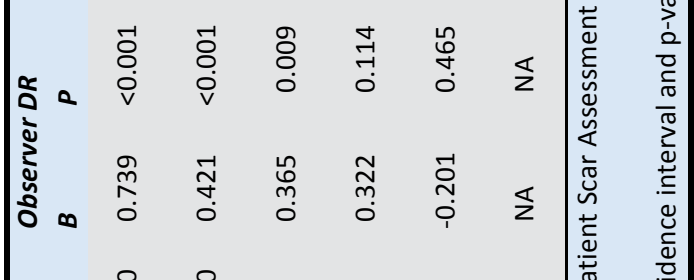

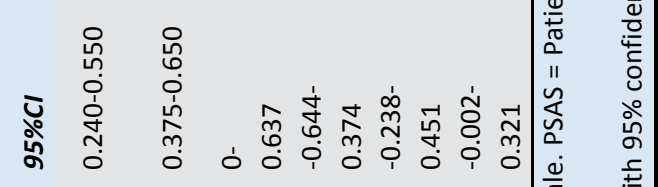

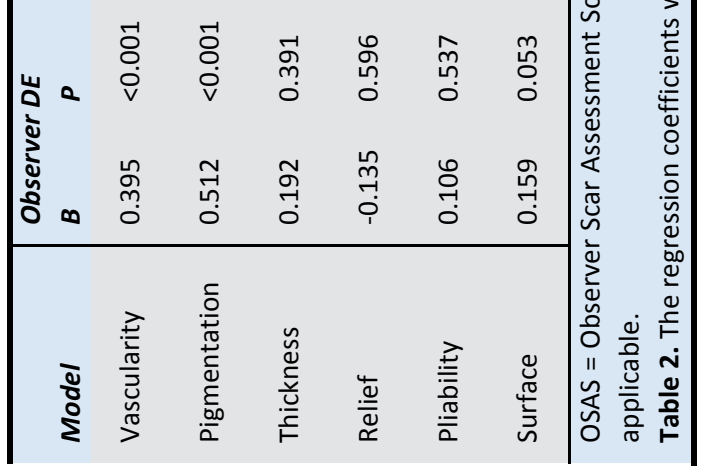




\section{References}

1. Rhodes LE, de Rie MA, Leifsdottir R, Yu RC, Bachmann I, Goulden V, et al. Five-year follow-up of a randomised, prospective trial of topical methyl aminolevulinate photodynamic therapy vs surgery for nodular basal cell carcinoma. Archives of dermatology. 2007 Sep;143(9):1131-6.

2. Roques C, Teot L. A critical analysis of measurements used to assess and manage scars. The international journal of lower extremity wounds. 2007 Dec;6(4):249-53.

3. Draaijers LJ, Tempelman FR, Botman YA, Tuinebreijer WE, Middelkoop E, Kreis RW, et al. The patient and observer scar assessment scale: a reliable and feasible tool for scar evaluation. Plastic and reconstructive surgery. 2004 Jun;113(7):1960-5; discussion 6-7.

4. van de Kar AL, Corion LU, Smeulders MJ, Draaijers $L$, van der Horst CM, van Zuijlen PP. Reliable and feasible evaluation of linear scars by the Patient and Observer Scar Assessment Scale. Plastic and reconstructive surgery. 2005 Aug;116(2):514-22.

5. Truong PT, Lee JC, Soer B, Gaul CA, Olivotto IA. Reliability and validity testing of the Patient and Observer Scar Assessment Scale in evaluating linear scars after breast cancer surgery. Plastic and reconstructive surgery. 2007 Feb;119(2):487-94.

6. Shrout PE, Fleiss JL. Intraclass correlations: uses in assessing rater reliability. Psychological bulletin. 1979 Mar;86(2):420-8.

7. Streiner DNG. Health measurement scales. Oxford: Oxford university press, 2003.

8. Rosner B. Fundamentals of biostatistics. 6 ed. Belmont: Duxbury, 2006. 



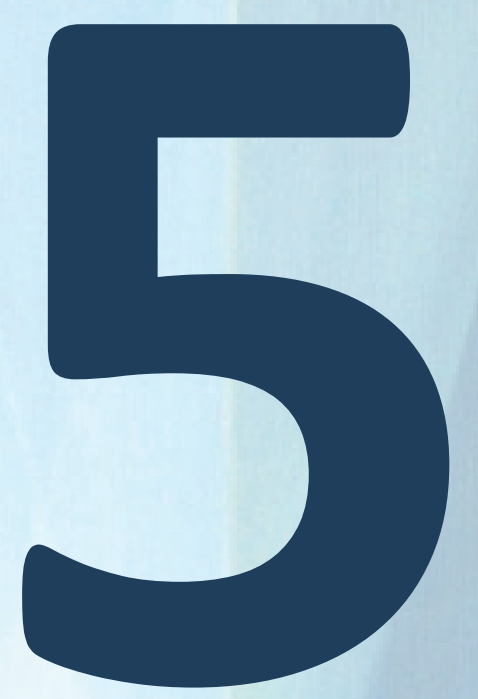

\section{Photodynamic therapy related pain: the truth or a myth}

Arits AHMM, van de Weert MM, Nelemans PJ, Kelleners-Smeets NWJ.

Pain during topical photodynamic therapy: uncomfortable and unpredictable. J Eur Acad Dermatol Venereol 2010; 24(12): 1452-7. 



\section{Abstract}

Background. The major drawback of the widely used photodynamic therapy (PDT) is treatment related pain. The objective of this study is to gain insight into the intensity of and predictive factors for painful burning sensation associated with PDT.

Methods. A prospective cohort study was performed at the department of Dermatology in the Maastricht University Medical Centre (MUMC) in Maastricht, a reference centre for dermatologic oncology in The Netherlands. 141 lesions in 108 patients were included, treated from November 2008 until June 2009 with PDT for superficial basal cell carcinoma (sBCC), Bowen's disease (BD) or actinic keratosis (AK). Painful burning sensation was scored based on an 11-point pain intensity numeric rating scale (PI-NRS) $(0=$ no pain; $10=$ worst possible pain).

Results. The percentage of patients with a PI-NRS score over six was $32.6 \%$ and $37.9 \%$ during the primary and follow up PDT session, respectively. $76.6 \%(95 / 124)$ of the patients was consistent in pain intensity score reporting. Factors associated with higher PI-NRS scores were treatment of $A K$ or $B D$, tumour localization in the head/neck region, patient's age over 70, Fitzpatrick skintype I/II, photosensitizer ALA and use of oral analgesics. After mutual adjustment of these factors, Fitzpatrick skintype remained the only independent predictor of PI-NRS scores during PDT.

Conclusion. It remains difficult to decide which patients should be considered for pain relieving measures. The solution remains to support all patients treated with PDT with pain relieving techniques or to let the support of pain relieving measures depend on the reported pain score for the primary session. 


\section{Introduction}

Worldwide, the number of non-melanoma skin cancer (NMSC) is increasing tremendously and with this the need for effective, pragmatic and reliable treatment modalities.

Photodynamic therapy (PDT) is based on the activation of a topical applied photosensitizer (5-aminolevulinic acid (ALA) or methyl aminolevulinate (MAL)) using illumination of the skin lesion with light of an appropriate wavelength. ALA or MAL are precursors for the formation of protoporphyrin IX (PpIX) in the biosynthetic pathway of haem. PpIX is produced in larger quantities in neoplastic cells than in normal tissue. When the PpIX containing cells are irradiated, a tissue-toxic photochemical reaction takes place in which reactive singlet oxygen is formed leading to apoptosis of the cells. ${ }^{1,2}$ PDT has been gaining weight in treating actinic keratosis (AK), Bowen's disease (BD) and superficial basal cell carcinoma (sBCC). It is shown to be an effective and safe treatment option with good cosmetic results. ${ }^{3}$ The major drawback of PDT is pain during treatment, sometimes causing extreme distress for the patient. Clinically, the intensity of this painful burning sensation seems to vary considerably between patients.

The objective of this prospective study is to gain insight into the intensity of the painful burning sensation associated with PDT treatment and to identify factors which can be used to predict which patient will experience high pain levels as a side effect of PDT treatment.

\section{Materials and methods}

\section{Patients}

This prospective study was performed at the department of dermatology in the Maastricht University Medical Centre in Maastricht (MUMC), one of the reference centres for dermatologic oncology in The Netherlands. The study was performed in accordance with the Helsinki declaration of 1975.

Included were all patients with primary, histologically confirmed AK, BD or SBCC treated with PDT from November the $1^{\text {st }} 2008$ until June the $30^{\text {th }} 2009$ at the department of Dermatology in the MUMC. Patients who met the inclusion criterion were asked to score the pain experienced during PDT treatment. All patients who were approached were willing to participate. Patients treated for lesion types with different histology on the same localization, were excluded because of problems to track down from which lesion the pain originated.

One of the investigators was present during the complete PDT treatment session. In this period of 7 months, 141 lesions (108 patients) were included. 98 patients with 124 lesions received two treatment sessions with one week in between. 


\section{Treatment protocols}

During the performance of the study the standard photosensitizer used at the department of Dermatology in the MUMC changed from ALA into MAL. Thus, 20\% ALA in Neribas cream (Bayer, Leverkusen, Germany) or 16\% MAL (Metvix ; Galderma Belgilux NV, Puurs, Belgium) was applied topically with a wooden spatula to the lesions in a $1 \mathrm{~mm}$ thick layer including $5 \mathrm{~mm}$ of the surrounding healthy skin. Then the area was covered with an occlusive dressing (Tegaderm ; $3 \mathrm{M}$, Leiden, The Netherlands). To block visual light aluminium foil was fixed over the Tegaderm . The incubation period was 3 hours for MAL and 4 hours for ALA. After the incubation period, the excess cream was wiped off and the area was irradiated with an incoherent metal halide lamp, PDT 1200L (Waldmann Medizintechnik, Schwenningen, Germany) or a light emitting diode (LED) light source, Aktilite (Galderma Belgilux NV, Puurs, Belgium). The PDT $1200 \mathrm{~L}$ has a wavelength interval of $580-750 \mathrm{~nm}$ and the lesions were irradiated during one session of 15 minutes with an intensity of 100 $\mathrm{mW} / \mathrm{cm}^{2}$ and a light dose of $100 \mathrm{~J} / \mathrm{cm}^{2}$. The Aktilite has an optimum wavelength of 630 $\mathrm{nm}$ and the lesions were irradiated during two treatment sessions with one week in between. Each session took 7.43 minutes with a light dose of $37 \mathrm{~J} / \mathrm{cm}^{2}$. Cooling of the treatment area with cold air and/or wet gauze dressings was used on all patients as part of our routine PDT protocol to try to relieve the unpleasant burning sensation during treatment.

\section{Data collection}

The nature of the sensation experienced by the patient during PDT is a subjective experience; some patients define it as pain, while others call it burning. Therefore we decided to refer to this experience as a painful burning sensation. Directly after treatment the patients were asked to report their painful burning sensation on an 11-point pain intensity numeric rating scale (PI-NRS) ( $0=$ no pain; $10=$ worst possible pain).

Data were collected on factors that were considered potential predictors of painful burning sensation. The following patient data were recorded: gender, age, Fitzpatrick skintype, medical history of PDT and whether or not the patient had received a renal transplant. The following tumour data were recorded: histological subtype (AK vs. BD vs. SBCC), tumour localization (head/neck vs. upper extremities vs. lower extremities vs. trunk) and largest diameter of lesions. Finally, treatment related data that were considered relevant were: Light source (PDT 1200 L vs. Aktilite ${ }^{\circ}$ ), type of photosensitizer (ALA vs. MAL), chronic use of oral analgesics (none vs. paracetamol vs. non-steroid anti-inflammatory drug vs. opiate vs. others), use of oral analgesics before PDT treatment (none vs. paracetamol vs. non-steroid anti-inflammatory drug vs. opiate vs. others), total area irradiated and interruption of irradiation (yes vs. no). The amount of PpIX formation was not considered in this study, because we were only interested in factors which can be easily measured in everyday dermatologic practice.

\section{Statistical analyses}

The effect of predictors for painful burning sensation during PDT was evaluated by categorizing patients into subgroups which indicated presence or absence of a specific character- 
istic. The mean PI-NRS scores were compared between subgroups using the t-test for independent samples or one-way analysis of variance (ANOVA). Multivariate linear regression models with PI-NRS score as dependent variable were used in order to evaluate the independent effect of factors on PI-NRS score. Factors were selected for inclusion into the multivariate linear regression model, if the $p$-value for difference in mean scores between subgroups was $p<0.1$. For each factor in the multivariate model regression coefficients with corresponding 95\% confidence intervals were calculated. Factors with two levels were coded as indicator variables and factors with more than two levels were coded as dummy variables. The corresponding regression coefficients represent the difference in mean scores between the compared subgroups after adjustment for other factors.

$P$ values of $<0.05$ were noted statistically significant. All statistical analyses were performed using the statistical program Statistical Package for the Social Sciences for Windows version 16.0 .

\section{Results}

\section{Patient characteristics}

We included 141 lesions in 108 patients. The mean patient age was 70.0 years (range 2493 years). Thirty-nine men (36\%) and sixty-nine (64\%) women were included. Of the 141 lesions included, twenty-nine (21\%) were diagnosed as AK, $52(37 \%)$ as BD and $60(42 \%)$ as SBCC. 130 lesions were treated with the Aktilite, whereas 11 lesions (all AK) were treated using the PDT 1200L. 124 lesions treated with the Aktilite, received two PDT sessions with one week in between. MAL was used in 26 lesions (1 AK, 6 BD, 19 SBCC); in all other cases ALA was used. In ten cases we had to turn off the PDT-lamp because of a severe painful burning sensation, four cases in the primary session (mean PI-NRS $=7$; after a mean of 2.9 min.) and six in the follow up session (mean PI-NRS = 7, after a mean of 2.28 min.). $60 \%$ $(6 / 10)$ of these patients could restart and complete the therapy after a couple of minutes.

\section{PI-NRS scores}

The PI-NRS scores reported for all 141 lesions during the primary PDT session showed a nearly normal distribution (mean 5.35, SD 2.24, range 0 to 10). The mean PI-NRS score of the follow up PDT session (124 lesions) was 5.61 (SD 2.51, range 0 to 10). The large standard deviations implicate a large inter-patient variance. We calculated the difference in mean PI-NRS value in 124 patients who received two PDT sessions with one week in between. The mean PI-NRS difference (follow up - primary session) was 0.40 (SD 1.75; P < 0.013). The percentage of patients reporting a PI-NRS score $>6$ was $32.6 \%(46 / 141)$ and $37.9 \%(47 / 124)$ during the primary and follow up PDT session, respectively. $22.5 \%$ $(28 / 124)$ of the patients reported pain scores over 6 for the primary as well as for the follow up treatment; whereas $54.0 \%(67 / 24)$ of the patients reported pain scores lower than 6 for the primary as well as for the follow up treatment. $15.3 \%(19 / 124)$ of the pa- 
tients reported pain scores lower than 6 during the primary treatment and pain scores over 6 during the follow up treatment.

\section{Predictive factors for painful burning sensation during PDT Univariate analyses}

The results from univariate analyses in Table 1 show that mean PI-NRS scores are significantly higher for subgroups with Fitzpatrick skintype I and II, lesion type AK and BD and chronic use of oral analgesics. There was a trend towards higher mean PI-NRS scores for subgroups with age over 70 , tumour localization in the head/neck region and use of oral analgesics before PDT. Again, large standard deviations were reported (Table 1). The univariate analyses shown in table 1 were repeated with respect to painful burning sensation experienced during the follow up PDT session. Results were similar, but now also a significant difference was found in mean PI-NRS score comparing ALA versus MAL, 5.86 (SD $2.36)$ vs. 4.69 (SD 2.90), respectively $(p=0.035)$.

\section{Multivariate analyses}

Table 2 shows the adjusted regression coefficients with 95\% confidence intervals which were derived from a multivariate linear regression model including all the factors that are mentioned in the table. After adjustment for other factors, Fitzpatrick skintype was the only variable that remained significantly associated with PI-NRS score. Compared to patients with skintype III, those with skintype I and II scored on average $3.30(p=0.003)$ and $3.10(p=0.002)$ points higher on the PI-NRS, respectively (Table 2$)$. The association between PI-NRS score and the other factors became less strong. Patients treated for a lesion on the head and neck region still had a mean PI-NRS score that was 0.65 points higher compared to lesions treated on the trunk, but the difference was not significant. The differences in mean PI-NRS scores between lesion types became smaller and decreased from 0.94 to 0.15 units and from 0.91 to 0.42 units for respectively $A K$ and $B D$ compared to sBCC (Table 2).

The multivariate analysis was repeated for painful burning scores with respect to the follow up PDT session. Again the strongest independent predictor was Fitzpatrick skintype. Moreover, patients treated with ALA reported scores that were on average 0.98 points higher compared to MAL, this difference was not statistically significant $(P=0.097)$. The factors that were incorporated in the multivariate linear regression models explained only a small part of the variance in reported painful burning scores. Adjusted $\mathrm{R}^{2}$ was $10.1 \%$ and $11.5 \%$ for the primary and follow up PDT session, respectively. 


\begin{tabular}{|c|c|c|c|}
\hline Characteristics & $n=141$ & Mean PI-NRS (SD) & $P$ \\
\hline Sex & & & 0.435 \\
\hline Female & 89 & $5.46(2.34)$ & \\
\hline Male & 52 & $5.15(2.08)$ & \\
\hline Patient age & & & 0.056 \\
\hline$<70$ years & 73 & $5.00(2.22)$ & \\
\hline$>70$ years & 68 & $5.72(2.22)$ & \\
\hline Kidney transplant & & & 0.539 \\
\hline No & 134 & $5.32(2.21)$ & \\
\hline Yes & 7 & $5.86(2.91)$ & \\
\hline Fitzpatrick skintype & & & 0.001 \\
\hline Type I & 24 & $5.62(1.79)$ & \\
\hline Type II & 112 & $5.45(2.25)$ & \\
\hline Type III & 5 & $1.80(1.10)$ & \\
\hline Chronic use of oral analgesics & & & 0.018 \\
\hline Yes & 47 & $5.98(2.25)$ & \\
\hline No & 94 & $5.03(2.18)$ & \\
\hline PDT sessions in history & & & 0.432 \\
\hline Yes & 7 & $6.00(2.89)$ & \\
\hline No & 134 & $5.31(2.21)$ & \\
\hline Oral analgesics before PDT session & & & 0.072 \\
\hline yes & 15 & $6.33(2.77)$ & \\
\hline No & 126 & $5.23(2.16)$ & \\
\hline Light source & & & 0.560 \\
\hline Aktilite (Galderma) & 130 & $5.32(2.21)$ & \\
\hline PDT 1200 L (Waldmann) & 11 & $5.73(2.72)$ & \\
\hline Photosensitizer & & & 0.498 \\
\hline 5-aminolevulinic acid & 115 & $5.41(2.14)$ & \\
\hline methyl aminolevulinate & 26 & $5.08(2.68)$ & \\
\hline Total treatment area & & & 0.356 \\
\hline$<40 \mathrm{~mm}^{2}$ & 44 & $5.48(2.33)$ & \\
\hline $40-100 \mathrm{~mm}^{2}$ & 49 & $4.98(2.21)$ & \\
\hline$>100 \mathrm{~mm}^{2}$ & 48 & $5.60(2.19)$ & \\
\hline Lesion type & & & 0.052 \\
\hline Actinic Keratosis & 29 & $5.76(2.67)$ & \\
\hline Bowen's disease & 52 & $5.73(2.32)$ & \\
\hline Superficial BCC & 60 & $4.82(1.85)$ & \\
\hline Tumor localization & & & 0.064 \\
\hline Head/neck & 47 & $6.00(2.28)$ & \\
\hline Forehead/temple & 17 & $6.18(2.04)$ & \\
\hline Jaw/chin & 6 & $4.50(2.59)$ & \\
\hline Vertex & 6 & $6.50(2.10)$ & \\
\hline Nose & 3 & $7.00(2.00)$ & \\
\hline Cheek & 5 & $6.00(2.65)$ & \\
\hline Neck & 11 & $6.18(2.32)$ & \\
\hline Trunk & 47 & $4.77(1.83)$ & \\
\hline Chest & 14 & $5.07(1.86)$ & \\
\hline Abdomen & 5 & $4.20(2.68)$ & \\
\hline Back & 27 & 4.59 (1.78) & \\
\hline Upper extremities & 23 & $5.30(2.72)$ & \\
\hline Back of the hand & 5 & $6.00(2.24)$ & \\
\hline Forearm & 7 & $4.71(1.90)$ & \\
\hline Upper arm & 12 & $5.25(2.45)$ & \\
\hline Lower extremities & 24 & $5.25(2.21)$ & \\
\hline Lower leg & 14 & $5.07(3.00)$ & \\
\hline Upper leg & 9 & $5.67(2.40)$ & \\
\hline
\end{tabular}




\begin{tabular}{|c|c|c|}
\hline & $\begin{array}{l}\text { Crude regression coefficient } \\
(95 \% \mathrm{Cl})\end{array}$ & $\begin{array}{l}\text { Adjusted regression coefficient } \\
(95 \% \mathrm{Cl})\end{array}$ \\
\hline \multicolumn{3}{|l|}{ Patient age } \\
\hline$>70$ years vs. $<70$ years & $0.72(-0.02-1.46)$ & $0.21(-0.55-0.98)$ \\
\hline \multicolumn{3}{|l|}{ Fitzpatrick skintype } \\
\hline Type I vs. III & $3.83(1.74-5.92)$ & $3.30(1.17-5.42)$ \\
\hline Type II vs. III & $3.65(1.70-5.59)$ & $3.10(1.14-5.07)$ \\
\hline \multicolumn{3}{|l|}{ Chronic use of oral analgesics } \\
\hline Yes vs. no & $0.95(0.17-1.73)$ & $0.44(-0.37-1.24)$ \\
\hline \multicolumn{3}{|l|}{$\begin{array}{l}\text { Oral analgesics before PDT } \\
\text { session }\end{array}$} \\
\hline Yes vs. no & $1.10(-0.98-2.30)$ & $0.81(-0.40-2.01)$ \\
\hline \multicolumn{3}{|l|}{ Lesion type } \\
\hline AK vs. sBCC & $0.94(-0.05-1.93)$ & $0.15(-1.03-1.32)$ \\
\hline$B D$ vs. $s B C C$ & $0.91(0.09-1.74)$ & $0.42(-0.56-1.41)$ \\
\hline \multicolumn{3}{|l|}{ Tumor localization } \\
\hline Head/neck vs. trunk & $1.23(0.33-2.14)$ & $0.65(-0.41-1.72)$ \\
\hline Upper extremities vs. trunk & $0.53(-0.57-1.65)$ & $0.10(-1.07-1.28)$ \\
\hline Lower extremities vs. trunk & $0.48(-0.61-1.58)$ & $0.05(-1.11-1.20)$ \\
\hline $\begin{array}{l}A K=\text { actinic keratosis. } \mathrm{SBCC} \\
\text { Table 2. results from linear } \\
\text { interval }\end{array}$ & $\begin{array}{l}\text { rficial BCC. BD = Bowen's disea } \\
\text { sion analysis crude and adjuste }\end{array}$ & $\begin{array}{l}\text { confidence interval } \\
\text { ssion coefficient with } 95 \% \text { confi }\end{array}$ \\
\hline
\end{tabular}

\section{Discussion}

This study shows that the mean painful burning sensation during PDT treatment is relatively high, showing PI-NRS of 5.35 (SD 2.24) and 5.61 (SD 2.51) during the primary and follow up PDT treatment, respectively. So patients reported a slightly higher pain score during the follow up PDT session. Lindeburg et al. also found that the follow up PDT sessions was experienced more painful by the patients compared to the first PDT session ${ }^{4}$. This could be explained by the fact that during the primary PDT treatment cell damage already occurred and one week later a damaged area is irradiated causing more pain. Moreover a bad experience during the first treatment could have lead to higher pain levels in follow up treatment. However, more important is the fact that one third of the patients reported a PI-NRS score higher than 6, showing that this is a serious problem with high prevalence. Factors that were associated with higher painful burning scores during PDT treatment were lesion type AK or BD, tumour localization in the head/neck region, patient's age over 70, Fitzpatrick skintype I/II and use of oral analgesics. During follow up treatment the type of photosensitizer also seemed to matter. Previous reports, studying the PDT associated pain, found similar results. ${ }^{5-7}$ However, these studies were frequently based on univariate analyses and therefore the independent contribution of these factors to pain intensity could not be assessed.

In this study multivariate analysis was performed. After mutual adjustment of all factors, only skintype remained significantly associated with painful burning sensation. We found PI-NRS scores up to three points higher in patients with skintype I/II compared to skintype 
III. We admit that the subgroup of patients with skintype III is limited, but the reported mean pain intensity scores of 1.8 in this subgroup should not be ignored. Grapengiesser et al. showed no correlation between Fitzpatrick skintype and PDT related pain levels in univariate analysis. ${ }^{5}$ Sandberg et al. showed a tendency for more PDT related pain in patients with Fitzpatrick skintype I-III $(n=88)$ compared to those with skintype IV $(n=4) .{ }^{6}$ They performed an ANCOVA analysis, but it is difficult to deduce from their report which potential predictors were incorporated as independent variables in the model. Two previous studies certainly performed multivariate analyses. First, Wiegell et al. concluded that PpIX fluorescence in the treated area was the only independent predictor of pain intensity during PDT treatment. ${ }^{8}$ However, they did not correct for Fitzpatrick skintype. In the current study the amount of PpIX formation was not considered, because we were only interested in factors which could be easily measured in the everyday dermatologic practice. To measure the amount of PpIX, a fluorescence camera and specific data processing techniques are needed. Few dermatologic practices are equipped with such a camera. Second, Steinbauer et al. showed that treatment site, lesion type and photosensitizer were independent predictors of severe pain in PDT treatment. ${ }^{9}$ They performed a retrospective study, histological confirmation of the included lesions was not required and they did not correct for Fitzpatrick skintype or for PpIX fluorescence. A difference with other studies is that we decided to use the PI-NRS instead of the visual analogue scale (VAS) to score pain. Both scales have been proven comparable accuracy. ${ }^{10}$

Knowledge about the pathogenesis of pain caused by PDT is limited. Basic research is needed to fully understand the origin of these burning pains. We tried to make the comparison with the pain mechanism in erythropoietic protoporphyria (EPP) to explain PDT associated pain with respect to skintype. Pain intensity in EPP can be described as a chemical burning sensation related to the reactivity of singlet oxygen. ${ }^{11}$ Could this also be the cause in PDT related pain? Skin color is determined primarily by the amount and type of melanin in the skin. An increase in the amount of melanin will lead to a fewer penetration of light into the skin. With respect to PDT treatment, this would lead to fewer penetration of the used red light into the skin of patients with Fitzpatrick skintype III/IV. This, on his part, would lead to a fewer production of reactive oxygen species in the skin. Because reactive oxygen species are essential in therapeutic mechanism of PDT, it is not recommended to interfere with it to try to relief pain. And if our hypothesis is correct, lower pain levels in Fitzpatrick skintype III patients, probably will interfere with clinical outcome. The perception of pain is a personal experience influenced by many factors, including genetic, ethnic and cultural issues. ${ }^{12}$ The observed large inter-patient variation and the fact that only $10 \%$ of the variance of pain as measured by PI-NRS during primary and $12 \%$ during follow up treatment could be explained by the study model, may reflect the importance of the biopsychosocial model of pain perception. Lindeburg et al. already reported on the large individual variation. ${ }^{4}$

The effect of different pain relieving measures has been investigated before. Cold air ${ }^{13}$ and cold water ${ }^{14}$ analgesia has shown some effect. Based on these studied, we used cold air and water analgesia as a standard procedure with PDT treatment. Besides pain relief by 
topical anesthesia with a eutectic mixture of lidocaine and prilocaine (EMLA ${ }^{\circ}$-cream, AstraZeneca, Luton, U.K.), tetracaine gel (Ametop ${ }^{\circ}$, Smith and Nephew, Hull, U.K.) or capsaicin cream has been found to provide insufficient pain relief. ${ }^{6,15,16}$ Topical methods can interfere with PDT efficacy due to their high pH which interferes with the stability acidic ALA or MAL. Although Borelli et al. showed that patients treated with subcutaneous infiltration anesthesia reported significantly less pain than patients treated with oral analgesics, reduction in the blood flow in the target lesion by vasoconstriction may interfere with the therapeutic process of PDT. ${ }^{17}$ In our study, patients were free to use oral analgesics before PDT treatment. We found that the use of oral analgesics was related to higher pain levels. Because oral analgesics were not used in a standard procedure in our study, we can not conclude that oral analgesics do not relief pain during PDT. Probably, the patients using analgesics before treatment usually experience more pain than non-users. Recently, a small study showed significant relief of MAL-PDT related pain in AK without affecting clinical outcome when nerve blocks were used. ${ }^{18,19}$ So far this is the only proven effective pain relieving technique not interfering with the clinical outcome.

The question remains 'should we use pain relieving techniques in PDT treatment?' On the one hand the current and previous studies show that PDT associated pain can be a serious problem for many patients. On the other hand it remained unclear at which subgroup of patients pain relieving measures should be directed. Although we showed that Fitzpatrick skintype is the only independent predictor of PDT related pain, clinical usefulness is low. The majority of patients treated with PDT for the treatment of skin neoplasms have skintype I or II. So if we choose to use pain relieving measures, we should give it to all patients with skintype I/II (read: to all patients treated with PDT). This will lead to over-treatment of the patients with no PDT-related pain. A possible solution is to restrict pain relief to patients who have experienced serious discomfort during the primary treatment, because we showed that $76.6 \%$ of the patients were consistent in reporting pain. This will lead to an under-treatment of $15.3 \%$ of the patients during the follow up session.

We performed the largest prospective study so far on the topic 'treatment associated pain during PDT', showing that the only independent predictive factor for PDT associated painintensity is Fitzpatrick skintype. A result with little clinical relevance. This supports the fact that pain experience is to a great extend a personal experience influenced by many factors, like genetic, ethnic and cultural issues rather than the supposed patient and treatment related factors studied. Therefore it remains difficult to decide before PDT treatment which patient should be considered for pain relieving measures. The solution remains to support all patients treated with PDT with pain relieving techniques or to let the support of pain relieving measures depend on the reported pain score for the primary treatment. 


\section{References}

1. Kennedy JC, Pottier RH, Pross DC. Photodynamic therapy with endogenous protoporphyrin IX: basic principles and present clinical experience. J Photochem Photobiol B. 1990 Jun;6(1-2):143-8.

2. Peng $Q$, Berg K, Moan J et al. 5-Aminolevulinic acid-based photodynamic therapy: principles and experimental research. Photochem Photobiol. 1997 Feb;65(2):235-51.

3. Morton CA, McKenna KE, Rhodes LE. Guidelines for topical photodynamic therapy: update. Br J Dermatol. 2008 Dec;159(6):1245-66.

4. Lindeburg KE, Brogaard HM, Jemec GB. Pain and photodynamic therapy. Dermatology. 2007;215(3):206-8.

5. Grapengiesser S, Ericson M, Gudmundsson F et al. Pain caused by photodynamic therapy of skin cancer. Clin Exp Dermatol. 2002 Sep;27(6):493-7.

6. Sandberg C, Stenquist B, Rosdahl I et al. Important factors for pain during photodynamic therapy for actinic keratosis. Acta Derm Venereol. 2006;86(5):404-8.

7. Wiegell SR, Stender IM, Na R, Wulf HC. Pain associated with photodynamic therapy using 5-aminolevulinic acid or 5-aminolevulinic acid methylester on tape-stripped normal skin. Arch Dermatol. 2003 Sep;139(9):1173-7.

8. Wiegell SR, Skiveren J, Philipsen PA, Wulf HC. Pain during photodynamic therapy is associated with protoporphyrin IX fluorescence and fluence rate. Br J Dermatol. 2008 Apr;158(4):727-33.

9. Steinbauer JM, Schreml S, Babilas P et al. Topical photodynamic therapy with porphyrin precursors-assessment of treatment-associated pain in a retrospective study. Photochem Photobiol Sci. 2009 Aug;8(8):1111-6.

10. Lara-Munoz C, De Leon SP, Feinstein AR et al. Comparison of three rating scales for measuring subjective phenomena in clinical research. I. Use of experimentally controlled auditory stimuli. Arch Med Res. 2004 Jan-Feb;35(1):43-8.

11. Lim HW. Pathophysiology of cutaneous lesions in porphyrias. Semin Hematol. 1989 Apr;26(2):114-9.

12. Nielsen CS, Staud R, Price DD. Individual differences in pain sensitivity: measurement, causation, and consequences. J Pain. 2009 Mar;10(3):231-7.

13. Pagliaro J, Elliott $T$, Bulsara $M$ et al. Cold air analgesia in photodynamic therapy of basal cell carcinomas and Bowen's disease: an effective addition to treatment: a pilot study. Dermatol Surg. 2004 Jan;30(1):63-6.

14. Wiegell SR, Haedersdal M, Wulf HC. Cold Water and Pauses in Illumination Reduces Pain During Photodynamic Therapy: A Randomised Clinical Study. Acta Derm Venereol. 2009 Mar;89(2):145-9.

15. Holmes MV, Dawe RS, Ferguson J, Ibbotson SH. A randomised, double-blind, placebocontrolled study of the efficacy of tetracaine gel (Ametop) for pain relief during topical photodynamic therapy. Br J Dermatol. 2004 Feb;150(2):337-40.

16. Langan SM, Collins P. Randomised, double-blind, placebo-controlled prospective study of the efficacy of topical anaesthesia with a eutetic mixture of lignocaine $2.5 \%$ and pri- 
locaine $2.5 \%$ for topical 5-aminolaevulinic acid-photodynamic therapy for extensive scalp actinic keratoses. Br J Dermatol. 2006 Jan;154(1):146-9.

17. Borelli $\mathrm{C}$, Herzinger $\mathrm{T}$, Merk $\mathrm{K}$ et al. Effect of subcutaneous infiltration anesthesia on pain in photodynamic therapy: a controlled open pilot trial. Dermatol Surg. 2007 Mar;33(3):314-8.

18. Halldin CB, Paoli J, Sandberg C et al. Transcutaneous electrical nerve stimulation for pain relief during photodynamic therapy of actinic keratoses. Acta Derm Venereol. 2008;88(3):311-3.

19. Halldin CB, Paoli J, Sandberg C et al. Nerve blocks enable adequate pain relief during topical photodynamic therapy of field cancerization on the forehead and scalp. $\mathrm{Br} \mathrm{J}$ Dermatol. 2009; 160: 795-800. 



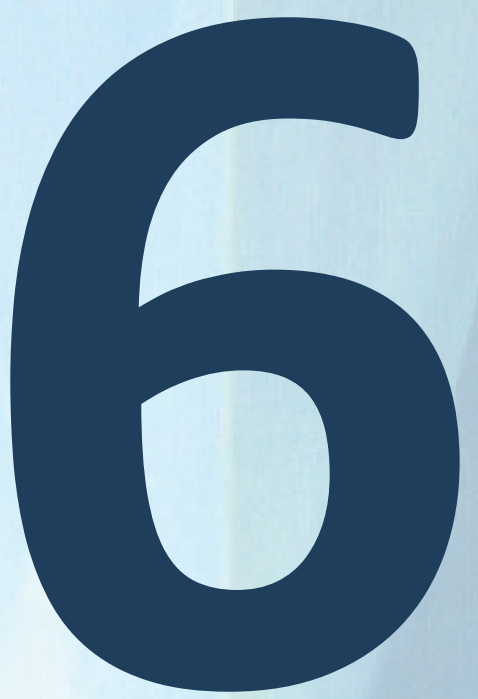

\section{Not everything is what it seems}

Arits AHMM, van Marion AM, Thissen CA, Kloos R, Kelleners-Smeets NWJ.

Development and progression of a periorbital sebaceous gland carcinoma in situ.

Acta Derm Venereol 2010; 90(5): 529-30.

Arits AHMM, Parren LJ, van Marion AM, Sommer A, Frank J, kelleners-Smeets NWJ.

Basal cell carcinoma and trichoepthelioma: a possible matter of confusion. Int J dermatol 2008; 47 (suppl 1): 13-7.

Arits AHMM, van Marion AM, Lohman BG, Thissen MR, Steijlen PM, Nelemans PJ, Kelleners-Smeets NWJ. Differentiation between basal cell carcinoma and trichoepthelioma by immunohistochemical staining of the androgen receptor: an overview.

Eur J Dermatol 2011; 21(6): 870-3. 



\title{
6.1 Basal cell carcinoma versus sebaceous carcinoma
}

\begin{abstract}
Here we present two patients with a different history of a persistent lesion in the periorbital area, both turned out to be an in situ sebaceous carcinoma. A sebaceous carcinoma $\mathrm{SC}$ ) is a high malignant neoplasm which most commonly develops de novo in the periorbital region. Little is known about the premalignant in situ SC.

Clinical presentation as well as histology of an in situ SC has a lot of pitfalls which we will discuss.
\end{abstract}




\section{Introduction}

Sebaceous carcinoma (SC) is a malignant neoplasm originating from sebaceous gland cells and occurring in $75 \%$ of cases on the periorbital region. ${ }^{1}$ So far, SC is believed to originate de novo or sporadically out of a sebaceous nevus. ${ }^{2}$ Here, we present the first case in which a benign sebaceous adenoma developed into a premalignant SC in situ. Furthermore, in our second case a SC in situ and a SC were seen simultaneously in the histopathological excision slide of one tumour, suggesting that a SC in situ can break through the boundaries of the basal membrane and develop into a SC with metastatic potential.

\section{Case Reports}

\section{Case 1}

An 82-year-old woman presented to our dermatology outpatient clinic with a 4 year history of an asymptomatic papule on the left eyebrow. Clinical examination showed a $7 \mathrm{~mm}$ yellowish papule, with a clinical differential diagnosis of a hyperplastic sebaceous gland, xanthelasma or a basal cell carcinoma (BCC) (Figure 1a). A $3 \mathrm{~mm}$ biopsy was taken, showing a sebaceous adenoma characterized by a sharply circumscribed proliferation of enlarged sebaceous lobules, comprised by fully mature sebocytes centrally and peripherallydisposed basaloid epithelial cells. A fibrous stroma separated these lobules from the adjacent dermis (Figure 1b). Because of the benign character of this asymptomatic lesion, no further intervention took place. Six years later this patient revisited our outpatient clinic because the lesion still existed and slowly continued to grow. A new punch biopsy was taken because the possibility of a sebaceous carcinoma had to be excluded. Again a proliferation of enlarged sebaceous lobules was seen, completely surrounded by a basal membrane. This process was characterized by atypical cells with big polymorphic nucleoli and cells with clear cytoplasm and sebaceous differentiation; mitotic figures were frequent (Figure 1c). Based on these findings, the tumour was diagnosed as a SC in situ. The lesion was excised completely with a $5 \mathrm{~mm}$ clinical margin. After one year of clinical follow up, the patient remains free of clinical recurrence.

\section{Case 2}

An 82-year-old woman was treated with complete surgical excision for a histologically reported nodular $\mathrm{BCC}$ on the right lower eyelid. At a follow up visit two years later a clinical recurrence was suspected. A $3 \mathrm{~mm}$ punch biopsy was taken to confirm clinical diagnosis. Examination of the biopsy slide showed a Bowen's disease; characteristics of a BCC were not found. Because of progression of tumour growth, despite multiple sessions of cryotherapy, this patient was referred to the Maastricht University Medical Centre (MUMC). On clinical examination we noted a $15 \mathrm{~mm}$ erythematous shiny telangiectatic 
plaque (Figure 2a). Because the lesion existed for many years, still grew and histological examination of the recurrent tumour did not match primary histology, we decided to do a diagnostic excision of the tumour. Histology of the excision slide showed intraepidermal nests of atypical cells with prominent nucleoli and increased nucleocytoplasmatic-index combined with cells with marked sebaceous gland differentiation. These nests remained within the basal membrane of the epithelium but spread along the sweat glands and the hair follicles. Diagnosis of a SC in situ with extensive intraepithelial growth pattern was made. Tumour cells were found directly to the left lateral border of the excision slide. The original excision slide, which was initially diagnosed as a nodular BCC, was reviewed by our dermatopathologist and regarded as a SC in situ with dermal invasion and thus diagnosed as a SC with metastatic potential (Figure $2 \mathrm{~b}, \mathrm{c}$ ). The patient was presented in our multidisciplinary head and neck oncology team. Because of the possibility of invasive growth and the chance of incomplete excision of the tumour, a magnetic resonance imaging of the head-neck area was performed. No intra-orbital growth or involvement of cervical lymph glands was found. Biopsies of the inferior fornical conjunctiva and inferior tarsal conjunctiva showed no evidence of malignancy. Mohs' micrographic surgery (MMS) was suggested by the multidisciplinary head and neck oncology team, but the patient refused further intervention. Two years after diagnosis, the patient was clinical free of tumour.

\section{Discussion}

Little is known about the incidence and aetiology of SC in situ. It is believed to be a rare premalignant stage of a SC without metastatic potential. The biological behaviour of development into an invasive carcinoma is unknown. ${ }^{3}$ The typical clinical presentation of a $\mathrm{SC}$ in situ is an erythematous or yellowish nodule or plaque with ulceration or crust formation. Clinically and histopathologically SC in situ is frequently misdiagnosed. Confusion with other epithelial (pre)malignant tumours of the skin, like BCC, squamous cell carcinoma or Bowen's disease, is common. There are no immunohistochemic markers to differentiate between these tumours. A correct diagnosis is essential because SC is an aggressive tumour and delay in treatment can have a negative effect on prognosis. Misdiagnosis occurs often on a small punch biopsy, so a larger wedge excision is advised for histopathological examination. First choice treatment for a SC is complete surgical excision with $5 \mathrm{~mm}$ clinical margins or MMS. ${ }^{1,5,6}$ The optimal treatment for SC in situ is controversial, because biological behaviour is unknown. Complete surgical excision and cryotherapy are advised. ${ }^{7}$ Based on the fact that SC in situ can grow deep into the dermis, along the skin appendages, cryotherapy may not be sufficient. Therefore, we recommend complete surgical excision with $5 \mathrm{~mm}$ margin. Involvement of the conjunctiva in SC localized on the eyelid is nearly $50 \%{ }^{8}$ Thus, biopsies of the conjunctiva are important.

Finally we want to point out that SC (in situ) can develop in the context of Muir-Torre syndrome (MTS, OMIM 158320). This is an uncommon autosomal dominant disorder characterized by germline mutations in the DNA mismatch repair genes MLH-1 or MSH-2. ${ }^{9}$ 
This is phenotypically characterized by the presence of at least one sebaceous gland neoplasm combined with at least one visceral neoplasm. ${ }^{10}$ Further evaluation to association with MTS is recommended when there is a positive family history of sebaceous gland neoplasms and visceral neoplasms occurring at young patient age.
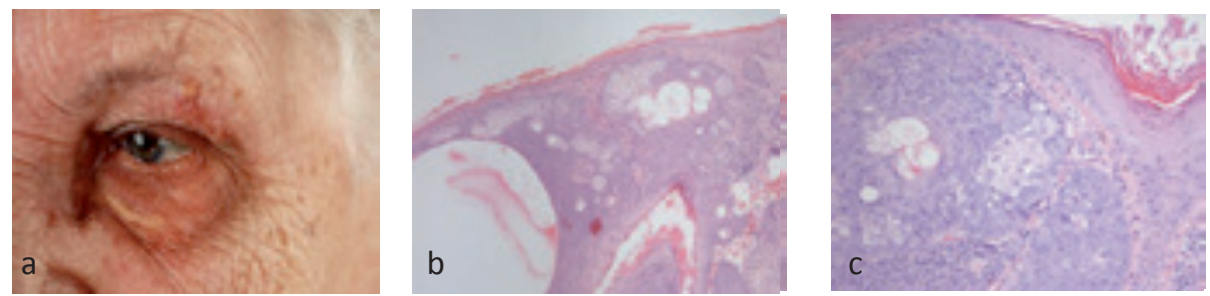

Figure 1. (a) Clinical presentation showing a yellowish papule of $7 \mathrm{~mm}$ on the left lateral eyebrow. (b) Sebaceous adenoma showing a sharply circumscribed proliferation of enlarged sebaceous lobules, composed of central fully mature sebocytes, and peripherally-disposed basaloid epithelial cells. Haematoxylin and eosin (H\&E) original magnification $\times 100$. (c) Sebaceous carcinoma in situ characterized by a proliferation of enlarged sebaceous lobules consisting of atypical cells with large polymorphic nucleoli and cells with clear cytoplasm with sebaceous differentiation. Mitotic figures are frequent. H\&E original magnification $\times 200$.
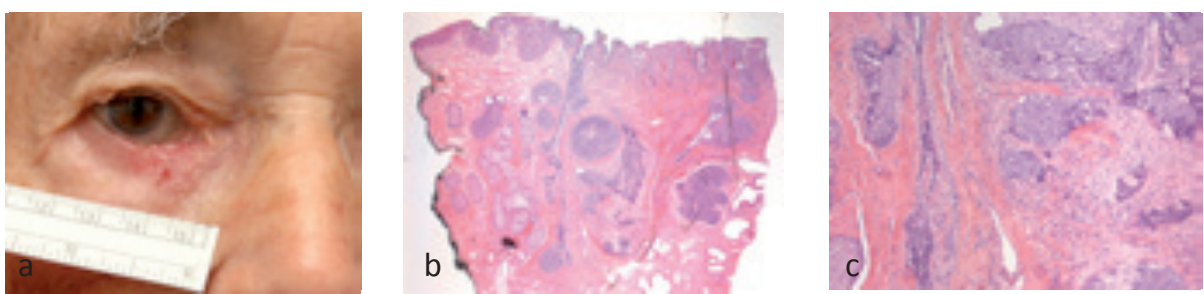

Figure 2. (a) Clinical presentation showing an erythematous shiny plaque of $15 \mathrm{~mm}$ with telangiectasias on the right lower eyelid. (b) Sebaceous carcinoma characterized by nests of atypical high mitotic cells with focally a basaloid aspect, foamy sebaceous gland cells and central necrosis, growing around the skin appendages within the basal membrane but locally suspect for invasive growth. Haematoxylin and eosin (H\&E) original magnification $\times 25$. (c) Figure $b(H \& E)$ original magnification $\times 100$. 


\section{References}

1. Shields JA, Demirci H, Marr BP, Eagle RC, Jr., Shields CL. Sebaceous carcinoma of the ocular region: a review. Surv Ophthalmol 2005;50:103-122.

2. Izumi M, Tang X, Chiu CS, Nagai T, Matsubayashi J, Iwaya K, et al. Ten cases of sebaceous carcinoma arising in nevus sebaceus. J Dermatol 2008;35:704-711.

3. Leibovitch I, Selva D, Huilgol S, Davis G, Dodd T, James CL. Intraepithelial sebaceous carcinoma of the eyelid misdiagnosed as Bowen\'s disease. J Cutan Pathol 2006;33:303-308.

4. Snow S, Larson P, Lucarelli M, Lemke B, Madjar D. Sebaceous Carcinoma of the Eyelids Treated by Mohs Micrographic Surgery: Report of Nine Cases with Review of the Literature. Dermatol Surg 2002;28:623-631.

5. Dogru M, Matsuo H, Inoue M, Okubo K, Yamamoto M. Management of eyelid sebaceous carcinomas. Ophthalmologica 1997;211:40-43.

6. Spencer JM, Nossa R, Tse DT, Sequeira M. Sebaceous carcinoma of the eyelid treated with Mohs micrographic surgery. J Am Acad Dermatol 2001;44:1004-1009.

7. Margo CE, Grossniklaus HE. Intraepithelial sebaceous neoplasia without underlying invasive carcinoma. Surv Opthalmol 1995; 39(4): 293-301.

8. Shields JA, Deirci H, Marr BP, Eagle RC jr., Stefanyszyn M, Shields CL. Conjunctival epithelial involvement by eyelid sebaceous carcinoma. The 2003 J. Howard Stokes lecture. Ophthal Plast Reconstr Surg 2005; 21(2): 92-6.

9. Hare HH, Mahendraker N, Sarwate S, Tangella K. Muir-Torre syndrome: a rare but important disorder. Cutis 2008;82(4):252-6.

10. Ingram JR, Griffiths AP, Roberts DL. All patients with sebaceous gland neoplasms should be screened for Muir-Torre syndrome. Clin Exp Dermatol 2009;34(2):264-6. 


\title{
6.2 Basal cell carcinoma versus trichoepithelioma
}

\subsubsection{A possible matter of confusion - Case report}

\begin{abstract}
Difficulty in differentiation between a solitary basal cell carcinoma, which is known as a malign skin lesion and a benign trichoepithelioma, is a frequent problem in all day dermatologic practice. Clinically as well as histopathologically there are a lot of resemblances between these skin tumours. By means of two real life cases, we give here an overview of the possible problems and appliances in distinguishing these two entities; at the end we do some recommendation about the policy.
\end{abstract}




\section{Introduction}

Basal cell carcinoma (BCC) is the most common skin cancer in the white population. Although it is still unclear from which cell this neoplasm derives, recent evidence has suggested that BCC is a hair follicle tumour. ${ }^{1}$ The World Health Organization has classified it as a "keratinocytic tumour." ${ }^{2}$ With a varying clinical picture, BCC predominantly manifests in the fifth and sixth decades of life in the head and neck region. ${ }^{3}$ Usually, the histopathology is quite typical, showing basophilic cells, which are classically arranged in globule-like clusters with palisading cells at their periphery. Both clinically and histologically, however, solitary BCC may be confused with another epithelial tumour, trichoepithelioma (TE). This benign neoplasm of follicular differentiation occurs mainly in young adults. As in BCC, the sites of predilection are the head and neck region, in particular the nose, upper lip, and cheeks. ${ }^{4}$ In this article, we illustrate the difficulties in the clinical and histopathologic differentiation of BCC from TE, in particular BCC with trichodifferentiation, and briefly review the currently available techniques that might be helpful in making an accurate diagnosis.

\section{Case report}

\section{Case 1}

A 30-year-old woman presented at our outpatient clinic with an easily bleeding skin lesion on the nose that had developed approximately 6 months earlier and had not undergone any changes since. Apart from regular therapy with a selective serotonin re-uptake inhibitor, Seroxat ${ }^{\circledR}$, her medical history was unremarkable, and she denied any extraordinary exposure to sunlight. On clinical examination, there was a skin-coloured papule of $5 \times 3$ $\mathrm{mm}$ with central crusting on the right side of the nose (data not shown). Based on the clinical findings, our differential diagnoses included basal cell carcinoma (BCC) and a sebaceous gland hyperplasia. For clarification, a punch biopsy was taken. Histopathology with hematoxylin and eosin staining showed a proliferation of clustered basaloid cells, sometimes in continuation with a hair follicle. In these clusters, there was peripheral palisading and a few retraction clefts at the contact zones with the surrounding stroma. Furthermore, follicular keratinization and a few mitotic figures were observed. On the basis of these findings, a differential diagnosis of BCC or TE was made. Additional studies by immunohistochemistry with both Bcl-2 and Ber-EP4 showed focal staining of cell nests in the tumour margin, but no staining in the centre. CD10 staining was mainly detectable in the stroma surrounding the basaloid cell clusters. Although the immunohistochemical pattern was suggestive of TE, BCC could not be excluded completely. Subsequently, the tumour was successfully treated with Mohs' micrographic surgery. As in the first histological examination, the additional tissue preparation for Mohs' frozen sections was not helpful in differentiating between BCC and TE. 


\section{Case 2}

In 2005, a 77-year-old man presented at our outpatient department with an easily bleeding skin lesion on the back. He had an unremarkable medical history and reported an average degree of sunlight exposure. At that time, a 4-mm skin-coloured papule with hemorrhagic crusts and telangiectasias was documented (Figure 1a,b), and a tentative diagnosis of BCC was made. Subsequent histopathological examination of a punch biopsy by routine hematoxylin and eosin staining showed a strong proliferation of basaloid cells with trichoid differentiation in the superficial dermis, without significant peripheral palisading or cleft formation between tumour aggregates and stroma (Figure 2a,b). Based on these findings, a diagnosis of TE was made and no further treatment was initiated.

Two years later, the patient returned for the evaluation of the same tumour that had approximately doubled in size. On clinical examination, there was an 8-mm, shiny, erythematous papule with telangiectasias (Figure 1c,d). With a tentative diagnosis of BCC, the tumor was radically excised. Histopathological examination showed a nodular tumour with a dermal proliferation of basaloid cells, peripheral palisading, and cleft formation, suspicious of a nodular BCC (Figure 2c,d). Histopathologic revision of the biopsy specimen from 2005 revealed that a differentiation between TE and BCC with trichodifferentiation based on routine histopathologic hematoxylin and eosin evaluation was not possible. Nevertheless, the detection of several mitotic figures and cleft formation, as well as the diffuse positive staining with the immunomarkers $\mathrm{BCl}-2$ and Ber-EP4 and peripheral staining of basaloid cells with $\mathrm{CD} 10$, was suggestive of $\mathrm{BCC}$ with trichodifferentiation.

\section{Discussion}

As noted above, BCC is a malignant tumour that is thought to be derived from the basal cell layer of the epidermis and/or the outer root sheath of the hair follicle. ${ }^{4}$ By contrast, TE is a dermal tumour that originates from hair follicles and may reveal focal continuity into the epidermis. ${ }^{4}$ The clinical presentation of BCC is variable. Normally, the tumour presents as a firm, skin-coloured, red or brown nodule. A pearly white to translucent and raised peripheral edge is one of the characteristic features. Sometimes, however, BCC manifests as an erythematosquamous macula, resembling eczema, or as a sclerotic plaque, resembling a scar.

TE mostly presents as a skin-coloured nodule or papule that does not usually exceed $1 \mathrm{~cm}$ in size. Both tumours can be traversed by telangiectasias. In addition to the clinical differentiation difficulties, histologic differentiation between BCC and TE may sometimes be problematic. Both tumours are composed of nests of basaloid cells with follicular differentiation. TE is characterized by epithelial structures resembling hair papillae, small keratinous cysts which, on rupture, can form stromal foreign-body granulomas, loose stroma, and fibroblast aggregates, referred to as papillary mesenchymal bodies. ${ }^{4}$ 


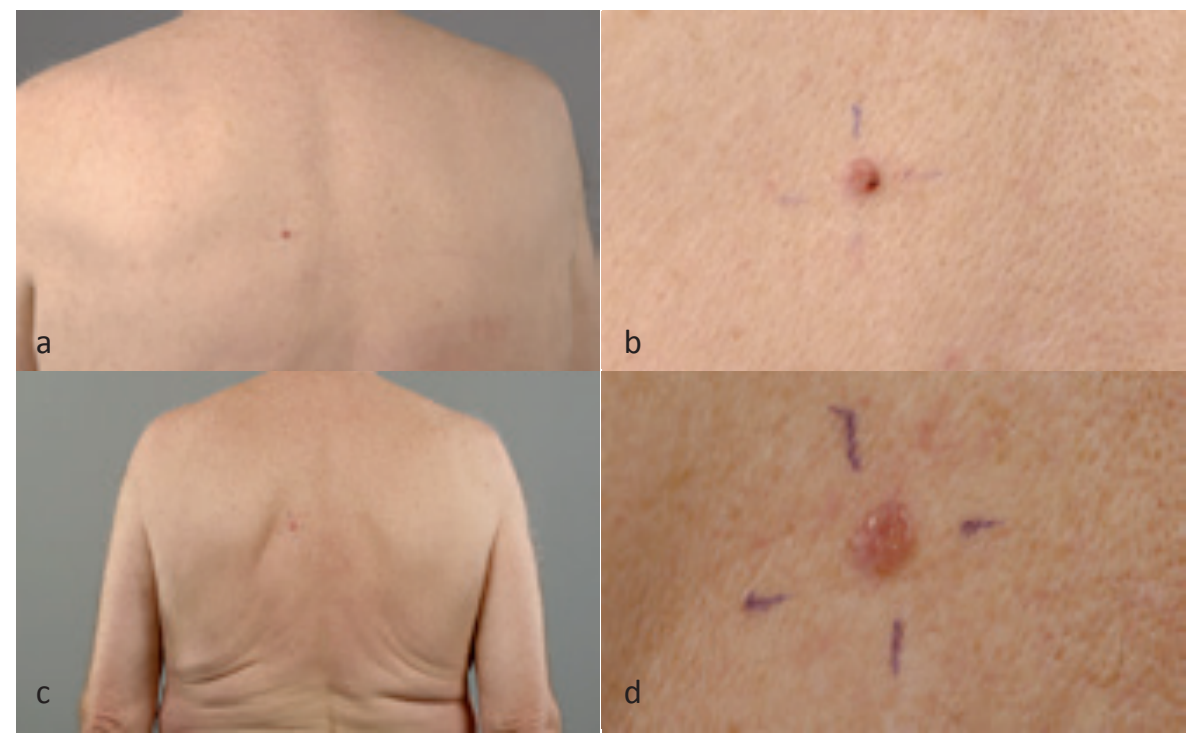

Figure 1. Clinical presentation of the lesion in Case 2: (a) overview 2005; (b) close-up 2005; (c) overview 2007; (d) close-up 2007

\begin{tabular}{l|lll}
\hline & Histologic characteristic & Basal cell carcinoma & Trichoepithelioma \\
1 & Tumour-stroma cleft formation & ++ & -- \\
2 & Ulceration & ++ & - \\
3 & Epithelial primitive structures & - & ++ \\
4 & Small keratinous cysts & - & + \\
5 & Inflammatory response & + & - \\
6 & Mitosis & + & - \\
7 & Necrotic tumour cells & + & + \\
8 & Papillary mesenchymal bodies & - & + \\
9 & Granulomatous inflammation & -- & - \\
10 & (around ruptured keratinous cysts & + & + \\
11 & Stromal edema & Peritumoral mucin production & + \\
\hline
\end{tabular}

BCC, by contrast, often shows cleft formation between tumour aggregates and stroma, peripheral palisading of keratinocytes, necrotic tumour cells and ulceration, and mitotic figures. ${ }^{4,5}$ Nevertheless, these characteristics are not always present. Therefore, sometimes it may be impossible to make a histopathologic differentiation on the basis of routine hematoxylin and eosin staining. In these instances, additional immunohistochemical examination may provide further information. In the past, several antibodies have been used to differentiate between BCC and TE, although most are not specific for one epithelial tumour. In line with this, the immunomarkers used in our patients, Bcl-2, Ber-EP4, and 
CD10, did not allow for a differentiation between BCC or TE. Recently however, increasing evidence has suggested that antibodies directed against androgen receptor and transforming growth factor- $\beta$ (TGF- $ß$ ) may be helpful in overcoming this dilemma. Androgen receptor is a nuclear ligand-dependent transcription factor that is activated by binding to androgens, testosterone, or dihydrotestosterone. Androgen receptor is expressed in normal skin, but has also been demonstrated in various cutaneous neoplasms, including BCC. ${ }^{6}$ Izikson et al. found positive androgen receptor immunostaining in approximately $80 \%$ of BCC cells compared with negative staining in TE $(P<0.001) .{ }^{6}$ TGF- $ß$ plays a key role in controlling cell proliferation and differentiation. Verhaegh et al. showed a diffuse cytoplasmic TGF- $\beta$ staining in TE tumour cells, whereas negative staining was observed in BCCs. ${ }^{7} \mathrm{BCl}-2$ is an oncogene associated with apoptosis, and can be over-expressed in some malignancies. A difference in Bcl-2 staining distribution between BCC and TE was found by three independent study groups; ${ }^{7,8}$ however, Abdelsayed et al. ${ }^{9}$ could not confirm this finding. Ber-EP4 is a monoclonal antibody that recognizes two glycopolypeptides found in most human epithelial cells. Krahl and Sellhayer ${ }^{10}$ did not find any consistency in the staining pattern of Ber-EP4 in BCC compared with TE. In contrast, Ber-EP4 has been shown to be an excellent marker in differentiating BCC from squamous cell carcinoma. ${ }^{10}$ CD10 is a cell surface enzyme with neutral metalloendopeptidase activity, and is involved in the inactivation of numerous biologically active peptides. Pham et al. showed strong CD10 immunoreactivity in both TE and $\mathrm{BCC}$, but with significantly different staining patterns. ${ }^{11}$

Recently, both germline and somatic mutations in different genes have been implicated in the etiopathogenesis of BCC and TE. There is strong evidence that virtually all BCCs arise from genetic defects affecting components of the Sonic Hedgehog $(\mathrm{SHH})$ pathway. About $80 \%$ of BCCs harbour mutations in the PTCH1 gene, coding for PATCHED, a seven-pass transmembrane protein that serves as a receptor for $\mathrm{SHH}$. The remaining $20 \%$ harbour mutations in either SMOH (coding for the SMOOTHENED protein) or SU(FU) (coding for the protein SUPPRESSOR of FUSED). ${ }^{12}$ TE can occur sporadically or in the context of a hereditary tumour syndrome, known as familial cylindromatosis or Brooke-Spiegler syndrome (BSS). BSS is caused by mutations in CYLD. ${ }^{13}$ The encoded protein, CYLD, is a ubiquitin hydrolase that targets by auto-ubiquitinating TRAF2 (tumour necrosis factor receptorassociated factor-2). Ubiquitinated TRAF2 can activate IKB kinase (IKK), which, in turn, phosphorylates the NF- $\mathrm{k} \beta$ inhibitor $\mathrm{IkB} \alpha$, triggering the nuclear translocation of active NF$\kappa \beta$. Thus, the absence of CYLD leads to uncontrolled NF- $\kappa \beta$ activity. Depending on the exact inputs, NF-k $\beta$ can induce apoptosis or, rather, its opposite, cell growth. ${ }^{14}$ Because TE and $\mathrm{BCC}$ may represent two different landmarks in the spectrum of one single entity, we strongly suggest the excision of every solitary TE with a small margin. Complete excision is also the treatment of choice for BCC. Follow-up of a patient with a solitary TE is not recommended.

In summary, clinical and histologic differentiation between BCC and TE can sometimes be difficult. Histopathologic criteria for the differentiation of these two tumours include the presence or lack of retraction between epithelium and stroma, a lack of ulceration, and the presence of primitive follicles in TE. Immunohistochemistry may provide additional 
information, in particular immunostaining with androgen receptor and TGF- $\beta$. Nevertheless, routine hematoxylin and eosin staining remains the standard for initial histopathologic examination. In the future, molecular genetic techniques may offer the possibility to differentiate with certainty between the two tumours.

\begin{tabular}{|c|c|c|c|}
\hline & Immunomarker & Basal cell carcinoma & Trichoepithelioma \\
\hline \multirow[t]{2}{*}{ Group 1} & Androgen receptor ${ }^{(10)}$ & ++ & - \\
\hline & Transforming growth factor- $\beta^{(11)}$ & - & + \\
\hline \multirow[t]{4}{*}{ Group 2} & $\mathrm{Ki} 67^{(13)}$ & + & + \\
\hline & Proliferating cell nuclear antigen ${ }^{(13)}$ & + & + \\
\hline & $\mathrm{P} 27^{\mathrm{kip} 1(18)}$ & + & + \\
\hline & $\mathrm{CD} 10^{(15)}$ & ++ & ++ \\
\hline \multirow[t]{3}{*}{ Group 3} & $\mathrm{Bcl}-2^{(11-13)}$ & ++ & $-/+$ \\
\hline & $\mathrm{CD} 34^{(19,20)}$ & $-1+$ & $+/-$ \\
\hline & Ber-EP ${ }^{(14)}$ & ++ & $+/-$ \\
\hline
\end{tabular}

+ , positive; ++ , strongly positive; - , negative; $-/+$, mostly negative; sometimes positive; $+/-$, mostly positive, sometimes negative. Group 1, different immunostaining patterns for the two tumours. Group 2, positive immunostaining for both tumours, but with a different staining pattern. Group 3, inconsistent immunostaining patterns.

Table 2. Immunohistochemical markers used to differentiate between basal cell carcinoma and trichoepithelioma 


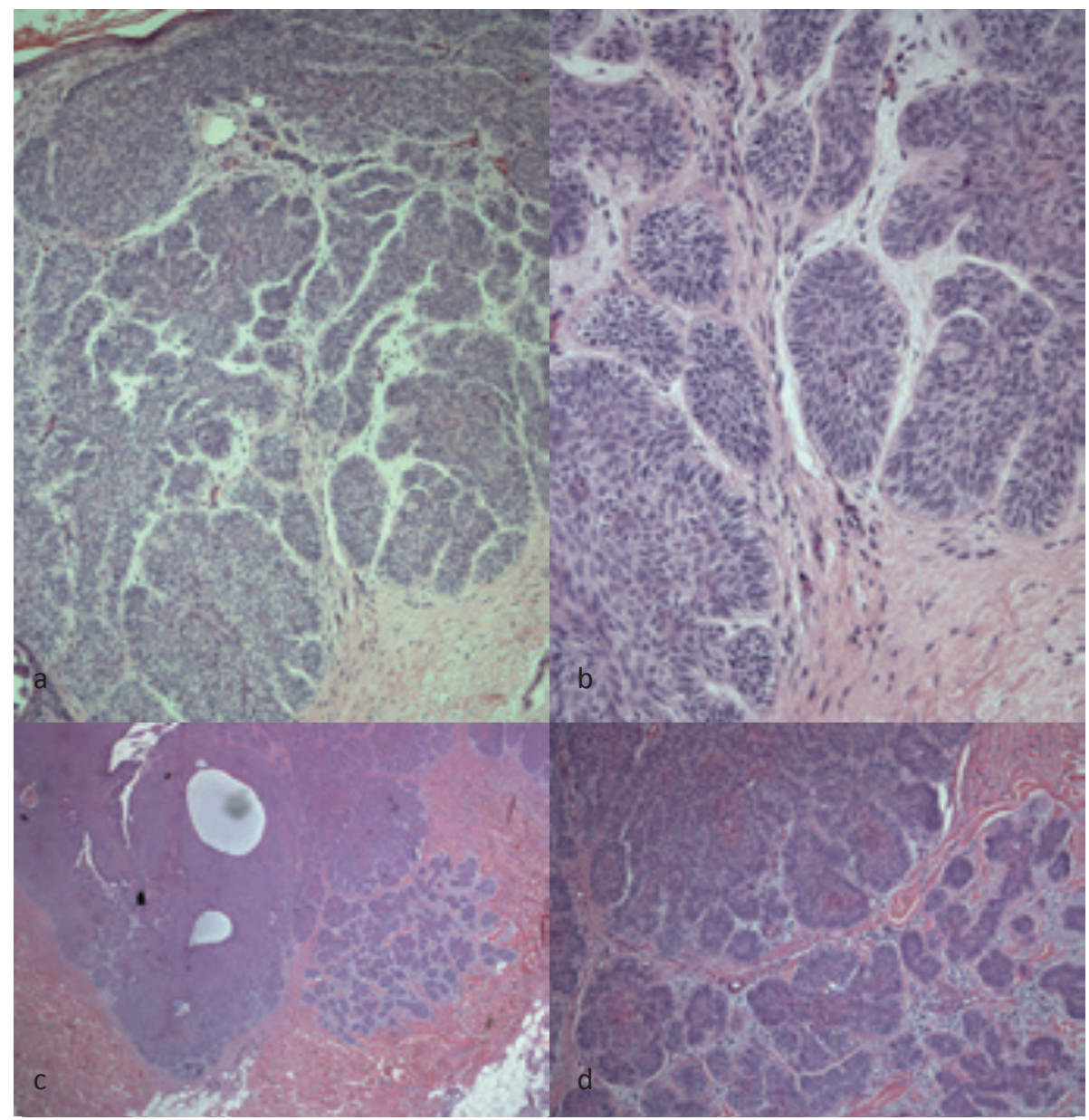

Figure 2. Histopathologic examination of the lesion in Case 2: $(a, b)$ trichoid keratinization and stromal clefting typical of trichoepithelioma (hematoxylin and eosin: $a, \times 100 ; b, \times 200$ ); (c, d) left, compact nests of basaloid cells, typical of basal cell carcinoma; right, smaller fields of basaloid cells, typical of trichoepithelioma (hematoxylin and eosin: $c, \times 25 ; d, \times 100$ ) 


\section{References}

1. Sellheyer K, Krahl D. Basal cell (trichoblastic) carcinoma common expression pattern for epithelial cell adhesion molecule links basal cell carcinoma to early follicular embryogenesis, secondary hair germ, and outer root sheath of the vellus hair follicle: A clue to the adnexal nature of basal cell carcinoma? J Am Acad Dermatol. 2008;58(1):158-67.

2. LeBoit $P$, Burg G, Weedon D, Sarasin A, editors. World Health Organization classification of tumours: pathology and genetics of skin tumors. Lyon: IARC Press; 2006.

3. de Vries E, Louwman M, Bastiaens M, de Gruijl F, Coebergh JW. Rapid and continuous increases in incidence rates of basal cell carcinoma in the southeast Netherlands since 1973. J Invest Dermatol. 2004;123(4):634-8.

4. Weedon D. Skin Pathology. Tokyo: Churchill Livingstone; 2001. Chapter 31, page 64749 and Chapter 33, page 715-16.

5. Kechijian P, Connors RC, Ackerman AB. Trichoepithelioma vs. basal-cell carcinoma: criteria for histologic differentiation. J Dermatol Surg. 1975;1(4):22-3.

6. Izikson L, Bhan A, Zembowicz A. Androgen receptor expression helps to differentiate basal cell carcinoma from benign trichoblastic tumors. Am J Dermatopathol. 2005;27(2):91-5.

7. Verhaegh ME, Arends JW, Majoie IM, Hoekzema R, Neumann HA. Transforming growth factor-beta and bcl-2 distribution patterns distinguish trichoepithelioma from basal cell carcinoma. Dermatol Surg. 1997;23(8):695-700.

8. Poniecka AW, Alexis JB. An immunohistochemical study of basal cell carcinoma and trichoepithelioma. Am J Dermatopathol 1999; 21: 332-336.

9. Abdelsayed RA, Guijarro-Rojas M, Ibrahim NA, et al. Immunohistochemical evaluation of basal cell carcinoma and trichoepithelioma using Bcl-2, Ki67, PCNA and P53. J Cutan Pathol 2000; 27: 169-175.

10. Krahl D, Sellheyer K. Monoclonal antibody Ber-EP4 reliably discriminates between microcystic adnexal carcinoma and basal cell carcinoma. J Cutan Pathol 2007; 34: 782787.

11. Pham TT, Selim MA, Burchette JL, et al. CD10 expression in trichoepithelioma and basal cell carcinoma. J Cutan Pathol 2006; 33: 123-128.

12. Reifenberger J, Wolter $M$, Knobbe $C B$, et al. Somatic mutations in the PTCH, SMOH, SUFUH and TP53 genes in sporadic basal cell carcinomas. Br J Dermatol 2005: 152: 4351

13. Bignell $G \mathrm{R}$, Warren $\mathrm{W}$, Seal $\mathrm{S}$, et al. Identification of the familial cylindromatosis tumour-suppressor gene. Nat Genet 2000: 25: 160-165.

14. Gilmore T D. Introduction to NF-kappaB: players, pathways, perspectives. Oncogene 2006: 25: 6680-6684. 


\title{
6.2.2 Differentiation by immunostaining of the androgen receptor
}

\begin{abstract}
Background. Clinical and histopathological differentiation between a basal cell carcinoma (BCC) and a trichoepithelioma (TE) is a frequent problem. Several attempts have been made to identify immunohistochemical markers helpful in differentiating between both entities. A correct diagnosis is important because both tumours are treated differently. Recent studies showed the absence of androgen receptor (AR) expression in benign hair follicle tumours like TE. The goal of this study is to examine if AR immunostaining is a useful diagnostic test to differentiate between BCC and TE.
\end{abstract}

Methods. We randomly selected 75 cases with histological diagnosis of either BCC (subtypes: superficial, nodular or infiltrative) or TE (subtypes: classic or desmoplastic) from the database of the department of pathology in the Maastricht University Medical Centre. The available Haematoxylin \& Eosin (H\&E) slides were reviewed by three independent investigators using predetermined characteristics.

Results. Fifty-six slides (38 BCC and $18 \mathrm{TE}$ ) with unequivocal histological characteristics of either tumour were used for immunohistochemistry with AR antibodies. Any nuclear expression within the tumour was considered positive. AR expression was present in 5/8 classic TE, 0/10 desmoplastic TE, 22/23 superficial or nodular BCC and in 10/15 infiltrative BCC.

Conclusion. Immunohistochemical stain for AR is useful to differentiate between TE and BCC; particularly in desmoplastic TE versus infiltrative BCC (specificity and positive predictive value of $100 \%$ ). 


\section{Introduction}

Basal cell carcinoma (BCC) is the most common cancer in Caucasians. Recently evidence has become available that BCC is an epithelial tumour arising from the progenitor cells of the interfollicular epidermis and the upper infundibulum. ${ }^{1}$ Histologically there are three main types of the BCC: Superficial, nodular and infiltrative (including morphoeic). ${ }^{2}$ The highest incidence of $B C C$ is seen in the middle-aged, with preference for the sun exposed body sites. ${ }^{3}$ Trichoepithelioma (TE) is another epithelial tumour originating from the outer root sheath of the hair follicle, but in contrast to BCC, this is a benign tumour with clear follicular differentiation. There are two types: the classic type and the desmoplastic type. ${ }^{4}$ TE mainly occurs in young adults with predilection sites as the nose, the upper lip and the cheeks. ${ }^{4}$ Clinical distinction between TE and BCC is difficult in some cases and this dilemma may extend to a microscopic level as well. Distinction between both neoplasms is important because they have different biological behaviour and need different treatment. On haematoxylin \& eosin (H\&E) stained slides, both tumours are composed of nests of basaloid cells with a degree of follicular differentiation. The histological differentiation between BCC and TE has been predominantly based on this degree of follicular differentiation. A high degree of follicular differentiation within the tumour, favours a benign tumour like TE. Other typical histological TE characteristics are the presence of epithelial primitive structures resembling hair papillae (known as papillary-mesenchymal bodies), the presence of small keratinous cysts and cleft formation in the peritumoral stroma. ${ }^{4}$ Conversely, BCC is characterized by cleft formation between tumour and stroma, peripheral palisading of basaloid keratinocytes, ulceration, inflammatory response, mitotic figures, necrosis and peritumoral mucin production. ${ }^{4,5}$ Histological confusion is mostly seen between a nodular BCC and a classic TE (CTE) or between an infiltrative BCC and desmoplastic TE (dTE). The last decade many studies showed the relevance of several additional immunomarkers in differentiating between both entities. As we discussed in an earlier case study, the usefulness of most of these antibodies, like oncogenes ( $\mathrm{BCl}-2)$, cell membrane glycoproteins (Ber-EP4, CD10 and CD34) and cytokeratins, was disappointing. ${ }^{5}$ Human sebaceous glands and hair follicles are target structures in the skin for androgen action. They contain steroid enzymes, capable of transforming weak androgens into the target-tissue-active androgens testosterone and dihydrotestosterone, which bind to the androgen receptor (AR) to regulate cellular transcription. ${ }^{6}$ The detection of AR antibodies seems to be a promising tool in the differentiation between BCC and TE. ${ }^{5}$ In the normal skin AR is expressed in sebaceous glands, pilosebaceous duct keratinocytes, interfollicular epidermal keratinocytes, dermal fibroblasts and certain cells of the secretory coils of eccrine sweat glands. ${ }^{7-9}$ Recently there has been assumed that AR is also expressed in some cutaneous neoplasms like BCC. ${ }^{7}$ In contrast, AR expression seemed absent in mature hair follicles and the epidermis thus also in benign hair follicle tumours like TE. ${ }^{9}$

Here we discuss the usefulness of AR immunohistochemistry in differentiating BCC from TE based on our own findings and the results of previous studies. 


\section{Materials and methods}

\section{Case selection}

This study was performed based on the code of proper behaviour of tissue. This means that in the process of collecting patient specimens, material was de-identified and was untraceable to the patient itself. From the Pathologic Anatomical National Automated Archive of the Department of Pathology in the Maastricht University Medical Centre (MUMC), we randomly selected $75 \mathrm{H} \& \mathrm{E}$ slides of BCC and TE. This archive is a database recording all reports of pathological diagnoses and mark them with a unique number. By using a combination of search terms, reports of specific histological diagnosis can be retrieved. With this unique number the representing paraffin blocks can be found in the pathology archive of the MUMC. Of these blocks new H\&E stained slides and immunohistochemic slides with AR antibody staining were created.

The available $75 \mathrm{H} \& \mathrm{E}$ slides were reviewed by three independent investigators (i.e. a dermato-pathologist (AM), a oncologic-dermatologist (MT) and a resident in dermatopathology (BL)) using predetermined characteristics. Four slides were excluded because no representing tumour could be found in the H\&E slide. This was due to further cutting up the paraffin blocks to create two new consecutive slides for H\&E and immunostaining. The seventy-one slides left were reviewed based on the presence or absence of the following characteristics: tumour-stroma cleft formation, ulceration, epithelial primitive structures, small keratinous cysts, inflammatory response, mitosis, necrotic tumour cells, papillar mesenchymal bodies, stromal oedema and peritumoral mucin production. Fifty-six slides (38 BCC and $18 \mathrm{TE}$ ) with unequivocal histological characteristics of either tumour were used for immunohistochemistry with AR antibodies. Based on the morphological classification mentioned by Rippey 1998, the investigators distinguished three subtypes of BCC: superficial, nodular and infiltrative. The infiltrative BCC included the morphoeic type. ${ }^{2} \mathrm{TE}$ was divided in a classical and a desmoplastic type.

In addition we searched PubMed, a service of the US National Library of Medicine including citations of MEDLINE and other life science journals and online books, to find other publications on this topic. To date we found three studies examining the role of AR expression in differentiating between BCC and TE by using immunohistochemical staining. ${ }^{10-}$

${ }^{12}$ We will also discuss the results of these studies.

\section{Immunostaining protocol}

We included biopsy as well as excision specimens. First, these were fixed in $4 \%$ formalin and embedded in paraffine blocks of which several four micron sections were cut. Staining with $A R$ was based on the standard immunoperoxidase technique after deparaffinisation. Sections were fixed on Dako silanized slides to accommodate alkaline retrieval by heat treatment at $\mathrm{PH}$ 9.5 for three minutes in Borg Decloker (Biocare Medical, Walnut Creek, CA). The tissue was stained for 20 minutes with a monoclonal antibody AR441 (Dako, Carpinteria, CA) (dilution 1:50). Afterwards, the sections were incubated for 20 seconds with a secondary reagent; envision Flex with mouse (linker) followed by labelled polymer detection (envision Flex/HRP). 
Colour reaction was developed by immersing slides in a solution of substrate chromogen (substrate working solution) up to 10 minutes, with the reaction being monitored microscopically. Sections of human prostate were used as positive control. The positive staining of sebaceous tissue was used as internal control. Any nuclear expression of AR was interpreted as positive staining.

Previous studies on this topic used the same clone of AR antibody and used almost the same immunohistochemical staining procedure as explained above.

\section{Results}

Eighteen TE and thirty-eight BCC were included. Eight TE were of the classic type and ten of the desmoplastic type. Ten superficial BCC, thirteen nodular BCC and fifteen infiltrative $B C C$ were included. The other patient and tumour characteristics are mentioned in table 1.

\begin{tabular}{l|ll}
\hline & Basal cell carcinoma & Trichoepithelioma \\
\hline Number tumours & 38 & 18 \\
Biopsy/excision* & $74 / 26(28 / 10)$ & $61 / 39(11 / 7)$ \\
$\square / \square *$ & $53 / 47(20 / 18)$ & $61 / 39(11 / 7)$ \\
Mean patient age in years & 64.9 & 55.4 \\
Tumour localization* & & \\
Head/neck & $50.0(19)$ & $88.9(16)$ \\
Trunk & $34.2(13)$ & $11.1(2)$ \\
Arms & $10.5(4)$ & $0.0(0)$ \\
Legs & $5.3(2)$ & $0.0(0)$ \\
\hline$*$ data are presented as percentages (no.) \\
Table 1. Tumour characteristics \\
\hline
\end{tabular}

\section{Androgen receptor expression}

Analyses comparing AR expression in nodular/superficial BCC versus CTE showed a sensitivity of $96 \%(22 / 23)$ for detection of BCC (Figure 1a-d), a specificity of $38 \%(3 / 8)$ (Figure $2 a-b)$ and a positive and negative predictive value of $82 \%(22 / 27)$ and $75 \%(3 / 4)$ respectively (table 2).

Analyses comparing AR expression in infiltrative BCC versus dTE showed a sensitivity of $67 \%(10 / 15)$ for detection of BCC (Figure 1e-f), a specificity of $100 \%(10 / 10)$ (Figure 2c-d) and a positive and negative predictive value of $100 \%(10 / 10)$ and $67 \%(10 / 15)$ respectively (table 2).

One of the superficial $B C C$ and five of the infiltrative $B C C$ were negative for $A R$ immunostaining. No correlation between the presence of trichodifferentiation (i.e. epithelial primitive structures, small keratinous cysts and, papillar mesenchymal bodies) and negative AR immunostaining in BCC was found. 


\begin{tabular}{|c|c|c|c|c|c|c|}
\hline \multirow[t]{2}{*}{ Methods } & \multicolumn{2}{|c|}{ Participants } & \multicolumn{4}{|l|}{ Results } \\
\hline & TE & BCC & Sensitivity & Specificity & $\begin{array}{l}\text { Positive } \\
\text { predictive value }\end{array}$ & $\begin{array}{l}\text { Negative } \\
\text { predictive value }\end{array}$ \\
\hline $\begin{array}{l}\text { cTE versus } \\
\mathrm{sBCC} / \mathrm{nBCC}\end{array}$ & 8 & 23 & $\begin{array}{l}0.96 \\
(22 / 23)\end{array}$ & $\begin{array}{l}0.38 \\
(3 / 8)\end{array}$ & $\begin{array}{l}0.82 \\
(22 / 27)\end{array}$ & $\begin{array}{l}0.75 \\
(3 / 4)\end{array}$ \\
\hline dTE versus $i B C C$ & 10 & 15 & $\begin{array}{l}\mathbf{0 . 6 7} \\
(10 / 15)\end{array}$ & $\begin{array}{l}1.00 \\
(10 / 10)\end{array}$ & $\begin{array}{l}1.00 \\
(10 / 10)\end{array}$ & $\begin{array}{l}\mathbf{0 . 6 7} \\
(10 / 15)\end{array}$ \\
\hline
\end{tabular}

$\mathrm{BCC}=$ basal cell carcinoma. $(\mathrm{c} / \mathrm{d}) \mathrm{TE}=$ (Classic/desmoplastic) trichoepithelioma. $\mathrm{sBCC}=$ superficial BCC. $\mathrm{nBCC}=$ nodular BCC. $\mathrm{iBCC}=$ infiltrative BCC. The data in parentheses are numbers used to calculate proportion.

Table 2. Relation between androgen receptor immunostaining and histological diagnosis of basal cell carcinoma and trichoepithelioma

\section{Results of previous studies}

Izikson et al. were very conclusive. None of the CTE they studied, showed positive AR immunoreactivitiy whereas in $78 \%$ of the BCC at least focal AR expression was detected. ${ }^{11}$ In two other papers the role of AR antibodies in differentiating between a dTE and morpheaform $B C C$ ( $m B C C)$ (i.e. one of the aggressive subtypes collectively referred as infiltrative) was studied. AR expression was seen in $13 \%$ of the $\mathrm{dTE}$, compared to $65 \%$ of the $\mathrm{mBCC}$ in the study by Katona et al.. ${ }^{12}$ Whereas Costache et al. showed consistent AR expression in $\mathrm{mBCC}$ and no expression in dTE. ${ }^{10}$ The results of these three studies are shown in table 3.

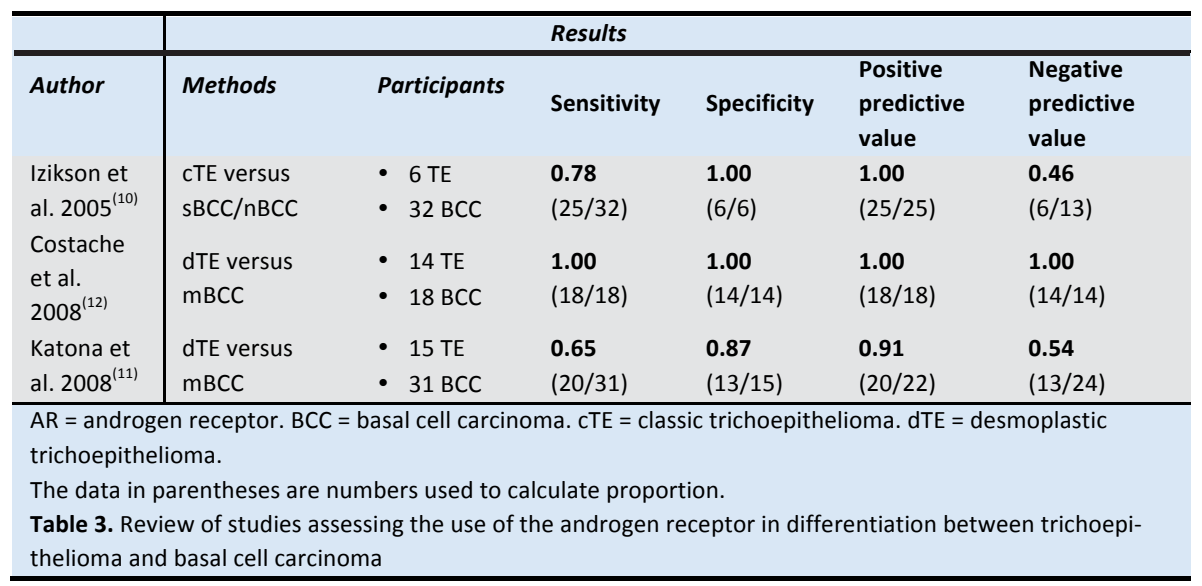




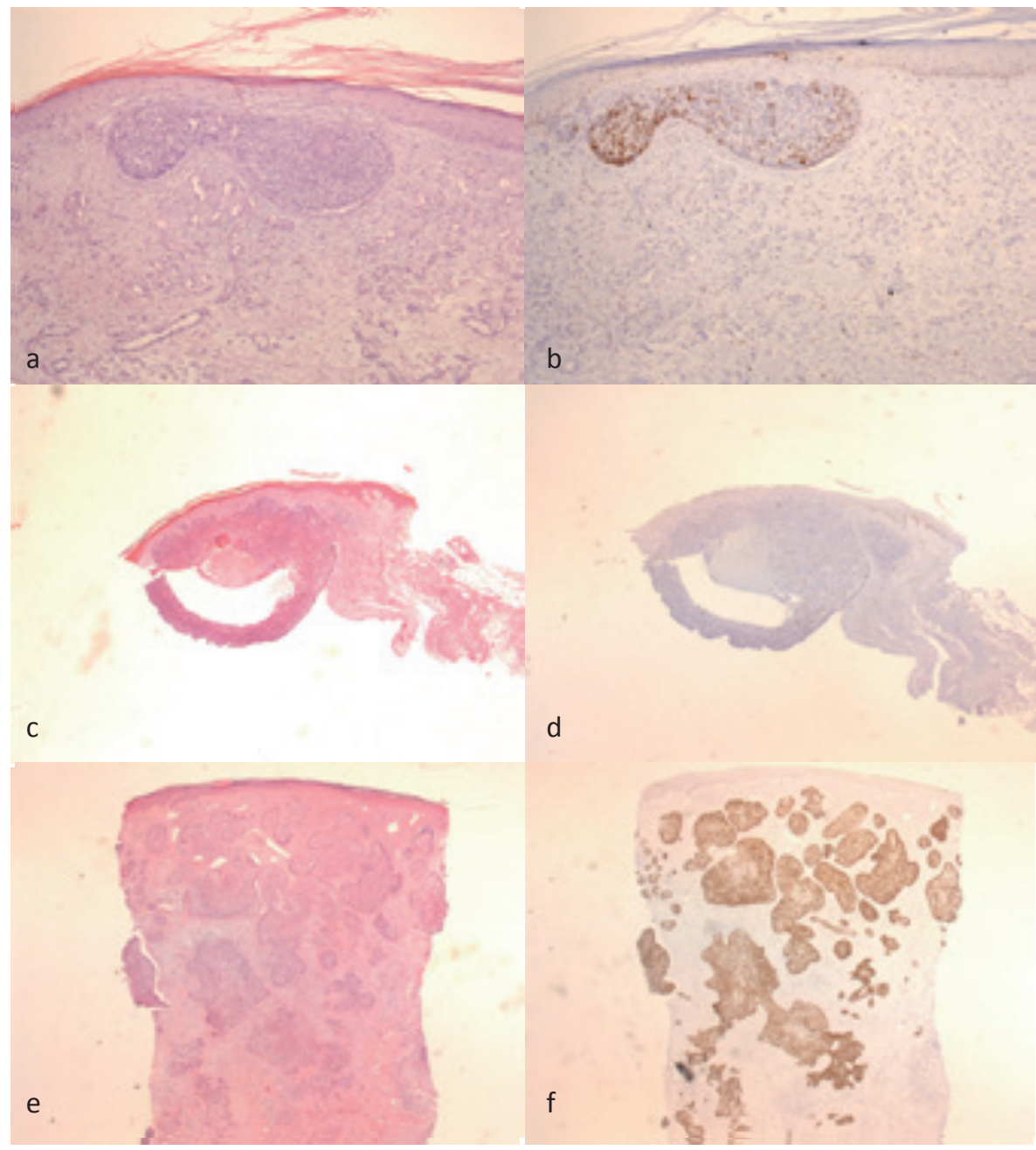

Figure 1. Basal cell carcinoma (BCC). a, b. Superficial BCC. a, Characteristic nest of basaloid cells continuous with the basal membrane of the epidermis and tumour-stroma cleft formation (H\&E 100x). b, AR positive (AR immunostain 100x). c, d. Nodular BCC. c, Characteristic nest of basaloid cells separated from the epidermis (H\&E 25x). d, AR positive (AR immunostain 25x). e, f. Infiltrative BCC. e, Characteristic multiple small nests of basaloid cells infiltrative deep into the dermis (H\&E 25x). f, AR positive (AR immunostain 25x). 


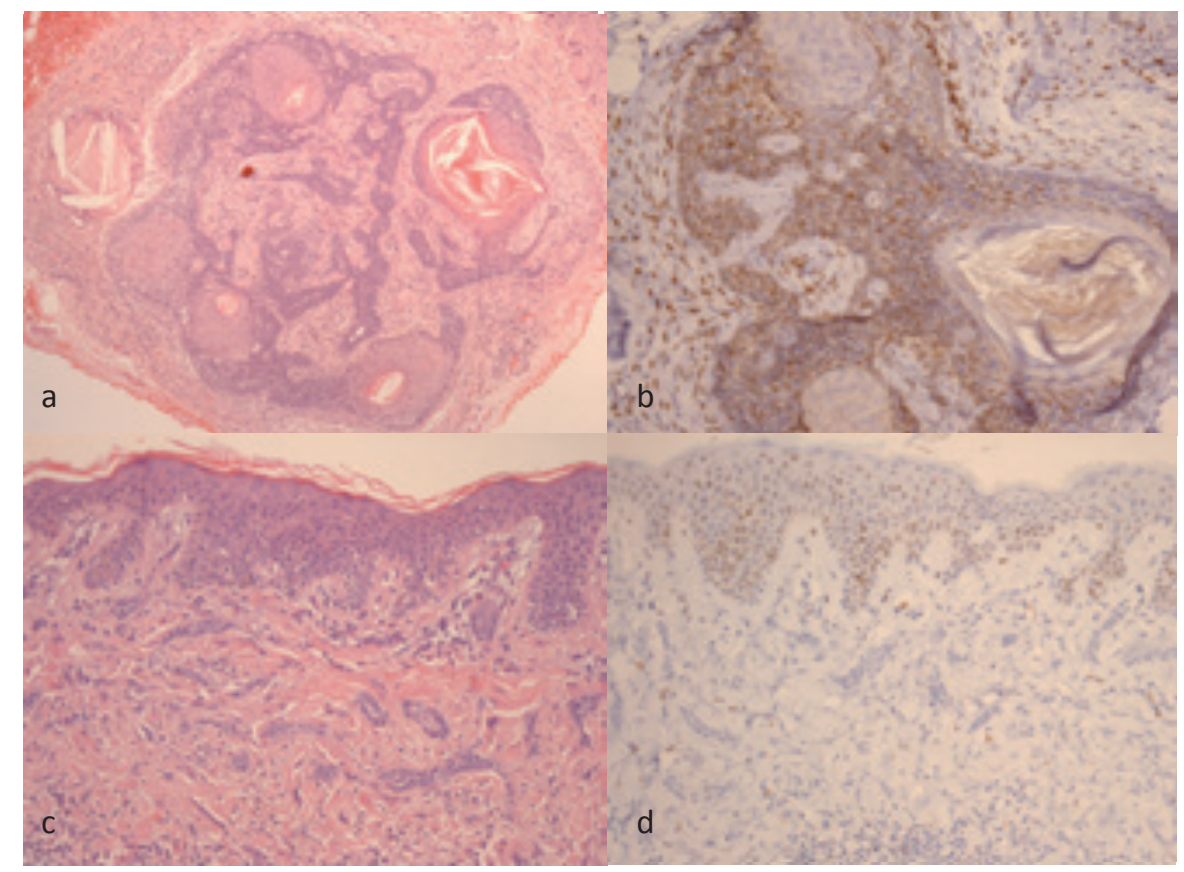

Figure 2. a, b. Classic trichoepithelioma. a, Characteristic nests of uniform basaloid cells in a variably fibrous stroma. Keratinous cysts with calcification are present. (H\&E 100x). b, AR positive (AR immunostain 100x). c, d. Desmoplastic trichoepithelioma. c, characteristic cords and small nests of uniform basaloid cells in a dense fibrotic stroma (H\&E 100x). d, AR negative (AR immunostain 100x).

\section{Discussion}

This study shows that the presence or absence of antibodies against AR in the tumour, shown by immunohistochemistry, can be helpful in differentiating between BCC en TE. First we need to explain how this difference in AR immunostaining between BCC and TE can happen. Probably because both tumours originate from different stem cells. Youssef et al. studied a mouse model to identify cells at the origin of BCC. ${ }^{1}$ They found that BCC arises from long-term resident progenitor cells of the interfollicular epidermis and the upper infudibulum instead of the hair follicle bulge stem cells as suggested earlier. ${ }^{1}$ These resident progenitor cells are also responsible for the maintenance of sebaceous glands. As mentioned in the introduction, AR is expressed in normal skin among other things in interfollicular epidermal keratinocytes, which arise from the same stem cells as BCC. ${ }^{1,7}$ This may explain AR presence in BCC. Instead, TE is an epidermal tumour originating from the outer root sheath of the hair follicle which arises from the multipotent stem cells in the bulge. ${ }^{13}$ Choudhry et al. showed AR absence of the germinative matrix, outer root sheath 
(including the bulge region), inner root sheath, hair shaft and hair bulb. ${ }^{8}$ Suggesting absence of $A R$ in TE.

We already mentioned that we used a panel of three independent investigators as gold standard test to evaluate the H\&E slides of the tumours. An important thing to notice is that in $1 / 5$ cases diagnosis could not be made unanimously by these observers. Lacking of this gold standard H\&E test in previous studies on this topic, could implicate that the results of these three studies ${ }^{10-12}$ are less reliable. Furthermore it justifies our study on this topic.

Our study showed, comparable to the studies by Costache et al. and Katona et al., that AR immunostaining is a test with a $100 \%$ positive predictive value (PPV) and a $100 \%$ specificity for detection of $\mathrm{dTE} .{ }^{10,12}$ This means that there are no false positive cases. On the other hand, we showed AR immunostaining to be a diagnostic test with a high sensitivity (96\%) for detection of superficial/nodular BCC. This outcome is consistent with the data shown by Izikson et al., showing a high sensitivity in combination with a high specificity as well. ${ }^{11}$ In most cases the histopathological diagnosis of a BCC is clear, however in $20 \%$ of cases confusion with a TE occurs. In these cases immunohistochemistry with AR antibodies can be helpful. Our results suggest a potential role for AR immunohistochemical stain in differentiating TE from BCC; especially desmoplastic TE from infiltrative BCC.

\section{References}

1. Youssef KK, Van Keymeulen A, Lapouge G, Beck B, Michaux C, Achouri Y, et al. Identification of the cell lineage at the origin of basal cell carcinoma. Nat Cell Biol. Mar;12(3):299-305.

2. Rippey JJ. Why classify basal cell carcinomas? Histopathology. 1998 May;32(5):393-8.

3. de Vries E, Louwman M, Bastiaens M, de Gruijl F, Coebergh JW. Rapid and continuous increases in incidence rates of basal cell carcinoma in the southeast Netherlands since 1973. J Invest Dermatol. 2004 Oct;123(4):634-8.

4. Weedon D. Skin Pathology. Tokyo: Churchill Livingstone; 2001.

5. Arits AH, Parren LJ, van Marion AM, Sommer A, Frank J, Kelleners-Smeets NW. Basal cell carcinoma and trichoepithelioma: a possible matter of confusion. Int J Dermatol. 2008 Nov;47 Suppl 1:13-7.

6. Sawaya ME. Purification of androgen receptors in human sebocytes and hair. J Invest Dermatol. 1992 Jun;98(6 Suppl):92S-6S.

7. Bayer-Garner IB, Givens V, Smoller B. Immunohistochemical staining for androgen receptors: a sensitive marker of sebaceous differentiation. Am J Dermatopathol. 1999 Oct;21(5):426-31.

8. Choudhry R, Hodgins MB, Van der Kwast TH, Brinkmann AO, Boersma WJ. Localization of androgen receptors in human skin by immunohistochemistry: implications for the hormonal regulation of hair growth, sebaceous glands and sweat glands. J Endocrinol. 1992 Jun;133(3):467-75. 
9. Shikata N, Kurokawa I, Andachi H, Tsubura A. Expression of androgen receptors in skin appendage tumors: an immunohistochemical study. J Cutan Pathol. 1995 Apr;22(2):149-53.

10. Costache $M$, Bresch $M$, Boer A. Desmoplastic trichoepithelioma versus morphoeic basal cell carcinoma: a critical reappraisal of histomorphological and immunohistochemical criteria for differentiation. Histopathology. 2008 Jun;52(7):865-76.

11. Izikson L, Bhan A, Zembowicz A. Androgen receptor expression helps to differentiate basal cell carcinoma from benign trichoblastic tumors. Am J Dermatopathol. 2005 Apr;27(2):91-5.

12. Katona TM, Perkins SM, Billings SD. Does the panel of cytokeratin 20 and androgen receptor antibodies differentiate desmoplastic trichoepithelioma from morpheaform/infiltrative basal cell carcinoma? J Cutan Pathol. 2008 Feb;35(2):174-9.

13. Demirkesen C, Hoede N, Moll R. Epithelial markers and differentiation in adnexal neoplasms of the skin: an immunohistochemical study including individual cytokeratins. J Cutan Pathol. 1995 Dec;22(6):518-35. 


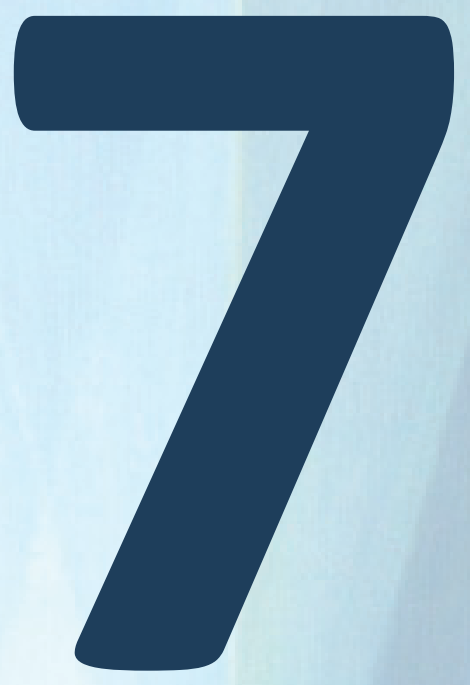

\section{Summary and general discussion}





\section{Summary}

Budget deficits and economic crisis dominate the daily news. The purse strings will have to be tightened, also in health care. Due to high recreational sun exposure, skin cancer is becoming an epidemical problem in Caucasians. Basal cell carcinoma (BCC) is the most common type of all skin cancers. Although it is not life-threatening, it is among the most costly of all cancers due to rising incidence and prevalence. Life-time risk for BCC is 1 in 5-6 for Dutch citizens and one-third of patients with a first BCC will develop one or more subsequent basal cell carcinomas (BCCs) within the next 5 years. This thesis focuses on superficial BCC, the subtype with the fastest growing incidence. To date there is no evidence based consensus on the treatment of superficial BCC but there is a trend towards noninvasive, less mutilating therapies. Although an in-hospital treatment with photodynamic therapy (PDT) is mostly used to treat superficial BCC, evidence that its efficacy is better compared to self-applying creams like imiquimod and 5-fluorouracil (5-FU) is missing. Knowing that the price of both creams is lower compared to a PDT treatment, they may be money-saving in case of equal effectiveness. This thesis gave an answer to the question which of the three mostly used non-invasive treatment modalities for superficial BCC is cost-effective and should be recommended as first-line treatment.

A general introduction tried to clarify the rationale behind this thesis. For those who took trouble to read this thesis and are not familiar with BCC, this chapter provides a brief overview of the incidence, pathogenesis, diagnosis and treatment of the most common type of skin cancer. Furthermore the aims of this thesis were discussed.

Only few cancer registries record BCC worldwide; this is probably due to the fact that mortality rates are low. Thus exact incidence rates are lacking.

In chapter $\mathbf{2}$ we hypothesised that the incidence of BCC still increases and that especially the proportion of superficial BCCs rises. We performed a retrospective registry-based study in the Maastricht University medical Centre (MUMC) and reported all histologically proven primary BCCs diagnosed in the years 1991, 1999 and 2007. An annual increase of the number of BCCs of $7 \%$ for both genders was found. The age-standardized incidence rates for BCC increased between 1991 and 2007 from 54.2 to 162.1 per 100.000 men and from 61.7 to 189.8 per 100.000 women. The nodular BCC remains the most common histological subtype, although the proportion of nodular BCC decreased from $60.8 \%$ in 1991 to $40.6 \%$ in 2007 . On the other hand, we found a significant increase in the proportion of superficial BCC from $17.6 \%$ in 1991 to $30.7 \%$ in 2007. Moreover the proportion of the infiltrative BCC also increases from $11.1 \%$ in 1991 to $28.7 \%$ in 2007 . We confirmed that the mean age of patients with superficial BCC is significantly lower than that of patients with other histological subtypes and superficial BCC is more commonly localised on the trunk. 
We showed that the incidence of BCC still increases this century. This will confront specialists and policymakers worldwide with higher costs and increasing demands for capacity to treat BCC. The observed increase in superficial BCC, which can be treated by less costly and time-consuming modalities, might cause some relief to the practice of the dermatologist.

Treatment of BCC will become a major health care problem, causing enormous health care costs and an increased workload for dermatologists and many other physicians. The costs can be reduced by choosing the most cost-effective therapy. The last two decades there is a growing interest in non-surgical therapies for especially superficial BCC. These therapies are particularly interesting because they offer the possibility to relief the busy practice of medical specialists. An international consensus on the use of PDT in nonmelanoma skin cancer (NMSC), recommended PDT as first-line treatment for superficial BCC. However, both 5-FU cream and imiquimod cream can be considered as an alternative treatment for this type of BCC. To determine residue, recurrence and tumour-free survival probabilities of patients treated for primary superficial BCC, we performed a systematic review of which the results were shown in chapter 3.1. We searched on Pubmed (January 1946 October 2010), EMBASE (January 1989 - October 2010), Cochrane databases (January 1993 - October 2010) and reference lists without date restriction. Studies, reporting on residue and/or recurrence probabilities after treatment of primary, histologically proven superficial BCC with a minimum follow-up of 12 weeks, were included. Both randomised and non-randomised studies were included. Two independent reviewers selected 36 studies (14 randomised and 22 non-randomised). Pooled estimates of percentages of tumourfree survival at one year follow-up, were $87.3 \%$ for imiquimod versus $84.0 \%$ for PDT. Only two studies reported on results of superficial BCC treatment with 5-FU, pooled estimates could not be performed. So, although PDT is most commonly used for treating superficial $B C C$, this systematic review could not prove that the effectiveness of PDT is higher compared to imiquimod.

Because randomised studies with head-to-head comparison of PDT and imiquimod and/or 5-FU are lacking, we performed a noninferiority randomised controlled trial (RCT) of which the results were discussed in chapter 3.2. We hypothesised that imiquimod and 5-FU cream are at least equally effective compared to PDT for treatment of superficial BCC and may be cost saving. We enrolled 601 patients with a histologically proven superficial BCC at seven hospitals in the Netherlands between March 1, 2008 and August 31, 2010. Patients were randomly assigned to receive treatment with methylaminolevulinate (MAL)PDT (two sessions with an interval of one week), imiquimod cream (once daily, five times a week for 6 weeks), or 5-FU cream (twice daily during 4 weeks). Follow-up occurred at three and twelve months post-treatment. Data were collected by one observer who was blinded to assigned treatment. The primary outcome measure was the proportion of patients free of tumour recurrence one year after treatment. Secondary outcome was costeffectiveness. A pre-specified noninferiority margin of $10 \%$ was used. We showed that the proportion of patients tumour-free at one year follow-up was $72.8 \%$ for MAL-PDT, $83.4 \%$ 
for imiquimod cream, and $80.1 \%$ for 5 -FU cream. The significant difference between imiquimod and MAL-PDT was $10.6 \%(p=0.021)$. The cost-effectiveness analyses showed that imiquimod and 5-FU cream were both more effective and less expensive compared to MAL-PDT. Dividing the difference in costs of both creams by their difference in effectiveness, led to an ICER of imiquimod versus 5-FU cream of $€ 4131$ per patient free of tumour recurrence. The acceptability curve showed that for this amount the probability of imiquimod being cost-effective reached fifty percent. In this situation, it depends on the decision maker's willingness to pay or ceiling ratio whether imiquimod can be considered good value for money when compared to 5-FU. In conclusion, 5-FU cream is not inferior and imiquimod is even superior to MAL-PDT for treatment of superficial BCC. Furthermore, imiquimod and 5-FU cream are cost-effective therapies compared to MAL-PDT. Therefore, it can be concluded, that guidelines for the management of superficial BCC should replace MAL-PDT as first-line treatment by imiquimod or 5-FU cream.

The growing group of young women with one or more superficial BCC localised on the trunk, leads to a trend towards non-invasive and less mutilating treatment options. Cosmetic outcome is becoming increasingly important and thus it is essential to find a valid scoring system to assess the cosmetic result after non-invasive therapies in dermatology. In chapter 4 we showed the results of a study comparing two different scar assessment methods. Although qualified objective scar assessment scales are available, they are not used in dermatological studies. Usually a simple 4-point scale (i.e. classifying cosmetic results in poor, fair, good or excellent) is used in dermatological scars. The reproducibility of this method has never been evaluated. The patient and observer scar assessment scale (POSAS) is a scale qualified for the assessments of surgical scars. It has proven to be as reliable as the widely used Vancouver Scar Scale, but has the advantage that it includes the patient's opinion and specifies different scar characteristics. A total of 54 lesions (in 54 patients) following non-invasive treatment for superficial BCC were evaluated with the traditional 4-point scale and the POSAS by three independent physicians and the patient himself. The 4-point scale showed the best reproducibility and had an intra-class correlation coefficient (ICC) of 0.66 for a single observer and 0.85 for multiple observers. The ICC of the POSAS was 0.41 for a single observer and 0.67 for three observers. The scar characteristics, vascularity and pigmentation were most decisive for the overall opinion. So we concluded that the 4-point scale is a valid method to compare scars caused by noninvasive dermatological treatments.

Although PDT is recommended as first-line treatment for superficial BCC, the major drawback is treatment related pain sometimes causing extreme distress for the patient. The intensity of this painful burning sensation seems to vary considerably between patients. It is not exactly known what patient or tumour characteristics are related to the intensity of this pain. The aim of the study discussed in chapter $\mathbf{5}$ was to gain insight into the intensity of the painful burning sensation associated with PDT treatment and to indentify factors that can be used to predict which patient will experience high pain levels as a side-effect 
of PDT treatment. All patients with a histologically proven type of NMSC (i.e. BCC, Bowen's disease (BD) or actinic keratosis (AK)) who were treated with PDT from November the $1^{\text {st }}$ 2008 until June the $30^{\text {th }} 2009$ were asked to report their painful burning sensation on a 11point pain intensity numeric rating scale (PI-NRS; $0=$ no pain $-10=$ worst possible pain). Data were collected on factors that were considered potential predictors of painful burning sensation. 108 patients (141 NMSC) were included. The mean PI-NRS was 5.35 (SD 2.24 and range $0-10$ ). The large standard deviation implicates a large inter-patient variance. Treatment of AK or BD, tumour localisation in the head/neck region, patient's age over 70 , Fitzpatrick skintype I/II, photosensitizer 5-aminolevulinic acid and use of oral analgesics were associated with higher pain scores. Of these factors, Fitzpatrick skintype remained the only independent predictor of pain intensity during PDT. An outcome with little clinical relevance because most patients suffering from NMSC will have skintype I or II. These results supported the fact that pain experience is to a great extend a personal experience influenced by many factors like genetic, ethnic and cultural issues rather than the supposed patient and treatment-related factors studied. Therefore, it remains difficult to decide before PDT treatment which patient should be considered for pain relieving measures.

Less frequently occurring benign and malign tumours of the skin appendages are frequently misdiagnosed as a BCC. In Chapter 6 we illustrated that, both on clinical and histological characteristics, BCC can be confused with less frequent skin tumours. Based on a case report, chapter 6.1 described the difficulties in diagnosing a periocular sebaceous carcinoma (SC). A small punch biopsy is often not sufficient to distinguish this tumour from a BCC or other less common skin tumours. Early diagnosis is essential because $\mathrm{SC}$ has a much worse prognosis compared to BCC. When a skin coloured tumour is localised in the periocular region, the possibility of a SC should be considered and a large wedge excision is recommended for correct diagnosis. Besides, differentiating a BCC from a trichoepithelioma (TE), which is a benign adnexal tumour, is also often difficult. Chapter 6.2.1 outlined this problem based on a case report and discussed the value of additional immunohistochemical staining. Of all immunomarkers reported in previous literature, the androgen receptor (AR), was the only one with diagnostic potential. Human sebaceous glands and hair follicles are target structures in the skin for androgen action. They contain steroid enzymes, capable of transforming weak androgens into target-tissue-active androgens testosterone and dihydrotestosterone, which bind to the AR to regulate cellular transcription. AR is expressed in normal skin but also in cutaneous neoplasms like BCC. In contrast, AR expression seems to be absent in mature hair follicles and the epidermis. So it is supposed to be absent in benign hair follicle tumours like TE. The aim of chapter 6.2.2 was to find out the usefulness of AR immunohistochemistry in differentiating BCC from TE. Seventy-five haematoxylin \& eosin (H\&E) slides were randomly selected and reviewed by three independent investigators. Fifty-six slides ( $38 \mathrm{BCC}$ and $18 \mathrm{TE}$ ) with unequivocal histological characteristics of either BCC or TE, were used for immunohistochemistry with $A R$ antibodies. AR expression was present in 5/8 classic TE, $0 / 10$ desmoplastic TE, 22/23 su- 
perficial and nodular BCC and in 10/15 infiltrative BCC. Based on these findings and previous published data, we concluded that additional immunostaining against AR can be useful to differentiate between BCC and TE; particularity in case of desmoplastic TE versus infiltrative BCC (specifity and positive predictive value of $100 \%$ ).

\section{Main conclusion of thesis}

The main aim of this thesis was to evaluate which of the mostly used non-invasive treatment options for superficial BCC is the most cost-effective and should become the firstline treatment.

Based on the scientific research that was discussed in this thesis, we concluded that both topical imiquimod and 5-fluorouracil (5-FU) are cost-effective first-line treatments for superficial BCC compared to photodynamic therapy (PDT). So, (inter)national guidelines on the management of superficial BCC should replace PDT as first-line treatment by imiquimod or 5-FU cream.

\section{Discussion and recommendations}

BCC is the most common and among the most costly of all cancers worldwide. The annual increase in incidence of $7 \%$ is definitely underestimated because cancer registries for BCC are scarce. So it should be clear that this presumed 'innocent' tumour will have a major impact on health care. Due to the rising incidence, solutions to manage the large number of BCCs, should be sought. Maintaining care in the office-based setting is more costefficient than utilizing ambulatory surgical centres or hospital operating rooms. Although surgery is the treatment of choice for most BCCs, there is already a trend towards noninvasive therapies to treat superficial BCC and premalignant skin disorders. Based on the results of this thesis, it became clear that over the last two decades a strong increase in the proportion of superficial BCC was observed. 5\% 5-FU cream was the first topical therapy approved by the U.S. Food and Drug Administration for the treatment of superficial BCC. The topical application of 5-FU was already discovered in the 1960s. However in the late twentieth century, dermatologist became more experienced in surgery. Topical treatment with 5-FU fell into oblivion. In that period it was already clear that the incidence of NMSC would occupy exorbitant proportions. The pharmaceutical industry also noted it and responded to the need for less time-consuming therapies. Within this framework, PDT and imiquimod cream were introduced on the market. In current guidelines, PDT is recommended as first-line non-invasive treatment for superficial BCC, but evidence that its effectiveness is higher compared to other topical therapies like imiquimod and 5-FU cream is lacking. In this thesis we discussed the results of the first RCT comparing the effectiveness and the costs of treatment with PDT, imiquimod and 5-FU cream for superficial BCC. We concluded that both topical imiquimod and 5-FU are cost-effective first-line 
treatments for superficial BCC compared to PDT. (Inter)national guidelines for the management of superficial BCC should replace PDT as first-line treatment by imiquimod or 5FU cream. We tried to estimate the cost-savings that the application of this new guideline will yield in the Netherlands. We showed that the proportion of superficial BCC rose to $30.7 \%$ in 2007 . A research group, led by the department of dermatology of the Erasmus medical centre in Rotterdam, showed that in 2010 the total number of newly diagnosed BCCs was expected to be around 33.000 . This means that in total 9.900 superficial BCCs are diagnosed yearly in the Netherlands. Assuming that all superficial BCCs were treated with MAL-PDT, the total potential cost-savings on a national level by replacing MAL-PDT with imiquimod cream could be $1.524 .600 €(9.900 \times 154 €)$ while replacing MAL-PDT by 5FU results in $2.890 .800 €(9.900 \times 292 €)$ cost-saving. Dividing the difference in costs of both creams by their difference in effectiveness, led to an incremental cost-effectiveness ratio (ICER) of imiquimod versus 5-FU cream of $4131 €$ per patient free of tumour recurrence. In this situation, it depends on the decision maker's willingness to pay or ceiling ratio whether imiquimod can be considered good value for money when compared to 5-FU. My opinion is that, based on the current data, we should opt for 5-FU cream as first-line treatment for superficial BCC. Although the chance of tumour recurrence is slightly higher after treating superficial BCC with 5-FU compared to imiquimod, the treatment costs of 5-FU cream are so much lower than those of imiquimod cream, that even adding the costs of a relapse to the 5-FU treatment will not transcend the costs of an imiquimod treatment. The most important thing of my consideration is that superficial BCC is a very innocent tumour in terms of morbidity and mortality and recurrent tumours are easy to treat. But, long-term follow-up data are required to achieve more conclusive results with respect to the relative costs and effectiveness when comparing imiquimod with 5-FU cream. It might be possible that the effect-difference between imiquimod and 5-FU cream becomes larger, which in turn might result in a more favourable ICER.

In conclusion it is very important to remain critical as a doctor. One must continue to wonder 'why am I doing this?' In recent years, PDT was applied massively for the treatment of NMSC in the Netherlands while good comparative studies demonstrating the superior effect of PDT were missing.

Based on the results of this RCT, there are a lot of ideas for follow up research. We are wondering what should be the most cost-effective therapy for actinic keratosis, which is the most frequent premalignant condition. The Dutch evidence based guideline on the treatment of actinic keratosis could not point out one treatment to be superior above the others. The incidence of the number of patients with actinic keratosis in the Netherlands in 2012 is estimated at more than 160.000. Finding the most cost-effective treatment modality for this premalignant skin condition, could also yield a gigantic cost-saving for medical health care. The first steps, to perform a RCT comparing MAL-PDT, imiquimod and 5 -FU cream for treatment of field cancerization in actinic keratosis, have already been taken.

Although the role of PDT in the treatment of superficial BCC is diminished, in some cases application of the creams would not be possible due to practical reasons. Elderly patients 
may have problems remembering the treatment schedule and due to comorbidity in some cases they will not be able to apply the cream by themselves. Also singles with a BCC on the back might have problems reaching the lesion. Sometimes they have the possibility to ask their neighbours or friends to apply the cream to the lesion daily. In other cases home care could be enabled. When application of the cream to the treatment area really is not possible, PDT can be considered as alternative treatment but perhaps, in these cases, surgery might be a more cost-effective alternative. Besides, someone can remark appropriately that patients participating in trials are more motivated than the average patient. We could assume that the compliance of the patients using the creams in regular care is lower, which can lead to lower effectiveness rates. Therefore it will be very important to explain the treatment procedure and the possible adverse effects to the patients. The nurse practitioner can play an important role in this. We will also have to make an extra effort to create good information brochures on imiquimod and 5-FU treatment for superficial BCC. These brochures should guide patients through the treatment.

In addition, someone can wonder whether the used treatment protocol for PDT in the performed RCT was the most optimal. Previous research showed good effectiveness of light fractionated ALA-PDT. Light fractionation using one or more short dark intervals may improve the response due to the fact that the availability of oxygen could be increased since oxygen rediffuses the treated area during the dark interval. Oxygen is an essential part for the efficacy of PDT. To date there is no RCT comparing the effectiveness and costs of MAL-PDT (two PDT cycles with one week interval) with light fractionated ALA-PDT (two $P D T$ cycles with a short dark interval on one day). ALA-PDT may be potentially cost-saving due to the lower costs of ALA cream compared to MAL (Metvix ${ }^{\circledR}$ ), besides fractionated illumination on one day can reduce overhead costs.

The last point for follow up research is based on the fact that it is an illusion to think that the upcoming large number of patients with NMSC can be managed by the dermatologist himself. Maybe the moment has come to think about what can be the role of the general practitioner in this. When expertise and capacity becomes available, diagnostics of NMSC and even topical treatments for NMSC can become part of primary health care. Before we can reach to this point, general practitioners should be trained in this subject. Training programs can be composed and their effectiveness should be tested in follow up research. Tele-dermatology can also play an important role. For example, in predefined situations, the general practitioner already can take a diagnostic punch biopsy together with a picture of the lesion. After a tele-consult with the dermatologist, a treatment plan can be draw up. Topical treatment of NMSC and surgical excision of small nodular BCCs outside the head and neck region can be performed in primary health care. Patients with multiple BCCs and BCCs in the head and neck region should be referred to the dermatologist. In this way it is possible to reduce unnecessary hospital health care and reduce overhead costs. 


\section{Samenvatting}

Dit proefschrift werd geschreven in een periode waarin begrotingstekorten en economische crisis het dagelijkse nieuws beheersten. Op alle vlakken moet er bezuinigd worden en ook de gezondheidszorg wordt wereldwijd serieus gekort. Huidkanker is een wereldwijde epidemie aan het worden en de belangrijkste reden hiervoor is de verandering in het zonnegedrag. Mensen doen steeds meer binnenwerk en gaan een of twee keer per jaar op vakantie waarbij ze langdurig en zonder de huid erop voor te bereiden, blootgesteld worden aan een grote hoeveel UV straling. Bovendien hebben steeds meer gezinnen een zonnebank in huis. Het is bekend dat UV blootstelling in combinatie met huidtype de grootste risicofactor is voor het ontwikkelen van huidkanker. Van alle typen huidkanker komt het basaalcelcarcinoom (BCC) het vaakste voor. Het BCC is geen levensbedreigende vorm van kanker maar door de zeer hoge incidentie en prevalentie behoort het tot de kankers die de gezondheidszorg het meeste geld kosten. Eén op de vijf à zes Nederlanders zal in de loop van het leven een BCC ontwikkelen. Een derde van deze patiënten zal binnen vijf jaar na de diagnose van het eerste BCC, één of meerdere nieuwe BCC's ontwikkelen. Van de drie subtypes van het BCC, neemt de incidentie van het superficiële type het snelste toe. Dit type bevindt zich, zoals de naam al doet vermoeden, heel oppervlakkig in de huid en het presenteert zich klinisch als een klein eczeemachtig plekje. In dit proefschrift wordt speciale aandacht besteed aan het superficiële BCC. Tot op heden is er nog geen evidence-based consensus voor de behandeling van dit type BCC. De laatste jaren is wel duidelijk geworden dat niet-invasieve behandeltechnieken de voorkeur genieten boven chirurgische excisie omdat ze doorgaans een beter cosmetisch resultaat geven. Van alle niet-invasieve technieken wordt photodynamische therapie (PDT) het vaakste toegepast, maar er is geen enkel wetenschappelijk bewijs dat het beter zou werken dan bijvoorbeeld imiquimod of 5 -fluorouracil (5-FU) crème. PDT is een behandeling die, vaak als dagbehandeling, in het ziekenhuis wordt uitgevoerd. Beide crèmes kunnen door de patient zelf aangebracht worden en nemen enkele weken in beslag. Het is bekend dat de kostprijs van beide crèmes lager is dan de prijs voor een PDT behandeling. Als het zo blijkt te zijn dat beide crèmes even goed werken als PDT, dan zou het toepassen van deze crèmes i.p.v. PDT een kostenbesparing voor de gezondheidszorg kunnen opleveren. Een extra voordeel is dat patiënten voor deze behandeling niet naar een ziekenhuis moeten komen, waardoor de praktijk van de dermatoloog wordt ontlast en er tijd vrij komt voor de behandeling van agressievere vormen van huidkanker.

In dit proefschrift werd een antwoord gegeven op de vraag welke van deze drie nietinvasieve behandelingsmogelijkheden (i.e. PDT, imiquimod crème of 5-FU crème) voor het superficieel BCC het meest kosteneffectief is. 
In de introductie werd getracht de zinvolheid van dit proefschrift te verduidelijken. Voor diegene die zich de moeite genomen hebben om dit proefschrift te lezen en niet vertrouwd waren met het BCC, biedt dit hoofdstuk een kort overzicht van de incidentie, pathogenese, diagnose en behandeling van de meest voorkomend vorm van huidkanker. Daarnaast worden de doelstellingen van het proefschrift verduidelijkt.

Het BCC wordt zelden opgenomen in kankerregistraties. Dit heeft vermoedelijk te maken met het feit dat het een zeer onschuldige vorm van kanker is en dat het sterftecijfer bijzonder laag ligt.

In hoofdstuk 2 werd verondersteld dat de incidentie van het BCC nog steeds stijgt en dat vooral het aandeel superficiële BCC's toeneemt. In het Maastrichts Universitair Medisch Centrum (MUMC) werd een retrospectief onderzoek verricht waarbij alle primaire, histologisch bevestigde BCC's die gediagnosticeerd werden in de jaren 1991, 1999 en 2007 opgenomen werden in een database. Er werd een jaarlijkse stijging vastgesteld van $7 \%$ voor zowel mannen als vrouwen. Het naar leeftijd gestandaardiseerd incidentiecijfer voor het BCC steeg tussen 1991 en 2007 van 54.2 naar 162.1 per 100000 mannen en van 61.7 naar 189.9 per 100000 vrouwen. Ook al zagen we een daling in het aantal nodulaire BCC's van $60.8 \%$ in 1991 naar $40.6 \%$ in 2007, toch blijft dit het meest voorkomende subtype. Daarnaast stelden we een sterke stijging vast in het aandeel superficiële basaalcelcarcinomen. In 1991 behoorde $17.6 \%$ van alle BCC's tot het superficiële histologische subtype terwijl dit in 2007 een derde (30.7\%) van alle BCC's betrof. Ook het infiltratieve BCC steeg van $11.1 \%$ in 1991 naar $28.7 \%$ in 2007 . Conform de resultaten van eerder onderzoek vonden ook wij dat patiënten met een superficieel BCC gemiddeld jonger zijn dan patiënten met een nodulair of infiltratief subtype BCC. Daarnaast ontwikkelt een superficieel BCC zich voornamelijk op de romp, terwijl de andere subtypes hoofdzakelijk in het hoofd-hals gebied gezien worden.

Samengevat konden we dus bevestigen dat ook deze eeuw de stijging in de incidentie van het BCC zich voortzet. We concludeerden dat deze toename wereldwijd zal leiden tot hoge kosten voor de gezondheidszorg. Bovendien moet er capaciteit voorzien worden om al deze BCC's in de toekomst te gaan behandelen. Om die reden hebben we onze aandacht verder gevestigd op het superficieel BCC. Door te kiezen voor de meest kosteneffectieve niet-invasieve behandeloptie voor dit subtype komt er geld en ruimte vrij die besteed kunnen worden aan agressievere vormen van huidkanker.

In een internationale consensus over het gebruikt van PDT bij niet-melanoom huidkanker, wordt PDT als eerste keus behandeling voor het superficieel BCC aanbevolen. Als alternatief kunnen imiquimod and 5-FU crème toegepast worden. Om te onderzoeken wat de kans is op een residu of een recidief tumor na behandeling van een superficieel BCC met een van deze niet-invasieve behandelingen werd er een systematische review van de literatuur verricht waarvan de resultaten besproken worden in hoofdstuk 3.1. We zochten op PubMed (januari 1946 - oktober 2010), EMBASE (januari 1989 - oktober 2010) en Cochrane database (januari 1993- oktober 2010). Daarnaast werden de referentielijsten van de gevonden artikelen nagetrokken. Alle studies, die het residu en recidiefpercentage na 
behandeling van een histologisch bevestigd primair superficieel BCC weergaven en een minimale follow up duur hadden van 12 weken, werden geïncludeerd. Zowel gerandomiseerde als niet-gerandomiseerde studies werden geïncludeerd. Twee onafhankelijke recensenten selecteerden 36 studies (14 gerandomiseerd, 22 niet-gerandomiseerd). De data werden gepooled en toonden een tumorvrije overleving na één jaar van $87.3 \%$ voor imiquimod en $84.0 \%$ voor PDT. Slechts 2 niet-gerandomiseerde studies rapporteerden resultaten na een behandeling met 5-FU. Deze studies hadden een zeer korte follow up, één-jaars resultaten zijn niet bekend. Op basis van deze review kunnen we dus concluderen dat PDT in elk geval niet effectiever is dan imiquimod voor de behandeling van het superficieel BCC. Echter een goede gerandomiseerde studie die deze drie niet-invasieve behandelingen met elkaar vergelijkt werd nog nooit verricht. Daarom hebben we een 'noninferiority' gerandomiseerde studie opgezet die het effect van PDT, imiquimod crème en 5-FU crème als behandeling van superficieel BCC met elkaar vergelijkt. De resultaten hiervan worden besproken in hoofdstuk 3.2. Er werd uitgegaan van de hypothese dat imiquimod en 5-FU crème minstens even effectief zijn als PDT voor de behandeling van superficieel BCC en dat beiden crèmes mogelijk kostenbesparend kunnen zijn. Tussen 1 maart 2008 en 31 augustus 2010 werden er 601 patiënten met een histologisch bevestigd primair superficieel BCC geïncludeerd. Patiënten werden at random toegewezen aan een van de drie behandelgroepen: methylaminolevulniaat (MAL)-PDT (twee sessies met een interval van één week), imiquimod crème (eenmaal daags, vijf dagen per week gedurende zes weken) of 5-FU crème (tweemaal daags dagelijks gedurende 4 weken). Patiënten werden drie en twaalf maanden na het einde van de behandeling terug gezien voor controle. De onderzoeksdata werden verzameld door één onderzoeker die geblindeerd was voor de behandeling. De primaire uitkomstmaat was het percentage patiënten dat tumorvrij was één jaar na de behandeling. De secundaire uitkomstmaat was kosteneffectiviteit. Een 'noninferiority' grens van $10 \%$ werd voor de start van de studie gedefinieerd. We vonden dat $72.8 \%$ van de patiënten behandeld met MAL-PDT, $83.4 \%$ van deze behandeld met imiquimod crème en $80.1 \%$ van de patiënten behandeld met 5 -FU crème tumorvrij waren één jaar na de behandeling. Het verschil in effectiviteit van $10.6 \%(p=0.021)$ tussen MALPDT en imiquimod was statistisch significant. Kosteneffectiviteitanalyses toonden aan dat zowel imiquimod als 5-FU crème effectievere en bovendien goedkopere behandelingen zijn voor het superficieel BCC vergeleken met MAL-PDT. De 'incremental costeffectiveness ratio' (ICER) wordt berekend door het verschil in effectiviteit tussen de twee crèmes te delen door het verschil in behandelkosten. Op basis van de ICER kan gesteld worden dat, wanneer men kiest voor een behandeling met imiquimod, er $4131 €$ geïnvesteerd moet worden om één extra recidief te voorkomen vergeleken met een behandeling met 5-FU crème. Het hangt er in deze situatie dus heel erg vanaf hoeveel geld we (i.e. de patiënt, de arts en de gezondheidszorg) willen investeren om dit recidief te voorkomen. Samengevat blijkt uit deze gerandomiseerde trial dat de effectiviteit van 5-FU crème niet inferieur is aan, en die van imiquimod crème zelfs superieur is boven een behandeling met MAL-PDT voor een superficieel BCC. Daarnaast kon geconcludeerd worden dat beide crèmes kosteneffectiever zijn vergeleken met MAL-PDT voor de behandeling van een superfi- 
cieel BCC. Dit betekent dat richtlijnen voor de behandeling van superficieel BCC aangepast moeten worden waarbij de crèmes als eerste keus behandeling geadviseerd worden.

Niet-invasieve behandelingen bieden een uitkomst aan de steeds groter wordende groep van jonge vrouwen met een of meerdere superficiële BCC's op de romp. Deze behandelingen geven doorgaans een beter cosmetisch resultaat vergeleken met excisie. In deze groep gaat het esthetische aspect van een behandeling ook een rol spelen daarom is het belangrijk om een valide scoringssysteem te ontwikkelen om het cosmetisch resultaat na niet-invasieve behandelingen te evalueren en te vergelijken. In hoofdstuk $\mathbf{4}$ toonden we de resultaten van een studie waarbij twee cosmetische scoringslijsten met elkaar vergeleken werden. Er bestaan gekwalificeerde objectieve scoringslijsten voor littekens, echter deze worden in de dermatologie nog niet toegepast. Normaliter wordt een simpele 4punten schaal gebruikt om het cosmetisch resultaat van een dermatologische ingreep te evalueren. Hierbij wordt het cosmetisch resultaat gescoord als 'slecht', 'matig', 'goed' of 'uitmuntend'. De reproduceerbaarheid van deze methode werd echter nooit geëvalueerd. Een andere scoringslijst is de zogenaamde POSAS (patient and observer scar assessment scale), die gevalideerd is voor de beoordeling van chirurgische littekens. Gebleken is dat de POSAS even betrouwbaar is als de op grote schaal toegepaste Vancouver scoringslijst. De POSAS heeft als voordeel dat zowel de opinie van de patiënt als die van de arts wordt meegenomen en dat er bovendien gescoord wordt op meerdere kenmerken van het litteken. In totaal werden er 54 littekens, ontstaan na een niet-invasieve behandeling voor het superficieel BCC, door drie onafhankelijke artsen en de patiënt zelf geëvalueerd gebruik makend van de traditionele 4-puntenschaal en de POSAS. De 4-puntsschaal bleek het best reproduceerbaar en had een correlatiecoëfficiënt van 0.66 voor een enkele beoordelaar en 0.85 voor meerdere beoordelaars. Voor de POSAS was deze coëfficiënt 0.41 voor één beoordelaar en 0.67 voor meerdere beoordelaars. Van alle littekenkenmerken bleken de vasculariteit en de pigmentatie het meest doorslaggevend voor het eindoordeel. We concludeerden dat de 4-puntsschaal een valide methode is om het cosmetisch resultaat na een niet-invasieve dermatologische behandeling te scoren.

De belangrijkste bijwerking van een behandeling met PDT is de branderige pijn die patiënten tijdens de belichtingsfase vaak ervaren. De intensiteit van deze pijn lijkt enorm te verschillen tussen patiënten. Het is niet precies bekend welke patiënt- of tumorkenmerken geassocieerd zijn met de intensiteit van de pijn. Het doel van de studie die besproken werd in hoofdstuk $\mathbf{5}$ was om inzicht te krijgen in de intensiteit van de pijn die gepaard kan gaan met een PDT behandeling. Daarnaast wilden we factoren identificeren die gebruikt kunnen worden om te voorspellen welke patiënten veel pijn zullen ervaren tijdens de PDT behandeling zodat vooraf beter ingeschat kan worden welke patiënten pijnbestrijding nodig zullen hebben. Alle patiënten met een histologisch bevestigd type van nietmelanoom huidkanker (i.e. superficieel BCC, morbus Bowen (MB) of aktinische keratose (AK)) die tussen 1 november 2008 en 30 juni 2009 behandeld werden met PDT in het MUMC werden gevraagd om de pijn gerelateerd aan de behandeling te scoren aan de 
hand van een 11-punten schaal (i.e. pain-intensity numeric rating scale, PI-NRS) waarbij een score van 0 gelijk staat aan geen pijn en 10 de ergst denkbare pijn vertegenwoordigd. Potentiële voorspellers van deze pijnsensatie werden per patiënt genoteerd. Er werden 108 patiënten met 141 te behandelen plekjes geïncludeerd. De gemiddelde pijnscore was 5.35 (SD 2.24 en range 0-10). De grote standaarddeviatie impliceert dat er een grote variatie is in pijnscore tussen de behandelde patiënten. Hogere pijnscores werden gezien bij behandeling van patiënten met een $\mathrm{AK}$ of $\mathrm{MB}$, wanneer de te behandelen laesie zich in het hoofd-hals gebied bevond, bij patiënten ouder dan 70 jaar, patiënten met een huidtype I of II, bij gebruik van ALA als fotosensitizer en bij patiënten die al standaard orale analgetica gebruikten. Van al deze factoren was alleen het huidtype een onafhankelijke voorspeller voor de intensiteit van de pijn gerelateerd aan een PDT behandeling. Echter deze bevinding heeft weinig klinische implicaties aangezien ruim $90 \%$ van de mensen behandeld voor huidkanker een huidtype I of II heeft. De resultaten ondersteunen het feit dat pijn voor een groot stuk een persoonlijke beleving is die beïnvloed kan worden door genetische, ethische en culturele factoren. Dus tumorkenmerken spelen een minder grote rol dan vooraf werd gedacht. Het blijft vooralsnog moeilijk om te voorspellen welke patiënten de meeste pijn zullen ervaren tijdens een behandeling met PDT en bijgevolg is het ook niet mogelijk om vooraf een gedegen selectie te maken van de patiënten die pijnstilling nodig gaan hebben.

De a priori kans dat een glanzende erythemateuze papel of plaque op de huid van een patiënt een BCC blijkt te zijn, is dusdanig groot dat de diagnose van klinische identieke maar minder frequent voorkomende maligne en benigne huidtumoren vaker gemist wordt.

In hoofdstuk 6 illustreerden we aan de hand van patiëntencasussen dat zowel op klinische als op histopathologische gronden het BCC verward kan worden met andere huidtumoren. In hoofdstuk 6.1 wordt de moeilijkheid van het stellen van de diagnose van een perioculair talgkliercarcinoom besproken. Een stansbiopt van enkele millimeters is doorgaans niet afdoende om deze agressief groeiende tumor te onderscheiden van een BCC. Vroege diagnose is belangrijk omdat een talgkliercarcinoom een veel slechtere prognose heeft vergeleken met een BCC. Wanneer een huidskleurige tumor zich bevindt in het perioculaire gebied moet altijd de mogelijkheid van een talgkliercarcinoom overwogen worden. Een grotere ellipsexcisie wordt geadviseerd om de diagnose histopathologisch te bevestigen. Daarnaast is het ook vaak moeilijk om een BCC van een benigne trichoepithelioom (TE) te onderscheiden. In hoofdstuk 6.2.1 wordt dit probleem besproken aan de hand van een case report en wordt de meerwaarde van aanvullend immunohistochemisch onderzoek voor het correct stellen van de diagnose toegelicht. Van alle immunomarkers die in eerdere publicaties besproken werden, lijkt de androgeen receptor (AR) de enige marker te zijn met potentiële mogelijkheden om de differentiatie tussen een BCC en TE te verbeteren. Zowel talgklieren als haarfollikels zijn doelwitten in de huid voor androgeenactiviteit. Ze bevatten namelijk steroïd enzymen, die de mogelijkheid hebben om zwakke androgenen om te zetten in testosteron en dihydrotestosterone, dat vervolgens bindt aan de AR en 
celtranscriptie reguleert. AR komt zowel in de normale huid als in cutane neoplasmata zoals bijvoorbeeld het BCC tot expressie. AR expressie lijkt dan weer afwezig te zijn in mature haarfollikels en in de epidermis. Aangenomen wordt dat AR expressie dan ook afwezig is in benigne haarfollikeltumoren zoals het TE. Het doel van het onderzoek dat besproken werd in hoofdstuk 6.2.2 was om na te gaan wat de meerwaarde is van immunokleuring met antilichamen tegen de AR om een BCC van een TE te differentiëren. 75 $H \& E$ coupes werden at random geselecteerd en herbeoordeeld door drie onafhankelijke beoordelaars. 56 coupes ( $38 \mathrm{BCC}$ en $18 \mathrm{TE}$ ), waarbij de drie beoordelaars het op basis van de histologische kenmerken unaniem eens waren over de diagnose BCC dan wel TE, werden gebruikt voor immunohistochemische kleuring met $A R$ antilichamen. AR expressie kwam tot uiting in 5/8 klassieke TE en 0/10 desmoplastische TE. Daarnaast kleurden 22/23 superfiële en nodulaire BCC's en 10/15 infiltratieve BCC's aan. Gebaseerd op onze eigen resultaten maar ook op basis van eerder gepubliceerd onderzoek, concludeerden we dat aanvullende immunokleuring met antilichamen tegen de AR zinvol kan zijn om te helpen differentiëren tussen een BCC en een TE. Dit is voornamelijk het geval wanneer zowel klinisch als histopathologisch moeilijk een onderscheid gemaakt kan worden tussen een desmoplatische TE en een infiltratief (morfeaform) BCC (specificiteit 100\% en positief voorspellende waarde $100 \%$ ).

\section{Hoofdconclusie van thesis}

In deze thesis onderzochten we welke de meest kosteneffectieve niet-invasieve therapie voor het superficieel BCC is en dus als eerste keus behandeling aanbevolen zou moeten worden. Wij concludeerden dat zowel imiquimod als 5-fluorouracil (FU) crème kosteneffectieve eerste keus behandelingen zijn voor het superficiële BCC vergeleken met photodynamische therapie (PDT).

(Inter)nationale richtlijnen over de behandeling van BCC moeten herzien worden en PDT moet vervangen worden door imiquimod of 5-FU crème als eerste keus behandeling van superficieel basaalcelcarcinomen. 



\section{List of abbreviations}

AK

ALA

$A R$

BCC

$\mathrm{BD}$

$\mathrm{Cl}$

CTE

dTE

GLI

$H \& E$

iBCC

ICC

ICER

ITT

LED

MAL

$\mathrm{mBCC}$

MMS

MUMC

NMSC

$\mathrm{nBCC}$

PDT

PI-NRS

POSAS

PpIX

PTCH1

RCT

SD

$\mathrm{SC}$

SBCC

(S) $\mathrm{HH}$

SMO

SCC

TE

TLR-7

UVR

5-FU

actinic keratosis

aminolevulinc acid

androgen receptor

basal cell carcinoma

bowen's disease

confidence interval

classical trichoepithelioma

desmoplastic trichoepithelioma

glioma

haematoxylin \& eosin

infiltrative basal cell carcinoma

intra-class correlation coefficient

incremental cost-effectiveness ratio

intention-to-treat

light emitting diode

methyl aminolevulinate

morpheaform basal cell carcinoma

Mohs' micrographic surgery

Maastricht university Medical Centre

nonmelanoma skin cancer

nodular basal cell carcinoma

photodynamic therapy

pain intensity numeric rating scale

patient and observer scar assessment scale

protoporhyrin IX

patched 1

randomised controlled trial

standard deviation

sebaceous carcinoma

superficial basal cell carcinoma

(Sonic) hedgehog

Smoothened

squamous cell carcinoma

trichoepithelioma

toll-like receptor 7

ultraviolet radiation

5-fluorouracil 



\section{Curriculum vitae}

Aimée Arits werd op 10 januari 1982 geboren in Maaseik. Nadat ze in 2000 het middelbaar onderwijs in de richting wetenschappen-wiskunde had afgerond, startte zij met de studie biomedische wetenschappen aan het Limburgs Universitair Centrum (thans Universiteit Hasselt) te Diepenbeek. Nadat ze het eerste jaar succesvol had volbracht, besloot ze toch te switchen van studierichting. In september 2001 startte ze met de studie geneeskunde aan de Universiteit Maastricht. Het laatste jaar van haar opleiding tot basisarts volbracht ze als semi-arts op de afdeling gynaecologie \& verloskunde van het Atrium medisch centrum in Heerlen. Tijdens dit jaar werd de interesse gewekt voor wetenschappelijk onderzoek en kreeg ze een eervolle vermelding tijdens de uitreiking van de Von Berckel wetenschapsprijs voor haar onderzoek 'Preoperative serum CA125 levels do not predict suboptimal cytoreductive surgery in epithelial ovarian cancer'. Dit onderzoek werd uitgevoerd onder leiding van Dr. Jan Stoot, gynaecoloog in het Atrium in Heerlen en Dr. Adri Voogd, klinisch epidemioloog verbonden aan de universiteit van Maastricht. In juli 2007 behaalde zij het artsexamen en in december 2007 kreeg zij het brevet acute geneeskunde uitgereikt door de Belgian Society of Emergency and Disaster Medicine. Haar interessegebied binnen de medische wereld was zeer gevarieerd en wetenschappelijk onderzoek maakte daar onderdeel vanuit. In januari 2008 begon ze als arts-onderzoeker op de afdeling dermatologie in het academisch ziekenhuis van Maastricht; dit was meteen ook de aanvang van dit promotie onderzoek. Om haar klinische vaardigheden te behouden begon ze in dezelfde periode als spoedarts te werken op de spoedgevallen dienst van het ziekenhuis OostLimburg te Genk. Tot op heden is ze hier nog steeds werkzaam. Sinds december 2009 combineert ze deze werkzaamheden met haar opleiding tot dermatoloog in het academisch ziekenhuis van Maastricht. In juni 2014 zal ze deze opleiding afronden. Zij won twee keer een prijs voor beste voordracht namelijk in 2010 op de SNNDV nascholing in Brugge en in 2012 op het dermato-oncologie congres in Spa. In oktober 2012 won ze in het MUMC+ de eerste prijs op het Pélerin wetenschapssymposium. 



\section{List of publications and oral presentations}

\section{List of publications}

Arits AH, Stoot JE, Botterweck AA, Roumen FJ, Voogd AC. Preoperative serum CA125 levels do not predict suboptimal cytoreductive surgery in epithelial ovarian cancer. Int J Gynecol Cancer. 2008; 18(4): 621-8.

Arits AH, Parren L, van Marion AM, Sommer A, Frank J, Kelleners-Smeets NW. Basal cell carcinoma and trichoepithelioma: a possible matter of confusion. Int J Dermatol. 2008; 47 Suppl 1: 13-7.

Mosterd K, Arits AH, Thissen MR, kelleners-Smeets NW. Histology-based treatment of basal cell carcinoma. Acta Derm Venereol 2009; 89(5): 454-8.

Arits AH, van de Weert MM, Nelemans PJ, Kelleners-Smeets NW. pain during topical photodynamic therapy: uncomfortable and unpredictable. J Eur Acad Dermatol Venereol 2010; 24(12): 1452-7.

Arits AH, van Marion AM, Thissen CA, Kloos R, Kelleners-Smeets NW. Development and progression of a periorbital sebaceous gland carcinoma in situ. Acta Derm Venereol 2010; 90(5): 529-30.

Van der Velden JJ, Arits AH, KI Gielen, JC Veraart. Zonder training een lichaam als een bodybuilder. Nederlands tijdschrift voor Dermatologie en Venereologie 2010; 20(9): 584-5

Arits AH, Schlangen MH, Nelemans PJ, Kelleners-Smeets NW. Trends in the incidence of basal cell carcinoma by histopathological subtype. J Eur Acad Dermatol venereol 2011; 25(5): 565-9.

Arits AH, van Marion AM, Lohman BG, Thissen MR, Steijlen PM, Nelemans PJ, KellenersSmeets NW. Differentiation between basal cell carcinoma and trichoepithelioma by immunostaining of the androgen receptor: an overview. Eur J Dermatol 2011; 21(6): 870-3.

Mosterd K, Arits AH, Nelemans PJ, Kelleners-Smeets NW. Aesthetic evaluation after noninvasive treatment for superficial basal cell carcinoma. J Eur Acad Dermatol Venereol 2011 Nov 21. doi: 10.1111/j.1468-3083.2011.04347.x. [Epub ahead of print] 
Roozeboom MH, Arits AH, Nelemans PJ, Kelleners-Smeets NW. Overall treatment success after treatment of primary superficial basal cell carcinoma: a systematic review and metaanalysis of randomised and non-randomised trials. Br J Dermatol. doi: 10.1111/j.13652133.2012.11061.x. Epub 2012 sept 7

Arits AH, Essers B, Mosterd K, Spoorenberg E, De Rooij M, van Pelt H, Krekels G, Quaedvlieg P, van Neer P, van Geest A, Rijzewijk J, Steijlen PM, Sommer A, Nelemans PJ, Kelleners-Smeets NW. Photodynamic therapy versus topical imiquimod versus topical 5fluorouracil for treatment of superficial basal cell carcinoma: a single blind, noninferiority, randomised controlled trial and cost-effectiveness analysis. Revisions of manuscript resubmitted to the Lancet

\section{Oral presentations}

Basal cell carcinoma versus trichoepithelioma: a possible matter of confusion. Regional evening seminar dermatology: southern Limburg, Maastricht, the Netherlands, May 2008

A randomised controlled multicenter trial in the Netherlands. Euro-PDT Meeting European Working Group for Photodynamic Therapy in Dermatology, Noordwijk, the Netherlands, March 2009

Development and progression of a periorbital sebaceous gland carcinoma in situ. Regional evening seminar dermatology: southern Limburg, Maastricht, the Netherlands, May 2009

Basal cell carcinoma: evidence based treatment. Symposium Integral Cancer Center Limburg, Sittard, the Netherlands, March 2010

A randomised controlled multicenter trial in the Netherlands. 6th EADO Congress European Association of Dermato-Oncology, Athens, Greece, June 2010

Non-invasive treatment options for non-melanoma skin cancer. V\&VN dermatology training, Roermond, the Netherlands, October 2010

Psorospermose folliculair végétante. Regional evening seminar dermatology: southern Limburg, Maastricht, the Netherlands, November 2010

The body of a bodybuilder without training. Foundation Dutch speaking course for Dermatology and Venereology, Bruges, Belgium, November 2010

Acrodermatitis enteropathica in infancy. Regional evening seminar dermatology: southern Limburg, Maastricht, the Netherlands, September 2011 
Treatment of the superficial basal cell carcinoma. Oncology in the pearl of the Ardennes $2^{\text {nd }}$ edition, Spa, Belgium, April 2012

Development and progression of a periorbital sebaceous gland carcinoma in situ. Annual meeting Dutch association for Dermatology en venereology, Maastricht, the Netherlands, June 2012

Treatment of the superficial basal cell carcinoma: a single blind, noninferiority randomised controlled trial and cost-effectiveness analysis. Pelerin arts-assistenten symposium, MUMC+, Maastricht, October 2012. 



\section{Dankwoord}

Multi multa; nemo omnia novit

Ik wil dit proefschrift afsluiten met een dankwoord aan iedereen, die heeft bijgedragen aan de totstandkoming van dit proefschrift.

Aan de volgende personen wil ik een persoonlijk woordje van dank richten:

Beste dokter Jan Stoot, u hebt mij richting wetenschap en dermatologie geleid. Ik heb een heel jaar als semiarts op uw afdeling gynaecologie in het Atrium Medisch Centrum te Heerlen mogen werken. Daarnaast hebben we samen een interessant retrospectief onderzoek opgezet waarvan de resultaten gepubliceerd werden in een internationaal gynaecologisch tijdschrift. We hebben voor dit onderzoek zelfs een aanmoedigingsprijs in ontvangst mogen nemen. Wat ons een goed team maakte was volgens mij het feit dat $u$ voor uw pensioen stond en ik de eerste stapjes zette in mijn professionele carrière. Bedankt voor al uw wijze raad.

Beste Adri Voogd, bedankt voor je geduld tijdens mijn eerste stapjes binnen de statistiek. Je hebt naast me gezeten om samen analyses te doen in SPSS, je hebt me boeken gegeven over statistiek om thuis door te lezen en je hebt me geholpen om mijn eerste artikel 'publicatie-proof' te maken. Ook al maakt het artikel dat we samen geschreven hebben geen onderdeel uit van dit proefschrift, het was de springplank voor mijn promotieonderzoek.

Beste dokter René Heylen, vanaf het eerste moment dat ik u kwam vragen voor een stageplaats op uw spoedafdeling gaf $u$ me vertrouwen. $\mathrm{lk}$ weet dat $\mathrm{u}$ diversiteit binnen een professionele carrière aanmoedigt. $\mathrm{lk}$ had mijn twijfels of ik een opleiding tot dermatoloog, promotieonderzoek en een functie als spoedarts wel met elkaar zou kunnen combineren. $U$ zei toen: 'C'est le ton qui fait la musique'! En zo is het ook. Bedankt voor uw vertrouwen.

Beste Professor Steijlen, hoe soepel ons contact nu verloopt zo stroef liep het in het begin. Ik had destijds nog teveel van de Belgische schuchterheid en verzonk al snel in mijn wetenschappelijk onderzoek. Toen ik uw goedkeuring kwam vragen om naast mijn activiteiten op uw afdeling, ook als spoedarts te werken in het ziekenhuis in Genk was u erg huiverig. $U$ was terecht bang dat mijn promotieonderzoek hieronder zou lijden. Ik denk dat ik $u$ heb kunnen overtuigen dat uw ongerustheid destijds nergens voor nodig was. Bedankt voor alle kansen die u mij geboden hebt.

Lieve Nicole en Patty, wat ben ik ontzettend dankbaar en trots dat jullie mijn co-promotores zijn. Jullie vullen elkaar perfect aan hetgeen tot dit prachtige werk geleid heeft. Nicole, je waakt als een moederkloek over je promovendi. We kunnen met alles bij je terecht. Als ik het weer eens niet zag zitten, trok jouw positivisme me uit die negatieve spiraal. Toen ik op 1 januari 2008 begon was je net moeder geworden. Ik mocht toen altijd bij jou langskomen en met Ellen op je arm gaf je me dan advies. En sorry Naud, voor alle late uurtjes die jij misschien anders wilde besteden maar die eindigde met een echtgenote op de bank die weer eens achter haar laptop een artikel aan het reviseren was.

Patty, jij bent een onderzoeker uit de duizend! De bijdrage die jij aan dit proefschrift geleverd hebt is van onschatbare waarde. Ik wil jou omschrijven als streng maar rechtvaardig. Jouw perfectionisme heeft ervoor gezorgd dat al mijn artikelen tot een hoger niveau werden getild. Je maakte altijd tijd voor me en ik heb meer dan eens opgemerkt dat jouw mails op een laat tijdstip verzonden werden. Nicole en Patty, bedankt voor alles! 
Lieve paranimfen, Dr. Klara Mosterd en Dr. Charlène Oduber. Ik heb niet moeten nadenken wie ik zou vragen om me op deze belangrijke dag bij te staan. Ondanks het feit dat we drie verschillende persoonlijkheden zijn, klikte het meteen.

Klara, jij hebt een groot deel van het ZonMW project geschreven en het was dan ook tegenover jou dat ik kwam te zitten tijdens mijn sollicitatie voor dit project. Op alles wat ik zei knikte je goedkeurend en dat gaf me rust en zelfvertrouwen. Jij hebt me op mijn eerste werkdag op de afdeling rondgeleid. Het klikte meteen zowel op als naast de werkvloer. Je hebt me zelfs kunnen overtuigen om deel te nemen aan het assistenten cabaret tijdens het lustrum van de afdeling. Ik hoop dat het beeldmateriaal hiervan kwijt is...

Lieve Char, je bent de grootste schat die er bestaat. Ik denk dat er geen twee mensen op deze aardbol bestaan die qua karakter zo verschillend zijn dan wij en toch hebben we ook zoveel gemeen. Ik kan met alles bij je terecht. Jij was mijn COCOM maatje. Mijn taak was ervoor te zorgen dat je na een avondje stappen niet te laat in bed belandde. Deze taak heb ik zelden tot een goed einde kunnen brengen! Stiekem hoop ik dat je volgend jaar niet terug gaat naar Aruba zodat we elkaar vaak kunnen blijven zien.

Brigitte bedankt voor je input in het ZonMw project. Jouw kritische blik heeft van het ZonMw project een prachtig wetenschappelijk project gemaakt.

Beste Dr. Sommer, lieve Anja, mijn allereerste orientatiegesprek over het ZonMW project was bij jou. Jij hebt een groot aandeel gehad in de aanvraag voor ZonMW sponsoring. Een deel van dit sponsorbedrag kon dienen om een ANIOS aan te nemen die het project zou leiden en uitvoeren. Bedankt dat ik die ANIOS mocht zijn.

Bedankt ook aan Marjo Schlangen, Martine van de Weert en Eefje Spoorenberg. Bedankt om mijn onderzoek te ondersteunen tijdens jullie wetenschapsparticipatie van de opleiding tot basisarts.

Lieve collega's van het onco-team, Monique, Nicole, Klara, Marieke, Tjinta en Annet bedankt voor al jullie input tijdens onze maandelijkse onco-clubjes. Laten we er samen voor zorgen dat onze dermato-oncologische onderzoekslijn nog jaren zinvolle wetenschappelijk publicaties mag opleveren. En natuurlijk betekent dit dat we ook nog vaak samen op congres moeten.

Lieve Marieke, tijdens het schrijven van dit proefschrift kon ik altijd ad hoc bij jou terecht voor vragen of wanneer ik op zoek was naar referenties. Jij hebt de follow-up van het ZonMw project van me overgenomen en je doet dat geweldig. Je bent ook een gedreven onderzoeker. Je hebt net de eerste maandjes in de kliniek achter de rug. Ik wil je veel succes wensen en je kunt altijd op me rekenen als je hulp nodig hebt bij je onderzoek.

Nicole Luckerhof, ik heb niet eens de plaats in dit proefschrift om op te sommen wat jij allemaal voor me gedaan hebt. Je bent de beste secretaresse die er bestaat en je hebt alle administratieve rompslomp rondom het ZonMw project geweldig opgevangen. Ook Annelies en Petra, bedankt voor jullie administratieve en informatieve hulp bij dit proefschrift en het zoeken naar sponsoring. En natuurlijk ook bedankt aan alle andere secretaresses.

Bedankt aan alle polimedewerkers van de dermatologie voor de ondersteuning en de fijne samenwerking bij het ZonMW project.

Beste Dr. Van Marion, lieve Ariënne, dank voor de beoordeling van alle histologische coupes.

Meneer Maesen, beste Harrie, bedankt voor de prachtige cover! Je bent een groot kunstenaar. Ik wil ook je vrouw Til bedanken, zij heeft ons bij elkaar gebracht.

Ik wil alle (ex)-promovendi bedanken. We hebben meermaals meegemaakt dat de bewaking het oxford kwam sluiten en dat wij nog druk bezig waren met ons onderzoek. Gewoon te weten dat je niet alleen bent geeft een ontzettende steun. Bedankt Charlène, Annemoon, Sadhanna, Nadia en Klara. Jullie begrijpen als geen ander 
het fenomeen 'onderzoek ontwijkend gedrag'. Soms moet je er gewoon aan toegeven en dan gingen we een lekker koffietje drinken op de universiteit.

Sharon en Eef, jullie zijn schatten. Ondanks het feit dat ik de hele dag misselijk was, was San Diego onvergetelijk. Ook mijn rolstoelervaring op Heathrow zal ik niet snel vergeten!

Als je gemotiveerd onderzoek wil blijven doen in combinatie met opleiding dan is er ook tijd nodig voor ontspanning. Ik wil alle (oud)-AIOS bedanken voor de leuke ski-reisjes en etentjes. Elk COCOM opnieuw wordt weer eens duidelijk dat wij de leukste AIOS groep dermatologie zijn van heel Nederland.

Ook bedankt aan alle stafleden dermatologie voor jullie medeleven en begrip. Jullie hebben meermaals door de vingers gezien wanneer ik niet bij besprekingen of overdrachten aanwezig kon zijn omdat ik weer eens een deadline had in het kader van het promotieonderzoek.

Mijn dank gaat ook uit naar alle patiënten die hebben meegewerkt aan de onderzoeken. Jullie zijn de basis van dit proefschrift.

Daarnaast dank aan alle vrienden en (schoon)familie voor wie ik de afgelopen jaren vaak onvoldoende tijd had. Ik beloof jullie, vanaf nu ga ik al die tijd inhalen!

Lieve mama en papa, ik heb dit boekje aan jullie opgedragen. Wie anders dan jullie verdient dit! Jullie hebben altijd geloofd in mijn kunnen, me altijd gesteund en met raad en daad bijgestaan. Ik heb niet veel woorden nodig om duidelijk te maken hoeveel jullie voor me betekenen.

Voor jullie zijn Solange en ik het belangrijkste op deze aardbol en dat geeft ons vleugels. Ik wil deze plaats in de toekomst met alle plezier afstaan aan jullie kleinkinderen!

Lieve zus en schoonbroer, Solange en Geert, ik ben zo blij dat we het goed met elkaar kunnen vinden. Ik ben ook trots lieve zus dat je de meter van ons dochtertje zal worden. Ook al is ze nog niet geboren, toch heb je nu al een hele garderobe voor haar aangelegd.

Sven, het lukte me gewoon niet om iets op papier te zetten. Hiervoor ben ik te emotioneel. En nee het zijn niet alleen de zwangerschapshormonen. Het is een lange en intense weg geweest, maar ik beloof je nu hebben we alle tijd om te genieten van ons huis en onze dochter in spé! 



\section{Sponsoring}

Het drukwerk van dit proefschrift werd mede mogelijk gemaakt door:

Abbott BV

Astellas Pharma BV

Fagron BV

Galderma Nederland

Laprolan

Leo Pharma BV

Louis Widmer Nederland

Meda Pharma BV

Pfizer BV

Roche Nederland 


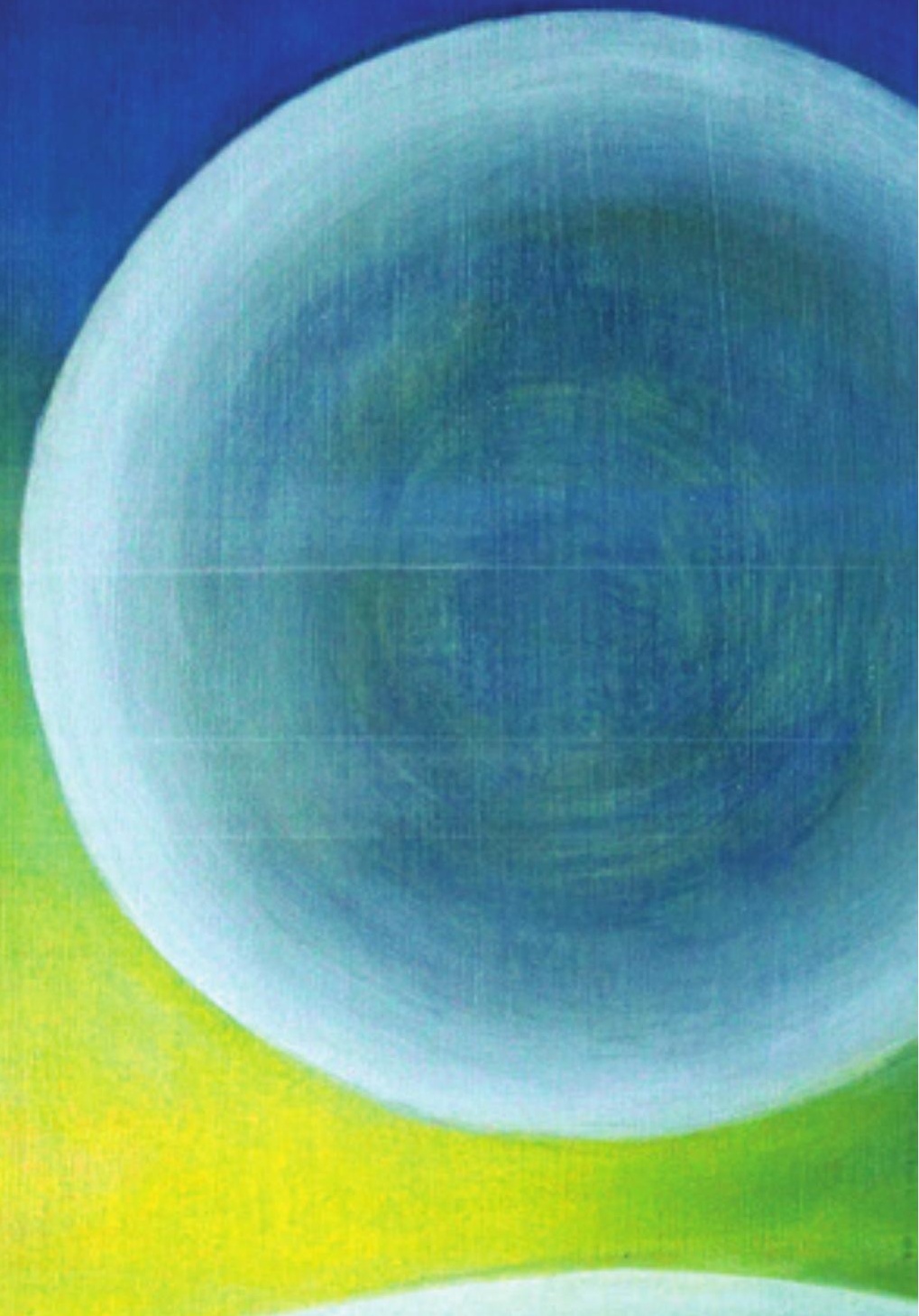

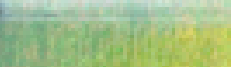

